\title{
Development of a Vertical Recirculation Well System for the A/M Area of the Savannah River Site (U)
}

September 13, 1996

Dennis G. Jackson $\mathrm{Jr}$.

Brian B. Looney

Environmental Sciences Section

Savannah River Technology Center

Authentication:

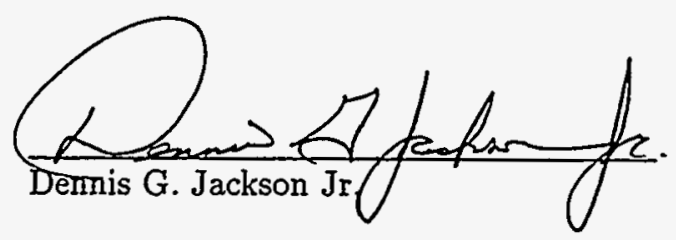

Westinghouse Savannah River Company

Aiken, South Carolina 29808

Prepared for the United States Department of Energy under Contract No. DE-AC09-89SR18035 


\section{DISCLAIMER}

This report was prepared as an account of work sponsored by an agency of the United States Government. Neither the United States Government nor any agency thereof, nor any of their employees, makes any warranty, express or implied, or assumes any legal liability or responsibility for the accuracy, completeness, or usefulness of any information, apparatus, product, or process disclosed, or represents that its use would not infringe privately owned rights. Reference herein to any specific commercial product, process, or service by trade name, trademark, manufacturer, or otherwise does not necessarily constitute or imply its endorsement, recommendation, or favoring by the United States Government or any agency thereof. The views and opinions of authors expressed herein do not necessarily state or reflect those of the United States Government or any agency thereof. 


\section{DISCLAIMER}

Portions of this document may be illegible electronic image products. Images are produced from the best available original document. 
WSRC-RP-96-477

September 13, 1996

\section{Executive Summary}

The purpose of this document is to provide preliminary information for the development of remediation technologies within the Western and Southern Sectors of the A/M Area. These technologies are being implemented to capture and remdiate those portions of the dissolved solvent plume delineated by the 500 part per billion trichloroethylene isoconcentration contour. This is the level specified by SCDHEC in the current Part B Permit for the M-Area Hazardous Waste Management Facility. In order to design and develop this remediation system, it was first necessary to develop an understanding of the distribution of the dissolved trichloroethylene plume within the A/M Area. The horizontal and vertical extent of the dissolved trichloroethylene plume within the Western and Southern Sector of the A/M Area has been examined by incorporating quarterly monitoring well data, depth discrete soil head-space data, and the physical laws governing ground-water flow and contaminant transport with source history information to develop a three-dimensional representation of the plume. This representation was then used to develop a remediation system for the Western and Southern Sectors incorporating a series of vertical recirculation wells. Within the Southern Sector a series of 8 wells are recommended and should begin at the southern most position of the 500 part per billion trichloroethylene isoconcentration, very near soil boring MSS-2SB. Each of these wells were selected to operate at a design flow-rate of $20 \mathrm{gpm}$. Towards the west a series of 6 wells along a line from MSB- 49 towards the northeast are recommended to capture the dissolved trichloroethylene plume originating from suspected DNAPL zones in the Western Sector. These wells were also selected to operate at a design flow-rate of $20 \mathrm{gpm}$. The model developed was based upon the previously developed models of the A/M Area and the three-dimensional model currently being developed using data fusion technologies. The model incorporates the results of available aquifer tests and field studies within the Western and Southern sectors. Due to the relatively low concentrations of - dissolved solvent present in the Western and Southern sectors and relatively large plume volume, remediation should incorporate carefully located wells screened vertically within the flow path trajectory to optimize the volume of contaminant removed. Incorporation of depth discrete sampling during the installation of additional recovery wells should be considered a necessity to optimize the performance of the future recovery systems. 


\section{Contents}

1 Executive Summary iv

2 Objective

3 Introduction $\quad 1$

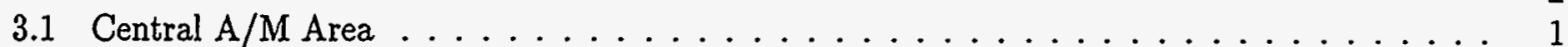

3.2 Northern Sector . . . . . . . . . . . . . . . . . . . . . . 3

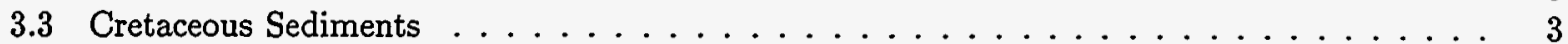

3.4 Western Sector $\ldots \ldots \ldots \ldots \ldots \ldots \ldots \ldots \ldots \ldots \ldots$

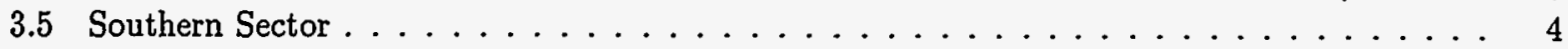

4 Background Information of the A/M Area 6

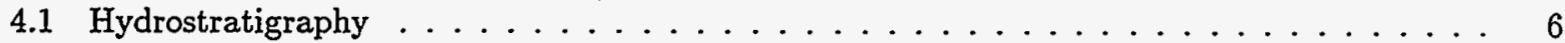

4.2 Groundwater Flow Patterns . . . . . . . . . . . . . . . . . . 8

4.3 Dissolved Contaminant Distributions . . . . . . . . . . . . . . . . . 17

4.3 .1 Southern Sector Transport and Distribution . . . . . . . . . . . . . 18

4.3.2 Western Sector Transport and Distribution . . . . . . . . . . . . . . 22

5 Vertical Recirculation Well Technology 35

5.1 Selection and Sizing a VRW System . . . . . . . . . . . . . . . . . 35

5.1 .1 Preliminary Development . . . . . . . . . . . . . . . . 38

5.1 .2 Eastern Front Analysis . . . . . . . . . . . . . . . . . . . . 39

5.1 .3 Western Front Analysis . . . . . . . . . . . . . . . . . . . . . . 39

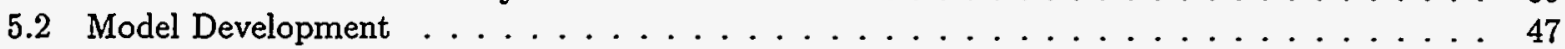

5.2 .1 Discretization . . . . . . . . . . . . . . . . . . 47

5.2 .2 Boundary Conditions $\ldots \ldots \ldots \ldots \ldots \ldots \ldots \ldots$

5.2 .3 Hydraulic Properties . . . . . . . . . . . . . . . . . . . . 61

5.3 Model Calibration . . . . . . . . . . . . . . . . . . . 69

6 Results and Discussion $\quad 69$

$\begin{array}{lll}7 & \text { Summary } & 76\end{array}$

8 Appendix A: Vertical Distributions of Mud Fraction $\quad 81$ 
WSRC-RP-96-477

September 13, 1996

\section{List of Tables}

1 Dimensioning for a System of Vertical Recirculation Wells along the Eastern Line of the Southern Sector using Herrling's Method. . . . . . . . . . . . . . . . . . . . 43

2 Dimensioning for a System of Vertical Recirculation Wells along the Western Line of the Southern Sector using Herrling's Method. . . . . . . . . . . . . . . . . . . . . 43

3 Siting Information for the Proposed Locations for Vertical Recirculation Wells as determined using Herrling's Method. . . . . . . . . . . . . . . . . . . . . . . 46

4 Statistical Parameters for the Bottom and Top of the Domain and for the Element Thickness of the Model. . . . . . . . . . . . . . . . . . . . . . . . . . . 54

5 Statistical Parameters for the Constant Head Boundary Conditions Applied to the North and East Faces of the Domain. . . . . . . . . . . . . . . . . . . . 54

6 Statistical Parameters for the Head and Thickness Distribution Prescribed Applied in Defining Head-Dependent Flux Boundary Conditions for the Bottom of the Model Domain. . . 60

7 Correlation of Mud Fraction Values to Hydraulic Conductivity. . . . . . . . . . . . . 67

8 Calibration Targets and Resulting Residuals used in the development and calibration of the Numerical model. . . . . . . . . . . . . . . . . . . . . . . . . 70

9 Calibration Targets and Resulting Residuals used in the development and calibration of the Numerical model. . . . . . . . . . . . . . . . . . . 71 


\section{List of Figures,}

1 Location and Distribution of Monitoring Wells, Recovery Wells, and Soil Borings within the M-Area Hazardous Waste Management Facility. . . . . . . . . . . . . . . . . .

2 Estimated Annual Discharge of Degreaser Solvents to the M-Area Process Sewer System. (Adopted from Marine and Bledsoe, 1984) . . . . . . . . . . . . . . . .

3 Relationship Between Aquifer Systems, Confining Systems, and Confining Units of the Southeastern Coastal Plain within the Vicinity of the Savannah River Site. . . . . . . . .

4 Hydrostratigraphic Nomenclature of the Southeastern Coastal Plain for the A/M Area Region of the Savannah River Site. . . . . . . . . . . . . . . . . . . 10

5 Cross Section from the M-Area Basin to Upper Three Runs Creek depicting Groundwater Flow Directions and Out-Cropping of the Green Clay Confining Unit. . . . . . . . . . . 12

6 Potentiometric Map for the M-Area Aquifer Zone of the A/M Area. . . . . . . . . . . . 13

7 Potentiometric Map for the Lost Lake Aquifer Zone of the A/M Area. . . . . . . . . . . . 14

8 Potentiometric Map for the Crouch Branch Aquifer of the A/M Area. . . . . . . . . . 16

9 Plan View of the Dissolved Trichloroethylene Plume in the A/M Area of the Savannah River Site showing groundwater concentrations greater than 500 parts per billion. . . . . . . 19

10 View of the Dissolved Trichloroethylene Plume Looking from the Southeast showing groundwater concentrations greater than 500 part per billion. . . . . . . . . . . . . 20

11 Historical Trichloroethylene Concentrations for wells MSB 1D, MSB 14C, MSB 39D, and MSB 40D located in the M-Area Aquifer. . . . . . . . . . . . . . . . .

12 Historical Trichloroethylene Concentrations for wells MSB 1CC, MSB 14B, MSB 39C, MSB 75C, and MSB 40C located in the Upper portion of the Lost Lake Aquifer. . . . . . . . . 24

.13 Historical Trichloroethylene Concentrations for wells MSB 1C, MSB 1B, MSB 14A, MSB 39B, MSB 75B, and MSB 40B located in the Lower portion of the Lost Lake Aquifer. . . .

14 Vertical Cross-Section along SRS Easting 48,500 Showing 4Q95 Distribution of Dissolved Trichloroethylene and migration path from the M-Area Basin to the Southern Sector of the A/M Area. . . . . . . . . . . . . . . . . . . . . .

15 Historical Trichloroethylene Concentrations for wells MSB 12D, MSB 5A, MSB 64D, MSB $6 \mathrm{~A}, \mathrm{MSB} 18 \mathrm{C}$, and MSB 49D located in the M-Area Aquifer Zone. . . . . . . . . . . 28

16 Historical Trichloroethylene Concentrations for wells MSB 12C, MSB 12B, MSB 5C, MSB $64 \mathrm{C}$, MSB 6C, and MSB 18B located in the upper portion of the Lost Lake Aquifer. . . . .

17 Historical Trichloroethylene Concentrations for wells MSB 5C, MSB 64C, MSB 6C, and MSB 18B located in the upper portion of the Lost Lake Aquifer. . . . . . . . . . . . .

18 Historical Trichloroethylene Concentrations for wells MSB 12A, MSB 5B, MSB64B, MSB $6 \mathrm{~B}$, and MSB $49 \mathrm{~B}$ located in the lower portion of the Lost Lake Aquifer. . . . . . . . . . .

19 Vertical Cross-Section along SRS Easting 46,000 Showing 4Q95 Distribution of Dissolved Trichloroethylene and migration path from the Suspected DNAPL path near MSB 76C to the Southern Sector of the $A / M$ Area. . . . . . . . . . . . . . . . . .

20 View of Dissolved Trichloroethylene Plume within the A/M Area Looking from the Northeast showing the elevation of the Plume along the A-014 Outfall. . . . . . . . . . . . 33

21 Plan View of the $500 \mathrm{ppb}$ TCE Isocontour with Proposed Lines of Remediation for Vertical Recirculation Wells. . . . . . . . . . . . . . . . . . . . .

22 Schematic Representation of a Vertical Recirculation Well showing the Resulting Flow Field without the Presence of a Natural Groundwater Gradient. . . . . . . . . . . . . . . . .

23 Streamlines for a Vertical Longitudinal Section through a Vertical Recirculation Well and the effect of horizontal gradient. (a) $0.0 \mathrm{~m} /$ day; (b) $0.3 \mathrm{~m} /$ day; (c) $1.0 \mathrm{~m} /$ day. (Adopted from Herrling et al., 1991b) . . . . . . . . . . . . . . . . . . .

24 Schematic Representation and Nomenclature applied in the Dimensioning of a VRW instal-

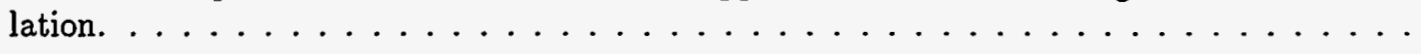
2 3 6 9 
25 Nomenclature used in identifying an upstream cross section through the capture zone for one and two VRW installations. . . . . . . . . . . . . . . . . .

26 (a) Widths $B_{T}$ and $B_{B}$ of the Upstream Capture Zone at the aquifer top and bottom; (b) Influx area $A$ of the upstream capture zone; (c) Upstream discharge $\left(Q_{0}\right)$ in hte capture zone, which is diluted with the circulating water to the total well discharge; (d) Maximum well distance (D) at which the contaminated groundwater cannot pass between the wells without being treated. (Adopted from Herrling et al., 1991b) . . . . . . . . . . . . . .

27 Upstream distance $(S)$ of the stagnation point from the well axis. (Adopted from Herrling et al., 1991b) . . . . . . . . . . . . . . . . . . . . .

28 Plan View of the $500 \mathrm{ppb}$ TCE Isocontour with Proposed Locations for Vertical Recirculation Wells determined using Herrling's Method. . . . . . . . . . . . . . . . . 45

29 Horizontal Domain of Model Showing Those Regions Greater than 500 ppb Trichloroethylene. 48

30 Altitude Contour for the Bottom of the Model Domain Represented by the "Upper-Clay" Confining Zone of the Crouch Branch Confining Unit. . . . . . . . . . . . . . . . 50

31 Top of the Model Domain Represented by the Water-Table within the M-Area Aquifer Zone. 51

32 View Looking from the Southwest of the Model Domain showing the Vertical Discretization employed. . . . . . . . . . . . . . . . . . . . . . . 52

33 Distribution of Constant Head Boundary Conditions in Model Coordinate System applied to the Northern Domain of the Model. (j equal 91 Plane) . . . . . . . . . . . . . . 55

34 Distribution of Constant Head Boundary Conditions in Model Coordinate System applied to the Eastern Domain of the Model. (i equal 1 Plane) . . . . . . . . . . . . . . 56

35 Distribution of Head Incorporated for the Dependent Flux Boundary Conditions applied to the Bottom Plane of the Model. (k equal 1 Plane) $\ldots \ldots \ldots \ldots \ldots \ldots$

36 - Distribution of Vertical Thickness Incorporated for the Dependent Flux Boundary Conditions applied to the Bottom Plane of the Model. (k equal 1 Plane) . . . . . . . . . . 58

37 Distance fom Southern Boundary to Upper Three Runs Creek and Corresponding Hydraulic Head used to specify Southern Head Dependent Boundary Conditions. . . . . . . . . . . .

38 Altitude Contour for the Green Clay Confining Zone that was used to supplement mud fraction data. . . . . . . . . . . . . . . . . . . .

39 Plan View Showing the Distribution of Mud Fraction over the Model Domain. . . . . . . .

40 View from the Southeast showing the Three-Dimensional Distribution of Mud Fraction and the resultant over the Model Domain. . . . . . . . . . . . . . . . . . 64

41 Vertical Cross-Section along SRS Easting 48,500 Showing Distribution of Mud Fraction within the model domain. . . . . . . . . . . . . . . . . 65

42 Frequency Histogram for the Distribution of Mud Fraction Incorporated in the Model. . . .

43 Plan View of the Capture Zone of the Dissolved Trichloroethylene Plume Resulting from a Series of 8 Vertical Recirculation Wells with a Design Flow-rate of 20 gpm located along the Eastern Front of the $500 \mathrm{ppb}$ Isocontour. . . . . . . . . . . . . . . . . . . .

44 View from the Southeast of the Capture Zone of the Dissolved Trichloroethylene Plume Resulting from a Series of 8 Vertical Recirculation Wells with a Design Flow-rate of $20 \mathrm{gpm}$ located along the Eastern Front of the $500 \mathrm{ppb}$ Isocontour. . . . . . . . . . . .

45 Plan View of the Capture Zone of the Dissolved Trichloroethylene Plume Resulting from a Series of 6 Vertical Recirculation Wells with a Design Flow-rate of $20 \mathrm{gpm}$ located along the Western Front of the $500 \mathrm{ppb}$ Isocontour. . . . . . . . . . . . . . (1) 0 (2) :5 s s7 


\section{Objective}

The objective of this work is to examine and develop a remediation scenario to provide long term hydraulic control and remediation of the dissolved chlorinated solvent plume within the Western and Southern Sectors of the A/M Area. This scope includes the development and siting of a remediation system that will contain the 500 part per billion trichloroethylene isoconcentration contour within each sector.

\section{Introduction}

The A/M-Area is located in the northern section of the Savannah River Site (SRS) and consists of those facilities that fabricated reactor fuel and target assemblies for the SRS reactors (M-Area), laboratory facilities (SRTC, formally SRL), and administrative and support facilities (A-Area). Operations at these and other facilities within the $A / M$ Area resulted in the release of chlorinated solvents, primarily trichloroethylene (TCE), tetrachloroethylene (PCE) and 1,1,1- trichloroethane (1,1,1-TCA) to the subsurface. (Marine and Bledsoe, 1984) These releases have resulted in the contamination of the soil and groundwater within the area. Since the discovery of dissolved solvents within the groundwater, SRS has pursued an aggressive path towards environmental remediation of the groundwater and subsurface contamination. To achieve this goal, SRS has installed an extensive groundwater recovery well network to treat contaminated groundwater, has supported the characterization of subsurface features to determine influences on groundwater flow, and has supported a demonstration program for developing soil and groundwater remediation technologies.

The effective remediation of chlorinated solvents from the subsurface of the $A / M$ Area presents several technical challenges to investigators and researchers. Historical releases in the area have resulted in all known aspects of subsurface contamination that are associated with chlorinated solvent. Typical of most waste sites, the $\mathrm{A} / \mathrm{M}$ Area has dissolved solvent present in the groundwater that has resulted in a large plume of groundwater contamination. SRS investigators have identified dissolved contamination in both the shallow Tertiary sediments and the deeper Cretaceous sediments. In addition, due to the large quantities of solvent released at the M-Area Basin and at the A-014 Outfall, non-aqueous phase liquids (NAPLs) are present in both the vadose and saturated zones. (Looney et al., 1992) Being essentially immiscible in water (1,100 parts per million for TCE and 150 parts per million for PCE) (Cohen and Mercer, 1993) the NAPL serves as long-term source below the subsurface. The density of the NAPL present in the A/M Area is greater than that of water. This causes the dense NAPL, or DNAPL, to migrate vertically through the vadose zone and below the water table eventually resting on the finer grain sediments. The vertical migration of the DNAPL is very dependent upon the height of the DNAPL and the local pore entry pressure. In order to efficiently manage the complete remediation program, the $A / M$ Area has been subdivided into five sectors. These sectors are the Central $A / M$ Area, Western Sector, Southern Sector, Northern Sector, and the Cretaceous. Although geographically and geologically identified, each of these sectors are defined based on the type of contaminants present and the remediation approach. Figure 1 presents this concept geographically along with the location and distribution of monitoring wells, recovery wells, and soil borings within the M-Area.

\subsection{Central A/M Area}

With the discovery of chlorinated solvents within the subsurface of the M-Area settling basin, a pilot air stripper was installed in 1983 with a full-scale remediation program in-place by 1985 . This system is referred to as the M1 System. The M1 system consists of eleven conventional pump and treat recovery wells, RWM-1 through RWM-11. The system provides groundwater remediation via pump and treat technology for the Central $\mathrm{A} / \mathrm{M}$ Area. Previous investigations provide excellent source term accounts regarding location, magnitude, and frequency of solvent releases within the $A / M$ Area. (Marine and 


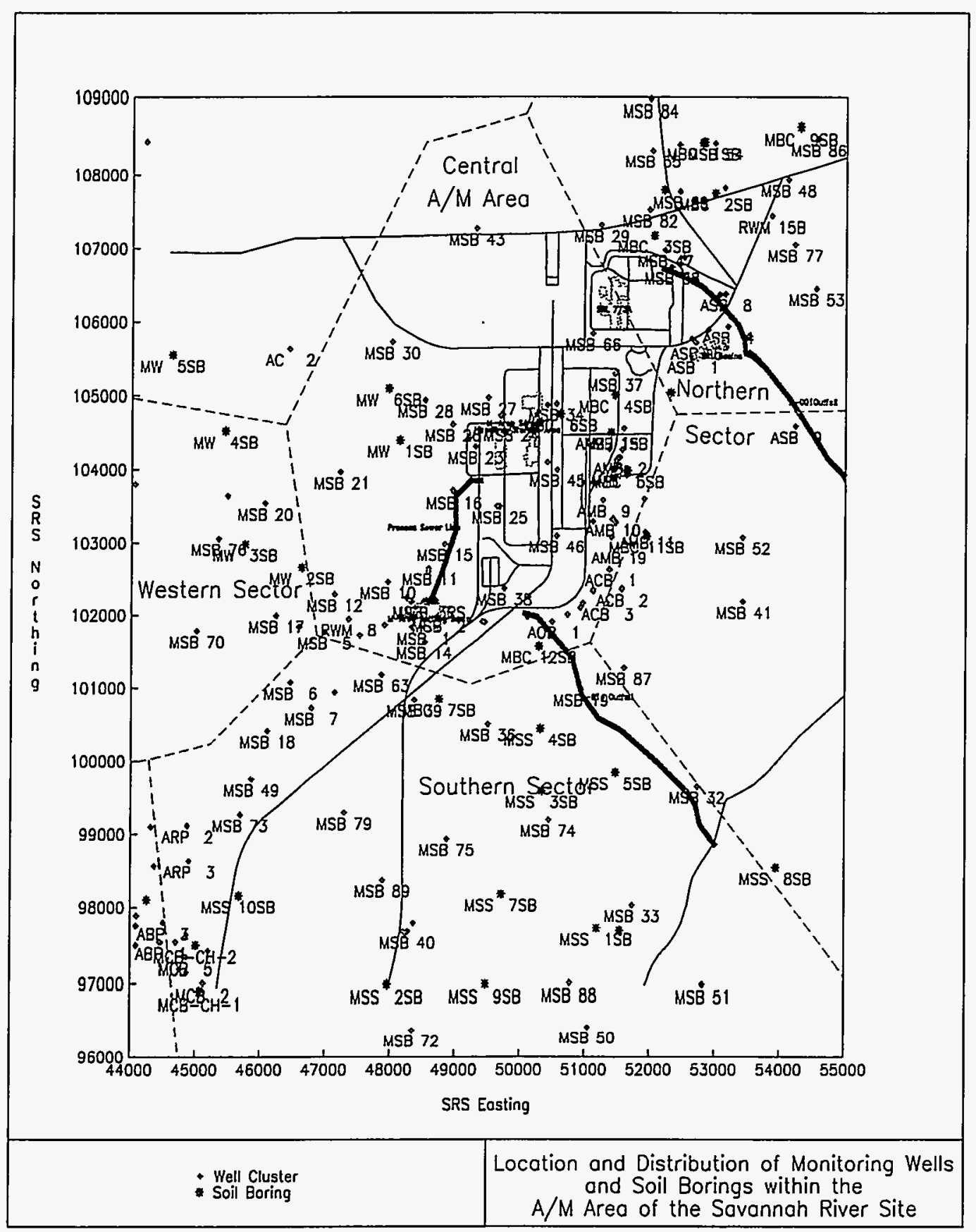

Figure 1: Location and Distribution of Monitoring Wells, Recovery Wells, and Soil Borings within the M-Area Hazardous Waste Management Facility. 
Bledsoe, 1984) The Central A/M Area has been historically defined based upon capture zone modeling of the M1 system. The effectiveness of this system in capturing the dissolved portion of the groundwater plume has been evaluated through extensive groundwater modeling activities. (S.S. Papadopulos \& Associates, 1987) (Haselow et al., 1991) (Jackson and Aleman, 1995) In addition to the dissolved plume present in the Central A/M Area, NAPL is present in both the unsaturated and saturated zones. (Looney et al., 1992) To address and remediate the NAPL in the unsaturated zone a series of soil vapor extraction units have been installed in the source zone regions along the process sewer line and beneath the M-Area Basin. These units have been very successful in the removal of contaminant mass in the vadose zone prior to entry into the saturated region.

\subsection{Northern Sector}

As reported, (Marine and Bledsoe, 1984) investigators have been unable to quantify the period and magnitude of releases in the Northern Sector to the extent that those at the M-Area Basin have been described. The primary source is believed to be the operation of degreasers located in the Fabrication Laboratory in the basement of 773-A. Spent solvents from this facility were discharged to a "trade waste stream" which led to the present A-1 Outfall. Usage of chlorinated solvent in and around this facility varied from 1954 to 1979 when the use of chlorinated solvents ceased. Since these facilities lie on the extreme northern boundary of the Savannah Rive Site, where a transition of hydrogeology occurs between the Atlantic Coastal Plain and the Piedmont Blue Ridge, these releases are considered to be the major source for the deeper Cretaceous contamination present in the Central and Southern A/M Area. To address the presence of the dissolved solvent associated with these releases the original pilot scale air stripper used in the Central $A / M$ Area was relocated to the northern portion of $A / M$ Area and is now designated as the A1 System which receives water pumped from RWM-12. This system along with the recently installed A2 system, which receives water from RWM-13B, RWM-13C, RWM-14B, RWM-14C, and RWM-15B, will provide groundwater remediation within the vicinity of the SRTC complex and is referred to as the Northern Sector of the A/M Area. As with the M1 System, the performance and effectiveness of the A1 and A2 Systems has been evaluated through extensive groundwater modeling activities. (Haselow et al., 1991) (Jackson and Aleman, 1995) The approach SRS is taking in regards to Northern Sector remediation is to maximize mass removal in the Tertiary sediments using conventional pump and treat technologies. The goal of this program is to prevent the further downward migration of contaminants from the shallow Tertiary sediments to the deeper Cretaceous sediments.

\subsection{Cretaceous Sediments}

The discontinuities of the confining zones associated with the transition of regional geology in the Northern Sector have resulted in the downward migration of a dissolved solvent plume into the Cretaceous age sediments, the Crouch Branch Aquifer system. This aquifer is part of the regional hydrologic system that is used both on-site and off-site as a domestic and process water resource. The first indication of solvent contamination in the Crouch Branch Aquifer occurred in July of 1981 when a water sample from production well $905-53 \mathrm{~A}$ indicated TCE contamination at $10 \mathrm{ppb}$, with subsequent indications from production wells $905-20 \mathrm{~A}$ and $905-31 \mathrm{~A}$. To aid in characterizing the extent of the contamination in the Crouch Branch Aquifer several monitoring wells have been installed and multiple bulk soil samples collected and analyzed for volatile organics using a head-space analysis procedure developed at the Savannah River Site. (WSRC, 1993a) (WSRC, 1994a) The present groundwater contamination in this aquifer is migrating in a southwesterly direction towards the interior of the site, away from the site boundary. As documented throughout the A/M Area corrective action program (Department of Energy, 1987) (WSRC, 1993b) the primary source of the Cretaceous contaminant plume is the past solvent discharges that occurred in the vicinity of the SRTC complex. SRS is currently pursuing an aggressive characterization program to determine the extent of the contamination and the hydrostratigraphy that controls groundwater flow in the Cretaceous Aquifer system. (Van Pelt et al., 
1993) (Jackson et al., 1996) The results of these ongoing programs will be used to develop remediation scenarios and examine alternatives for the Cretaceous sediments.

\subsection{Western Sector}

The downward DNAPL migration in the vadose and saturated zone is currently being characterized with a variety of remediation alternatives being examined. The conceptual model currently applied is that the dense NAPL, DNAPL, has migrated vertically due to gravitational forces in the vicinity of the M-Area Basin and possibly at the A-014 Outfall. (Looney et al., 1992) Since the specific gravity of the limited solubility liquid is greater than that of the groundwater, the DNAPL continues its downward migration into the saturated zone until reaching finer grain sediments. These finer grain sediments have a higher pore entry pressure which impede the vertical migration of the DNAPL. Upon reaching the finer grain sediments the NAPL begins to pool and flow laterally along the this horizon. Within the A/M Area this horizon is along the top of the Green Clay Confining Zone. Within the vicinity of the the M-Area Basin the altitude of this unit slopes in such a manner that a suspected DNAPL flow path exists westward from the basin and then turning northward towards the MSB-76 cluster. Effective remediation plans associated with the DNAPL will require identifying pools of subsurface NAPL in the saturated zone which is complicated by the heterogeneous strata, the multiple DNAPLs used in the process, and the release history. The presence of subsurface DNAPL serves as a long-term source zone for dissolved groundwater contamination within the A/M Area. This, with the local groundwater flow pattern, has resulted in the migration of dissolved contaminants downward across the Green Clay Confining Zone and southward towards Upper Three Runs Creek.

\subsection{Southern Sector}

The portion of the dissolved plume within the Southern Sector is primarily the result of southward migration of dissolved solvent via advective transport from the M-Area Settling Basin and the A-014 Outfall source zones. DNAPL has been detected above the Green Clay at the M-Area Settling Basin. Due to the local groundwater flow patterns, this DNAPL serves as a long-term source for dissolved contamination present towards the south and west in the Lost Lake Aquifer Zone. Initial remediation programs within the Southern Sector included the application of conventional pump and treat technologies at recovery well RWM-16 with additional treatment technologies being examined. (Looney and Phifer, 1994) The influence of RWM-16 in providing plume containment and control within the Southern Sector has been examined in the latest zone of capture analysis. (Jackson and Aleman, 1995) This analysis indicated that RWM-16 provides capture of only a portion of the groundwater plume that is currently located within the Southern Sector. The analysis revealed that in order to accomplish complete plume control and capture within the Southern Sector additional wells and extraction volume are required. The analysis could not fully assess the vertical component regarding plume containment and control due to the limited vertical refinement of the Lost Lake Aquifer and M-Area Aquifer Zones. The model used to perform the capture analysis for RWM-16 was developed by explicitly discretizing each of the aquifer and confining zones within the model. This approach resulted in each aquifer and confining zone being represented in the model by one vertical element. The lack of vertical refinement limits the assuracy of the previous model in accessing the performance of partially penetrating wells of the type required to optimize the Southern Sector remediation system. As presented in following sections, the distribution of the dissolved TCE plume within the Southern Sector is influenced by several parameters which result in a distinct wedge shaped plume when examined in cross section. Due to the relatively low concentrations of contaminant within the Southern Sector and the large plume size, optimum Southern Sector remediation should incorporate carefully located wells selectively screened vertically within the flow path trajectory. This approach will minimize water treatment costs and maximize contaminant removal. 
In addressing remediation programs within the Southern Sector of the A/M-Area, SRS investigators are seeking alternative methods over conventional pump and treat technologies. (Looney and Phifer, 1994) The conventional pump and treat systems provide excellent hydraulic control and remediation in regions where the contamination levels are significantly high and extend over a large vertical extent. These are the conditions that are present near the suspected source regions within the Central and Northern Sectors of the A/M Area. The application of conventional pump and treat technologies within these regions have been very successful and effective in regards to capturing and controlling the plume. The fully penetrating well configuration provides a very effective means of plume containment and control in these regions that contain possible DNAPL source terms below the water table. Contrasting that, within the Southern Sector average groundwater concentrations are several orders of magnitude less than those found in the source zones. In addition, recent characterization programs within the Southern Sector reveal that the majority of the dissolved plume is located in the lower portion of the Lost Lake Aquifer Zone. (WSRC, 1993c) In accordance with the renewal RCRA permit for the M-Area Hazardous Waste Management Facility submitted in 1992, actions required include the installation of a groundwater recovery system to establish hydraulic control and treatment of groundwater contaminated with greater than $500 \mathrm{ppb}$ trichloroethylene within the Southern Sector. In order to cost effectively achieve the necessary hydraulic control and treatment, a series of vertical recirculation wells are planned for installation within the Southern Sector of the A/M Area.

The application of vertical recirculation wells (VRW) for the treatment of VOC contaminated groundwater is an in-situ process developed at Stanford University. The system uses a combination of existing technologies including air stripping, air-lift pumping, and extraction well pumping. (Gvirtzman and Gorelick, 1992) The VRW system consists of a well with an upper and lower screen zone, an air injection blower with an associated eductor placed in the well at the lower screen zone, and vacuum removal of the off-gas at the well-head. Air is injected into the eductor at the lower screen zone. As the air bubbles rise, the density of the water decreases and an upward flow is induced within the well-bore. This creates a localized groundwater recirculation zone between the upper and lower screen sections. When this recirculation zone is combined with the regional groundwater flow pattern, the up-gradient contaminant plume is captured and treated via multiple circulations through the well. One of the major advantages of the system is that the contaminated groundwater is not brought to the surface, thus there is no surface water discharge associated with the technology. Within the well-bore, the rising water and air bubbles flow upward and the volatile contaminants are transferred from the water phase to the vapor phase. If concentration levels in the gas phase are significant, the off-gas removed by vacuum removal at the well-head can be treated prior to atmospheric discharge. Dependent upon local conditions the hydraulic performance of the system can be enhanced with the addition of a pump to lift the water in the well. However, this technique reduces contact between the injected air and the contaminated water which decreases stripping efficiency of the system. (Herrling et al., 1991b) An additional advantage of the VRW system is that oxygen and nitrogen from the injected air dissolve into the water and are transported into the aquifer. These components are often used by indigenous bacteria in the bioremediation of certain organic compounds. 


\section{Background Information of the A/M Area}

The A/M Area soil and groundwater contamination is a result of previous waste disposal practices. The primary source of contamination is the former M-Area Settling Basin, an 8-million gallon impoundment that received waste effluent from the fabrication of reactor fuel and target assemblies in the M-Area. The effluent discharged to the unlined M-Area Settling Basin contained heavy metals and chlorinated solvents. The majority of the metals, which include aluminum, nickel, depleted uranium, and lead, where effectively captured in the shallow sediments beneath the basin. In regards to the chlorinated solvents, an estimated 13 million pounds of solvents were used in the M-Area process from 1952 through 1982.

(Marine and Bledsoe, 1984) Of this approximately 3.5 million pounds were released as process waste to the M-Area Basin and the A-014 Outfall. Best available estimates contribute 2 million pounds released to the M-Area basin and 1.5 million pounds released to the A-014 Outfall. Figure 2 presents the estimated release rates to the M-Area Basin and the A-014 Outfall as presented from these previous studies. These releases have resulted in the contamination of the soil and groundwater within the A/M Area.

\subsection{Hydrostratigraphy}

With the discovery of dissolved chlorinated solvents within the subsurface in 1981, several efforts have been supported by SRS to characterize the sediments within the A/M Area. (Gordon, 1982) (Christensen and Gordon, 1983) (Marine and Bledsoe, 1984) (Fallaw and Sargent, 1982) (Fallaw, 1991) (Snipes, 1991) (Lewis and Aadland, 1992) (Lewis and Aadland, 1994) (Aadland et al., 1995b) The latest of these representations (Aadland et al., 1995b) defines hydrostratigraphic units based upon hydraulic properties of unconsolidated sediments. This hydrostratigraphic representation was originally presented in 1992 (Lewis and Aadland, 1992), and reissued in 1994 to include additional well information not available for the 1992 publication. (Lewis and Aadland, 1994) The most recent version (Aadland et al., 1995b) includes information from the characterization activities associated with the Northern Sector, the Southern Sector (WSRC, 1993c) and the Cretaceous sediments. (WSRC, 1993a) (WSRC, 1994a) These characterization efforts focused on the collection and analysis of soil cores to define and characterize lithology, hydrostratigraphy, and contaminant distribution. The hydrostratigraphic units are defined based upon the hydraulic properties of the sediments within the $A / M$ Area. These properties include hydraulic conductivity, porosity, and specific storage. The A/M Area lies on the northern boundary of the Savannah River Site, which corresponds to the region where a transition of hydrogeology occurs between the Atlantic Coastal Plain to the south and the Piedmont Blue Ridge setting to the north. The Atlantic Coastal Plain is characterized by unconsolidated sediments that consist principally of sands, silts, and clays. These sediments were originally deposited on the coastal plains and deltas during numerous invasions by the sea, and these invasions caused those previously deposited sediments to be reworked by waves, ocean currents and tidal flow. These actions resulted in the development of complexly inter-bedded sediments of sand, silt, and clay that dip towards the coast line. This representation is summarized below.

In hydrogeological terms the Savannah River Site lies within the Southeastern Coastal Plain. This plain underlies the coastal regions of South Carolina, Georgia, Alabama, and Mississippi, southeastern North Carolina, and northern Florida. The Southeastern Coastal Plain is characterized by inter-bedded sands, silts, and clays that are typical of a shallow marine depositional environment. The Southeastern Coastal Plain is divided from the underlying Piedmont Hydrogeologic Providence by the Appleton Confining Zone. Within the region of the Savannah River Site the sediments of the Southeastern Coastal Plain have been grouped into three aquifer systems divided by one confining unit and one confining system. The three aquifer systems are the Floridan Aquifer System, the Dublin Aquifer System, and the Midville Aquifer System. These aquifer systems are separated by the Meyers Branch Confining System and the Allendale/McQueen Branch Confining Unit. The relationship between the aquifer systems, confining systems, and confining units within the vicinity of SRS is presented in Figure 3. As shown in Figure 3 
ESTIMATED DEGREASER SOLVENT RELEASES

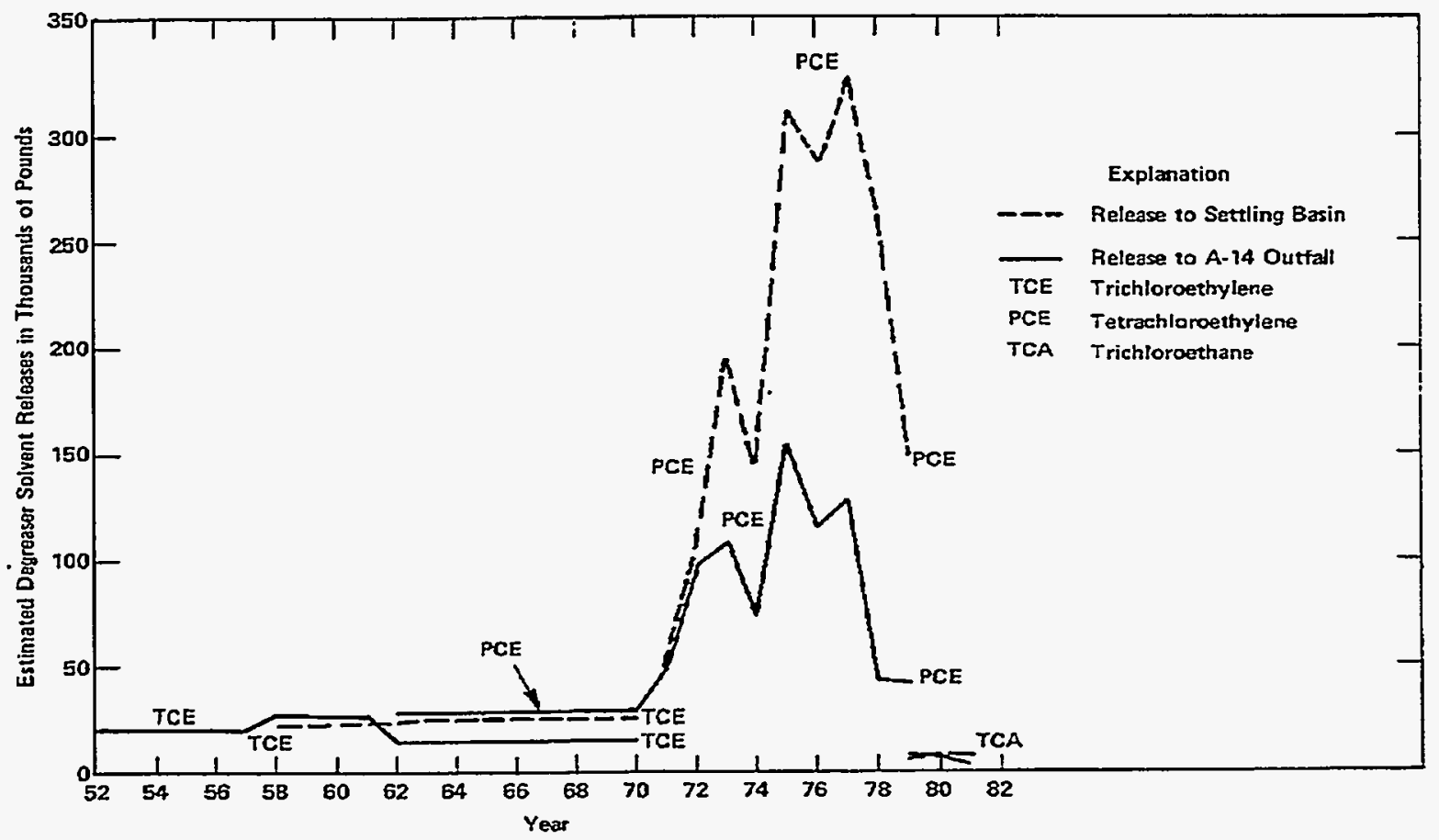

Figure 2: Estimated Annual Discharge of Degreaser Solvents to the M-Area Process Sewer System. (Adopted from Marine and Bledsoe, 1984) 
these three distinct aquifer systems become thin and discontinuous in a northerly direction. Within the vicinity of Upper Three Runs Creek, to the south of A/M Area, the three distinct aquifer systems have coalesced and are delineated as two distinct aquifer systems. Moving further northward the system forms into the single aquifer referred to as the Floridan-Midville Aquifer System. At the northern boundary of the site the three distinct units identified in the southern portion of the site have coalesced and are combined to form a single aquifer system referred to as the Floridan-Midville Aquifer System. Sediments of similar hydraulic properties of the Floridan-Midville Aquifer System have been subdivided into regional "aquifer zones" and "confining zones" that on a local scale behave as a single hydrostratigraphic unit.

The hydrostratigraphy in $\mathrm{A} / \mathrm{M}$ Area consists of three aquifers of the Floridan-Midville Aquifer System. These aquifers, in descending order, are the Steed Pond Aquifer, the Crouch Branch Aquifer, and the McQueen Branch Aquifer. The Steed Pond Aquifer is comprised of the regionally defined M-Area Aquifer Zone, the Green Clay Confining Zone, and the Lost Lake Aquifer Zone. In those regions where the Green Clay Confining Zone thins and disappears the M-Area Aquifer Zone coalesces with the Lost Lake Aquifer Zone and is referred to as the Steed Pond Aquifer. The Steed Pond Aquifer is separated from the Crouch Branch Aquifer by the Crouch Branch Confining Unit. This confining unit is represented by three distinct zones. These zones in descending order are the "Upper Clay" Confining Zone, the "Middle Sand" Aquifer Zone, and the "Lower Clay" Confining Zone. The "Upper Clay" Confining Zone thins and disappears towards the northern edge of A/M Area. In this region the "Middle Sand" Aquifer Zone coalesces with the Lost Lake Aquifer Zone and the M-Area Aquifer to form the Steed Pond Aquifer. Beneath the Crouch Branch Confining Unit lies the Crouch Branch Aquifer. This unit is the principal water-producing aquifer at SRS and is the deepest unit that is penetrated with the current monitoring well system. Separating the Crouch Branch Aquifer from the lower McQueen Branch Aquifer is the McQueen Branch Confining Unit.

- This unit consists of silty sandy dark clays and is considered to be in the middle portion of the Black Creek formation. The regional zones of the Floridan-Midville Aquifer System and there relationship to each other are presented in Figure 4. Collectively, these regional zones are referred to as the hydrostratigraphy in $\mathrm{A} / \mathrm{M}$ Area and form the foundation of the remediation program in the $\mathrm{A} / \mathrm{M}$ Area.

\subsection{Groundwater Flow Patterns}

The northern extent of the $\mathrm{A} / \mathrm{M}$ Area lies just south of the groundwater divide between the Hollow Creek tributary and the Upper Three Runs Creek tributary of the the Savannah River. The major components that influence the groundwater flow within this area are recharge from precipitation, southern discharge to Upper Three Runs Creek, and drainage to the Western Swamps. The primary source of water to the subsurface is the resultant recharge from precipitation minus runoff. Recharge for the $A / M$ area enters the vadose zone and supplies the water-table with approximately 15 inches per year of groundwater recharge. (Beaudoin et al., 1991) The migration of the dissolved plume within the $A / M$ Area is generally controlled and predicted by the groundwater movement. Within the A/M Area a strong downward gradient between the Lost Lake Aquifer Zone and the M-Area Aquifer Zone exists due to the elevated topography and the mounding of the water-table. When this mounding effect is combined with the inter-bedded layers of silts, sands, and clays that are present in the subsurface of the A/M Area, a highly three-dimensional groundwater flow field is created. Within the M-Area Aquifer and the upper portion of the Lost Lake Aquifer Zone the flow is predominantly downward. Once within the lower portion of the Lost Lake Aquifer Zone the flow transitions to a horizontal southward flow due the combined presence of the Crouch Branch Confining Zone and Upper Three Runs Creek. This tributary of the Savannah River serves as a source of regional drainage for the tertiary sediments, the M-Area and Lost Lake Aquifer Zones, within the region of the A/M. A small branch referred to as Tim's Branch feeds Upper Three Runs Creek and crosses southeast of the A/M Area. Within the upper portions of Tim's Branch stream elevations are above that of the water table and the stream loses water to the aquifer system. Stream flow-rates in these regions are supported and maintained by runoff and discharges from plant operations. 


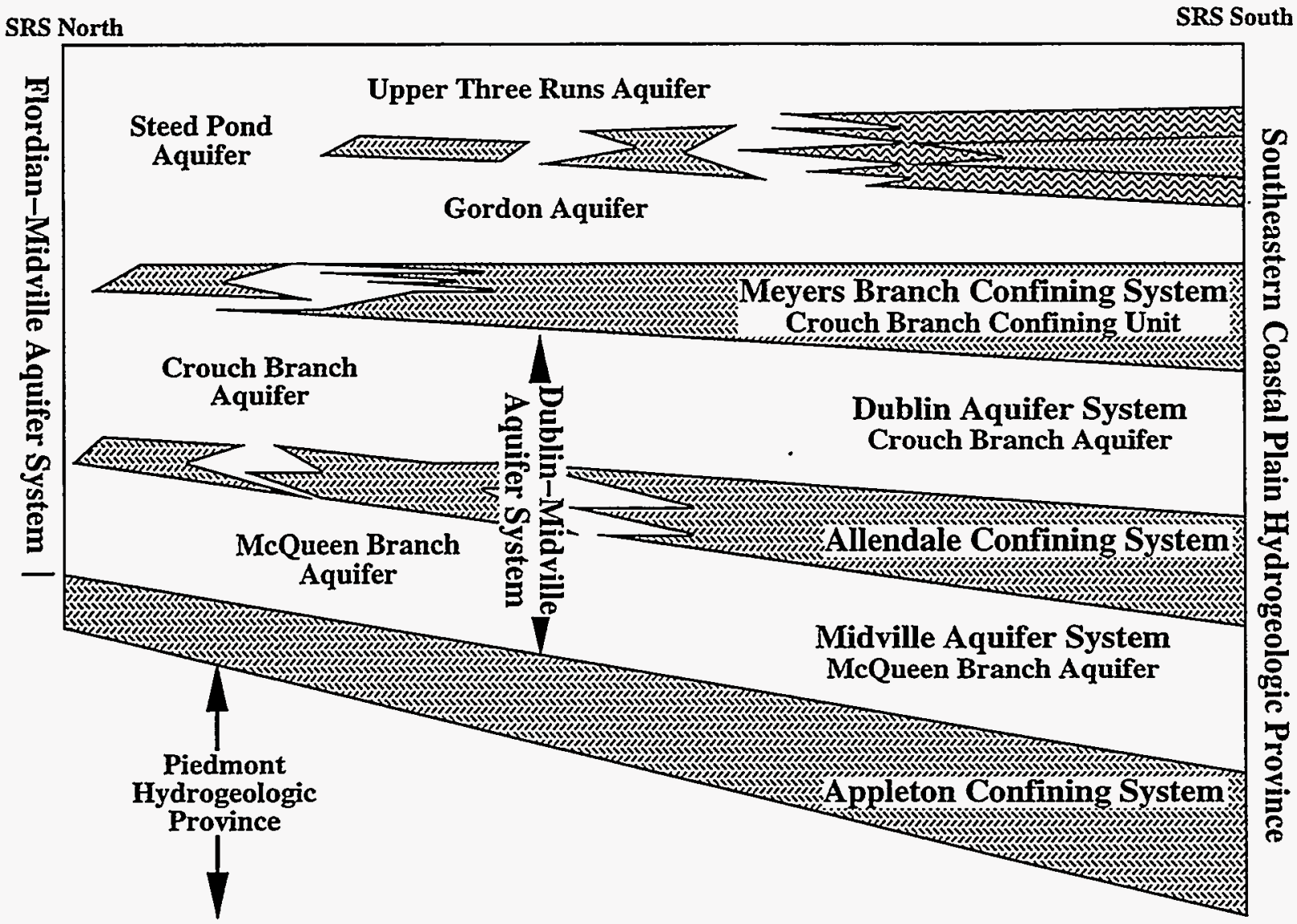

Figure 3: Relationship Between Aquifer Systems, Confining Systems, and Confining Units of the Southeastern Coastal Plain within the Vicinity of the Savannah River Site. 
Schematic Representation of the Eyctrostratigraphy of the $A / M$ Area

SRS South

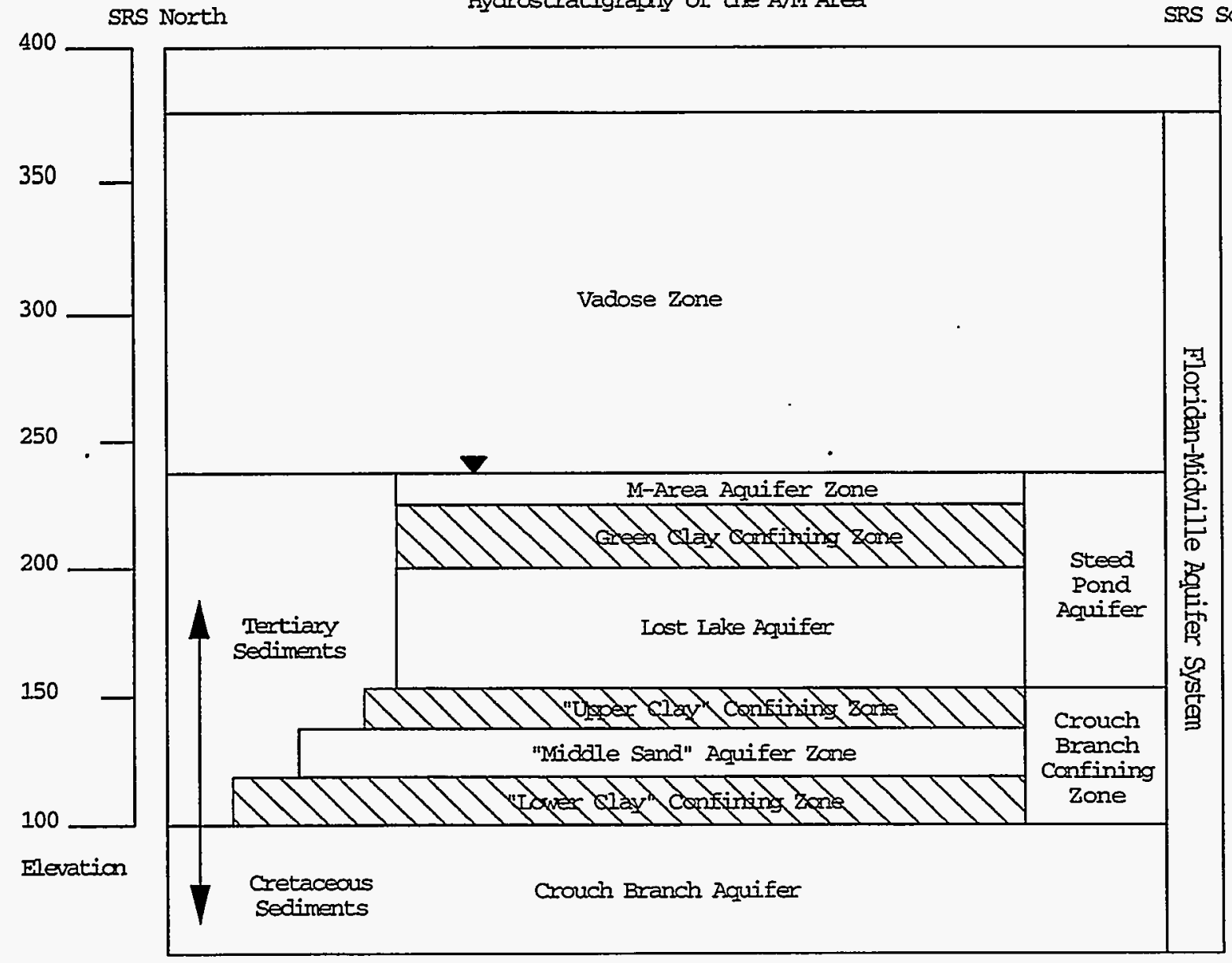

Figure 4: Hydrostratigraphic Nomenclature of the Southeastern Coastal Plain for the A/M Area Region of the Savannah River Site. 
It is likely that within these regions, particularly along the A-014 Outfall, these controlled drainages result in elevated levels of recharge to the subsurface, artificially raising the local water-table and resulting in a locally perched water. As the topography decreases along Tim's Branch the stream flow is sustained by discharge from the water table.

In addition to the transition of flow direction within the Lost Lake Aquifer Zone, the decreasing topography that occurs towards the east and south of the Central A/M Area result in the out-cropping of the regional Green Clay Confining Zone. This out-cropping results in the transition of the water table from the M-Area Aquifer Zone to the Lost Lake Aquifer Zone. Figure 5 presents a conceptual view of these conditions by presenting a North-South cross-section from the M-Area Basin to Upper Three Runs Creek. In the vicinity of the M-Area settling basin the natural elevation of the water table is mounded due to elevated topography and the presence of the Green Clay and the Crouch Branch Confining Units. Within the Lost Lake Aquifer Zone the elevated heads in the above M-Area Aquifer Zone result in a downward flow towards the lower portion of the Lost Lake Aquifer Zone. Along the horizon of the Crouch Branch Confining Unit the flow transitions from vertical to horizontal as a result of the competency of this confining zone and the natural drainage mechanism provided by Upper Three Runs creek towards the south.

As part of the groundwater remediation program in $A / M$ Area, an extensive monitoring well network has been developed and is used to detect groundwater levels and to collect samples for analysis in order to determine groundwater quality on a quarterly basis. Water level data for each quarter of 1995 (WSRC, 1995a) (WSRC, 1995b) (WSRC, 1996b) (WSRC, 1996a) was averaged and used with a minimum tension gridding algorithm to develop potentiometric maps for each of the aquifer zones. Figures 6 through 8 present the resulting distribution of hydraulic head within each aquifer zone. The data for the M-Area Aquifer Zone and the Lost Lake Aquifer Zone were supplemented with stream elevation data and applicable surface elevations to accurately represent the influences of Tim's Branch, Upper Three Runs Creek, and the Western Swamps on the potentiometric surfaces. Figure 6 presents the potentiometric surface for the M-Area Aquifer Zone which represents water-table conditions within the A/M Area. As illustrated within this figure the water level elevations vary from 220 feet above mean sea level to slightly over 240 feet above mean sea level. A significant cone of depression within the Central A/M Area is evident which results from the operation of the existing recovery well system, RWM-1 through RWM-11. A smaller cone of depression is also evident in the Northern Sector and is a result of pump and treat operations at RWM-12.

Although not evident from the potentiometric surface presented in Figure 6, the general direction of groundwater flow is downward across the Green Clay Confining Zone into the Lost Lake Aquifer Zone. The potentiometric surface for the Lost Lake Aquifer Zone is presented in Figure 7 and is significantly lower than that within the M-Area Aquifer Zone. The potentiometric levels within this aquifer zone range from 215 feet above mean sea level in the extreme south, to approximately 230 feet above mean sea level just north of the site boundary across SRS Road 1. As with the above M-Area Aquifer Zone, groundwater levels are depressed and a cone of depression is present both in the Central A/M Area and in the Northern Sector due to pump and treat operations. Within the Lost Lake Aquifer Zone a locally strong downward gradient exists across the vertical extent of the aquifer. This downward gradient is a combined result of the elevated heads in the above M-Area Aquifer, the presence of a thin and highly discontinuous clay informally separating the Lost Lake Aquifer into "upper" and "lower" regions, operation of the pump and treat remediation system, and the southward drainage to Upper Three Runs Creek. These effects combine to create locally strong downward gradients that decrease towards the south.

The Lost Lake Aquifer Zone is separated from the deeper Crouch Branch Aquifer by the Crouch Branch Confining Unit. The Crouch Branch Confining Unit is subdivided into zones referred to as the "Upper Clay" Confining Zone, the "Middle Sand" Aquifer Zone, and the "Lower Clay" Confining Zone. As previously discussed these three zones become thin and discontinuous towards the north and coalesce 
WSRC-RP-96-477

September 13,1996

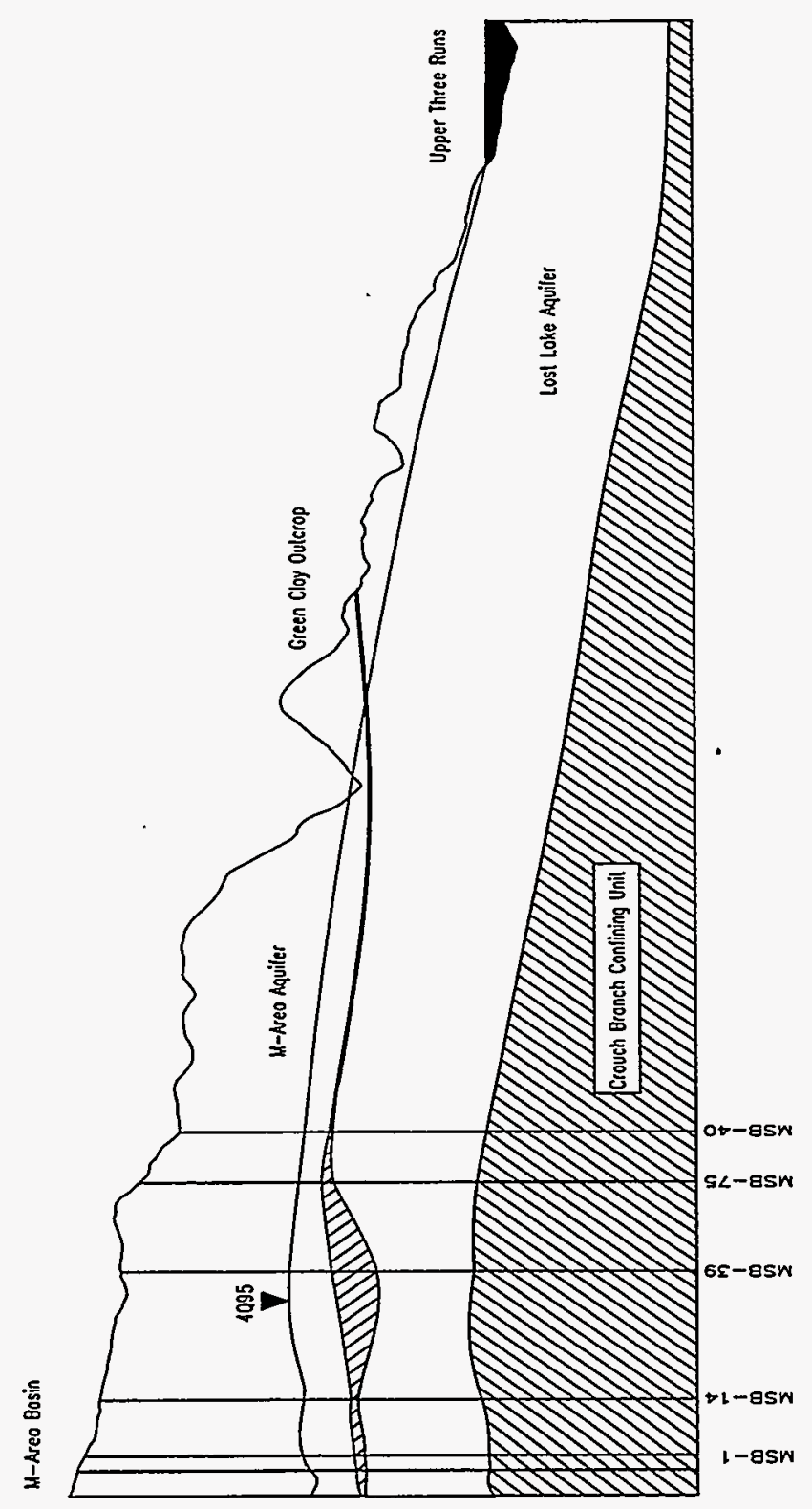

Figure 5: Cross Section from the M-Area Basin to Upper Three Runs Creek depicting Groundwater Flow Directions and Out-Cropping of the Green Clay Confining Unit. 


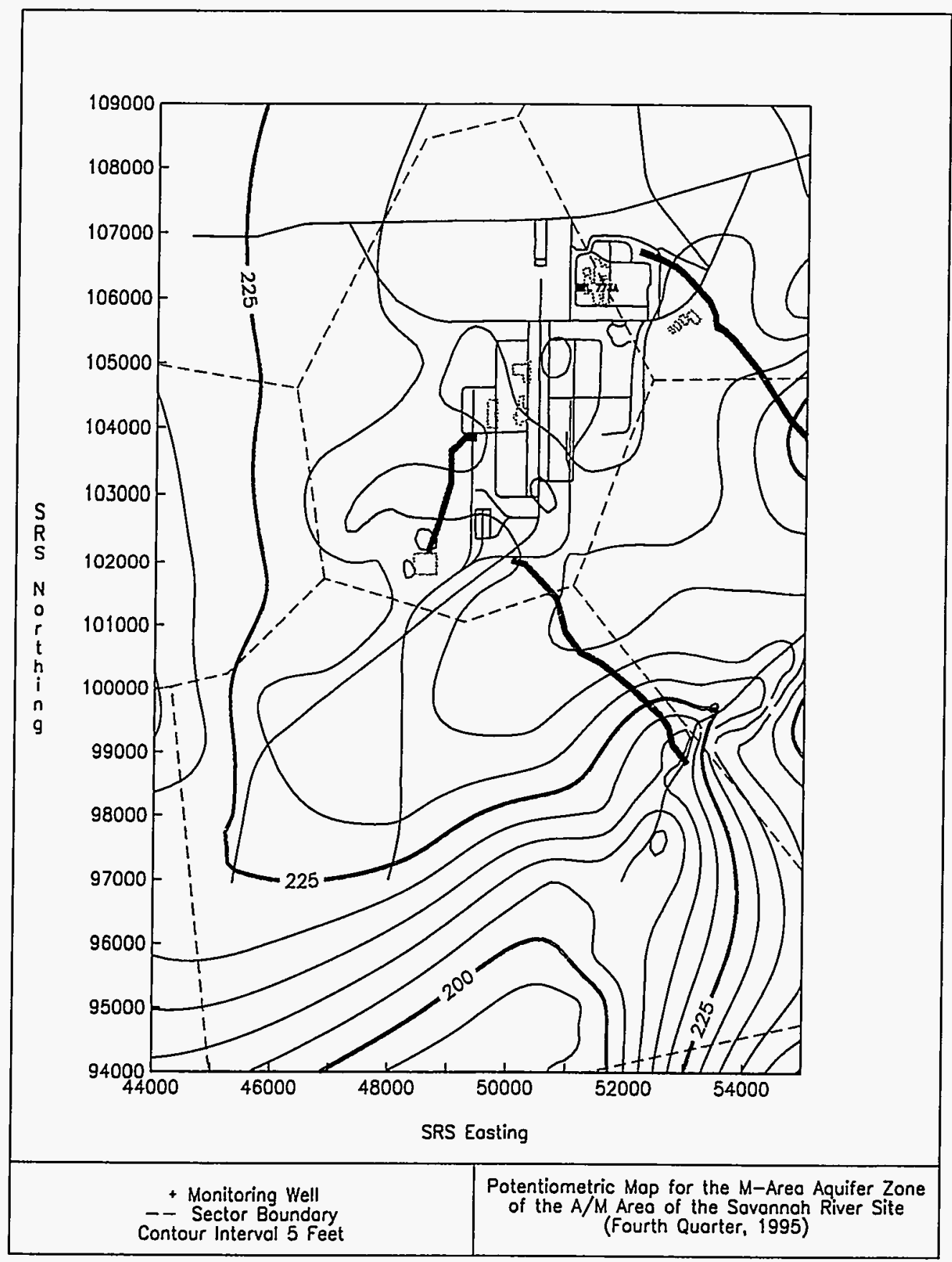

Figure 6: Potentiometric Map for the M-Area Aquifer Zone of the A/M Area. 


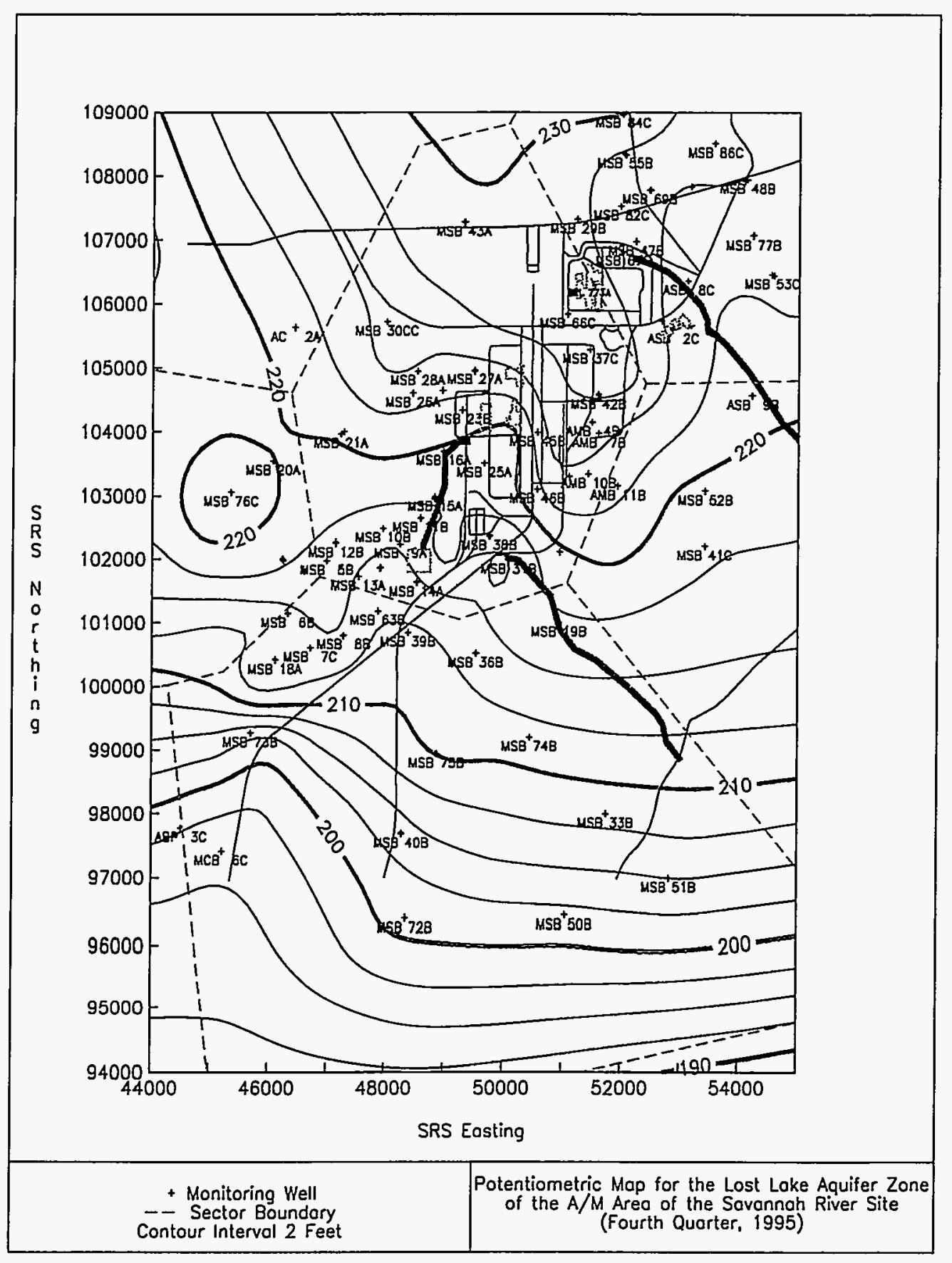

Figure 7: Potentiometric Map for the Lost Lake Aquifer Zone of the A/M Area. 
with the Lost Lake Aquifer, the Green Clay Confining Unit, and the M-Area Aquifer to form the Steed Pond Aquifer. In this region a locally strong downward gradient exists from the Tertiary to the Cretaceous sediment. This results in a recharge zone around the SRTC complex that provides water for the Crouch Branch Aquifer. Within the southern portion of the Central A/M Area and the Southern Sector, the combined Crouch Branch Confining Unit is a competent unit that separates the Tertiary and Cretaceous sediment. Figure 8 presents the potentiometric map for the Crouch Branch Aquifer Zone.

Within the A/M Area, the potentiometric levels range from approximately 184 feet above mean sea level in the extreme southwest, to slightly over 224 feet above mean sea level in the extreme northeast. The general direction of groundwater flow in this aquifer is from the northeast to the southwest. 


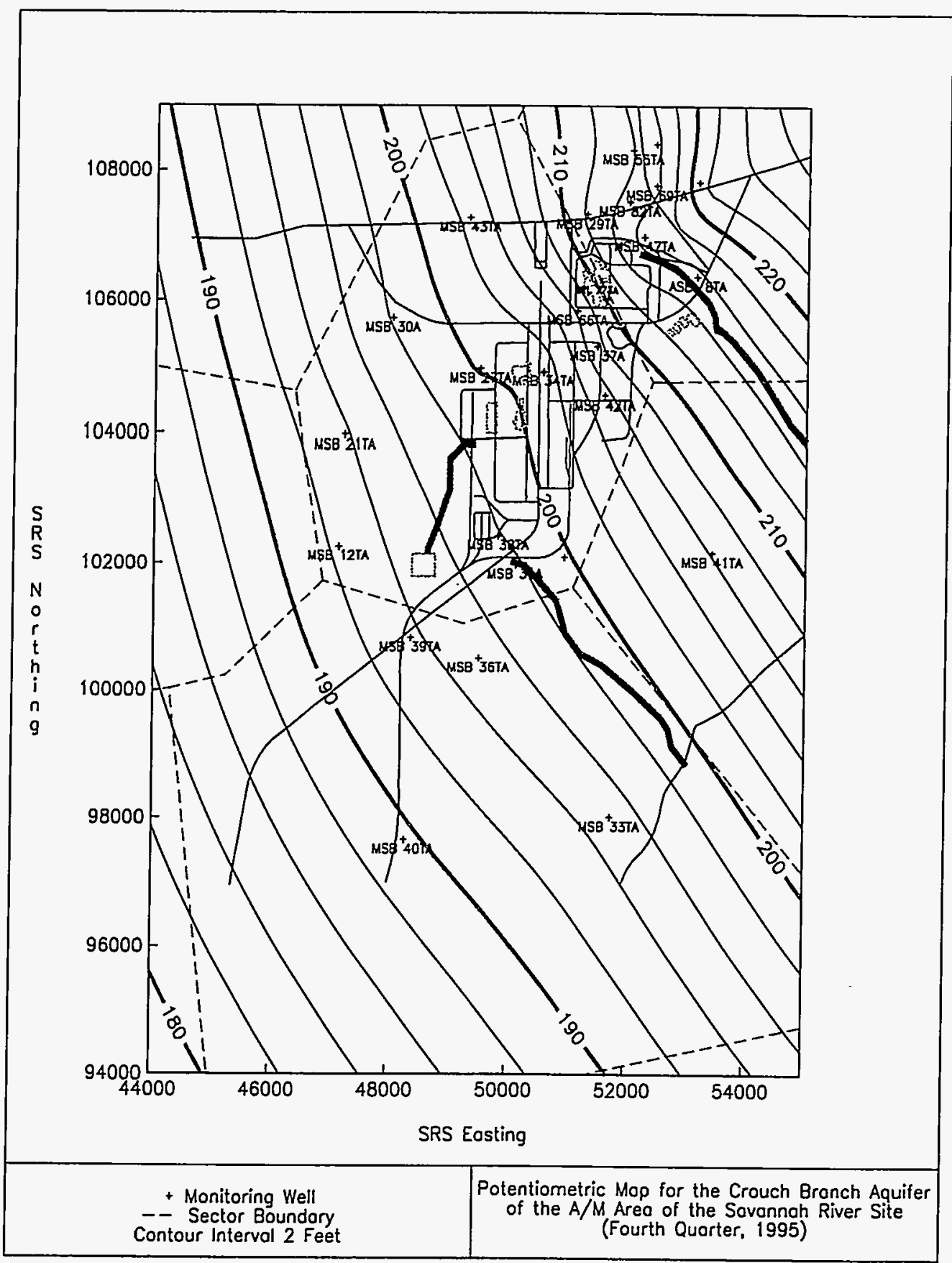

Figure 8: Potentiometric Map for the Crouch Branch Aquifer of the A/M Area. 
WSRC-RP-96-477

September 13, 1996

\subsection{Dissolved Contaminant Distributions}

As previously discussed, the general groundwater flow direction in the A/M Area is downward from the M-Area Aquifer Zone, across the Green Clay to the bottom of the Lost Lake Aquifer Zone. The flow then turns south due to drainage influence of Upper Three Runs Creek to the south and the low hydraulic conductivity of the Crouch Branch Confining Unit. As a result the primary contaminant transport mechanisms are advection and mechanical dispersion away from the source zones in the direction of groundwater flow. Molecular diffusion contributions to contaminant transport in these flow conditions are insignificant.

In order to effectively locate a system of vertical recirculation wells it necessary to understand the distribution of contaminates within the desired region. To aid in developing this understanding the three-dimensional distribution of the dissolved trichloroethylene plume within the $A / M$ Area was developed and examined. This process involved judiciously incorporating quarterly monitoring well data, depth discrete soil head-space data, the physical laws governing groundwater flow and contaminant transport with source history information. Each of these data sources provide different information as to the vertical and horizontal extent of the dissolved trichloroethylene plume. Previously developed distribution of the trichloroethylene were developed by taking horizons through each of the aquifer systems and were not able to capture the three-dimensional aspect of the dissolved contaminant plume within the A/M Area.

The purpose of the quarterly monitoring well program is to ensure that groundwater quality conditions are monitored at specific intervals and reported to authorities to satisfy federal and state regulations administered by the Environmental Protection Agency and the South Carolina Department of Health and Environmental Control. This data set provides information regarding field conditions and the results of laboratory analysis for the detection of a variety of chemical compounds that may be present within the groundwater. Groundwater samples are collected by the Environmental Monitoring Section and then analyzed by either the EPD/EMS and M-Area laboratories at SRS or by one of many off-site laboratories contracted to perform the analysis. The site's Environmental Monitoring Section has developed a rigorous quality assurance and quality control program to ensure the validity of the reported results. The design of the typical groundwater monitoring well and the method of collecting a groundwater sample results in a value representative of the bulk properties of the groundwater present in the aquifer in the vicinity of the screen zone. A monitoring well sample, typical of those reported quarterly, results in an average water sample that is representative of 5 to 20 feet of vertical extent of the aquifer. The head-space data is a screening method that provides point source data at very discrete vertical locations. The head-space data are collected during coring operations and infer the solvent present by analyzing the contaminants present in the head-space of the sample vial. (Looney et al., 1993) This screening technique is an inexpensive method that allows for the rapid characterization of the vertical distribution of volatile contaminants present. It is emphasized that due to the depth dependent nature of the head-space data, incorporation of these data types with conventional monitoring data should be very judicious. This is especially important when developing conventional two-dimensional, horizontal distributions of contaminants for a particular aquifer zone. Even though the two data sources used differ significantly they can be prudently combined to adequately represent the horizontal extent and magnitude of the contaminant plumes within each aquifer.

By incorporating the quarterly monitoring well data (WSRC, 1995a) (WSRC, 1995b) (WSRC, 1996b) (WSRC, 1996a), depth discrete soil head-space data (WSRC, 1993a) (WSRC, 1994a) (WSRC, 1993c) (WSRC, 1994b) (Van Pelt and McAdams, 1995), physical laws governing groundwater flow and contaminant transport (Freeze and Cherry, 1979) (Fetter, 1988) (Fetter, 1993), and source history information (Marine and Bledsoe, 1984), a three-dimensional representation of the dissolved trichloroethylene plume within the A/M Area has been developed. The representation was developed using a three-dimensional minimum tension algorithm. (Dynamic Graphics Inc., 1995) Figure 9 presents 
a plan view of the dissolved trichloroethylene plume determined from this process that has concentration levels greater than 500 parts per billion. Figure 10 presents a perspective view looking from the southeast into the plume with horizontal transects through the M-Area Basin. The distribution of the dissolve trichloroethylene presented is consistent with the conceptual model presented earlier. The heart of the plume is located within the Central A/M Area beneath the M-Area process facilities and along the abandoned process sewer line that led to the M-Area Basin. In examining the distribution within the Central $\mathrm{A} / \mathrm{M}$ Area a region along the process sewer line just north of the $\mathrm{M}$-Area basin has groundwater concentrations on the order of $500 \mathrm{ppb}$ at the water table compared to concentrations an order of magnitude higher in the vicinity of the M-Area process facilities. These decreased concentrations immediately north of the basin are attributed to the aggressive remediation programs along the M-Area process sewer line. (Eddy et al., 1993) Within the Northern Sector high concentrations are present that are associated with solvent disposals in the vicinity of the SRTC complex. This is the source of contamination associated with the deeper Cretaceous Aquifer system.

\subsubsection{Southern Sector Transport and Distribution}

The major source of the trichloroethylene plume within the southern sector of the A/M Area is the southward migration of dissolved solvent via advective transport mechanisms from the M-Area Settling Basin and the A-014 Outfall source zones. As shown in the extreme southwest corner of Figure 9 chlorinated solvents have been identified in the subsurface at the Miscellaneous Chemical Basin and at the A-Area Burning Rubble Pits. These source zones are not the primary source of groundwater contamination in the Southern Sector. Dissolved chlorinated solvents have been detected at several horizons using a variety of methods including quarterly monitoring well data and depth discrete head-space analysis. The current conceptual model attributes the Miscellaneous Chemical Basin and the A-Area Burning Rubble Pits source zones with the dissolved plume present in shallow M-Area Aquifer Zone. The deeper contaminants present in the lower portion of the Lost Lake are attributed to the southward migration of the dissolved plume from the M-Area basin and the A-14 Outfall. The deepest contaminants present in the Cretaceous sediments are attributed to the migration of a dissolved plume from the Northern Sector. The horizontal and vertical extent of this plume within the Southern Sector is complex due to the heterogeneous subsurface conditions found within the A/M Area. As shown in Figure 10 the heterogeneous conditions, which govern the advective transport mechanisms, have distributed the dissolved solvent away from the M-Area Basin source zone in a wedge of decreasing thickness that lies along the principle direction of groundwater flow.

The conceptual model of plume migration and distribution presented is supported by examination of the historical concentrations of trichloroethylene for those wells along a southward path from the M-Area basin towards Upper Three Runs creek. The cross-section presented in Figure 5 is comprised of well clusters MSB 1, MSB 14, MSB 39, MSB 75, and MSB 40. With the exception of MSB 75, which lacks a water table well, each of these clusters has an individual well screened within the M-Area Aquifer (water table), the upper portion of the Lost Lake Aquifer Zone, and the lower portion of the Lost Lake Aquifer Zone. Figure 11 presents the historical concentrations from $1 Q 88$ to $2 Q 95$ for trichloroethylene in the M-Area Aquifer (water table) for each of these well clusters. Similar plots are presented in Figure 12 for the upper portion of the Lost Lake Aquifer Zone and in Figure 13 for the lower portion of the Lost Lake Aquifer Zone. Figure 11 indicates that the concentration of TCE present in the water table immediately south of the M-Area Basin is on the order of 10-20 parts per billion in MSB 1D and MSB 14C and drops to below detection as one moves southward towards wells MSB 39D and MSB 40D. The fact that concentrations in MSB $1 \mathrm{D}$ and MSB 14C are not significantly high is attributed to the depression of water-levels in the Central A/M Area, both wells historically go dry during purging preventing the collection of a sample that is "representative" of groundwater conditions. The historical concentrations presented are in agreement with the conceptual model in that waste solvents entered the basin from the process sewer at the northeast corner where the principle direction of groundwater flow is downward into 


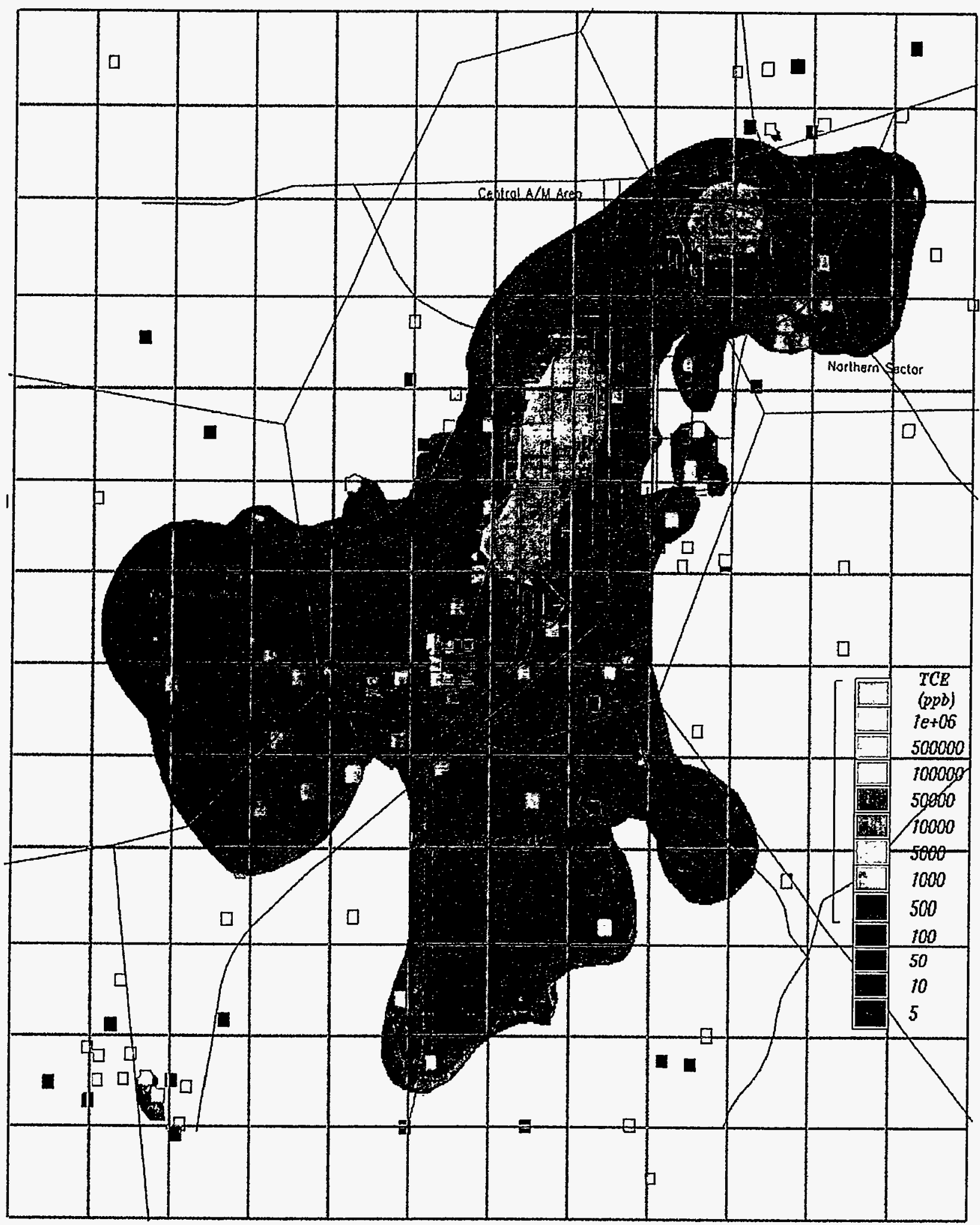

Figure 9: Plan View of the Dissolved Trichloroethylene Plume in the A/M Area of the Savannah River Site showing groundwater concentrations greater than 500 parts per billion. 


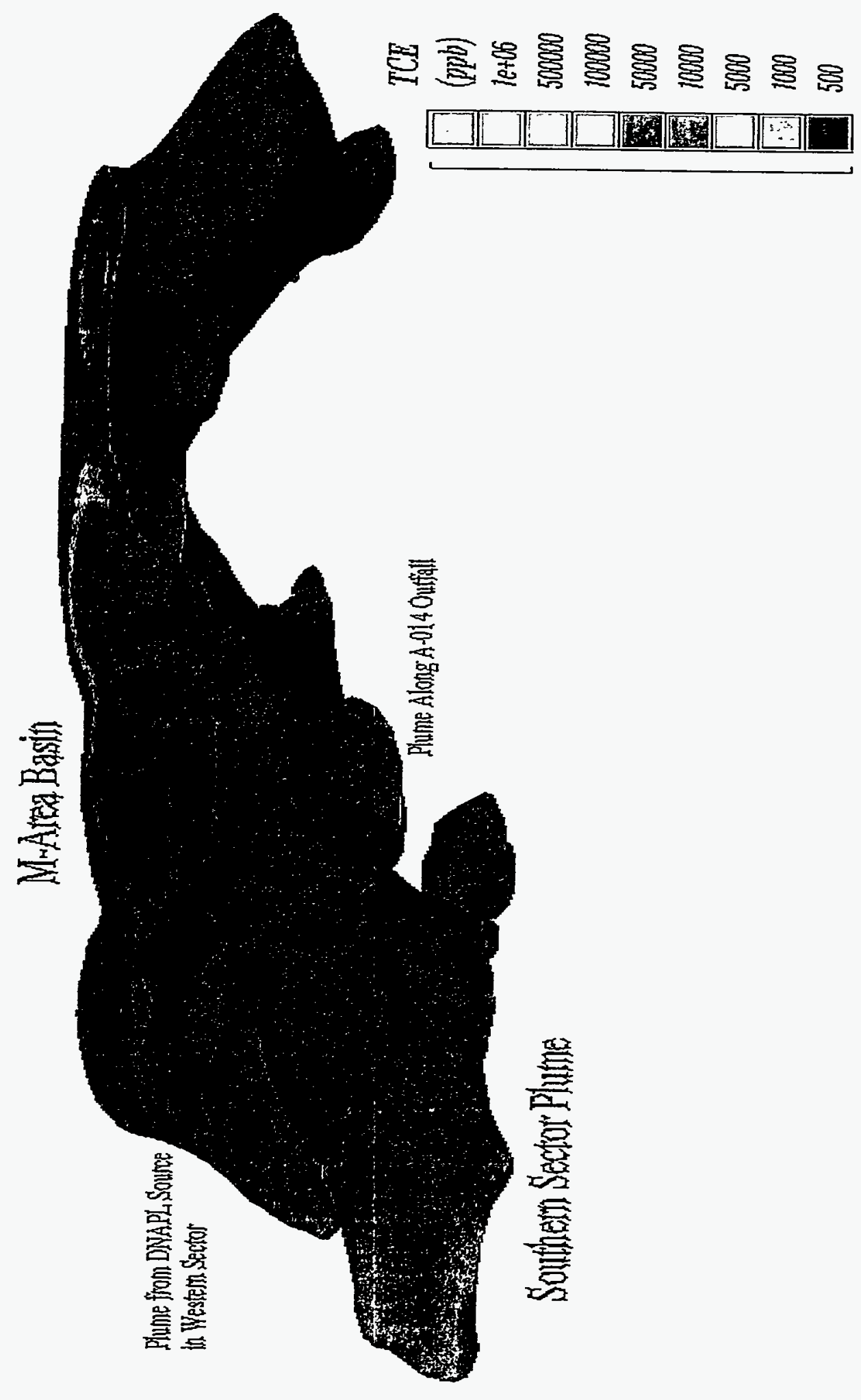

Figure 10: View of the Dissolved Trichloroethylene Plume Looking from the Southeast showing groundwater concentrations greater than 500 part per billion. 
the Lost Lake Aquifer Zone. As one moves southward in the M-Area Aquifer towards MSB 39D and MSB 40D, away from the source zones and perpendicular to the direction of groundwater flow, the trichloroethylene concentrations are below detection limits.

Comparing the time histories for the wells screened within the M-Area Aquifer to those for wells screened within the upper portion of the Lost Lake Aquifer Zone, Figure 12, it is observed that the trichloroethylene concentration at MSB 14B was approximately $110 \mathrm{pbb}$ in 1988 , and has decreased at a constant rate to approximately $45 \mathrm{ppb}$ in 1995 . Again well MSB 1CC traditionally goes dry during purging, but well MSB 14B is properly purged and provides a "representative" sample of the aquifer conditions. The steady decline in concentrations observed at well MSB 14B can be attributed to pump and treat remediation activities, most notably the operation of RWM 10 on the western side of the basin. The trend and behavior of trichloroethylene concentrations at MSB $39 \mathrm{C}$ is analogous to those observed at MSB 14B. Further towards the south the historical Concentrations at MSB 40C began increasing above detection limits in mid 1990 and reached a maximum value $19.7 \mathrm{ppb}$ in the second quarter of 1993 . Since this time trichloroethylene values have steadily decreased to a level of $5.37 \mathrm{ppb}$ in the second quarter of 1995. The increase and decrease of dissolved trichloroethylene observed in the upper portion of the Lost Lake Aquifer is again attributed to the operation of the pump and treat system within the A/M Area. Applying a very simplistic conceptual model the increase of concentrations observed can be associated with the that portion of the dissolved plume that had migrated south of the M-Area Basin prior to pump and treat operations, which began in September 1985. With the pump and treat system installed and operating the portion of the plume in the upper Lost Lake that was migrating towards MSB 40C was captured, as observed by the decline in concentrations at MSB 14B and MSB 39C during this period. This capture was observed exactly eight years later in the third quarter of 1993 when the dissolved trichloroethylene concentrations in the groundwater dropped to $13 \mathrm{ppb}$ and have steadily.decreased with the same rate observed at MSB $14 \mathrm{~B}$ and MSB 39C. Well MSB $75 \mathrm{C}$ historically goes dry during sampling, precluding the collection of a "representative" sample of the aquifer conditions. This is most likely associated with poor well development after the initial installation. Based upon the siting and positioning of MSB 75C, concentrations should have increased steadily reaching a maximum value of approximately 30-40 ppb in 1991 and then decreasing at the same rate observed at MSB 14B, MSB 39C, and MSB 40C.

Within the lower portion of the Lost Lake Aquifer Zone the historical concentrations as shown in Figure 13 are significantly greater than those observed in the M-Area Aquifer or in the upper portion of the Lost Lake Aquifer. Additionally it is observed that the pump and treat operations have had little or no impact on historical concentrations along this horizon. In applying the conceptual model with historical concentration values along this horizon several factors must additionally be considered. First, Well MSB $1 \mathrm{C}$ historically goes dry during sampling, again precluding the collection of a "representative" sample of the aquifer conditions. Well MSB 14A has a screen length of 20 feet compared to only five feet for each of the other wells screened along this horizon. This longer screen zone accounts for the level of noise observed in the historical concentrations for MSB 14A that is presented in Figure 13. Wells MSB 1B, MSB 39B, and MSB 40B are positioned immediately on top of the Crouch Branch Confining Unit in the lowest portion of the Lost Lake Aquifer Zone while MSB 75B is located more towards the center of the Lost Lake Aquifer Zone. These factors and the historical concentration values allow for the refinement of our conceptual model in order to understand how the core of the dissolved trichloroethylene plume in the Southern Sector has migrated from the source zones to MSB 40B. Originating at the M-Area Basin, most likely near the DNAPL zone on the northern side, the plume has migrated downward into the upper portion of the Lost Lake Aquifer where the plume turns toward the south and Upper Three Runs Creek. As the plume emerges on the south edge of the M-Area basin the core of the plume intersects wells MSB $1 \mathrm{C}, \mathrm{MSB} 1 \mathrm{CC}$ and MSB 14A. The core of the plume then passes over the effective screen zone of MSB 39B before fully migrating to the bottom of the Lost Lake Aquifer Zone. Since well MSB 75B is screened more towards the center of the Lost Lake Aquifer zone the core of the plume passes below the screen zone and accounts for the historical concentrations less than those observed at well MSB 40B which is 
down-gradient and screened immediately on top of the Crouch Branch Confining Unit. This depiction is presented in Figure 14 which shows the trichloroethylene concentrations in a vertical cross section through the M-Area Basin towards MSB 40.

\subsubsection{Western Sector Transport and Distribution}

The dissolved trichloroethylene plume present in the M-Area Aquifer Zone and in the Lost Lake Aquifer Zone in the Western Sector of the A/M Area is attributed to the subsurface migration of DNAPL from the M-Area Basin westwards towards MSB 76C. The subsurface DNAPL serves as a long term source zone for dissolved contamination. Groundwater flow patterns result in the advective transport of dissolved solvent downward across the Green Clay Confining Zone and into the Lost Lake Aquifer Zone. Unlike the plume directly south of the basin, once within the Lost Lake the groundwater flow patterns turn towards the southwest due to the combined effects of Upper Three Runs Creek and the "Western Swamps" creating a large plume within the Lost Lake Aquifer that is migrating from the M-Area Basin and the DNAPL source zones towards the southwest. Migration of this portion of the plume appears to be concentrated along a southwest line from MSB 12 towards MSB 49 . Figure 19 presents a vertical cross-section along this line showing the distribution of dissolved trichloroethylene and migration path from the suspected DNAPL towards MSB 76C to the southwest. As with the Southern Sector portion of the plume earlier, historical trichloroethylene concentration levels are examined to aid in validation of the distribution presented in Figure 19. The historical concentration levels for the monitoring wells in the Western Sector were examined and indicate that the higher concentrations of dissolved contaminants have migrated from the upper portion of the Lost Lake Aquifer into the lower portion of the Lost Lake Aquifer Zone. Figure 15 presents historical trichloroethylene concentrations for wells MSB 12D, MSB 5A, MSB 64D, MSB 6A, MSB 18C.and MSB 49D located in the M-Area Aquifer Zone. As shown the historical concentrations are very low with wells MSB 12D and MSB 5A having maximum concentration values on the order of $40-60 \mathrm{ppb}$ in the early 1990's. Since then the concentration values have decreased to below detection in each of these wells. The low concentration values for these two wells is attributed to the fact that they are located well above the altitude of the Green Clay Confining Zone. The groundwater flow directions in the suspected DNAPL zones to the north are downward away from these screen zones. Figures 16 and Figure 17 presents historical trichloroethylene concentrations for wells MSB 12C, MSB 12B, MSB 5C, MSB 64C, MSB 6C, and MSB 18B located in the upper portion of the Lost Lake Aquifer. Due to the order of magnitude differences in the concentration levels from MSB $12 \mathrm{C}$ to MSB 12B, the data is presented in two separate figures. The first figure, Figure 16 presents historical concentrations of dissolved trichloroethylene at MSB 12C and MSB 12B well over 20,000 ppb. As with the data from the Southern Sector, the historical concentrations at MSB 12C and MSB 12B began increasing at a sharp rate in the fourth quarter of 1991 and reached a maximum in the first quarter of 1993 and have continued decreasing at a constant rate. This trend can most likely be attributed to the operation of the existing pump and treat system within the Central A/M Area. Continuing along the southwest-ward flow line in the upper Lost Lake Aquifer the groundwater concentrations at wells MSB 5C, MSB 64C, MSB 6C, and MSB 18B are presented in Figure 17. These wells have historical concentration levels two orders of magnitude less than those present at MSB 12C and MSB 12B. It is noted that well MSB $5 \mathrm{C}$ historically goes dry during sampling, precluding the collection of a "representative" sample of the aquifer conditions. Concentration levels at MSB 64C have steadily decreased, while it appears that concentration levels at MSB 6C are starting to increase. This behavior can again be attributed to the installation and operation of the groundwater pump and treat system in the Central A/M Area. As additional data is collected the decreasing trend at MSB 64C should continue and concentrations at MSB $6 \mathrm{C}$ should reach a maximum and begin an analogous decreasing trend. Figure 18 presents historical trichloroethylene concentrations for wells MSB 12A, MSB 5B, MSB64B, MSB 6B, and MSB 49B located in the lower portion of the Lost Lake Aquifer. Each of the wells within this set exhibit an analogous increasing trend in dissolved trichloroethylene concentration. These factors and the historical concentration values allow for the refinement of the conceptual model in order to understand 


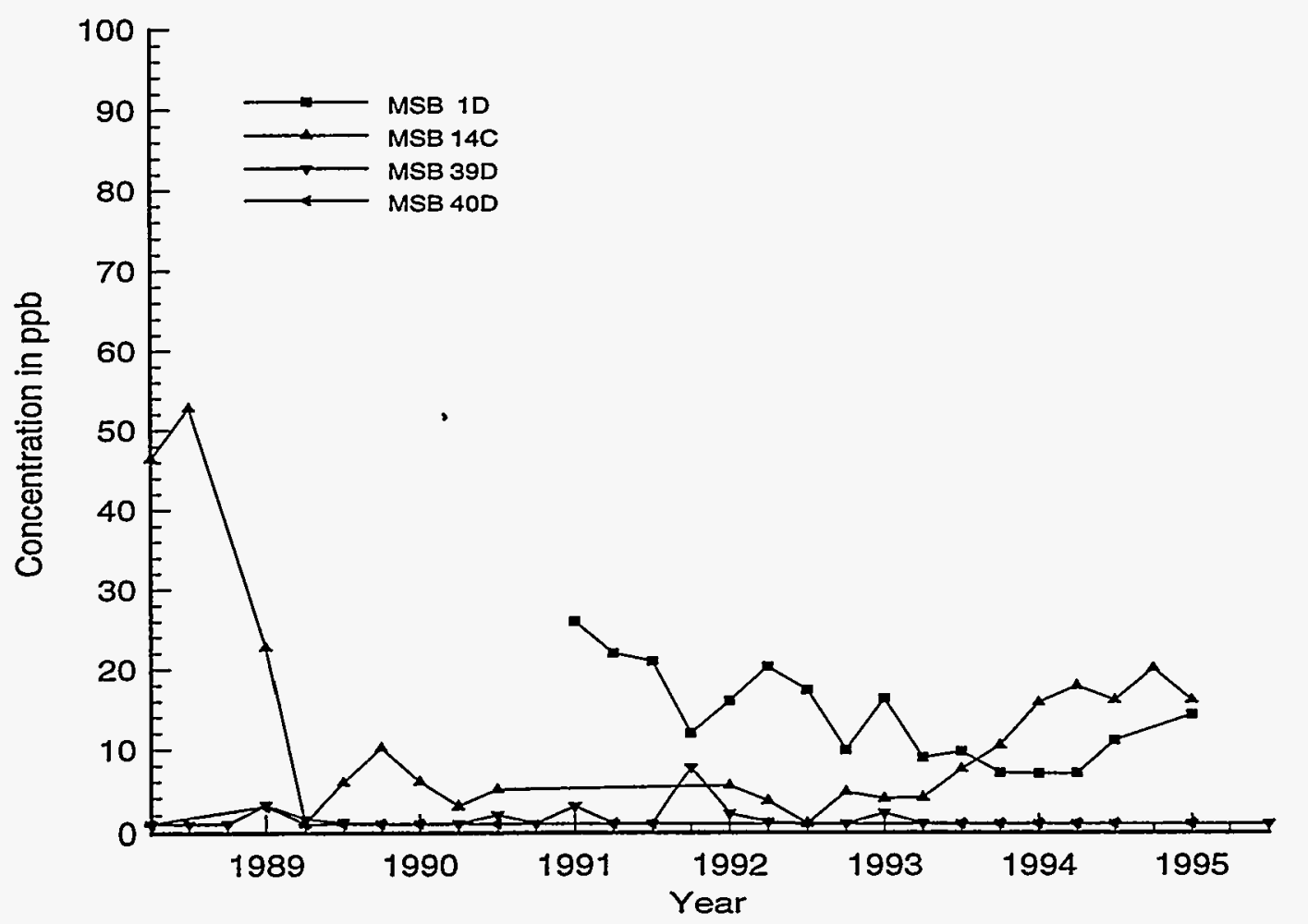

Figure 11: Historical Trichloroethylene Concentrations for wells MSB 1D, MSB 14C, MSB 39D, and MSB $40 \mathrm{D}$ located in the M-Area Aquifer. 


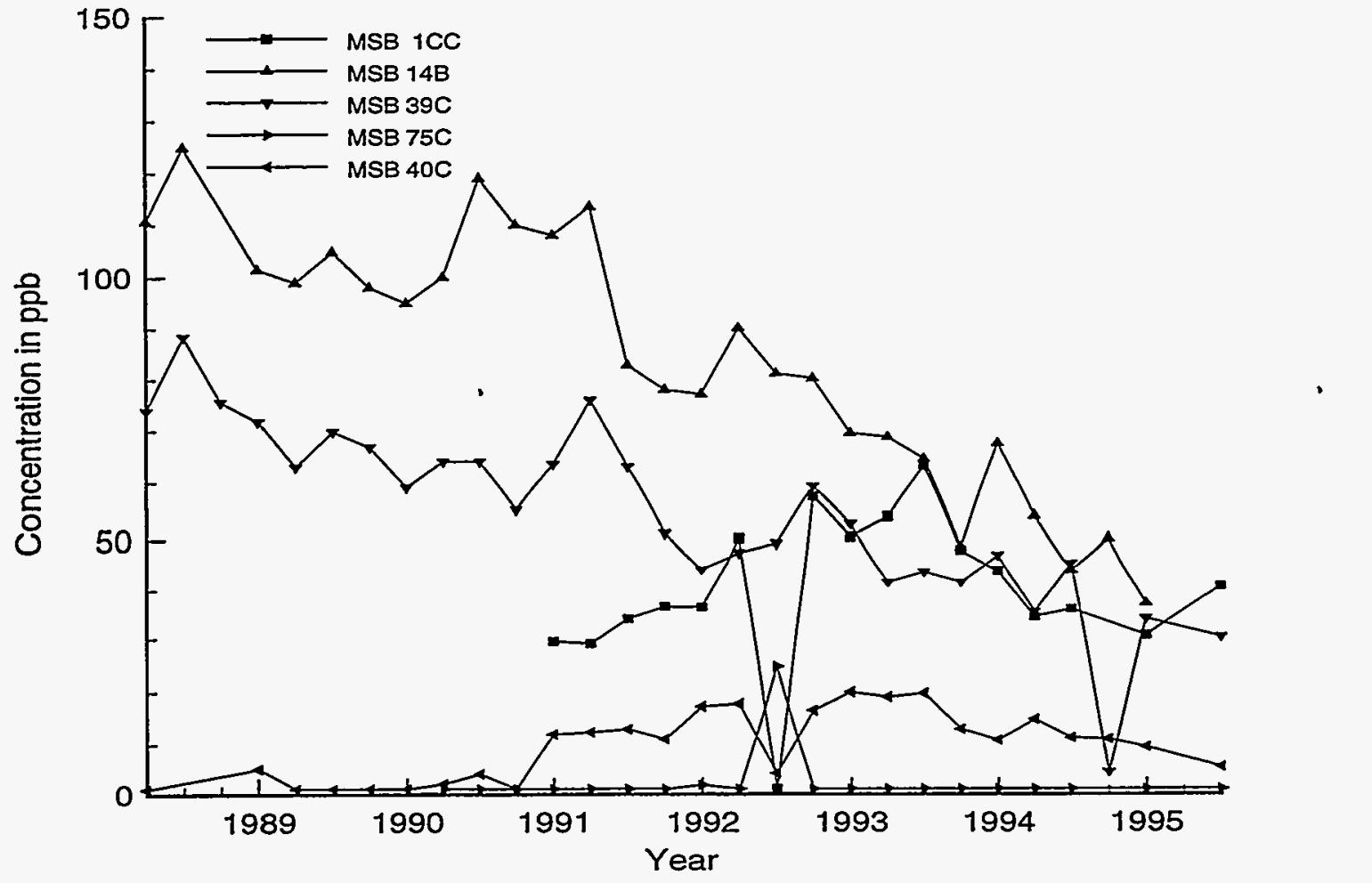

Figure 12: Historical Trichloroethylene Concentrations for wells MSB 1CC, MSB 14B, MSB 39C, MSB $75 \mathrm{C}$, and MSB $40 \mathrm{C}$ located in the Upper portion of the Lost Lake Aquifer. 


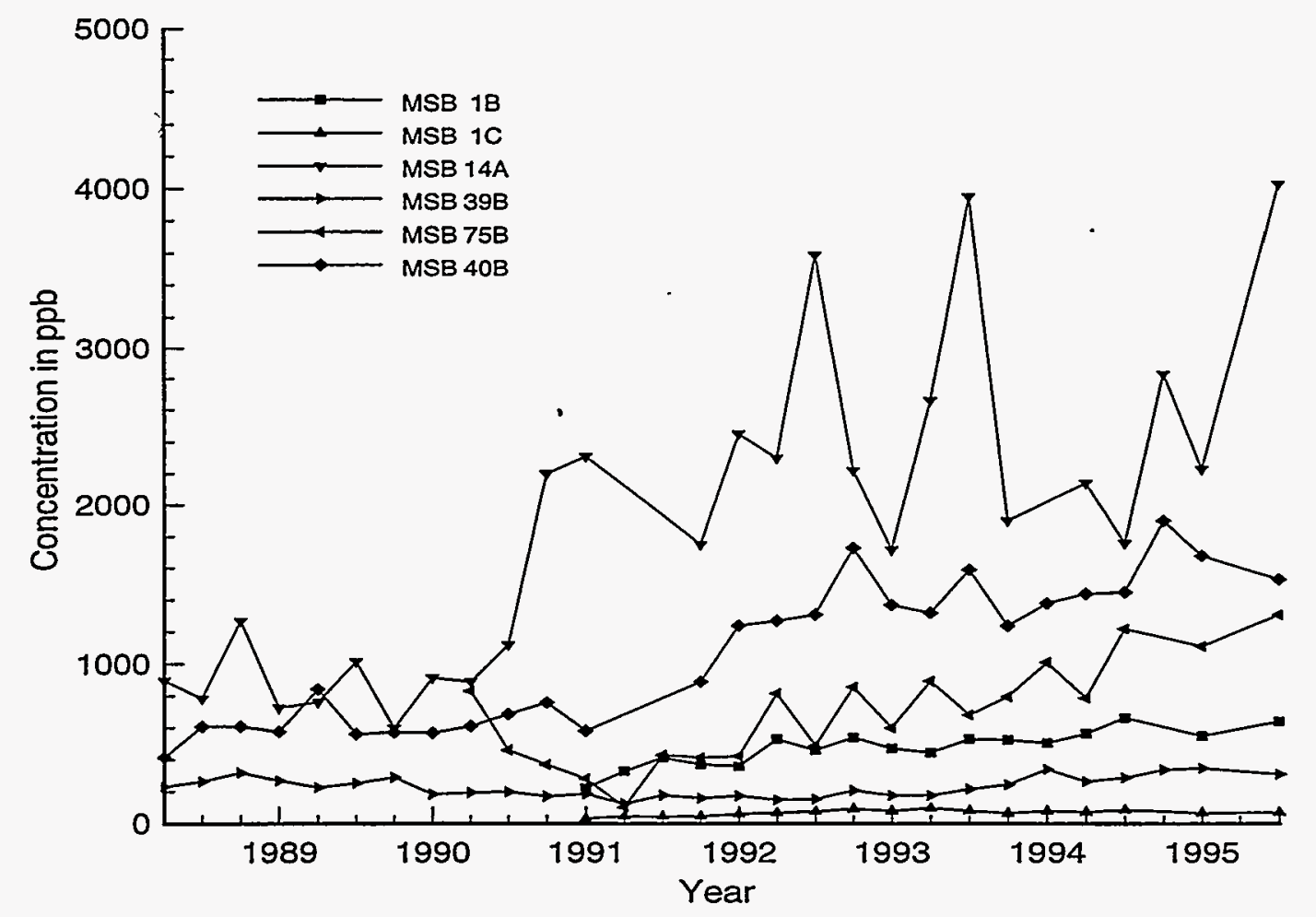

Figure 13: Historical Trichloroethylene Concentrations for wells MSB 1C, MSB 1B, MSB 14A, MSB 39B, MSB 75B, and MSB 40B located in the Lower portion of the Lost Lake Aquifer. 


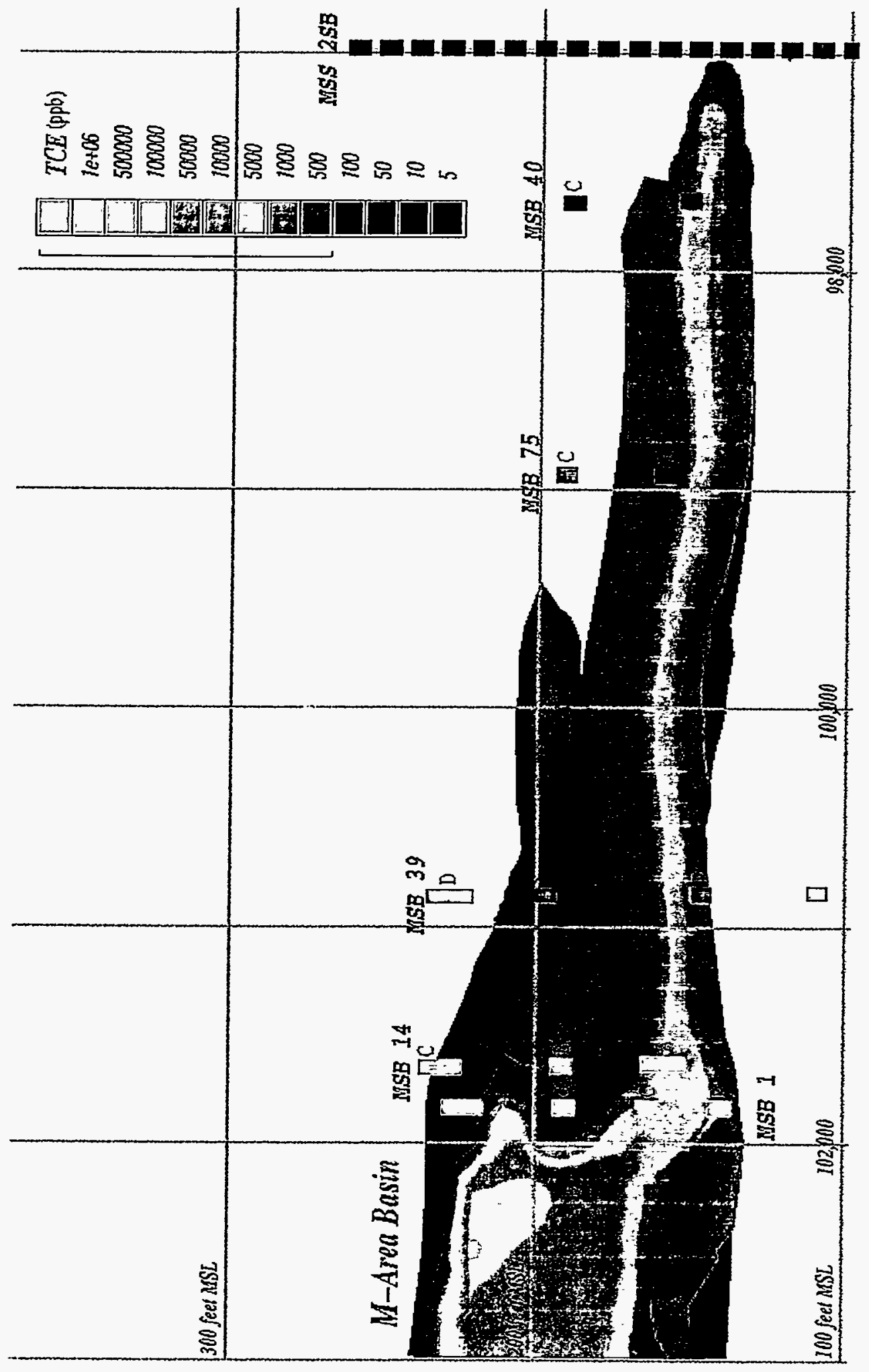

Figure 14: Vertical Cross-Section along SRS Easting 48,500 Showing 4Q95 Distribution of Dissolved Trichloroethylene and migration path from the MI-Area Basin to the Southern Sector of the A/M Area. 
the migration path of the dissolved trichloroethylene plume southwest of the M-Area Basin towards MSB 49. The groundwater in the DNAPL source zones west of the M-Area Basin moves downward across the Green Clay Confining Zone into the upper portion of the Lost lake Aquifer. Within the Lost Lake regional drainage features of Upper Three Runs Creek to the south and the "Western Swamps" result in groundwater flow directions that are towards the southwest. The principle flow line is from MSB $12 \mathrm{C}$ in the upper portion of the Lost Lake to MSB $49 \mathrm{M}$ in the lower portion of the Lost Lake as evident from historical dissolved concentration levels. Of note is the relatively low concentrations observed at MSB 5B, which is located along the flow-path from MSB 12C and MSB 12B towards MSB 64B. This flow path creates the distinct lobe shaped pattern observed in Figures 9 and 19.

The A-014 Outfall Source Area As shown in Figure 9 a separate distinct lobe of the plume greater than $500 \mathrm{ppb}$ lies along the line of the A-014 Outfall. Figure 20 presents a view of the plume looking from the Northeast corner that indicates that this portion of the dissolved trichloroethylene plume is within the M-Area Aquifer Zone. As shown in the figure the main plume in the Southern Sector is beneath that along the A-014 Outfall.

In order to select and size a system of vertical recirculation wells for the dissolved trichloroethylene plume present in the Lost Lake Aquifer Zone of the Southern Sector two separate fronts are identified. These fronts were identified as the width of the dissolved trichloroethylene plume perpendicular to the direction of groundwater flow in the lower portion of the Lost Lake Aquifer Zone. The Eastern Front ranges from SRS Easting 47,700 to 50,900 and has a horizontal distance perpendicular to the direction of groundwater flow of of 3200 feet. The Western Front ranges lies along a line beginning at MSB 49 and going towards the northeast. This front has an overall length of 2300 feet and is perpendicular to the direction of groundwater flow in this vicinity. A series of vertical recirculation wells sited along the $500 \mathrm{ppb}$ trichloroethylene isocontour will capture and treat that portion of the dissolved trichloroethylene that is migrating towards the south and southwest. Figure 21 presents the $500 \mathrm{ppb}$ TCE isocontour with proposed lines of remediation for vertical recirculation wells. 


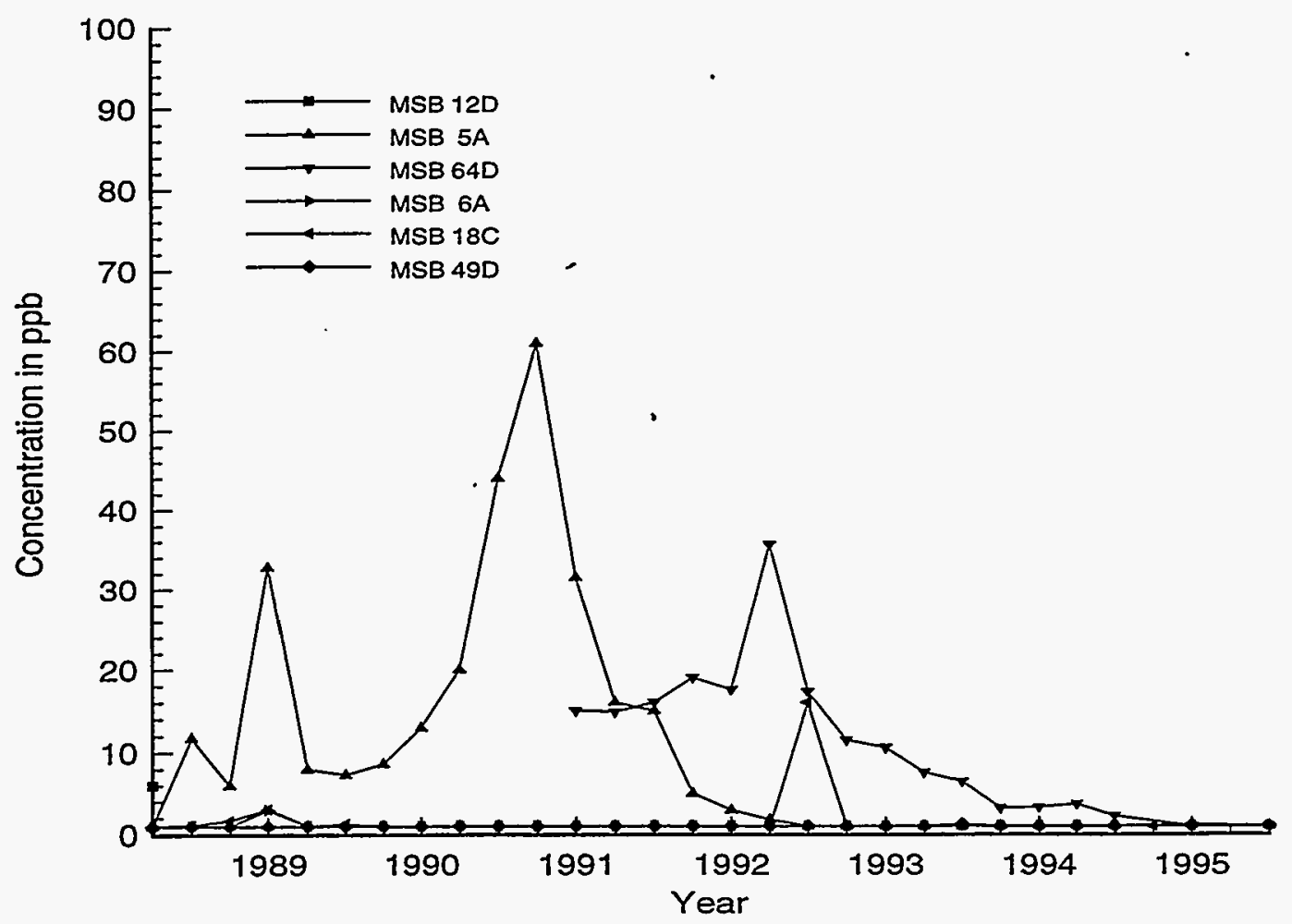

Figure 15: Historical Trichloroethylene Concentrations for wells MSB 12D, MSB 5A, MSB 64D, MSB 6A, MSB 18C, and MSB 49D located in the M-Area Aquifer Zone. 


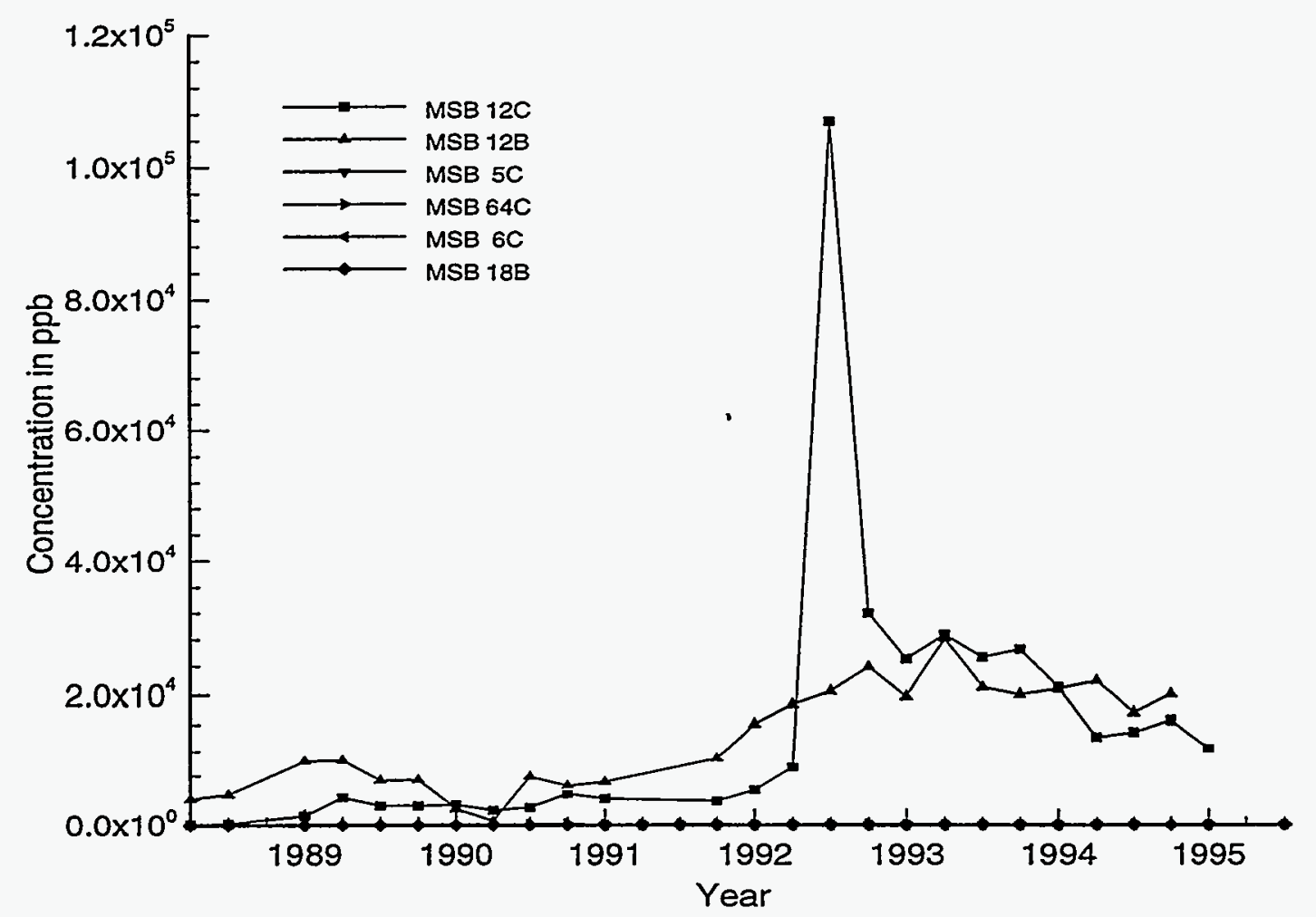

Figure 16: Historical Trichloroethylene Concentrations for wells MSB 12C, MSB 12B, MSB 5C, MSB 64C, MSB 6C, and MSB 18B located in the upper portion of the Lost Lake Aquifer. 
WSRC-RP-96-477

September 13, 1996

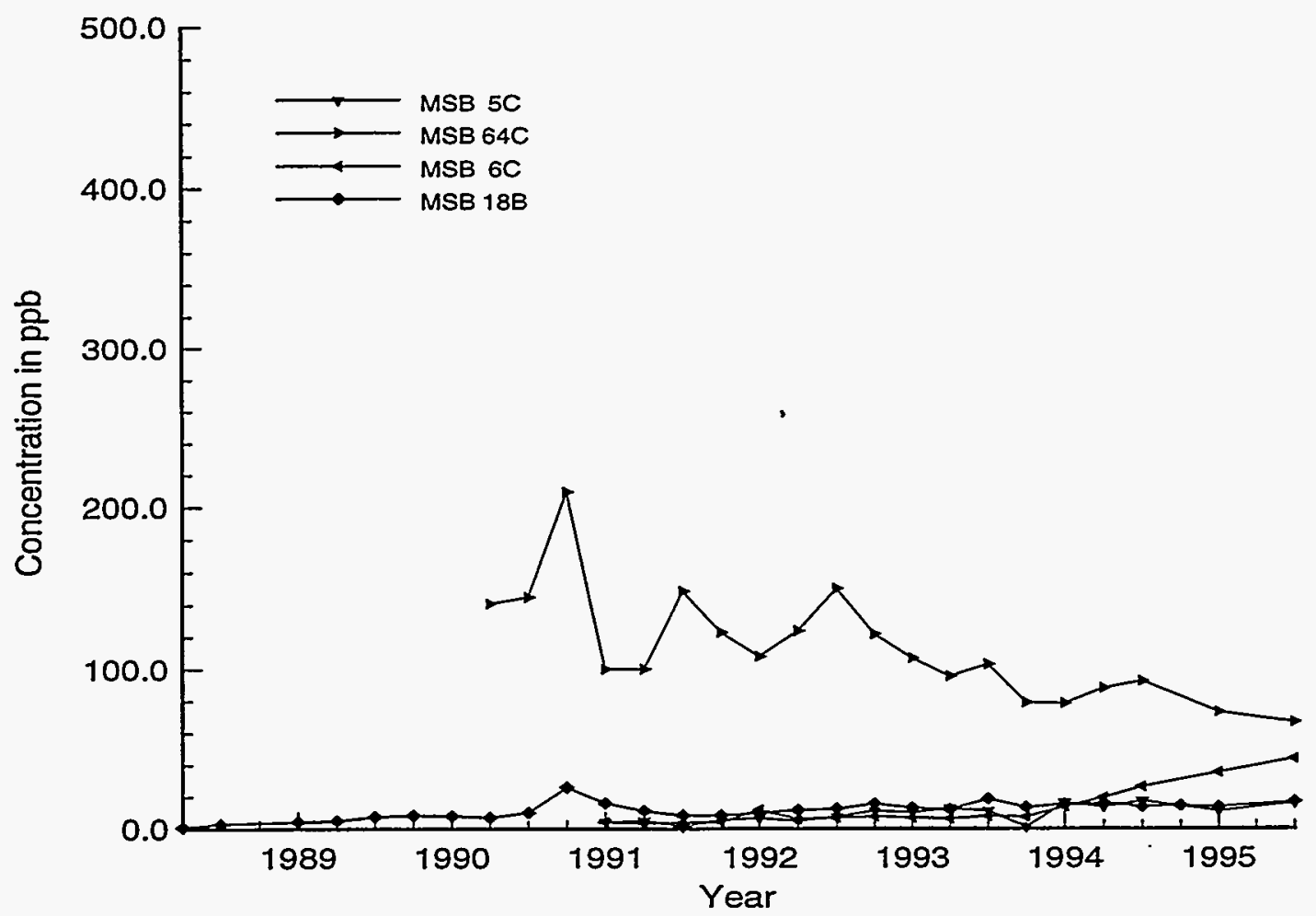

Figure 17: Historical Trichloroethylene Concentrations for wells MSB 5C, MSB 64C, MSB 6C, and MSB 18B located in the upper portion of the Lost Lake Aquifer. 


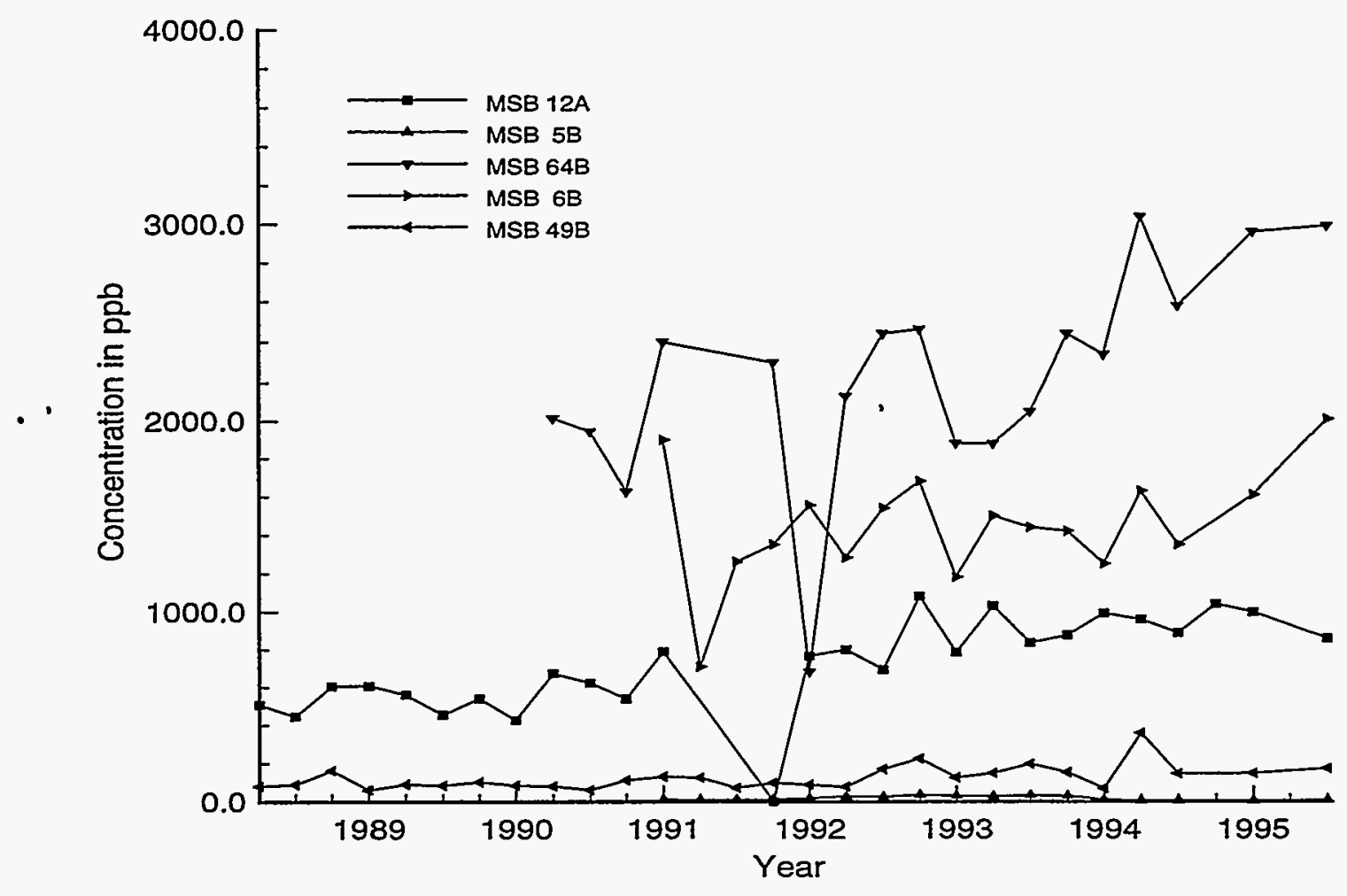

Figure 18: Historical Trichloroethylene Concentrations for wells MSB 12A, MSB 5B, MSB64B, MSB 6B, and MSB 49B located in the lower portion of the Lost Lake Aquifer. 


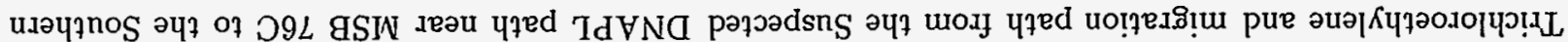

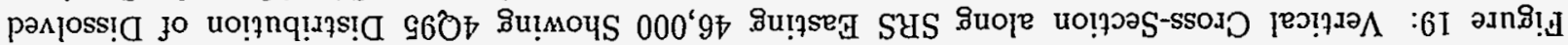

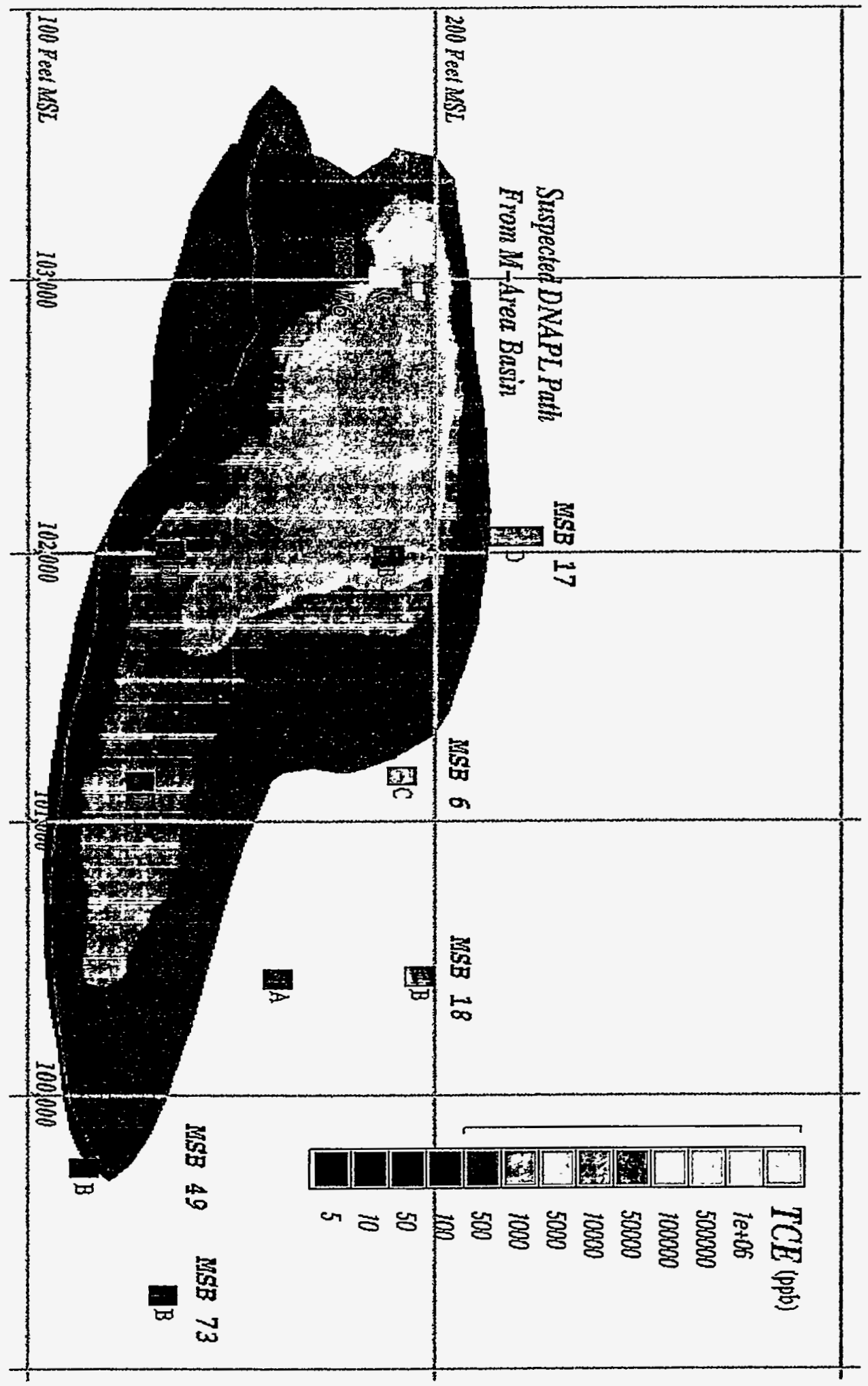




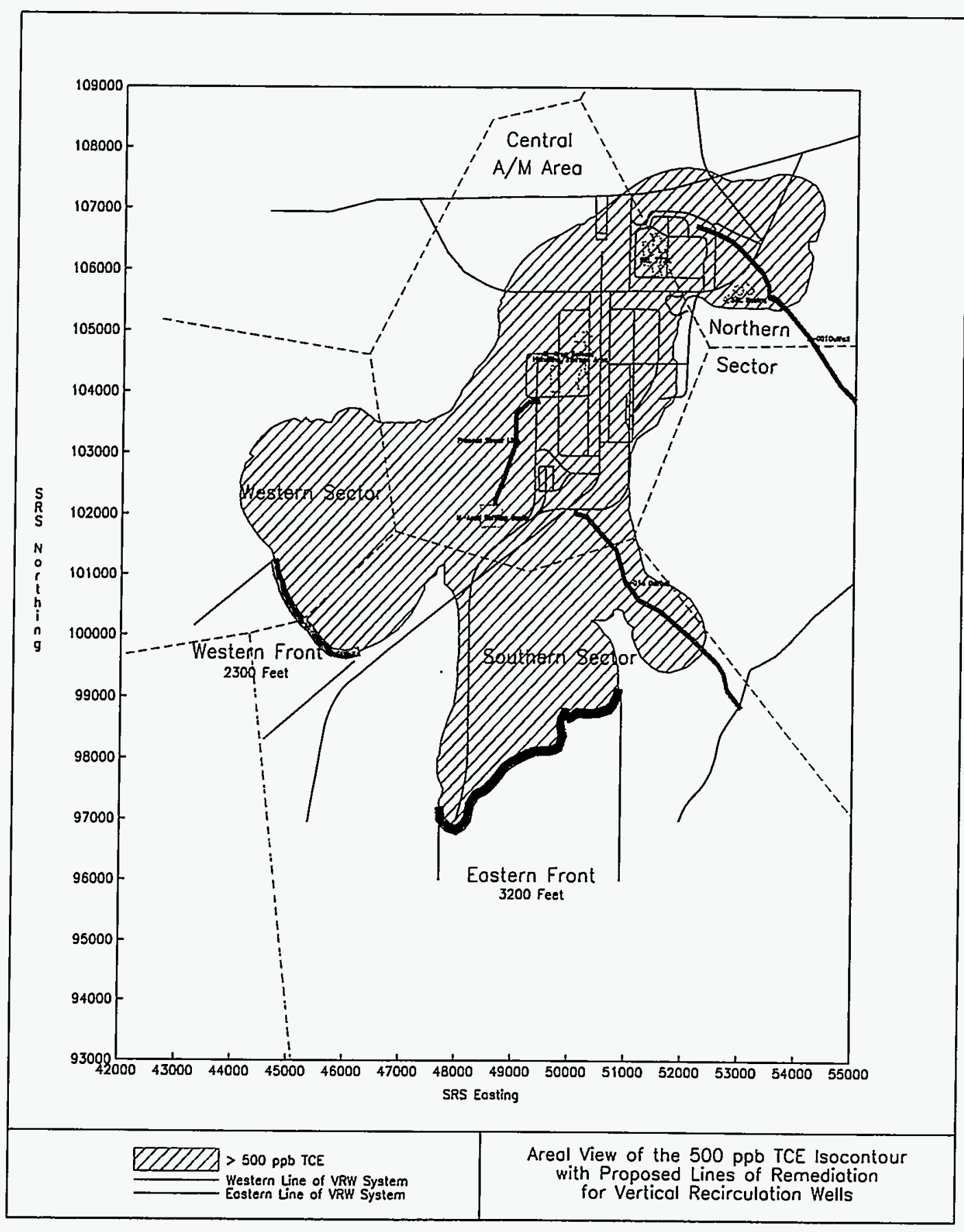

Figure 21: Plan View of the $500 \mathrm{ppb}$ TCE Isocontour with Proposed Lines of Remediation for Vertical Recirculation Wells. 


\section{Vertical Recirculation Well Technology}

Vertical recirculation wells are an emerging technology for the in-situ clean up of groundwater contaminated with volatile compounds, most notably dissolved chlorinated volatile organic compounds. (Herrling et al., 1991c) (Herrling et al., 1991b) (Herrling et al., 1991a) (Gorelick and Gvirtzman, 1993) The vertical recirculation well is a pump and treat system that uses a combination of existing technologies, including air stripping, air lift pumping, and groundwater wells in one complete in-situ assembly. The system consists of a well with an upper and lower screen zone, an air injection blower having an associated eductor placed at the lower well screen, an optional submersible type well pump to reinforce the pumping effect, and vacuum removal of the off-gas at the well head. The conventional design configuration calls for the siting of the lower screen zone near the bottom of the aquifer and the siting of the upper screen near the top of the aquifer, just below the confining zone. During operation, air is injected using an eductor lowered inside the well bore to the lower screen zone. As the air rises to the surface in the well, the chlorinated volatile organic compounds are removed by air stripping. As the air bubbles rise within the well-bore, the density of the water is decreased and an upward flow field is developed within the well-bore. This naturally induced upward flow field is often enhanced via a mechanical pump to increase performance and capture zone. The groundwater flow pattern into the lower screen zone and out of the upper screen zone causes development of a recirculation pattern around the well screens. Figure 22 presents a schematic representation of a vertical recirculation well and the resultant flow field without the presence of a natural groundwater gradient. As presented by (Herrling and Buermann, 1990) (Herrling and Stramm, 1991) when this flow field is combined with that of a uniform horizontal flow field, the result is the capture and remediation of the up-gradient plume and treatment via air stripping by the multiple recirculations through the well. The effect of this is illustrated in Figure 23 which presents a vertical longitudinal section through a single VRW. This figure illustrates the influence of Darcy velocity on the flow field and resultant capture zone of a single VRW installation. Within this figure the Darcy velocity, flowing from left to right, varies from $0.0 \mathrm{~m} /$ day, $0.3 \mathrm{~m} /$ day, and 1.0 $\mathrm{m} /$ day. The remaining VRW properties remained constant: the discharge (Q) through the well casing is $20.16 \mathrm{~m}^{3} / \mathrm{hr}$, the thickness $(\mathrm{H})$ of the aquifer is $10 \mathrm{~m}$, the anisotropic hydraulic conductivities are $K_{H}=0.001 \mathrm{~m} / \mathrm{sec}$ (horizontal) and $K_{V}=0.0001 \mathrm{~m} / \mathrm{sec}$ (vertical), and the lengths of the screen sections are $a_{B}=1.2 \mathrm{~m}$ at the bottom and $a_{T}=2.1 \mathrm{~m}$ at the top. As shown in Figure 23 the presence of a natural horizontal gradient results in the groundwater up-gradient flowing downward into the lower screen zone where it is captured and then treated via numerous circulations through the system.

\subsection{Selection and Sizing a VRW System}

The initial effort necessary to develop a successful vertical recirculation well system for the A/M Area involves the horizontal siting of the wells. For the purpose of groundwater remediation, the horizontal extent of the circulation field inside and outside of the recirculation well is of primary interest. The region inside of the circulation field is the treatment zone where the contaminated groundwater is cycled through the system removing volatile constituents. The region of the aquifer outside of the circulation zone can be considered the zone of influence of the system and has two significant portions. The region up-gradient from the VRW system that supplies water to the VRW system can be defined using the appropriate numerical models with conventional capture zone analysis techniques, i.e advective particle tracking. It is important to note that since the performance and operation of a VRW system has a net-zero effect the appropriate numerical models should have sufficient horizontal and vertical resolutions necessary to assess the performance of these systems. The region down-gradient from the VRW system receives effluent from the upper-screen zone. As a result of the in-situ air-stripping process, this effluent will contain elevated levels of dissolved oxygen and nitrogen which may be used by indigenous bacteria for additional bioremediation of VOCs. In examining these effects advective particle tracking can also be employed to identify "enhanced" bioremediation zones. 


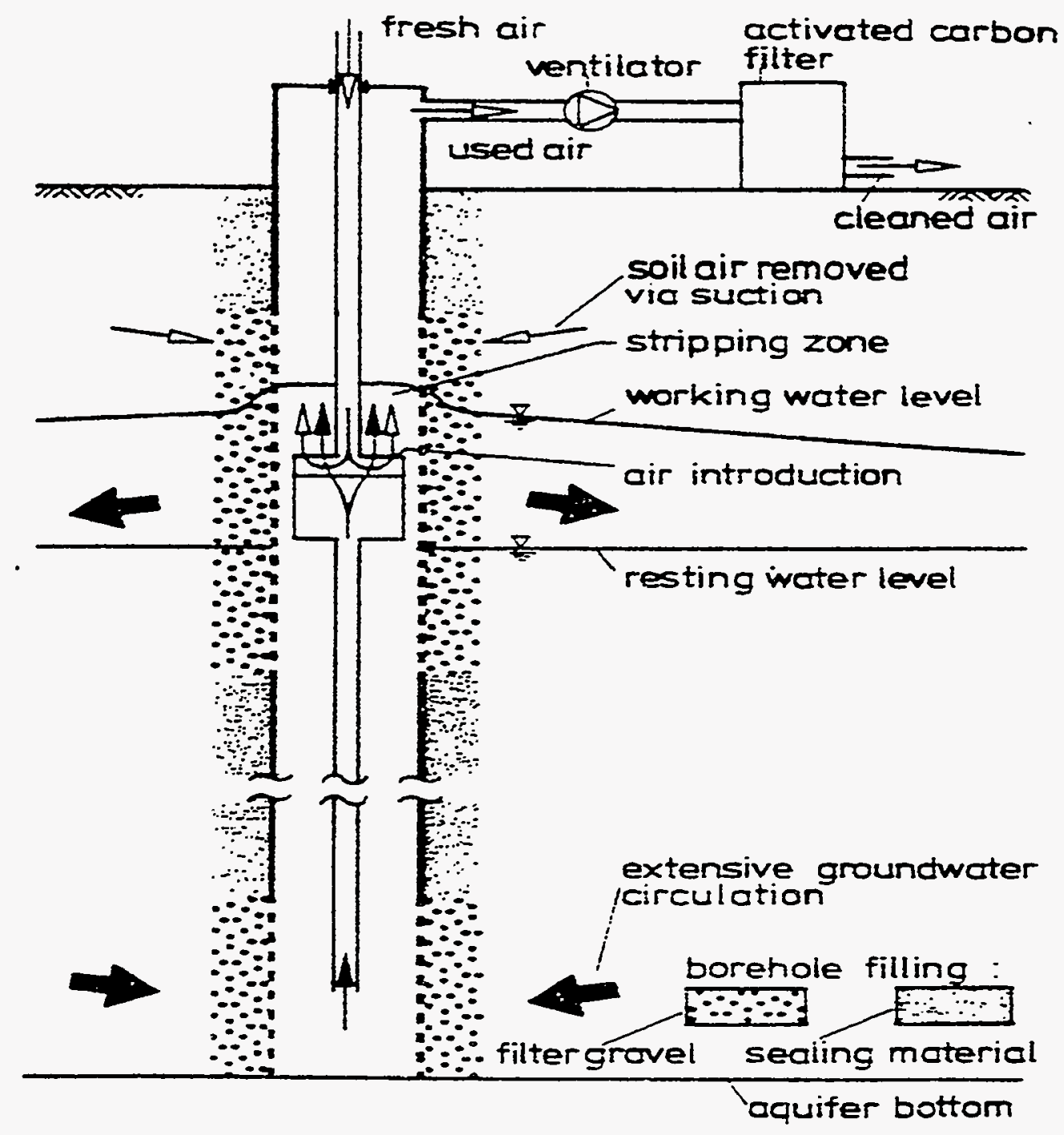

Figure 22: Schematic Representation of a Vertical Recirculation Well showing the Resulting Flow Field without the Presence of a Natural Groundwater Gradient. 
WSRC-RP-96-477

September 13, 1996

\section{(a)}

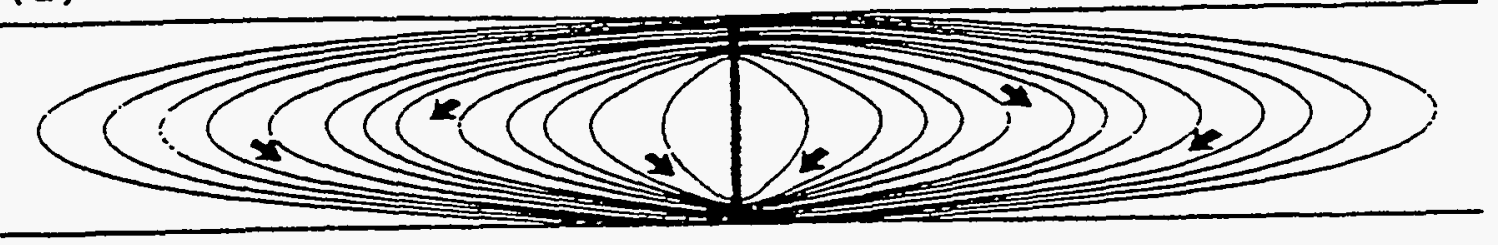

(b)

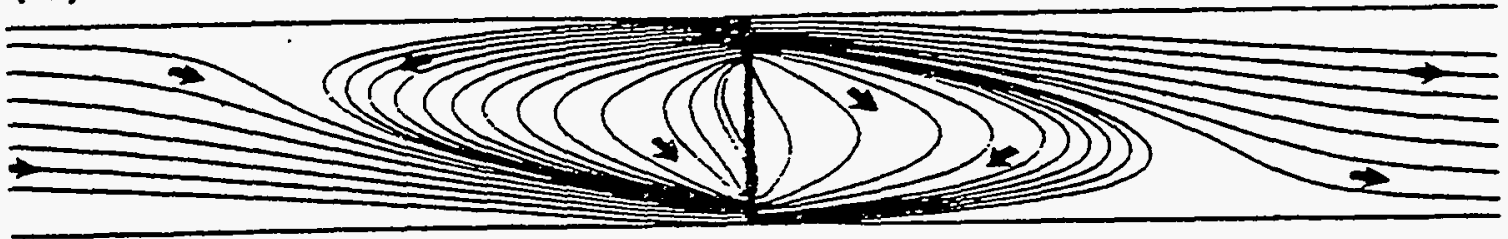

\section{(c)}

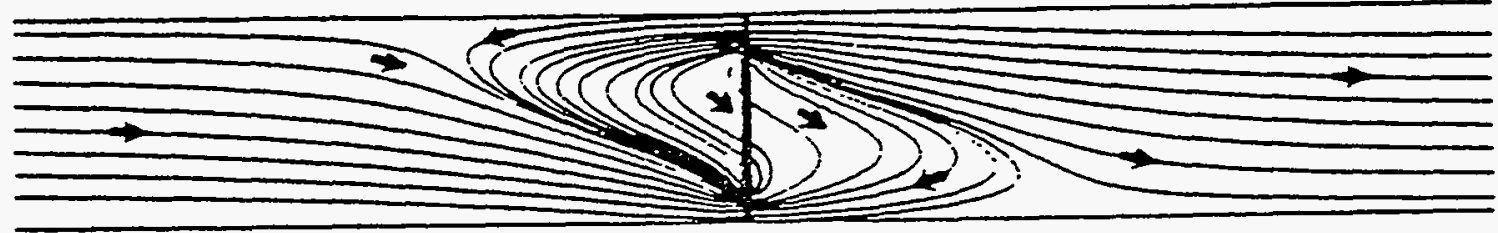

Figure 23: Streamlines for a Vertical Longitudinal Section through a Vertical Recirculation Well and the effect of horizontal gradient. (a) $0.0 \mathrm{~m} /$ day; (b) $0.3 \mathrm{~m} /$ day; (c) $1.0 \mathrm{~m} /$ day. (Adopted from Herrling et al., 1991b) 
Several methods exist, ranging from simple semi-analytical techniques (Herrling et al., 1991b) to the development of three-dimensional models using numerical techniques (Herrling and Buermann, 1990) (Herrling and Stramm, 1991) for characterizing the circulation zone and the zone of influence of a VRW system. For the current analysis the semi-analytical techniques will first be used to identify the circulation zone and to develop preliminary estimates regarding the number of wells, general configuration, and siting necessary to provide the necessary remediation. This information will then be applied with an appropriate three-dimensional numerical flow model to perform the regional flow investigations necessary to identify the up-gradient capture zone of the system.

\subsubsection{Preliminary Development}

As discussed previously the groundwater flow patterns within the A/M-Area are very complex and three-dimensional in regard. Within the region of the $500 \mathrm{ppb}$ trichloroethylene plume in the Southern Sector the predominate flow direction is south towards Upper Three Runs Creek while from the Western Sector the predominate flow direction is towards the southwest. The presence of the strong downward component characteristic throughout the Central A/M Area and the Northern Sector has been relieved as water levels in the M-Area Aquifer Zone decrease due to decreasing topography towards Upper Three Runs Creek and the "Western Swamps." The following assumptions are applied in order to develop an estimate regarding number of wells, general configuration, and necessary siting.

1. The aquifer thickness is constant.

2. Only confined aquifer conditions are considered in the analysis, even if the natural aquifer is phreatic.

3. The aquifer structure is assumed radially homogeneous to hydraulic conductivities. Hydraulic conductivities may be anisotropic, but each horizontal aquifer may only have one vertical and one horizontal value of hydraulic conductivity.

4. The local below-atmospheric pressure field near the system is neglected.

5. Density effects within the aquifer are neglected.

6. The computations assume steady-state conditions.

The technique presented is based upon numerical analysis for the siting and performance estimation of a system of vertical recirculation wells. (Herrling et al., 1991b) The flow field that occurs from the operation of one or several vertical recirculation wells is limited to an area immediately around the well since source and sink terms lie along a concurrent vertical axis. Figures 24 and 25 presents the nomenclature adopted by Herrling and will be used for dimensioning the VRW installation within the A/M Area. As shown in Figure 24 the significant aquifer properties are horizontal and vertical hydraulic conductivity, $K_{H}$ and $K_{V}$, the aquifer thickness $\mathrm{H}$, the upper and lower screen lengths a, and the pumping rate $Q$. As shown in Figure 23 the presence of a natural horizontal groundwater gradient dramatically impacts the upstream capture zone. Figure 25 presents the nomenclature adopted for defining the up-gradient capture zone widths at the top $\left(B_{T}\right)$ and bottom $\left(B_{B}\right)$ of the aquifer. Within the lower portion of Figure 25 the effect of multiple VRW installations and the resulting up-gradient capture zone width is illustrated. The Length (D) denotes the maximum well distance at which the contaminated groundwater cannot pass without being treated.

Figures 26 and 27 present the information necessary to dimension single or multiple VRW installations as presented by Herrling. The widths $B_{T}$ and $B_{B}$ of the upstream capture zone is presented in Figure 26(a) and is dependent upon the parameters $K_{H} / K_{V}$ and $Q /\left(H^{2} \nu\right)$ where $\nu$ is Darcy Velocity. As shown by the small offset present, for very low values of $Q /\left(H^{2} \nu\right)$, the upper part of the capture zone may not reach the top of an aquifer. Figure 26(b) shows the influx area $(\mathrm{A})$ of the upstream capture zone and Figure 
26(d) presents the maximum well distance (D) between two wells to ensure the capture of contaminated groundwater. Again the influx area and the maximum well distance are dependent upon the parameters $K_{H} / K_{V}$ and $Q /\left(H^{2} \nu\right)$. Using Figure 26(d) the number of wells n required to remediate a plume of width W can be estimated using $n=\left(W-B_{T}\right) / D+1$. When using VRW systems to remediate a groundwater plume whose primary transport mechanism is advection, contaminated water flows into the upstream capture zone at a rate of $Q_{0}$. Upon reaching the VRW site, this water is diluted with water that has already flowed through the well and circulates around the system. This results in a lower contamination concentration of water within the well casing than that in the upstream plume. Figure 26(c) can be used to estimate the portion $Q_{0}$ of the total well discharge $Q$, which is beneficial in evaluating the progress of remediation at a site. As with the other parameters, the upstream discharge $\left(Q_{0}\right)$ is dependent upon the parameters $K_{H} / K_{V}$ and $Q /\left(H^{2} \nu\right)$. In Figure 27 the upstream distance (S) of the stagnation point is presented again as a function of $K_{H} / K_{V}$ and $Q /\left(H^{2} \nu\right)$. The stagnation point of the system determines the length of the up gradient and down gradient circulation zones. The extent of the circulation zone perpendicular to the horizontal gradient is approximated by $\left(B_{T}+B_{B}\right) / 4$ for single well installations and by $\mathrm{D} / 2$ for multiple wells. With the information in Figures 26 and 27 a single VRW or multiple VRW installations can be dimensioned using the non-dimensional parameters $K_{H} / K_{V}$ and $Q /\left(H^{2} \nu\right)$.

\subsubsection{Eastern Front Analysis}

For the Eastern Front that ranges from SRS Easting 47,700 to 50,900, parameters and hydraulic conditions from MSB 39B and MSB 40B were selected to position and size a series of vertical recirculation wells. For this analysis a vertical thickness of 89 feet (Aadland et al., 1995a) and hydraulic conductivity values from Southern Sector Aquifer tests were applied. (Hiergesell, 1992) (Hiergesell, 1993) (Hiergesell and Pemberton, 1995) Screen lengths of 22 feet were selected. The width of the capture zone is measured perpendicular to the flow direction and for this analysis along the Eastern Front a length of 3200 feet was applied. Table 1 presents the results of this analysis for well design flow-rates ranging from 5 to $80 \mathrm{gpm}$. As shown this results in a system of anywhere between 5 and 13 wells dependent upon the well operating conditions. The well operating conditions are dependent upon local hydrogeologic parameters which must be considered when selecting the design conditions.

\subsubsection{Western Front Analysis}

The Western Front ranges along a northwest line from SRS $(43300,100200)$ to SRS $(44600,98300)$ and has an approximate length of 2300 feet. Parameters and hydraulic conditions from from MSB $49 B$ and MSB 73B were selected to position and size a series of vertical recirculation wells. For this analysis a vertical thickness of 72 feet (Aadland et al., 1995a) was applied with the hydraulic conductivity values from Southern Sector Aquifer tests. (Hiergesell, 1992) (Hiergesell, 1993) (Hiergesell and Pemberton, 1995) Table 2 presents the results of this analysis for well design flow-rates ranging from 5 to $50 \mathrm{gpm}$. As shown this results in a system of anywhere between 5 and 10 wells dependent upon the well operating conditions.

In selecting the operating parameters of the system the local and regional hydrogeologic parameters must be considered. As discussed the A/M Area consists of inter-bedded layers of sands, silts, and clays with hydraulic conductivity values on the order of 10-100 ft/day for the "aquifer" zones. In selecting the number of wells conservative operating conditions should be applied to prevent inadequate well spacing due to inefficient operation as a result of hydrogeologic conditions. For the current analysis design conditions of $20 \mathrm{gpm}$ were selected as the conservative minimum operating condition. This results a series of 8 wells each along the Eastern Front and 6 wells located along the Western Front. Horizontal well spacing along each of these fronts is determined from the Well Spacing Distance (D) presented in Table 1 and Table 2. In selecting the vertical spacing it is important to have the recirculation zone of each individual well overlap relative to the principle direction of groundwater flow. The up-gradient distance of 
WSRC-RP-96-477

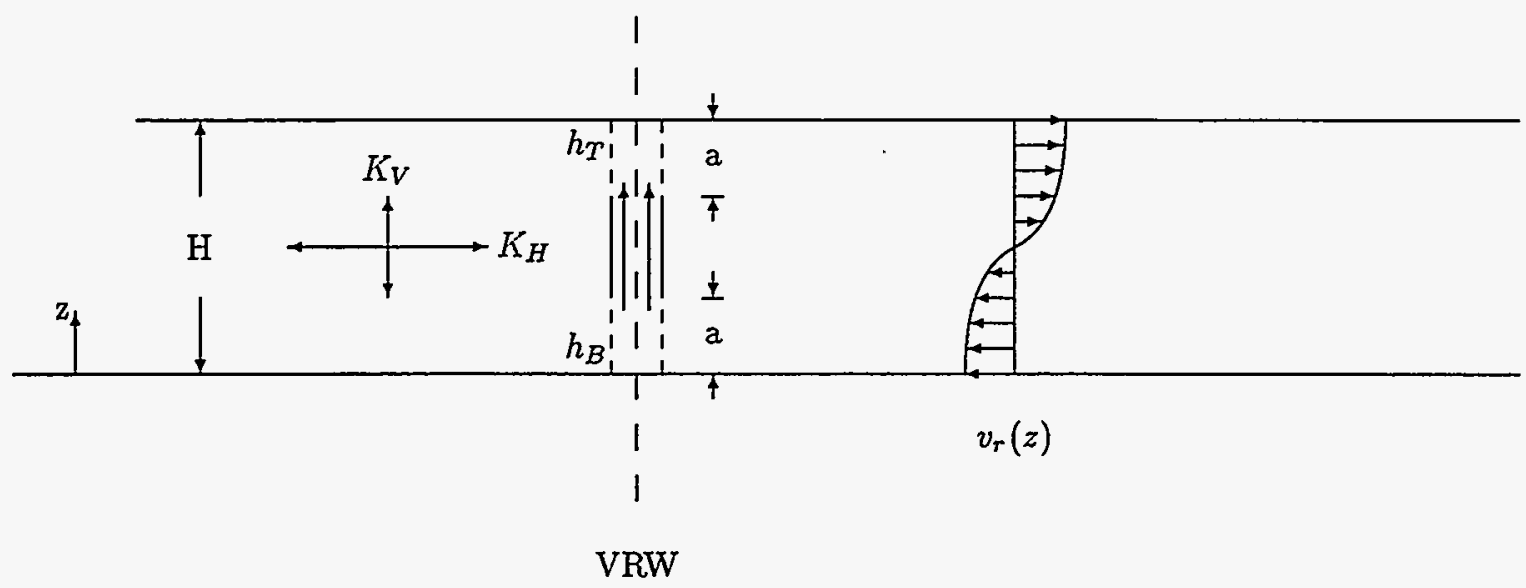

Figure 24: Schematic Representation and Nomenclature applied in the Dimensioning of a VRW installation.
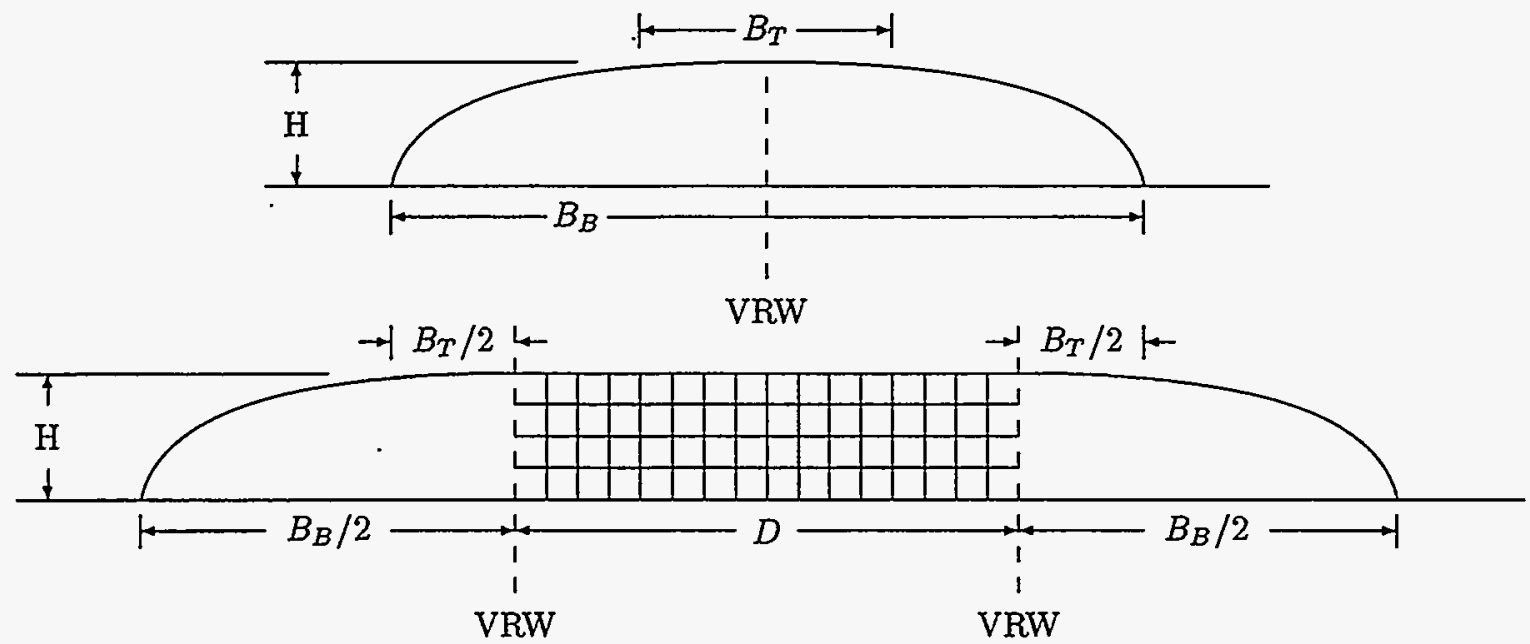

Figure 25: Nomenclature used in identifying an upstream cross section through the capture zone for one and two VRW installations. 
(a)

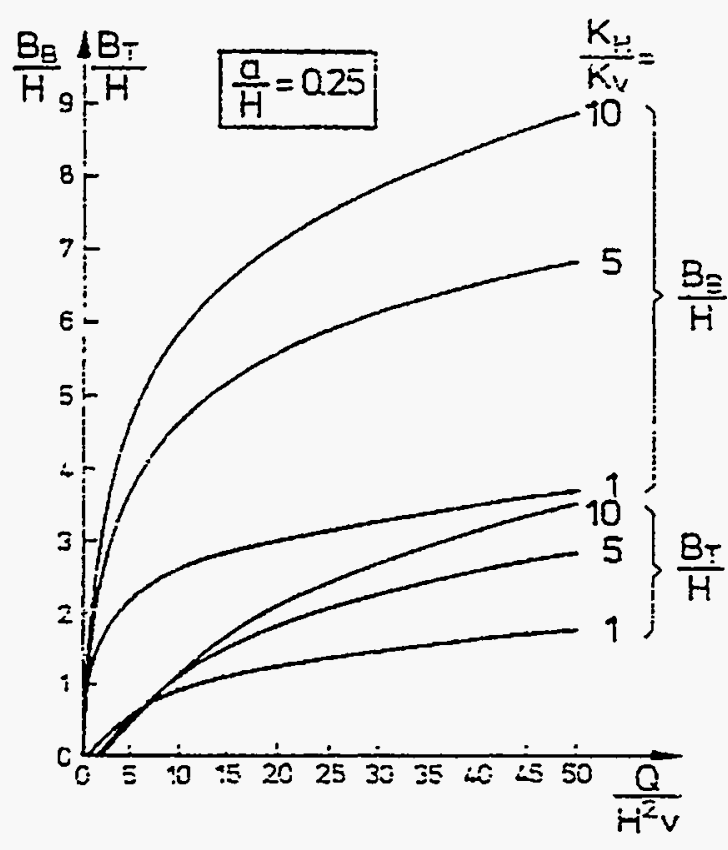

(c)

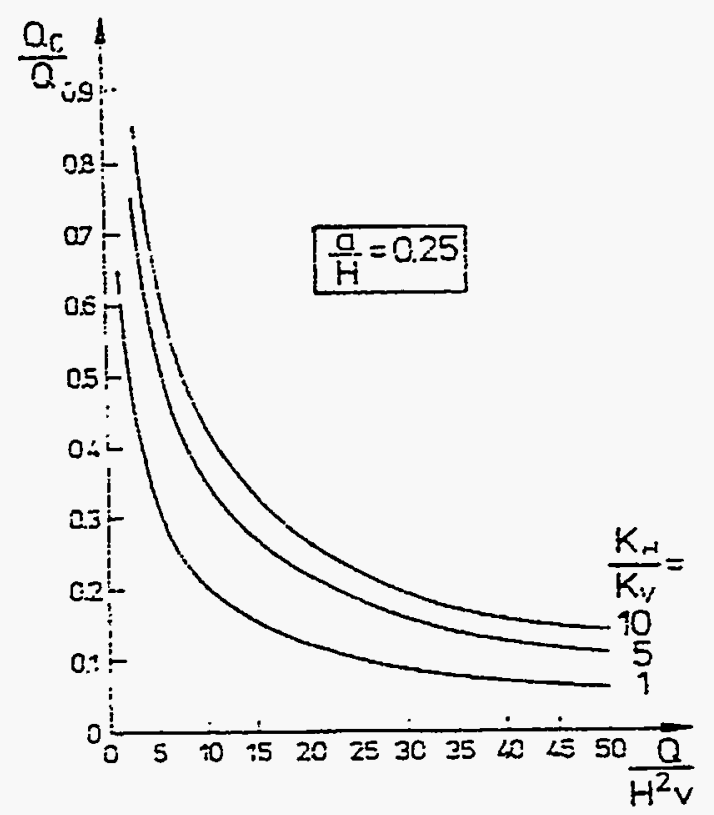

(b)

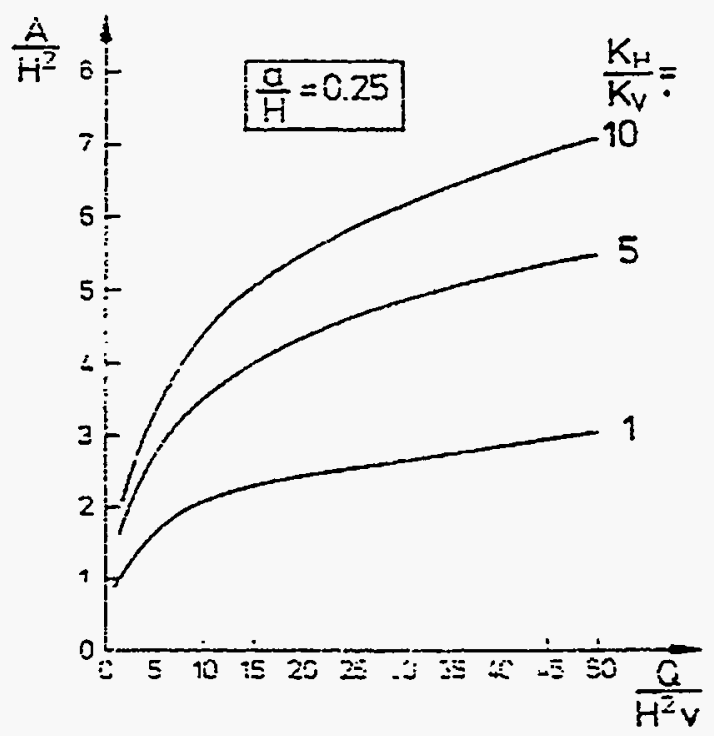

(d)

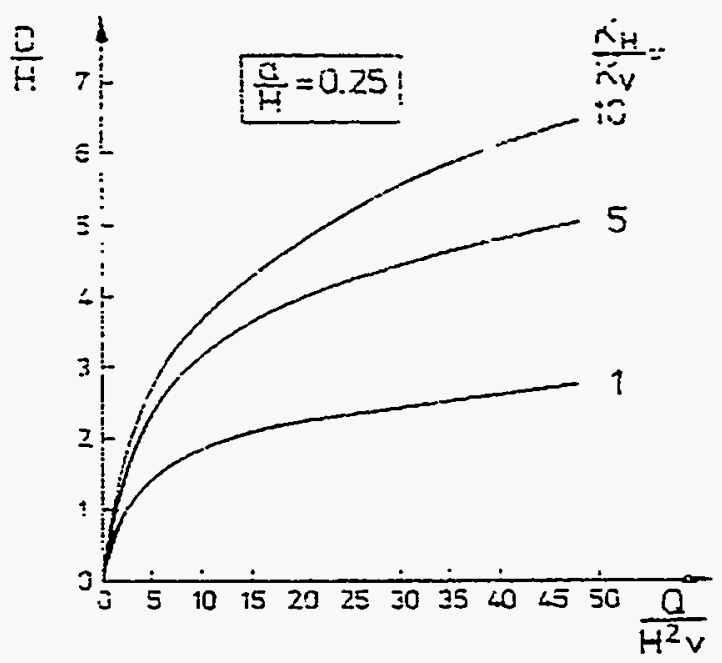

Figure 26: (a) Widths $B_{T}$ and $B_{B}$ of the Upstream Capture Zone at the aquifer top and bottom; (b) Influx area $A$ of the upstream capture zone; (c) Upstream discharge $\left(Q_{0}\right)$ in hte capture zone, which is diluted with the circulating water to the total well discharge; (d) Maximum well distance (D) at which the contaminated groundwater cannot pass between the wells without being treated. (Adopted from Herrling et al., 1991b) 


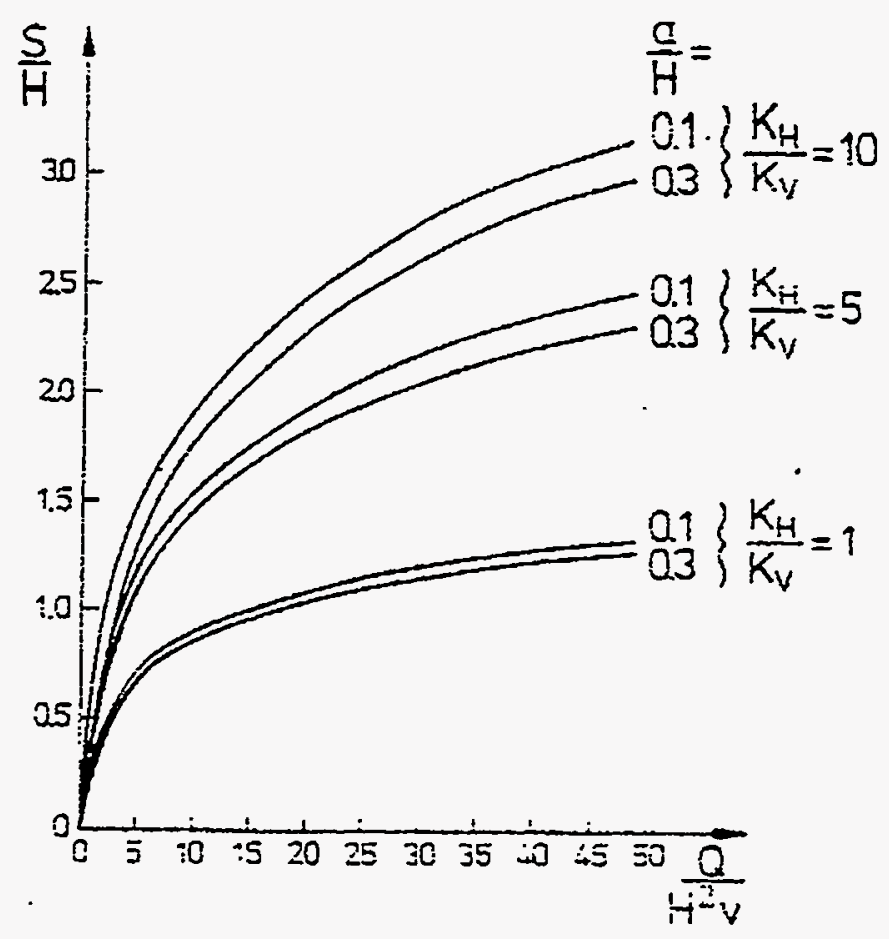

Figure 27: Upstream distance (S) of the stagnation point from the well axis. (Adopted from Herrling et al., 1991b) 
Table 1: Dimensioning for a System of Vertical Recirculation Wells along the Eastern Line of the Southern Sector using Herrling's Method.

\begin{tabular}{|c|c|c|c|c|c|c|c|c|}
\hline $\mathrm{Q}$ & $B_{B}$ & $B_{T}$ & $\mathrm{~A}$ & $Q_{0}$ & $\mathrm{D}$ & $\mathrm{S}$ & \# Well & $\sum Q$ \\
\hline $\mathrm{gpm}$ & feet & feet & $f^{2}$ & $\mathrm{gpm}$ & feet & feet & - & $\mathrm{gpm}$ \\
\hline \hline 5 & 476.4 & 72.4 & 29958.4 & 2.7 & 270.7 & 133.3 & 13 & 65 \\
\hline 10 & 579.7 & 133.0 & 38076.9 & 3.4 & 361.9 & 165.1 & 10 & 100 \\
\hline 15 & 640.2 & 184.9 & 43364.8 & 3.9 & 426.6 & 184.6 & 9 & 135 \\
\hline 20 & 683.1 & 227.9 & 47421.5 & 4.2 & 478.7 & 199.0 & 8 & 160 \\
\hline 25 & 716.3 & 262.1 & 50767.2 & 4.4 & 523.1 & 210.6 & 7 & 175 \\
\hline 30 & 743.5 & 287.6 & 53642.5 & 4.6 & 562.2 & 220.4 & 7 & 210 \\
\hline 35 & 766.5 & 304.2 & 56180.3 & 4.8 & 597.4 & 228.9 & 6 & 210 \\
\hline 40 & 786.4 & 312.1 & 58462.2 & 5.0 & 629.7 & 236.5 & 6 & 240 \\
\hline 45 & 804.0 & 311.2 & 60542.7 & 5.1 & 659.5 & 243.3 & 6 & 270 \\
\hline 50 & 819.7 & 301.5 & 62459.8 & 5.3 & 687.3 & 249.6 & 6 & 300 \\
\hline 55 & 833.9 & 283.0 & 64241.2 & 5.4 & 713.5 & 255.3 & 6 & 330 \\
\hline 60 & 846.9 & 255.7 & 65907.9 & 5.5 & 738.2 & 260.7 & 5 & 300 \\
\hline 65 & 858.8 & 219.6 & 67476.3 & 5.6 & 761.6 & 265.7 & 5 & 325 \\
\hline 70 & 869.8 & 174.7 & 68959.2 & 5.7 & 784.0 & 270.4 & 5 & 350 \\
\hline 75 & 880.1 & 121.0 & 70366.9 & 5.8 & 805.4 & 274.9 & 5 & 375 \\
\hline 80 & 889.7 & 58.5 & 71708.1 & 5.9 & 826.0 & 279.1 & 5 & 400 \\
\hline
\end{tabular}

Table 2: Dimensioning for a System of Vertical Recirculation Wells along the Western Line of the Southern Sector using Herrling's Method.

\begin{tabular}{|c|c|c|c|c|c|c|c|c|}
\hline $\mathrm{Q}$ & $B_{B}$ & $B_{T}$ & $\mathrm{~A}$ & $Q_{0}$ & $\mathrm{D}$ & $\mathrm{S}$ & \# Well & $\sum Q$ \\
\hline gpm & feet & feet & $f^{2}$ & gpm & feet & feet & - & gpm \\
\hline \hline 5 & 436.5 & 85.4 & 22777.3 & 2.1 & 262.0 & 123.5 & 10 & 50 \\
\hline 10 & 520.1 & 151.7 & 28545.9 & 2.6 & 347.7 & 150.1 & 8 & 80 \\
\hline 15 & 569.0 & 201.4 & 32358.3 & 2.8 & 408.8 & 166.7 & 7 & 105 \\
\hline 20 & 603.7 & 234.5 & 35302.6 & 3.1 & 458.1 & 179.1 & 6 & 120 \\
\hline 25 & 630.6 & 251.0 & 37740.3 & 3.2 & 500.3 & 189.2 & 6 & 150 \\
\hline 30 & 652.6 & 250.9 & 39840.4 & 3.4 & 537.4 & 197.7 & 5 & 150 \\
\hline 35 & 671.2 & 234.2 & 41697.3 & 3.5 & 570.9 & 205.2 & 5 & 175 \\
\hline 40 & 687.3 & 200.9 & 43369.2 & 3.6 & 601.5 & 211.8 & 5 & 200 \\
\hline 45 & 701.5 & 151.0 & 44895.1 & 3.7 & 629.9 & 217.8 & 5 & 225 \\
\hline 50 & 714.2 & 84.5 & 46302.2 & 3.8 & 656.3 & 223.3 & 5 & 250 \\
\hline 55 & 725.7 & 1.3 & 47610.6 & 3.9 & 681.2 & 228.4 & 5 & 275 \\
\hline
\end{tabular}


the recirculation zone is the stagnation point and is presented in column 7 of Table 1 and Table 2. Using these parameters an ellipse oriented in the direction of groundwater flow can be used to represent the recirculation zone of each well. The minor axis of the ellipse has a length of $2 S$ and the major axis has a length of $D$. Horizontal spacing and stagnation point distance from Table 1 and Table 2 were used to site a series of wells operating at $20 \mathrm{gpm}$. The results of this are presented in Figure 28 and in Table 3. Table 3 also presents the vertical extent of the well as defined by the extent of the Lost Lake Aquifer Zone. 


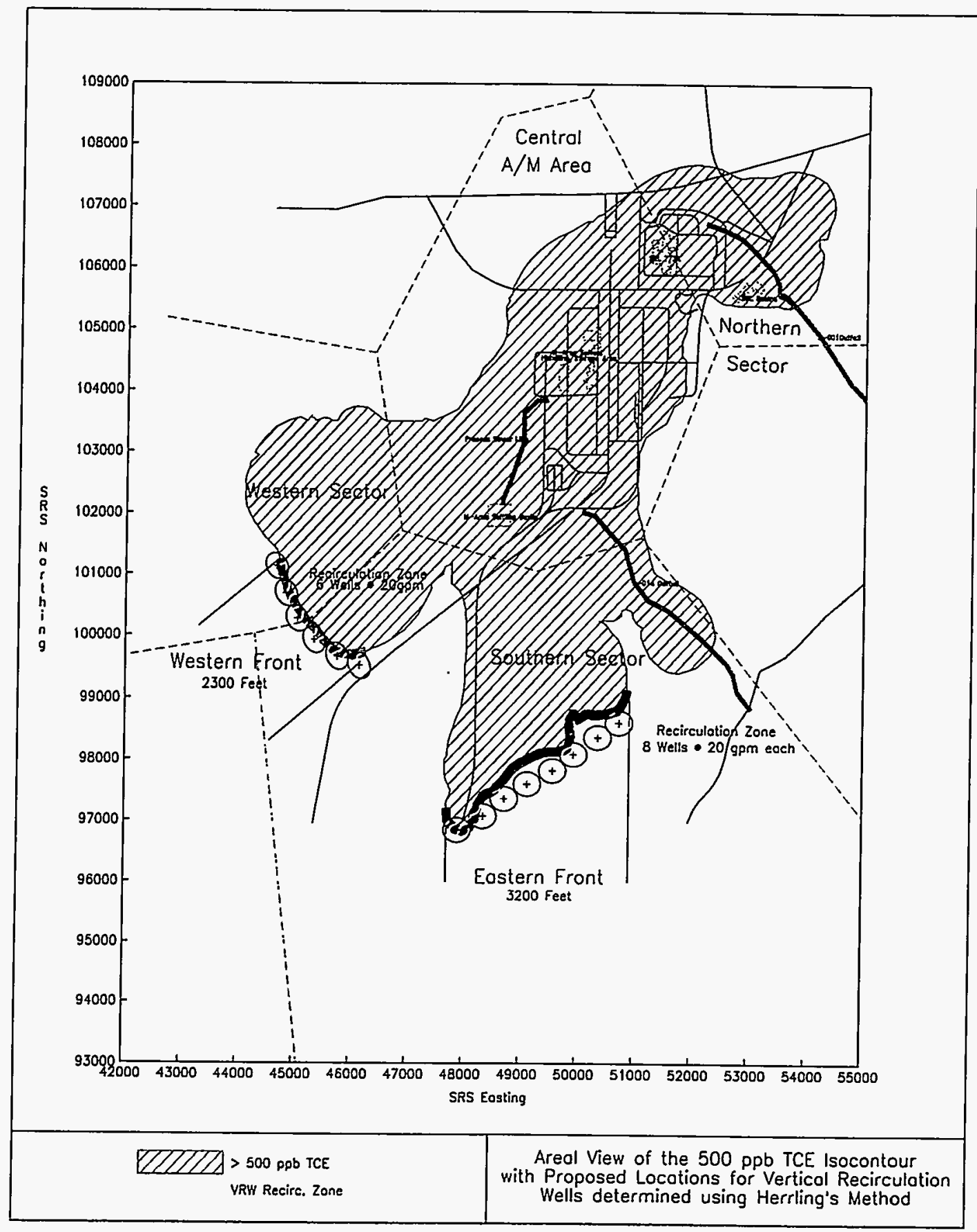

Figure 28: Plan View of the $500 \mathrm{ppb}$ TCE Isocontour with Proposed Locations for Vertical Recirculation Wells determined using Herrling's Method. 
Table 3: Siting Information for the Proposed Locations for Vertical Recirculation Wells as determined using Herrling's Method.

\begin{tabular}{|c|c|c|c|c|c|}
\hline SRS Easting & SRS Northing & Flow-rate & Bottom of Well & Top of Well & Location \\
\hline \hline 44660 & 101130 & 20 & 121 & 189 & Western \\
\hline 44830 & 100690 & 20 & 120 & 192 & Western \\
\hline 45030 & 100270 & 20 & 121 & 195 & Western \\
\hline 45330 & 99930 & 20 & 122 & 198 & Western \\
\hline 45740 & 99660 & 20 & 127 & 201 & Western \\
\hline 46130 & 99520 & 20 & 134 & 200 & Western \\
\hline 47900 & 96850 & 20 & 135 & 216 & Eastern \\
\hline 48350 & 97075 & 20 & 136 & 218 & Eastern \\
\hline 48725 & 97350 & 20 & 138 & 216 & Eastern \\
\hline 49125 & 97600 & 20 & 138 & 210 & Eastern \\
\hline 49550 & 97825 & 20 & 137 & 205 & Eastern \\
\hline 49950 & 98100 & 20 & 136 & 200 & Eastern \\
\hline 50350 & 98375 & 20 & 135 & 196 & Eastern \\
\hline 50725 & 98600 & 20 & 134 & 193 & Eastern \\
\hline
\end{tabular}




\subsection{Model Development}

In order to evaluate the resulting up-gradient capture zone of the series of vertical recirculation wells sited and presented in Table 28, a numerical model simulating the groundwater flow in the Southern and Western Sector was developed. The development of this groundwater model requires the discretization of the domain in the horizontal and vertical directions. This process results in a series of nodes and elements that are combined to represent the aquifers and confining zones within the domain. Appropriate material properties are assigned to the elements to represent the aquifer and confining zones and boundary conditions are applied. The boundary conditions represent how externally applied stresses, such as pumping wells, streams, and recharge are included into the solution technique. The information regarding the spatial distributions of nodes, element material properties, and boundary conditions are compiled to develop a set of equations representative of the distribution of hydraulic heads throughout the domain. This set of equations is solved and the resultant head values are compared to the observed data and modifications of material properties and boundary condition are employed to minimize the difference between the predicted solution and the actual data. This difference between the predicted solution and the actual data is the residual. The process of minimizing the residual by changing the material properties, and to a lesser extent the boundary conditions, is referred to as model calibration and is discussed in detail later within this report. This section provides details regarding the horizontal and vertical discretization, and the incorporation of boundary condition data during the development of the model. The model was developed utilizing SRTC's groundwater flow and transport analysis code FACT (WSRC,1995b). This code uses a finite element technique to simulate fully three-dimensional groundwater flow and solute transport in subsurface porous media.

\subsubsection{Discretization ,}

Since the area of influence of a VRW is limited in both the plan and vertical extent careful attention is necessary in the selection of the horizontal and vertical discretization parameters. Since a typical VRW system operates within the vertical extent of a "single" aquifer zone, the previously developed models of the $\mathrm{A} / \mathrm{M}$ Area are inadequate for the assessment. Each of the previously developed models incorporated the traditional layer-cake approach for vertical discretization. Within each of the the previous models, each layer represented a specific hydrostratigraphic unit. Although adequate for determining regional flow patterns and the assessment of large-scale pump-and-treat scenarios, these models do not provide either the horizontal or vertical resolution necessary to access the extremely localized effects of a VRW.

Horizontal Domain With regards to the selection of horizontal discretization parameters the effect on the groundwater flow pattern due to the operation of a VRW is extremely localized. This is a result of the design being that both extraction and injection both occur within a "single" aquifer zone at the same location. In selection of the horizontal discretization parameters it is important to take into account both the distance and influence that the applied boundary conditions will have on the assessment. In addition it is necessary to ensure that the selected discretization will provide adequate numerical resolution so that the impact of the proposed remediation system can be determined.

In performing the assessment of VRW technologies within the $A / M$ Area the horizontal domain for the model ranges from SRS Easting 44,000 to 53,000 feet in the x-direction, and SRS Northing 94,000 to 102,000 feet in the $y$-direction. This region was discretizized with a uniform horizontal spacing of 100 feet, which resulted in a numerical model of 91 nodes in the X-direction and 81 nodes in the Y-direction. This domain encompasses approximately 2.5 square miles and contains those portions of the TCE plume within the Southern and Western Sectors greater than $500 \mathrm{ppb}$. The aerial domain for the model showing the horizontal discretization, portions of the Trichloroethylene plume greater than $500 \mathrm{ppb}$, and relevant features within the A/M Area is presented in Figure 29. 


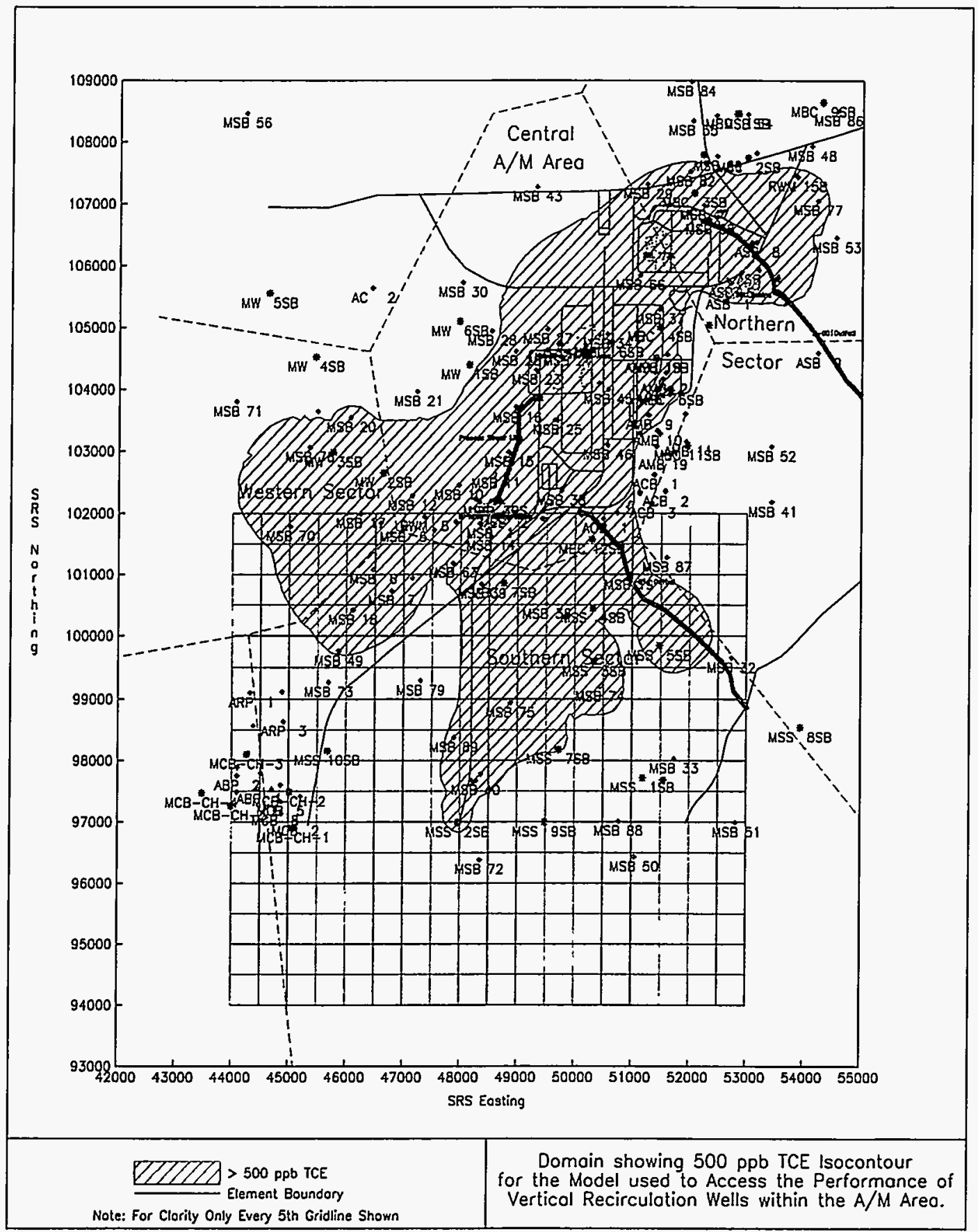

Figure 29: Horizontal Domain of Model Showing: Those Regions Greater than $500 \mathrm{ppb}$ Trichloroethylene. 
Vertical Domain The performance and area of influence of a VRW is extremely localized, and highly dependent upon the "average" vertical hydraulic conductivity between the injection and extraction screens. In order to effectively access this type of system within the A/M Area, it was necessary to develop the model with sufficient vertical resolution and incorporate localized variations in vertical hydraulic conductivity. The vertical region of interest during model development is the Lost Lake Aquifer Zone since this is where the portion of the plume targeted for remediation with vertical recirculation wells primarily resides. For the current assessment the bottom of the "Upper-Clay" Confining Zone of the Crouch Branch Confining Unit was selected as the bottom domain of the model. The altitude contour incorporated was derived from the previously developed regional groundwater flow model of the $A / M$ Area. Since the proposed VRW system is located within the Lost Lake Aquifer the simulation is not extremely sensitive to the specification of the bottom of the domain. This is especially true with the vertical discretization process employed and the method developed for the assignment of material properties. Figure 30 presents the altitude contour of this unit and Table 4 presents statistical information for this surface. As shown, the bottom of the domain has a mean value of 106.6 feet above mean sea level and ranges from 73.17 feet to 138.82 feet above mean sea level. The water table was selected for the top of the model domain. Since the proposed VRW system will be located entirely within the Lost Lake Aquifer Zone, the water table located in the above M-Area Aquifer Zone will be minimally effected by the system's operation. Figure 31 presents the water table conditions within the model domain and as shown in Table 4 the top of the domain has a mean value of 215.5 feet above mean sea level and ranges from 180.2 feet to 240.7 feet above mean sea level. These two surfaces were discretized vertically into 20 intervals represented by 21 nodes in the vertical direction. Figure 32 presents the resulting model discretization. The vertical thickness of each element was determined by the local vertical range of the domain. The vertical discretization process results in an average element thickness of 5.4 feet with a minimum element thickness of 4.2 feet and a maximum element thickness of 7.3 feet."

\subsubsection{Boundary Conditions}

The boundary conditions that are incorporated into the model represent how externally applied stresses are included into the solution technique. The boundary conditions are mathematical representations that either specify the dependent variable (head) or the derivative of the dependent variable (fluid flux) at specific locations within the model domain. Three different types of hydrogeologic boundary conditions exist. These types are the specified head condition (Dirichlet condition), specified flux (Neumann condition), and the head-dependent flux conditions (Cauchy or mixed boundary conditions). For the solution of the flow equation, these stresses include pumping and extraction wells, groundwater recharge from precipitation, groundwater supply and discharge from surface streams, and interactions with the remaining hydrologic system at the model boundaries. The operating recovery wells, RWM-7 and RWM-8, were incorporated as steady-state flux conditions based upon historical operating conditions.

Specified Head Boundaries on the top, the northern face, and the eastern face of the domain were constrained using the specified head (Dirichlet) condition. Since the simulation is based only on saturated portion of the aquifer the heads at the nodes on the top of the domain were specified as the elevation of each node as presented in Figure 31. Head conditions on the northern face and the eastern face were specified using three-dimensional minimum tension distributions of potentiometric head within the domain. The three-dimensional minimum tension distributions were derived using minimum tension gridding techniques to develop the nodal estimates of the potentiometric head of the northern face and the eastern face. Figure 33 presents the distribution of constant head values that were applied along the northern edge of the domain. It is noted that Figure 33 is referenced to the model $(i, j, k)$ coordinate system. As shown in Figure 33 the potentiometric head decreases at the top of the domain to the bottom. As shown in Table 6 these heads range from 205.9 feet to 240.6 feet with an average value of 220.3 feet. Notice that the effects of RWM-7 and RWM- 8 are observed in Figure 33 by the depression of heads at 


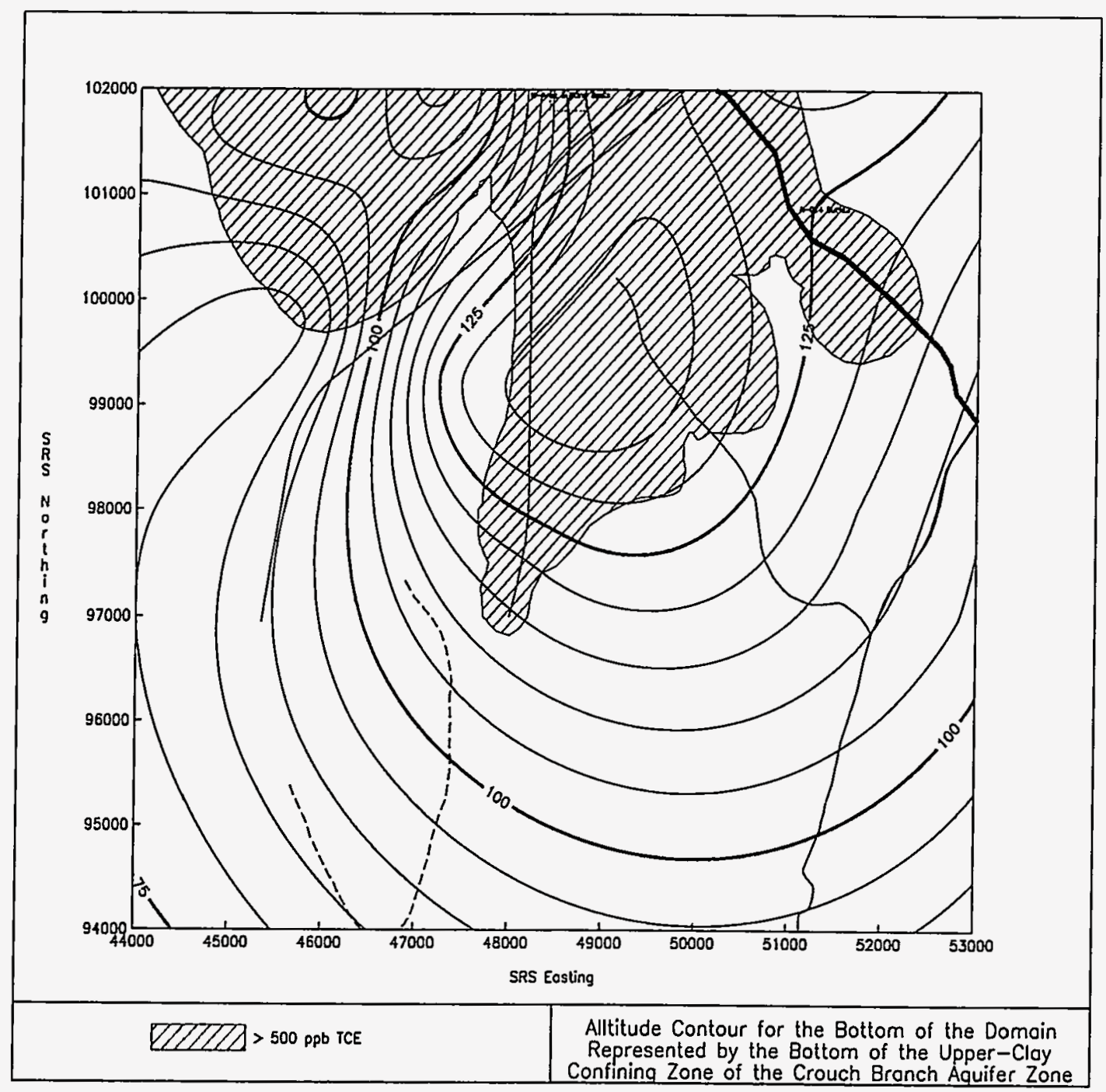

Figure 30: Altitude Contour for the Bottom of the Model Domain Represented by the "Upper-Clay" Confining Zone of the Crouch Branch Confining Unit. 


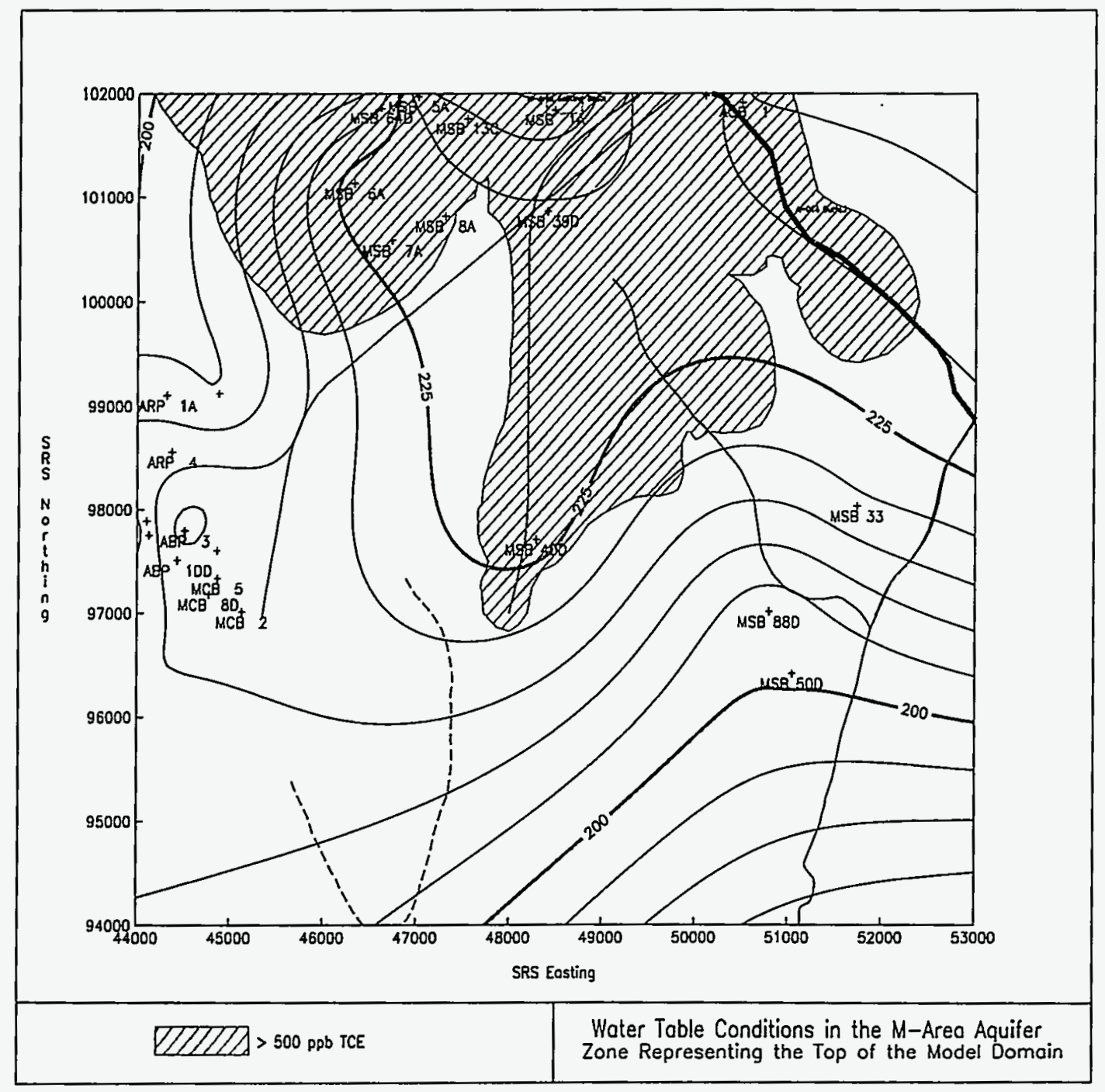

Figure 31: Top of the Model Domain Represented by the Water-Table within the M-Area Aquifer Zone. 


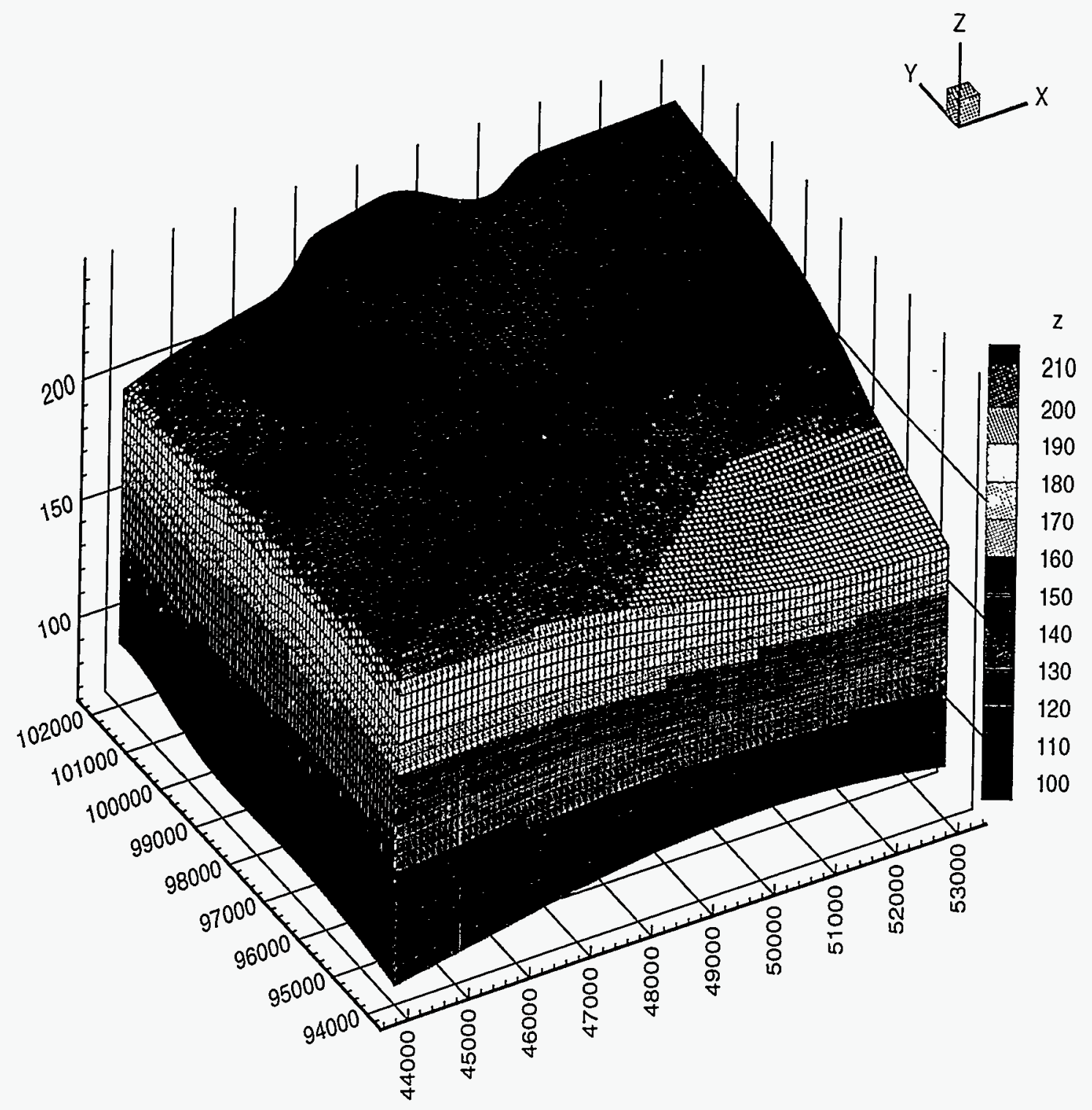

Figure 32: View Looking from the Southwest of the Model Domain showing the Vertical Discretization employed. 
$(56,16)$ and at $(43,13)$. Figure 34 presents the distribution of constant head values that were applied along the eastern edge of the domain. As with Figure 33, Figure 34 is referenced to the model $(\mathrm{i}, \mathrm{j}, \mathrm{k})$ coordinate system. As shown in Figure 34 the potentiometric head decreases from the upper left to the lower right. This reflects the downward head from the M-Area Aquifer to the Lost Lake Aquifer along with flow towards the south. As shown in Table 6 these heads range from 180.8 feet to 226.1 feet with an average value of 202.3 feet.

Head Dependent Boundary conditions on the bottom plane of the model were specified as head-dependent fluxes that were controlled by the heads in the Crouch Branch Aquifer. The intent of these boundary conditions is to control the amount of vertical flux between the Lost Lake Aquifer and the Crouch Branch Aquifer Zone. The leakance term associated with the nodal head dependent flux was derived using the combined local thickness of the "Lower Clay" and "Middle Sand" Zones of the Crouch Branch Confining Unit. This value was combined with an average vertical hydraulic conductivity value in order to prescribe local leakance values for each node. The average vertical hydraulic conductivity value applied was determined during the calibration process and was constrained to values expected of shallow marine clays. The resultant value of vertical hydraulic conductivity incorporated was $5.5 \times 10^{-03}$ feet/day which represents an un-weathered marine clay or silt. (Freeze and Cherry, 1979)I The head values applied were extracted at the appropriate node locations from Figure 8 and are presented referenced to the model domain in Figure 35. As shown in Table 6 these heads range from 178.6 feet to 204.6 feet with an average value of 190.0 feet. The leakance thickness that was incorporated was determined from the previously developed model of the A/M Area. The thickness was determined using the difference between Model Layer \#2 and Model Layer \#4 of the previously developed fully three-dimensional model. (Jackson and Aleman, 1995) The distribution of applied vertical thickness is presented in Figure 36, again referenced to the applied model domain. As shown in Table 6 the vertical thickness ranged from 29.2 to $93.4^{\circ}$ with an average value of 57.7 feet.

Boundary conditions on the southern face of the model were specified to simulate the horizontal flow from the Lost Lake Aquifer to Upper Three Runs Creek to the south. The flux across this face accounts for the majority of the groundwater drainage for the A/M Area. The following parameters were included as input in controlling the magnitude of the flux at each node: 1) effective horizontal flow area of each node, 2) horizontal leakance to Upper Three Runs Creek, and 3) the head value at Upper Three Runs Creek at the horizontal (x) position. In determining the horizontal leakance to Upper Three Runs Creek at each node an average value of horizontal hydraulic conductivity was divided by the distance to Upper Three Runs Creek. As with the vertical leakance on the bottom plane, the average horizontal hydraulic conductivity value applied was determined during the calibration process and was constrained to those values expected of silty and clean sands. The resultant value of horizontal hydraulic conductivity incorporated was $1.5 \times 10^{02}$ feet/day which is within the range expected for silty and clean sands. (Freeze and Cherry, 1979) Figure 37 presents the distance to Upper Three Runs Creek from the southern boundary of the model and the corresponding value of head (creek elevation) used to control the horizontal flux.

No Flux As shown in Figure 7 the heads in the Lost Lake Aquifer along the eastern edge of the model domain decrease uniformly towards Upper Three Runs creek. Flow conditions of this type relative to the model domain indicate that the groundwater flow directions are parallel with the particular boundary. As a result no flux boundary conditions were incorporated on the eastern face of the domain. 
Table 4: Statistical Parameters for the Bottom and Top of the Domain and for the Element Thickness of the Model.

\begin{tabular}{|l|r|r|r|}
\hline & Domain Bottom & Domain Top & Element Thickness \\
\hline Minimum: & 73.179 & 180.199 & 4.285 \\
\hline Maximum: & 138.827 & 240.67 & 7.324 \\
\hline Range: & 65.647 & 60.470 & 3.038 \\
\hline Average Z value: & 106.608 & 215.529 & 5.446 \\
\hline Standard deviation: & 17.2285 & 12.4687 & 0.7396 \\
\hline Relative deviation: & 0.188232 & 0.0673833 & 0.158193 \\
\hline Coefficient of variation: & 0.161606 & 0.0578516 & 0.135816 \\
\hline Geometric mean: & 105.202 & 215.16 & 5.39646 \\
\hline Harmonic mean: & 103.792 & 214.782 & 5.34783 \\
\hline Skew: & 0.0716569 & -0.52137 & 0.266382 \\
\hline Kurtosis: & -1.12735 & -0.352141 & -1.17316 \\
\hline Center of gravity: & $(48758.6,98160.1)$ & $(48501.6,98099.8)$ & $(48250,98040.7)$ \\
\hline
\end{tabular}

Table 5: Statistical Parameters for the Constant Head Boundary Conditions Applied to the North and East Faces of the Domain.

\begin{tabular}{|l|r|r|}
\hline & North Face & East Face \\
\hline Minimum: & 205.965 & 180.876 \\
\hline Maximum: & 240.608 & 226.131 \\
\hline Range: & 34.6435 & 45.2545 \\
\hline Average value: & 220.315 & 202.383 \\
\hline Standard deviation: & 7.84396 & 10.0271 \\
\hline Relative deviation: & 0.0814443 & 0.120129 \\
\hline Coefficient of variation: & 0.0356034 & 0.049545 \\
\hline Geometric mean: & 220.178 & 202.134 \\
\hline Harmonic mean: & 220.043 & 201.886 \\
\hline Skew: & 0.785732 & 0.069032 \\
\hline Kurtosis: & 0.0854551 & -0.849106 \\
\hline Center of gravity: & $(46.4554,11.1501)$ & $(41.6154,11.2247)$ \\
\hline
\end{tabular}




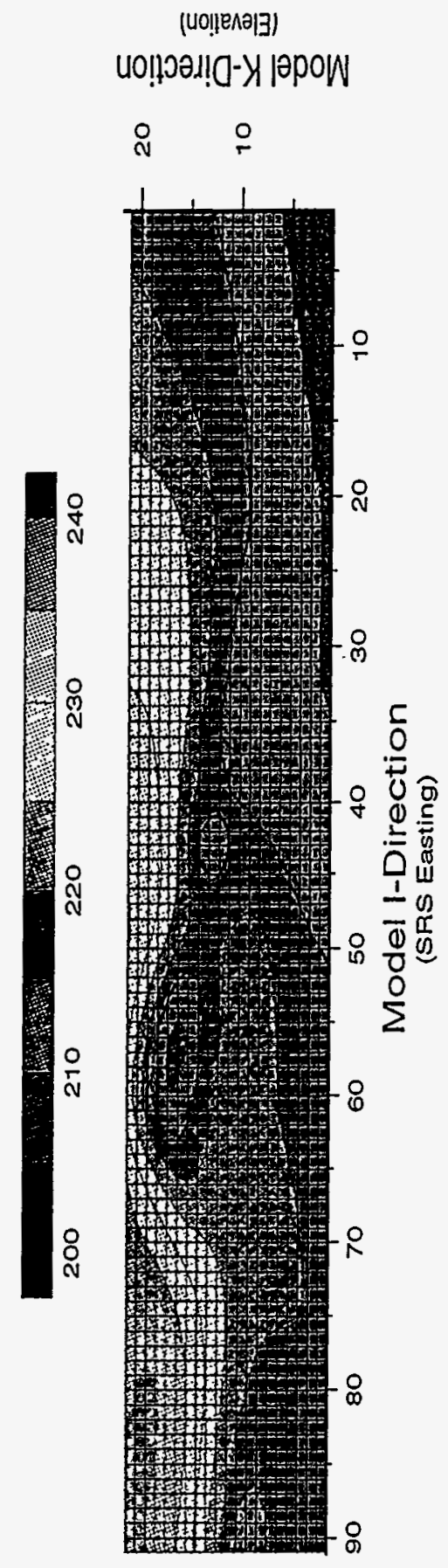

Figure 33: Distribution of Constant Head Boundary Conditions in Model Coordinate System applied to the Northern Domain of the Model. ( $\mathrm{j}$ equal 91 Plane) 


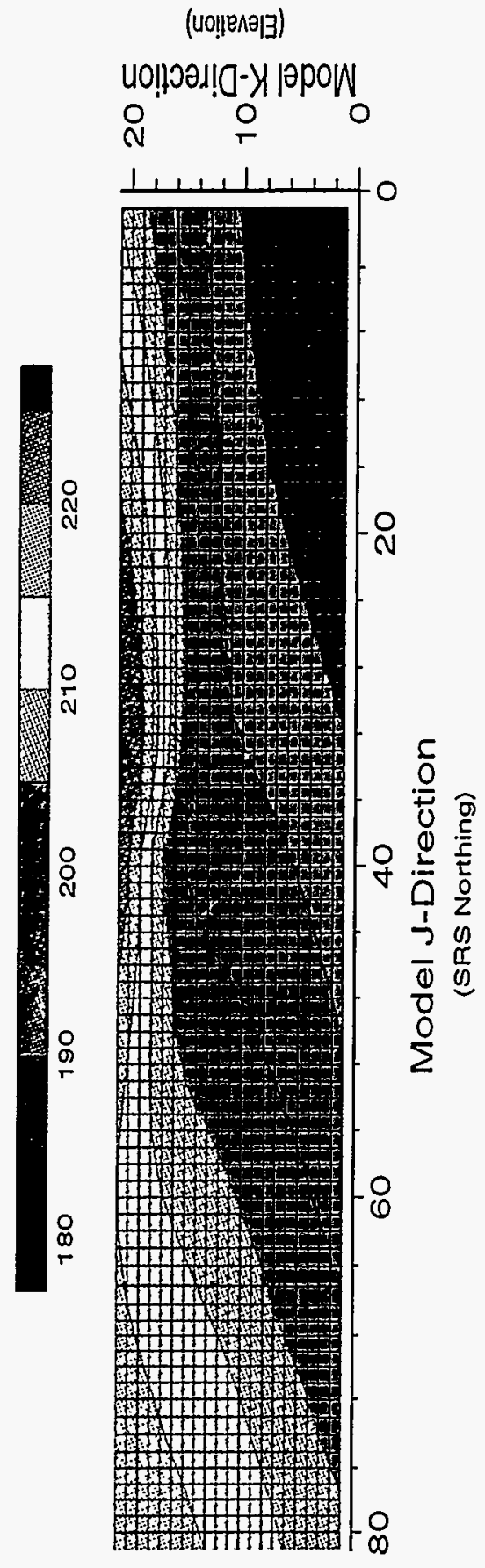

Figure 34: Distribution of Constant Head Boundary Conditions in Model Coordinate System applied to the Eastern Domain of the Model. (i equal 1 Plane) 
WSRC-RP-96-477

September 13, 1996
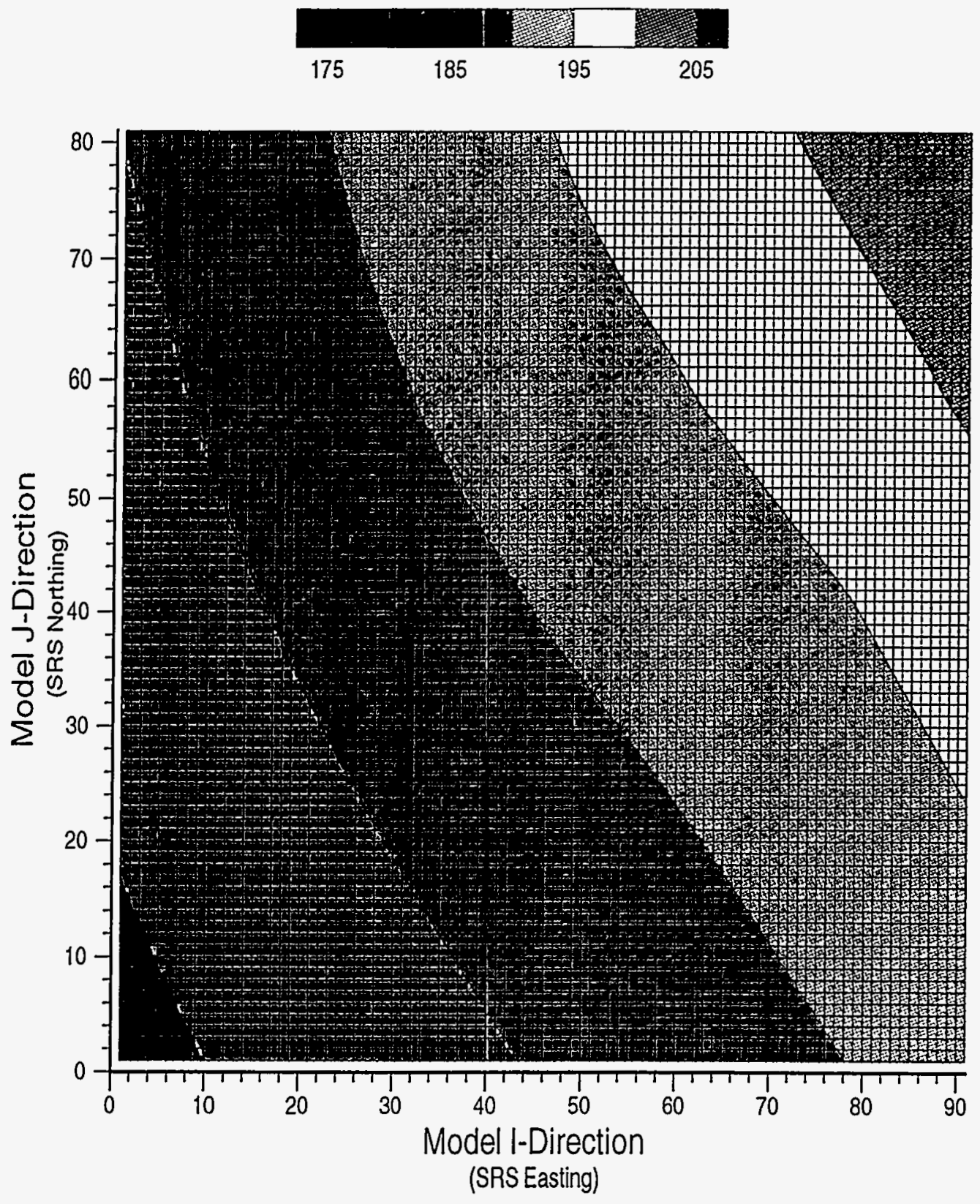

Figure 35: Distribution of Head Incorporated for the Dependent Flux Boundary Conditions applied to the Bottom Plane of the Model. (k equal 1 Plane) 

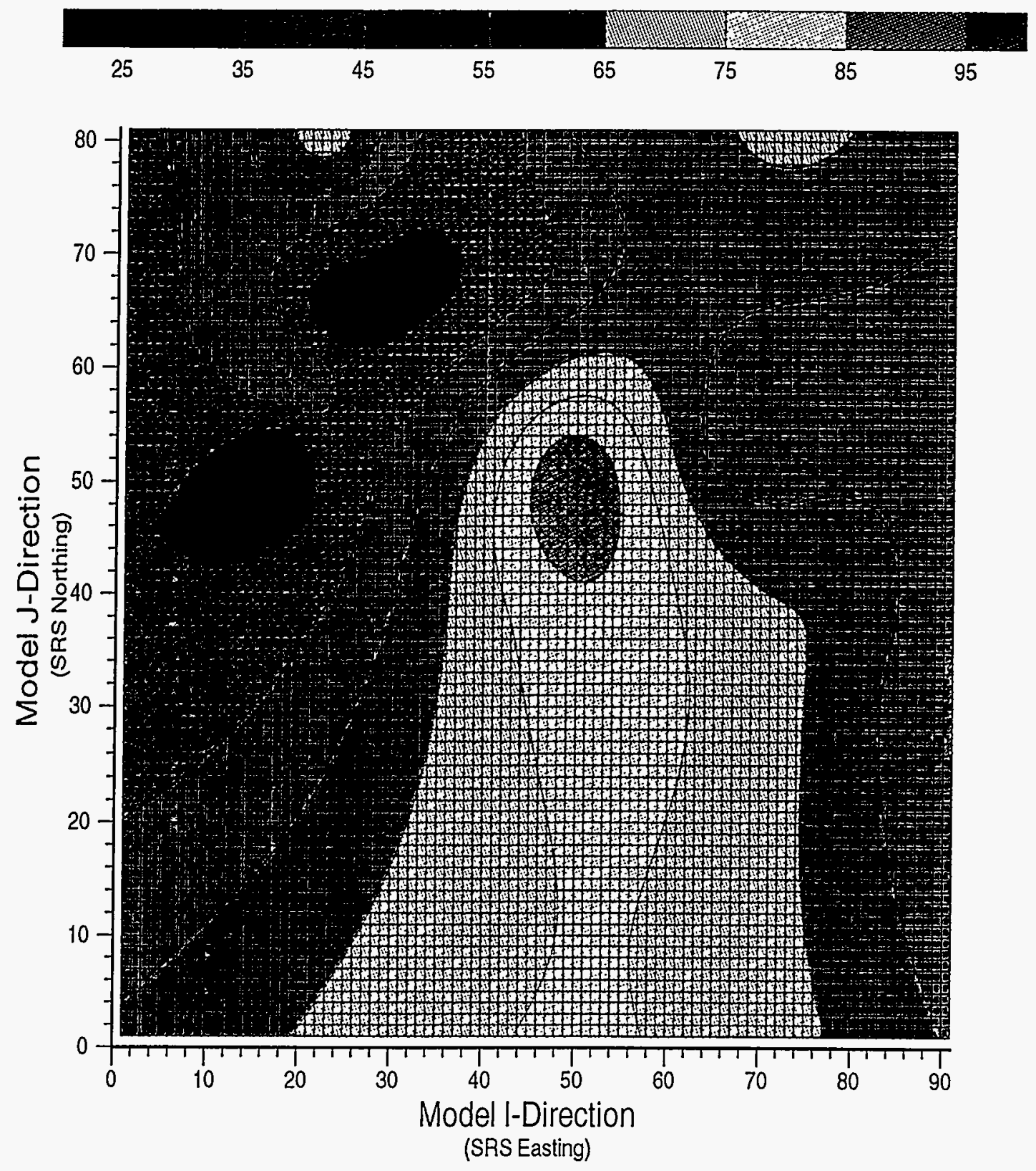

Figure 36: Distribution of Vertical Thickness Incorporated for the Dependent Flux Boundary Conditions applied to the Bottom Plane of the Model. (k equal 1 Plane) 


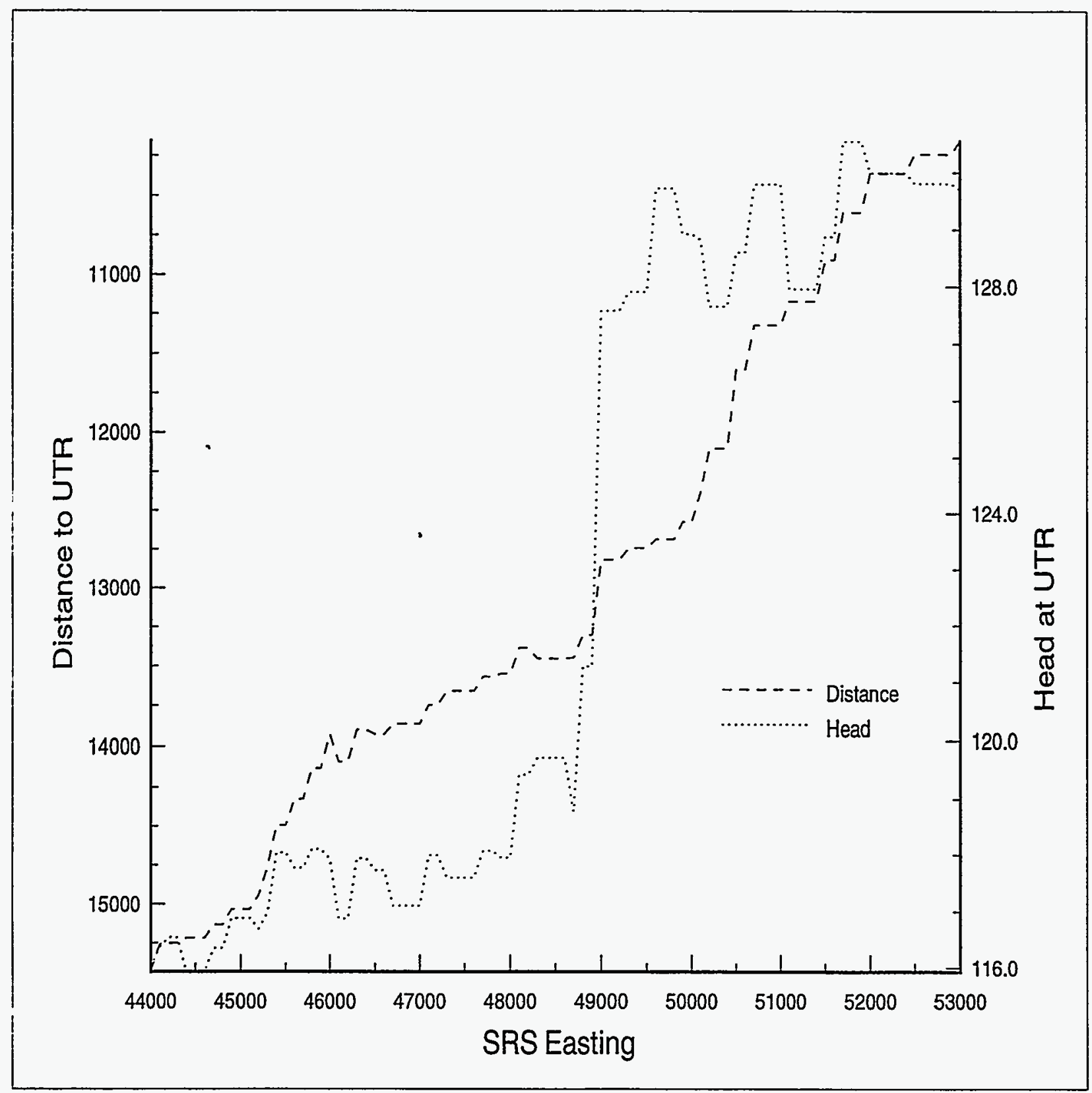

Figure 37: Distance fom Southern Boundary to Upper Three Runs Creek and Corresponding Hydraulic Head used to specify Southern Head Dependent Boundary Conditions. 
WSRC-RP-96-477

September 13, 1996

Table 6: Statistical Parameters for the Head and Thickness Distribution Prescribed Applied in Defining Head-Dependent Flux Boundary Conditions for the Bottom of the Model Domain.

\begin{tabular}{|l|r|r|}
\hline & Head & Thickness Top \\
\hline Minimum: & 178.62 & 29.20 \\
\hline Maximum: & 204.63 & 93.42 \\
\hline Range: & 26.01 & 64.21 \\
\hline Average Z value: & 190.04 & 57.774 \\
\hline Standard deviation: & 5.298 & 13.122 \\
\hline Relative deviation: & 0.0324 & 0.264 \\
\hline Coefficient of variation: & 0.0278 & 0.227 \\
\hline Geometric mean: & 189.97 & 56.221 \\
\hline Harmonic mean: & 189.896 & 54.610 \\
\hline Skew: & 0.201 & 0.0475 \\
\hline Kurtosis: & -0.583 & -0.719 \\
\hline Center of gravity: & $(48561.6,98034.7)$ & $(48729.6,97782.9)$ \\
\hline
\end{tabular}


WSRC-RP-96-477

September 13, 1996

\subsubsection{Hydraulic Properties}

Model properties of horizontal and vertical hydraulic conductivity were derived using mud fraction data from cores within the model domain. Appendix A presents the vertical distribution of mud fraction for each of the cores that were incorporated along with the corresponding accepted hydrostratigraphic pics. (Aadland et al., 1995a) The mud fraction observations provide a quantitative vertical variability representative of local variations of hydraulic conductivity. Using this data a three-dimensional distribution of mud fraction within the model domain was developed on a 500 foot horizontal resolution using a conformal minimum tension conformal gridding technique (Dynamic Graphics Inc., 1995). Using this distribution the 100 foot elements spacing incorporated in the model was mapped to the 500 foot distribution of mud fraction to obtain a horizontally and vertically heterogeneous distribution of mud fraction that was then used to estimate $\log _{10}\left(K_{H}\right)$ and $\log _{10}\left(K_{V}\right)$. In development of the distribution of mud fraction the vertical resolution applied was the same as that used within the model. This technique ensures that local vertical heterogenieties identified from the core description information are incorporated into the model. Within the core description data regions of "No Recovery" were assigned a value of $100 \%$ sand and $0 \%$ mud. This value was selected based upon personal observations and knowledge of drilling techniques. In order to develop horizontal continuity along the horizons of the Green Clay Confining Zone and the Crouch Branch Confining Unit, the mud fraction data from the cores was supplemented with additional data along these specific horizons. The lack of continuity of mud fraction experienced along these horizons is a result of numerical limitations of the minimum tension gridding process and not related to geological conditions. The minimum tension gridding process maintains the continuity of second order derivatives of the estimated parameter. As a result in the fitting of the mud fraction data, the mud fraction in those regions of sparse data are minimized resulting in the under estimation of the mud fraction. These effects are essentially eliminated in regions with adequate well control, however as with any extrapolation technique in regions without adequate control the minimum tension process can result in very unrealistic estimates. To develop the continuity of the Green Clay the mud fraction data was supplemented with data points on a 500 foot interval representative to the top of the Green Clay Confining Zone. These points were assigned an arbitrary mud fraction value of 0.6. Figure 38 presents the distribution of these data over the model domain. The continuity of the Crouch Branch Confining Unit was maintained in an analogous manner by supplementing mud fraction values of 0.8 using the distribution presented in Figure 30. Figure 39 presents a plan view of the resulting three-dimensional distribution of mud fraction. Figure 40 presents the distribution of mud fraction in the model domain as viewed from the southeast. In this figure percent mud values less than $25 \%$ have been removed. As shown in Figure 40 the removed area represents the Lost Lake Aquifer Zone. In the extreme southeast corner of the domain the mud fraction reduces analogous to the out-cropping of the Green Clay Confining Zone along the reach of Tim's Branch. Figure 41 presents the familiar cross-section through the elements along SRS Easting 48,500. This figure serves to illustrate the higher mud fraction values along the horizon of the Green Clay and the Crouch Branch Confining Units. Between these two horizons mud fractions vary from approximately $0.0 \%$ to $0.30 \%$ and represent the heterogeneous environment typical of coastal plain sediments.

In order to incorporate the heterogeneous aspect of the three-dimensional distribution of mud fraction into the numerical simulation, a correlation relating mud fraction to hydraulic conductivity was required. In developing this correlation for the model several inherent features were desired. Since hydraulic conductivity values can range over several orders of magnitude, the applied functional form should predict hydraulic conductivities over these same ranges. To accomplish this the correlation incorporated $\log _{10}$ as a function of mud fraction, where by definition mud fraction is allowed to vary over the range from 0 to 1 . The applied functional form should also predict $\log _{10}(K)$ values over the range expected for the Tertiary sediments of the A/M Area. As previously discussed these sediments consist of inter-bedded sands, silts, and clays with varying degrees of cleanliness and sorting. Hydraulic conductivity values for these types of sediments should range from $10^{-5}$ to $10^{3}$. (Freeze and Cherry, 1979) It is intuitive that as 


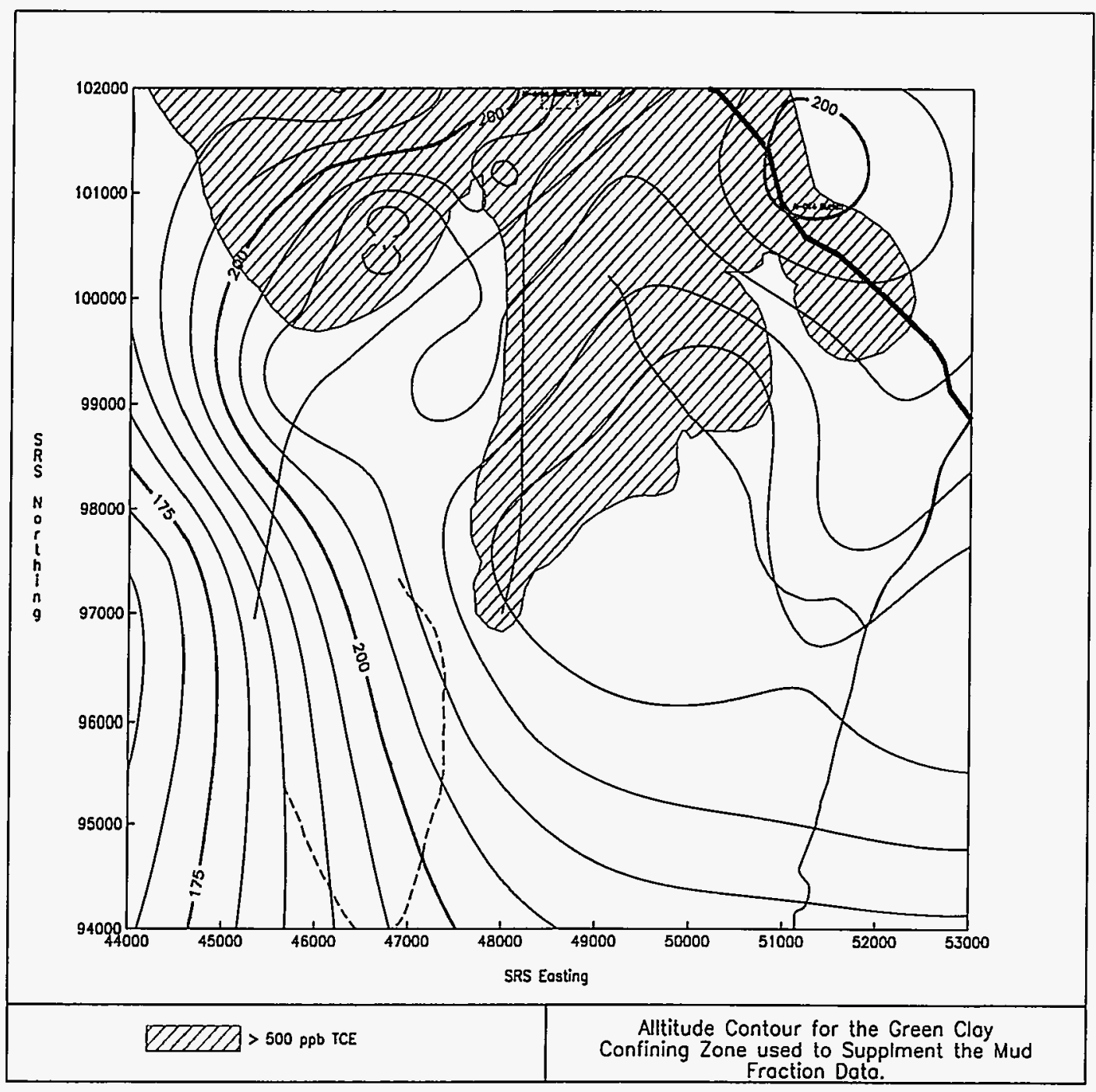

Figure 38: Altitude Contour for the Green Clay Confining Zone that was used to supplement mud fraction data. 


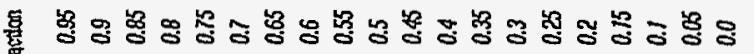

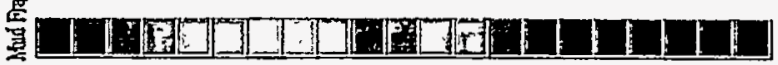

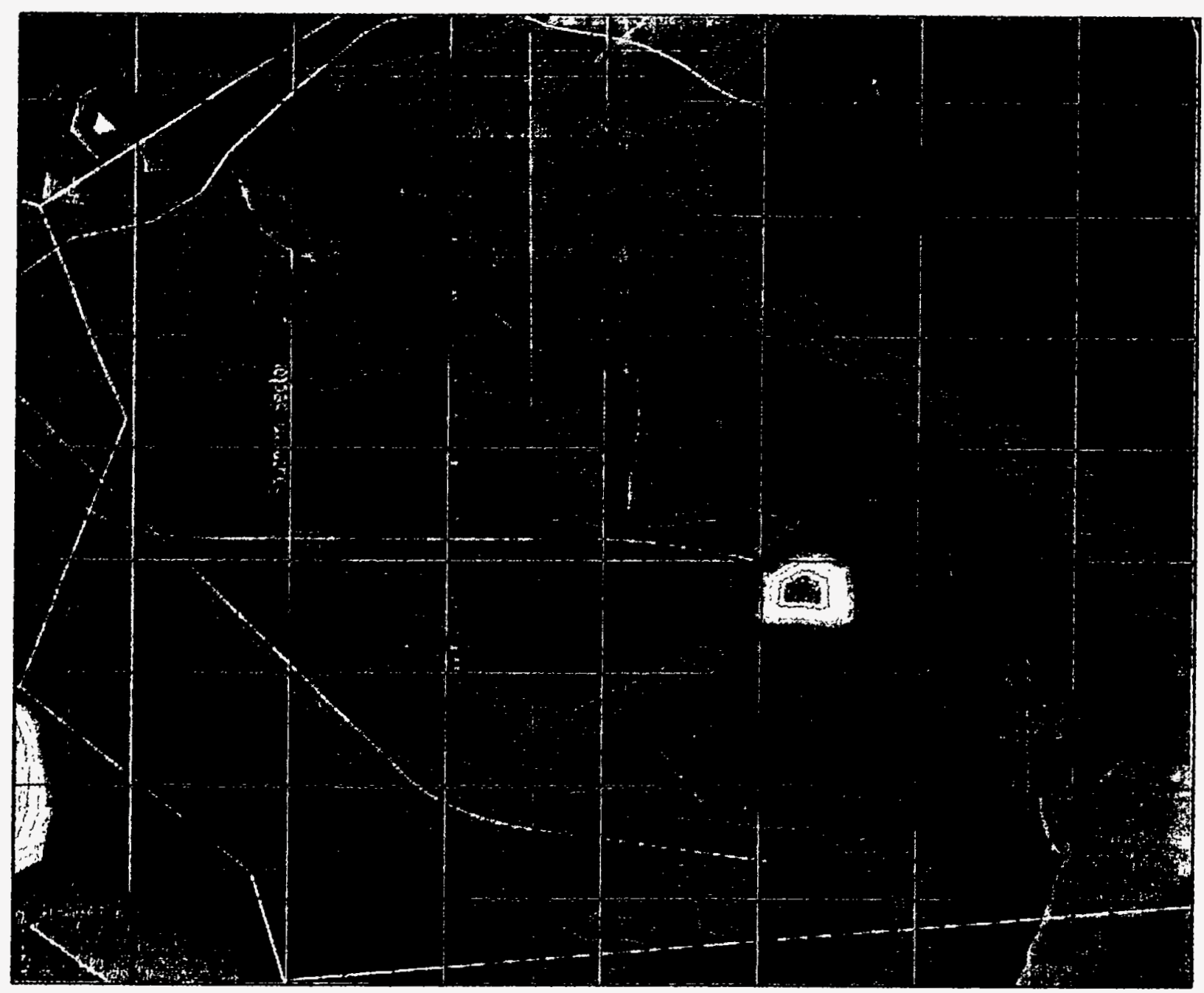

Figure 39: Plan View Showing the Distribution of Mud Fraction over the Model Domain. 

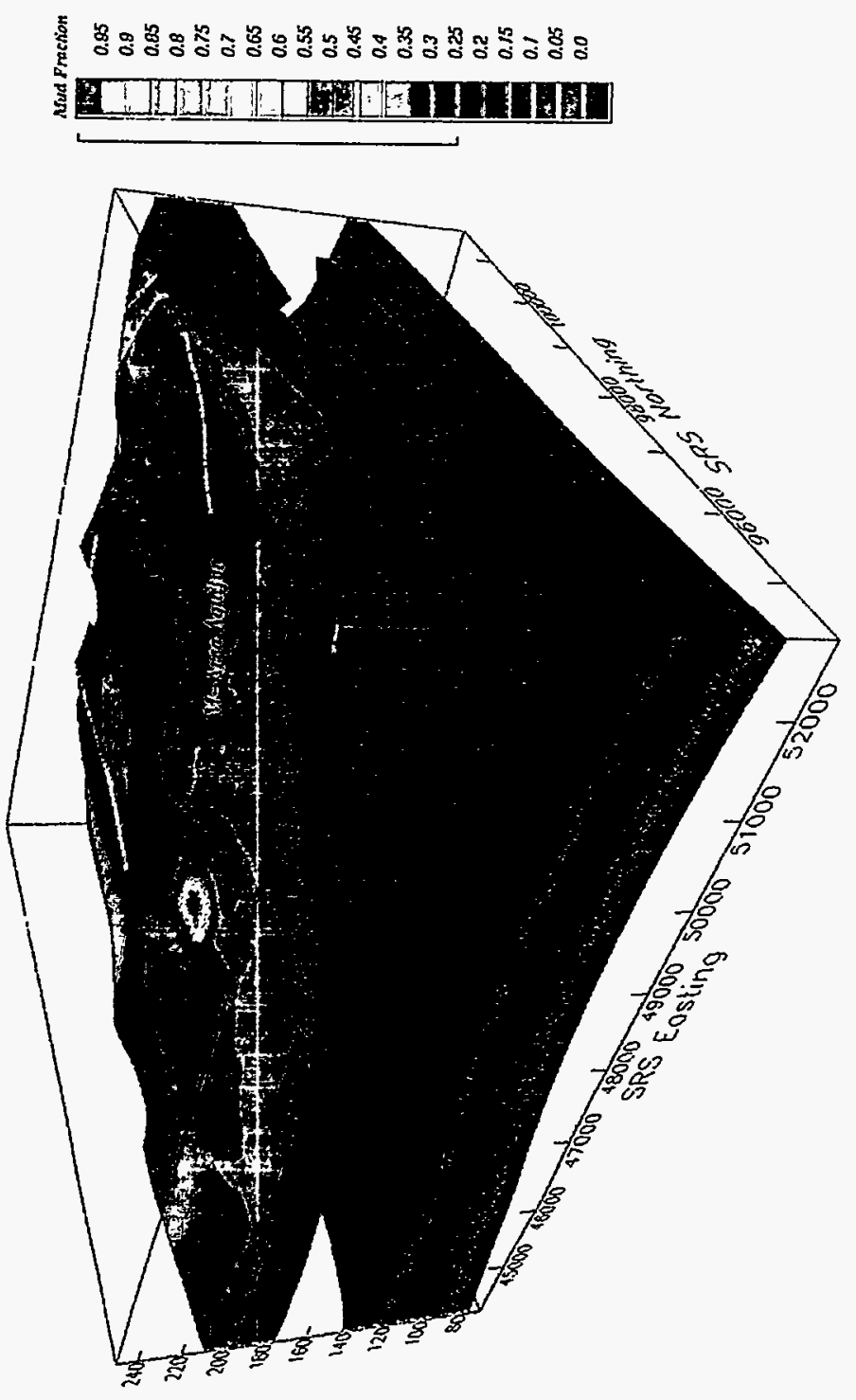

Figure 40: View from the Southeast showing the Three-Dimensional Distribution of Mud Fraction and the resultant over the Model Domain. 

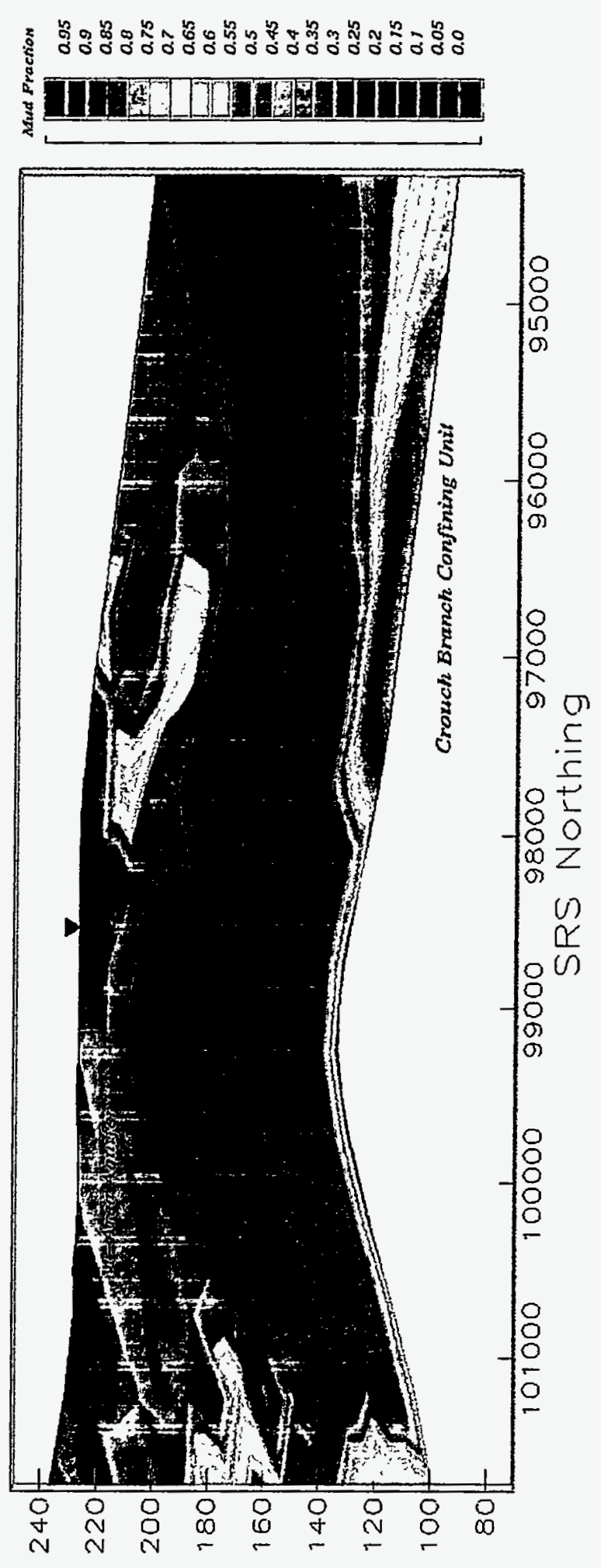

Figure 41: Vertical Cross-Section along SRS Easting 48,500 Showing Distribution of Mud Fraction within the model domain. 
the mud fraction increases the corresponding rate at which $\log _{10}(K)$ decreases should also decrease, i.e $\log _{10}(K)$ should reach a minimum value for high values of mud fraction. In order to incorporate each of these attributes the following functional form was developed based upon the hyperbolic tangent function tanh, which is a combination of exponential functions. In the functional form presented, $f$ is the $\log _{10}$ of the horizontal hydraulic conductivity, $x$ is the mud fraction and $c_{1}$ to $c_{5}$ are parameters to be estimated.

$$
f(x)=c_{1}+\frac{c_{2}-c_{x}}{2}\left(1-\tanh \left[\left(c_{4}-c_{3}\right) x+c_{3}\right]+c_{5}\right)
$$

The set of parameters $\left\{c_{1}, c_{2}, c_{3}, c_{4}, c_{5}\right\}$ control the range, the minimum and maximum values, and the zero offset. The function $f$ is a decreasing function with $c_{1} \leq f(x) \leq c_{2}$ for all $x$. The parameters $\left\{c_{1}, c_{2}, c_{3}, c_{4}, c_{5}\right\}$ are found by solving a non-linear least squares fit to minimize

$$
\chi^{2}=\sum_{i=1}^{n}\left(\log _{10}\left(K_{i}\right)-\log _{10}\left(K_{i}\right)\right)^{2}
$$

The bulk properties of hydraulic conductivity from pumping tests in the A/M Area (Hiergesell, 1992) (Hiergesell, 1993) (Hiergesell and Pemberton, 1995) were used to to determine and constrain the average hydraulic conductivity for the corresponding mud fraction data. The Levenberg-Marquardt method (Press et al., 1992) was used to minimize $\chi^{2}$. The initial estimate of the parameters:

$$
\left\{c_{1}, c_{2}, c_{3}, c_{4}, c_{5}\right\}=(-2.0,1.5,0.0,-1.0,1.0)
$$

upon convergence the Levenberg-Marquardt method provides a minimum $\chi^{2}=24.3$ with the following parameters:

$$
\left\{c_{1}, c_{2}, c_{3}, c_{4}, c_{5}\right\}=(-3.8,8.25,-0.54,2.0,-0.49)
$$

Table 7 presents the resulting distribution of $\log _{10}\left(K_{h}\right)$ as well as frequency distribution of each property set within the model domain. The vertical hydraulic conductivity of each element was determined using a linear relationship between $\log _{10}\left(K_{h}\right)$ and $\log _{10}\left(K_{v}\right)$ as a function of mud fraction. Values of anisotropy and the applied vertical hydraulic conductivity are also presented in Table 7 . Figure 42 presents the frequency histogram of mud fraction within the domain. As observed in this figure the majority of the elements have mud fraction less than 0.50 . The large quantity of elements with a mud fraction of 0.0 is most likely associated with the arbitrary assignment of $0.0 \mathrm{mud} / 1.0$ sand for regions of no recovery. 
Table 7: Correlation of Mud Fraction Values to Hydraulic Conductivity.

\begin{tabular}{|c|c|c|c|c|c|c|c|}
\hline iprop & \%Mud & $\log \left(K_{h}\right)$ & $K_{h}$ & $\overline{K_{h} / K_{v}}$ & $K_{v}$ & Frequency & Cum. Freq.) \\
\hline 1 & 0.00 & 3.0010 & $1.00 e+03$ & 1.0 & $1.00 \mathrm{e}+03$ & 28425 & 28425 \\
\hline 2 & 0.05 & 2.5759 & $3.77 e+02$ & 1.1 & $1.78 \mathrm{e}+02$ & 10900 & 39325 \\
\hline 3 & 0.10 & 2.1525 & $1.42 \mathrm{e}+02$ & 1.3 & $3.26 \mathrm{e}+01$ & 12200 & 51525 \\
\hline 4 & 0.15 & 1.7358 & $5.44 e+01$ & 1.4 & $6.46 e+00$ & 12400 & 63925 \\
\hline 5 & 0.20 & 1.3304 & $2.14 e+01$ & 1.6 & $1.44 \mathrm{e}+00$ & 11475 & 75400 \\
\hline 6 & 0.25 & 0.9404 & $8.72 \mathrm{e}+00$ & 1.8 & $3.69 \mathrm{e}+01$ & 10700 & 86100 \\
\hline 7 & 0.30 & 0.5693 & $3.71 e+00$ & 2.0 & $1.11 \mathrm{e}+01$ & 10500 & 96600 \\
\hline 8 & 0.35 & 0.2198 & $1.66 \mathrm{e}+00$ & 2.2 & $3.88 \mathrm{e}+02$ & 9475 & 106075 \\
\hline 9 & 0.40 & -0.1061 & $7.83 \mathrm{e}-01$ & 2.5 & $1.58 \mathrm{e}-02$ & 8150 & 114225 \\
\hline 10 & 0.45 & -0.4073 & $3.91 \mathrm{e}-01$ & 2.8 & $7.35 e-03$ & 4925 & 119150 \\
\hline 11 & 0.50 & -0.6834 & $2.07 e-01$ & 3.2 & $3.85 \mathrm{e}-03$ & 3050 & 122200 \\
\hline 12 & 0.55 & -0.9345 & $1.16 \mathrm{e}-01$ & 3.5 & $2.24 \mathrm{e}-03$ & 2800 & 125000 \\
\hline 13 & 0.60 & -1.1613 & $6.90 \mathrm{e}-02$ & 4.0 & $1.41 \mathrm{e}-03$ & 2725 & 127725 \\
\hline 14 & 0.65 & -1.3648 & $4.32 \mathrm{e}-02$ & 4.5 & $9.59 \mathrm{e}-04$ & 1875 & 129600 \\
\hline 15 & 0.70 & -1.5464 & $2.84 e-02$ & 5.0 & $6.89 \mathrm{e}-04$ & 2325 & 131925 \\
\hline 16 & 0.75 & -1.7076 & $1.96 \mathrm{e}-02$ & 5.6 & $5.18 \mathrm{e}-04$ & 2925 & 134850 \\
\hline 17 & 0.80 & -1.8501 & $1.41 \mathrm{e}-02$ & 6.3 & $4.04 \mathrm{e}-04$ & 4075 & 138925 \\
\hline 18 & 0.85 & -1.9756 & $1.06 \mathrm{e}-02$ & 7.1 & $3.24 \mathrm{e}-04$ & 2050 & 140975 \\
\hline 19 & 0.90 & -2.0857 & $8.21 \mathrm{e}-03$ & 7.9 & $2.66 \mathrm{e}-04$ & 1250 & 142225 \\
\hline 20 & 0.95 & -2.1819 & $6.58 \mathrm{e}-03$ & 8.9 & $2.22 \mathrm{e}-04$ & 1775 & 144000 \\
\hline 21 & 1.00 & -2.2659 & $5.42 \mathrm{e}-03$ & 10.0 & $1.89 \mathrm{e}-04$ & 0 & 144000 \\
\hline
\end{tabular}




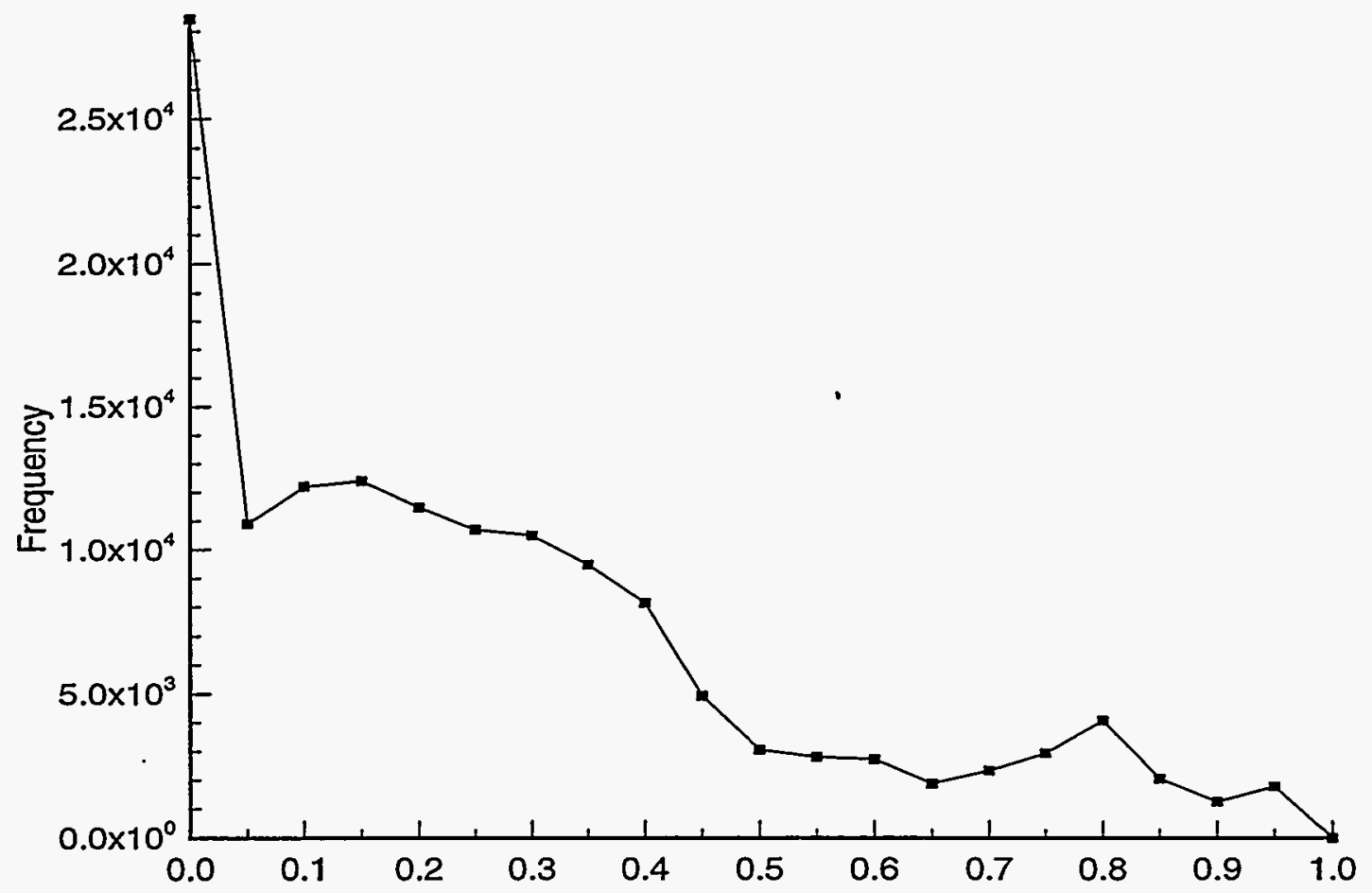

Figure 42: Frequency Histogram for the Distribution of Mud Fraction Incorporated in the Model. 
WSRC-RP-96-477

September 13,1996

\subsection{Model Calibration}

The evaluation and distribution of hydraulic parameters over the model domain was the final step in model development. This process of model calibration is an iterative process in which simulated parameters were compared to actual values from field measurements. During the calibration process, the goal was to maintain realistic material properties based upon past pumping tests and expected ranges for unconsolidated deposits. The model was considered calibrated when: 1) the predicted water levels in each layer approximately matched the average water levels and gradients, 2) discharges calculated from drain and stream nodes were on the same order as the determined stream base nodes 3) aquifer parameters were within reported ranges. Calibration was run under steady-state simulation, draw-down from recovery wells had reached an equilibrium. With the majority of the boundary conditions and material properties well defined the calibration process involved the selection of horizontal and vertical conductivity values necessary to minimize residuals. Optimum properties for vertical hydraulic conductivity used to simulate leakance across the Crouch Branch and horizontal hydraulic conductivity from the south to Upper Three Runs Creek. After numerous simulations the a value of $5.5 \times 10^{-03}$ feet/day was selected for the vertical hydraulic conductivity across the Crouch Branch Confining Unit. A value of $1.5 x 10^{02}$ feet/day was selected for the horizontal hydraulic conductivity controlling leakance to Upper Three Runs Creek. These parameters resulted in a root-mean-square residual of 6.9 feet, the average residual was 3.4 feet, and the absolute average value was 4.8 feet. The maximum residual 21.1 feet and occurred at MSB $40 \mathrm{C}$. Several efforts were made to optimize the residual in this vicinity using a variety of boundary condition specifications and correlations for $\log _{10}\left(K_{H}\right)$. The large residual present is driven by the constant head specification at the surface. Table 8 and Table 9 presents the calibration target information used and the resulting residuals.

\section{Results and Discussion}

The vertical recirculation wells that were sited and presented in Table 3 were incorporated into the developed model using FACT's steady state well boundary condition. By specifying the areal and vertical siting information of the representative screen sections along with the the extraction or injection flux, appropriate flux values are apportioned to the proper nodes to effectively simulate the performance of the well. The VRW wells were incorporated in consecutive simulations, one for wells located along the Eastern Front and another incorporating wells along the Western Front. The siting information presented in Table 3 was used to specify the horizontal and vertical location of each well with the upper and lower screen lengths selected as $25 \%$ of the aquifer height. Each of the wells were configured with an extraction flux of $20 \mathrm{gpm}$ from the lower screen zone and an injection flux of $20 \mathrm{gpm}$ in the upper screen zone. The up-gradient capture zone for each system was analyzed using reverse particle tracking techniques to identify the $0-5,5-15$, and 15-30 year capture zones. The purpose of the analysis is to focus on plume control and containment within the Southern and Western Sector and to provide an insight to additional remediation needs.

Particle tracking is completed by simulating the backward paths of a distribution of particles emanating from a region encompassing each of the recovery wells. The analysis employs a Runge-Kutta (Press et al., 1992 ) integration algorithm for the calculation of particle tracks. This technique creates particle tracks by moving in a series of increments in the direction opposite of the local velocity field. This method allows determination of the hydrologic control of a plume and estimation of the region of water that is recovered by the network during a specific time period. For this analysis, the particle tracking method incorporated advection transport only and does not account for mechanical dispersion, retardation, or bioremediation. In addition, it is important to point out that the analysis performed assumes that the contaminant is completely miscible within the aqueous phase, and thus no non-aqueous phase is present in the saturated portion of the subsurface. When this is the case, the direction of transport of the contaminant is typically in the direction of the hydraulic gradient. For dense non-aqueous phase liquids (DNAPL), gravitational 
Table 8: Calibration Targets and Resulting Residuals used in the development and calibration of the Numerical model.

\begin{tabular}{|c|c|c|c|c|c|c|}
\hline Well ID & SRS Easting & SRS Northing & Calibration & Residual & Target & \\
\hline $\mathrm{AOB} 1$ & 50485.90 & 101910.70 & 219.00 & -6.63 & 235.40 & 228.77 \\
\hline ARP 1A & 44317.40 & 99102.90 & 193.50 & -1.93 & 215.10 & 213.17 \\
\hline ARP 2 & 44876.10 & 99119.80 & 190.80 & 0.57 & 217.98 & 218.55 \\
\hline ARP 3 & 44903.70 & 98638.20 & 203.20 & -2.58 & 221.03 & 218.45 \\
\hline ARP 4 & 44374.80 & 98567.70 & 198.30 & -1.32 & 218.10 & 216.78 \\
\hline MSB 1A & 48467.30 & 101833.70 & 223.70 & 1.54 & 231.62 & 233.16 \\
\hline MSB 1B & 48483.20 & 101833.00 & 140.25 & 5.94 & 214.73 & 220.67 \\
\hline MSB 1C & 48512.70 & 101832.50 & 163.65 & 6.49 & 218.63 & 225.12 \\
\hline MSB 1CC & 48498.00 & 101832.50 & 190.15 & 2.23 & 220.13 & 222.36 \\
\hline MSB 1D & 48452.20 & 101833.40 & 220.10 & $\overline{3.14}$ & 230.13 & 233.27 \\
\hline MSB 2B & 48748.20 & 101997.90 & 147.95 & 0.71 & 215.28 & 215.99 \\
\hline MSB 2C & 48749.30 & 101982.50 & 192.35 & -2.47 & 219.75 & 217.28 \\
\hline MSB 4A & 48313.00 & 101933.40 & 225.30 & 2.00 & 230.03 & 232.03 \\
\hline MSB 4B & 48312.80 & 101978.30 & 140.75 & -0.34 & 214.98 & 214.64 \\
\hline MSB 4C & 48313.60 & 101963.20 & 165.70 & 0.88 & 218.69 & 219.57 \\
\hline MSB 5A & 46998.70 & 101971.50 & 217.70 & 1.67 & 226.33 & 228.00 \\
\hline MSB 5B & 46983.60 & 101971.10 & 133.75 & 1.21 & 210.49 & 211.70 \\
\hline MSB 5C & 46968.60 & 101970.40 & 185.75 & 1.84 & 222.86 & 224.70 \\
\hline MSB 6A & 46319.90 & 101133.80 & 212.40 & -0.55 & 226.51 & 225.96 \\
\hline MSB 6B & 46321.60 & 101148.50 & 127.45 & 8.81 & 207.19 & 216.00 \\
\hline MSB 6C & 46324.10 & 101169.10 & 191.65 & 1.94 & 223.37 & 225.31 \\
\hline MSB 7A & 46726.10 & 100585.70 & 212.50 & -0.13 & 226.96 & 226.83 \\
\hline MSB 7B & 46718.10 & 100597.60 & 145.10 & 5.68 & 207.57 & 213.25 \\
\hline MSB 7C & 46709.10 & 100609.20 & 197.75 & 5.50 & 221.42 & 226.92 \\
\hline MSB 8A & 47293.20 & 100815.10 & 212.90 & -0.88 & 228.66 & 227.78 \\
\hline MSB 8B & 47281.90 & 100805.80 & 148.45 & -1.23 & 209.19 & 207.96 \\
\hline MSB 8C & 47264.60 & 100793.20 & 193.55 & 8.18 & 219.59 & 227.77 \\
\hline MSB 14A & 48521.90 & 101629.50 & 154.60 & 13.81 & 217.55 & 231.36 \\
\hline MSB 14B & 48519.10 & 101639.00 & 191.40 & 12.97 & 218.99 & 231.96 \\
\hline MSB 17A & 46245.70 & 101976.60 & 158.10 & 0.99 & 216.32 & 217.31 \\
\hline MSB 17B & 46237.70 & 101994.60 & 188.30 & 1.31 & 224.75 & 226.06 \\
\hline MSB 18A & 46110.40 & $\overline{100416.10}$ & 161.40 & 11.05 & 211.79 & 222.84 \\
\hline MSB 18B & 46115.70 & 100424.10 & 196.00 & 1.98 & 220.75 & 222.73 \\
\hline MSB 19B & 50934.80 & 100999.30 & 145.20 & 3.21 & 217.05 & 220.26 \\
\hline MSB 19C & 50942.40 & 100992.10 & 208.70 & -6.56 & 237.06 & 230.50 \\
\hline MSB 31B & 50078.70 & 101981.30 & 154.80 & 5.91 & 214.85 & 220.76 \\
\hline MSB 31C & 50089.90 & 101979.60 & 216.60 & 0.01 & 234.14 & 234.13 \\
\hline MSB 31CC & 50067.90 & 101983.10 & 179.05 & 6.62 & 214.70 & 221.32 \\
\hline MSB 32 & 52733.90 & 99655.60 & 208.10 & 7.18 & 222.50 & 229.68 \\
\hline MSB 32B & 52742.50 & 99676.00 & 130.00 & 9.01 & 210.66 & 219.67 \\
\hline MSB 32C & 52746.90 & 99684.90 & 186.15 & 14.69 & 215.10 & 229.79 \\
\hline MSB 33 & 51736.30 & 98031.00 & 209.20 & 2.56 & 215.52 & 218.08 \\
\hline MSB 33B & 51741.90 & 97995.90 & 123.50 & 5.29 & 206.66 & 211.95 \\
\hline MSB 33C & 51746.70 & 97984.80 & 168.20 & 2.33 & 208.93 & 211.26 \\
\hline
\end{tabular}


Table 9: Calibration Targets and Resulting Residuals used in the development and calibration of the Numerical model.

\begin{tabular}{|c|c|c|c|c|c|c|}
\hline$\overline{M S B} 36 \bar{B}$ & 49526.30 & 100514.90 & 160.90 & -1.29 & 214.67 & 213.38 \\
\hline$\overline{\mathrm{MSB}} 36 \mathrm{C}$ & 49537.20 & 100518.30 & 191.40 & 13.38 & 215.10 & 228.48 \\
\hline$\overline{\mathrm{MSB}} 39 \overline{\mathrm{B}}$ & 48376.90 & 100844.60 & 146.80 & -13.19 & 212.68 & 199.49 \\
\hline MSB 39C & 48386.70 & 100852.10 & 196.80 & 12.61 & 216.08 & 228.69 \\
\hline MSB 39D & 48396.00 & 100858.70 & 219.50 & -2.31 & 231.38 & 229.07 \\
\hline MSB $40 B$ & 48281.60 & 97685.00 & 151.90 & 0.06 & 203.57 & 203.63 \\
\hline MSB 40C & 48283.50 & 97697.80 & 189.60 & 21.14 & 203.91 & 225.05 \\
\hline MSB 40D & 48285.10 & 97709.30 & 216.70 & -0.29 & 225.96 & 225.67 \\
\hline MSB 49B & 45868.20 & 99737.80 & 113.50 & 1.14 & 202.03 & 203.17 \\
\hline$\overline{M S B} 50 \mathrm{~B}$ & 51053.50 & 96433.00 & 152.40 & 5.38 & 200.00 & 205.38 \\
\hline MSB 50D & 51044.10 & 96416.70 & 191.30 & 1.67 & 198.95 & 200.62 \\
\hline MSB 51B & 52818.00 & 96992.70 & 157.20 & 3.75 & 203.20 & 206.95 \\
\hline MSB 57D & 48701.50 & 101829.50 & 219.85 & 1.21 & 230.87 & 232.08 \\
\hline$\overline{M S B}$ 60D & 48326.80 & 101835.50 & 218.60 & 3.18 & 229.63 & 232.81 \\
\hline MSB $62 \mathrm{~B}$ & 47906.80 & 101865.30 & 138.65 & $-1.56^{\circ}$ & 212.97 & 211.41 \\
\hline MSB 62C & 47895.00 & 101857.20 & 187.60 & -3.06 & 223.58 & 220.52 \\
\hline MSB 63B & 47861.00 & 101184.40 & 138.55 & -4.52 & 210.83 & 206.31 \\
\hline MSB 63C & 47849.20 & 101174.60 & 193.45 & 11.15 & 220.12 & 231.27 \\
\hline MSB 64B & 46579.70 & 101831.00 & 121.95 & 3.09 & 209.66 & 212.75 \\
\hline MSB 64C & 46589.20 & 101842.90 & 178.85 & -0.22 & 222.09 & 221.87 \\
\hline MSB 64D & 46598.50 & 101854.80 & 210.60 & 0.50 & 226.13 & 226.63 \\
\hline MSB 70C & 45012.00 & 101785.20 & 176.45 & -0.84 & 216.81 & 215.97 \\
\hline MSB 72B & 48350.30 & 96387.60 & 154.35 & 9.64 & 199.18 & 208.82 \\
\hline MSB 73B & 45694.00 & 99270.30 & 133.15 & 18.05 & 200.69 & 218.74 \\
\hline MSB 74B & 50443.20 & 99197.40 & 145.15 & 5.58 & 210.06 & 215.64 \\
\hline MSB 74C & 50457.10 & 99191.10 & 175.45 & 9.50 & 209.73 & 219.23 \\
\hline MSB 75B & 48875.50 & 98937.40 & 159.30 & 2.77 & 209.14 & 211.91 \\
\hline MSB 75C & 48859.70 & 98942.30 & 191.15 & 17.72 & 208.67 & 226.39 \\
\hline MSB 79B & 47300.20 & 99296.90 & 138.45 & 1.74 & 207.18 & 208.92 \\
\hline MSB 79C & 47286.80 & 99290.20 & 197.25 & 16.39 & 208.95 & 225.34 \\
\hline MSB 87B & 51607.00 & 101276.00 & 171.60 & 1.76 & 218.29 & 220.05 \\
\hline MSB 88C & 50784.00 & 97012.70 & 124.70 & 5.31 & 201.68 & 206.99 \\
\hline MSB 88D & 50793.50 & 97012.30 & 192.60 & 0.73 & 202.58 & 203.31 \\
\hline MSB 89B & 47889.90 & 98374.10 & 159.50 & 0.16 & 206.12 & 206.28 \\
\hline MSB 89C & 47881.60 & 98379.40 & 220.10 & -1.01 & 227.51 & 226.50 \\
\hline
\end{tabular}


forces and the distribution and orientation of low permeability units, along with hydraulic gradient, influence the direction of contaminant flow. Zone of capture analysis performed using only particle tracking may not adequately depict the control or recovery of DNAPL.

Figure 43 presents the up-gradient capture zone for the wells located on the Eastern Front of the $500 \mathrm{ppb}$ Isocontour. As shown in Figure 43 a capture zone is established up-gradient of the proposed recirculation wells. The 0-5 year capture zone lies predominately within the Lost lake Aquifer Zone and results in the containment of a significant portion of the dissolved trichloroethylene plume in the Southern Sector. The 5-15 year capture zone presented captures those portions of the plume in the upper portion of the Lost Lake Aquifer Zone. Within the 15-30 year capture zone the majority of the particles have crossed the horizon of the Green Clay and reached the surface of the water table. Those particles that continue to move up-gradient within the Lost Lake Aquifer are strongly influenced by the effects of the existing recovery well system and model boundary conditions. Of particular note is the behavior of those particles that emanate from the eastern most well in the series. This particle move in a northward direction towards the A-014 Outfall. Nearing the out-fall the particles cross into the M-Area Aquifer Zone as noted by the radical turn from the northwest to the northeast. This well should provide long-term remediation of the that portion of the dissolved trichloroethylene plume identified within the M-Area Aquifer Zone along the A-014 Outfall. The three-dimensional aspect of the capture zone is presented in Figure 44 that presents the resulting capture zone for the system of 8 wells located on the Eastern Front. From this representation the three-dimensional aspect of the resulting capture zone is observed. The 0-5 year capture zone occurs within the lower portion of the Lost Lake Aquifer Zone and will provide contaminated groundwater on the order of $500 \mathrm{ppb}$ trichloroethylene for into the recirculation zone of the VRW System.

Figure 45 presents the up-gradient capture zone for the 6 wells located on the Western Front of the 500 $\mathrm{ppb}$ Isocontour. As indicated by the displayed reverse particle tracks the strong downward gradient in this region of the model results in the upward movement of the particles into the M-Area Aquifer Zone. This is evident by the concentric patterns of the 0-5, 5-15, and 15-30 year capture zone. Examination of the capture zones for the two northern most wells sited at $(44660,101130)$ and $(44830,100690)$ indicate a southeast flow direction towards the capture zone of the other wells located along the Western front. It is understood that the general groundwater flow patterns in this area are towards the basin and that the path-lines are a result of the proximity of these two wells to the northern and eastern domain of the model. The general direction of flow is from the M-Area Basin, along a south westward line towards MSB 49. Within this region the particles move eastward and then turn northward where they are again terminated due to the effects of the existing recovery wells. An interesting feature is observed when comparing the capture zone presented in Figure 43 with that presented in Figure 45 . Reverse particles that approach from either the east or the west are turned northward along the line of 48,000 feet. It is along this line that the distribution of chlorinated solvent is also divided between the Southern and Western Sectors. 


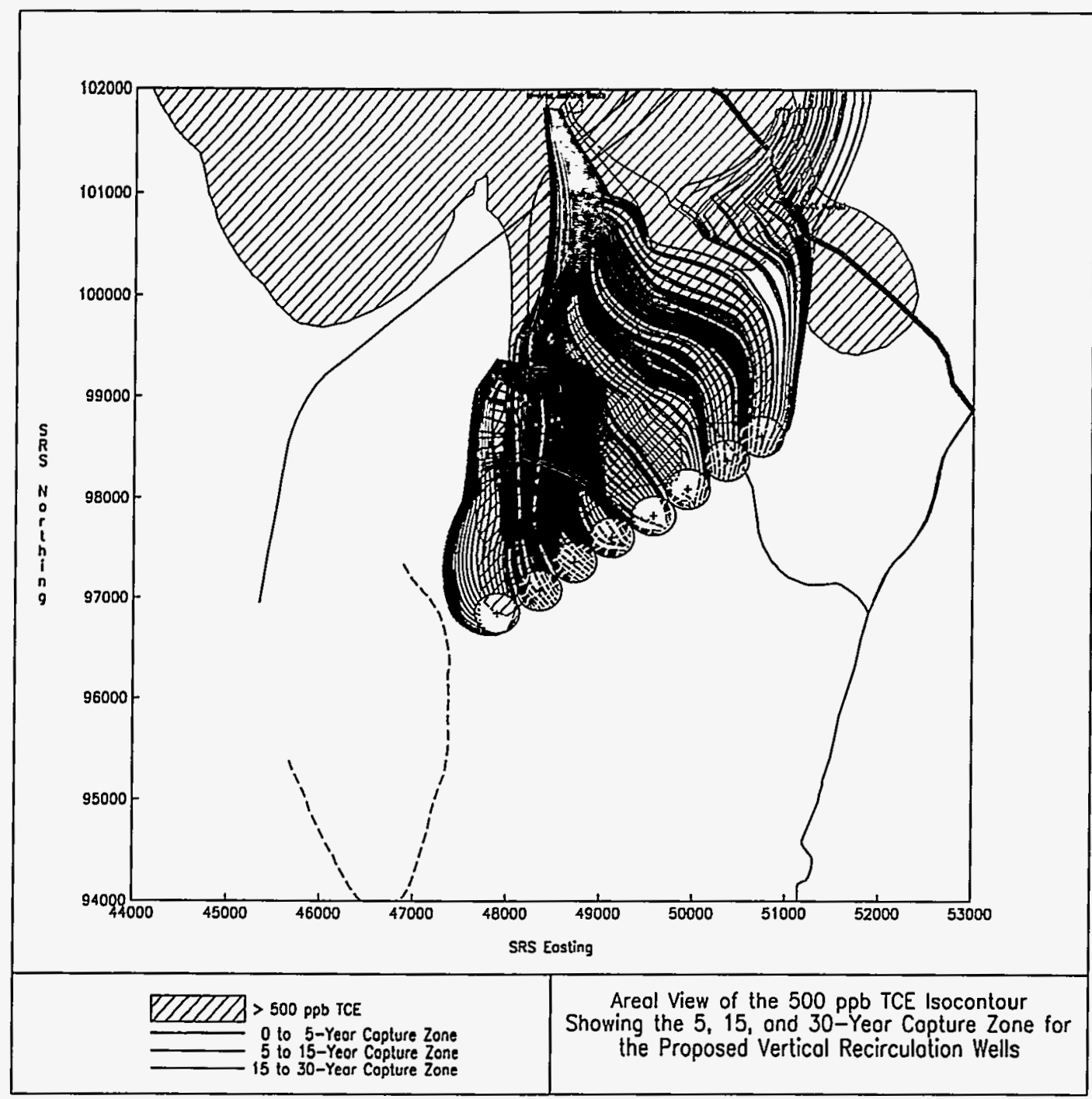

Figure 43: Plan View of the Capture Zone of the Dissolved Trichloroethylene Plume Resulting from a Series of 8 Vertical Recirculation Wells with a Design Flow-rate of 20 gpm located along the Eastern Front of the $500 \mathrm{ppb}$ Isocontour. 


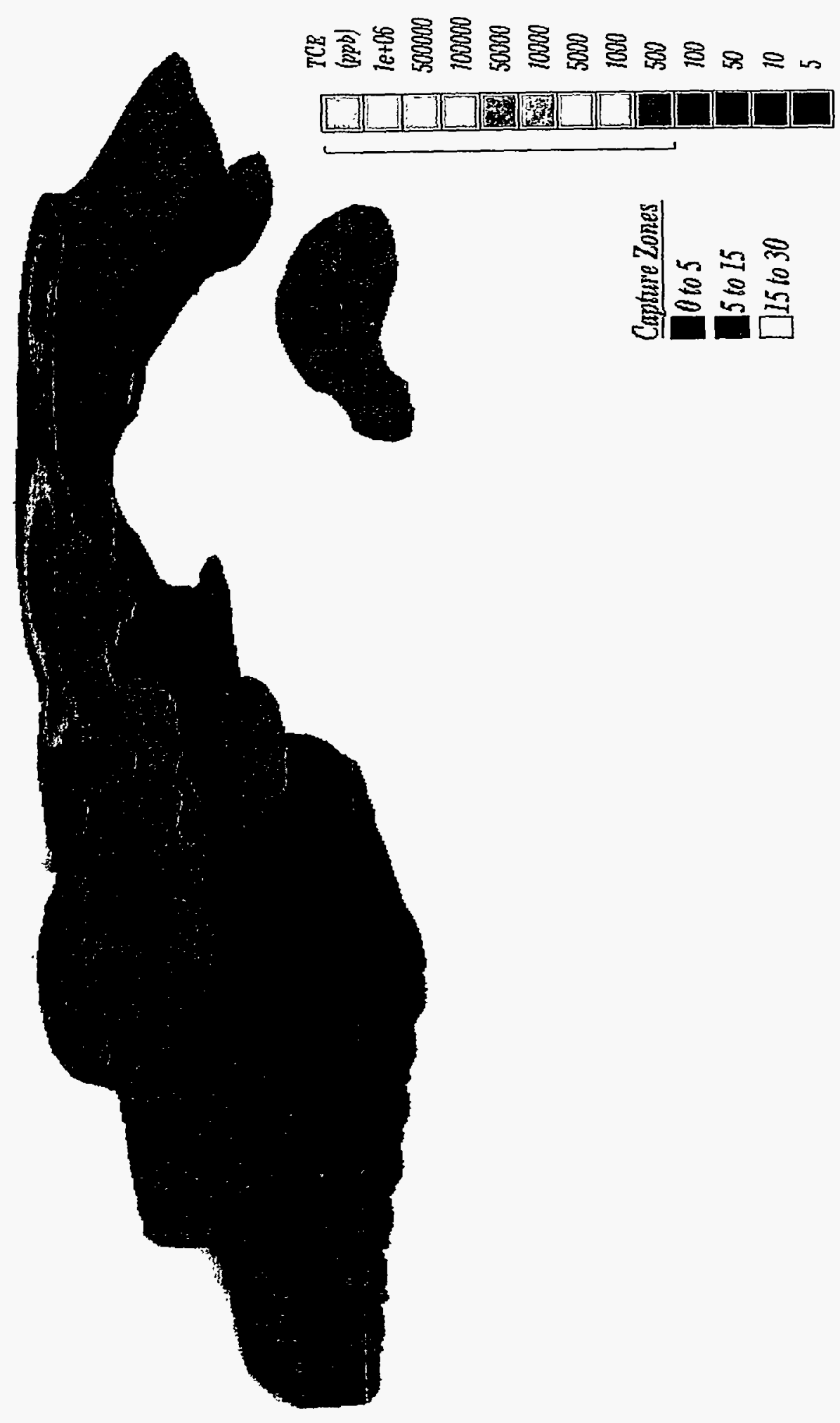

Figure 44: View from the Southeast of the Capture Zone of the Dissolved Trichloroethylene Plume Resulting from a Series of 8 Vertical Recirculation Wells with a Design Flow-rate of 20 gpm located along the Eastern Front of the $500 \mathrm{ppb}$ Isocontour. 


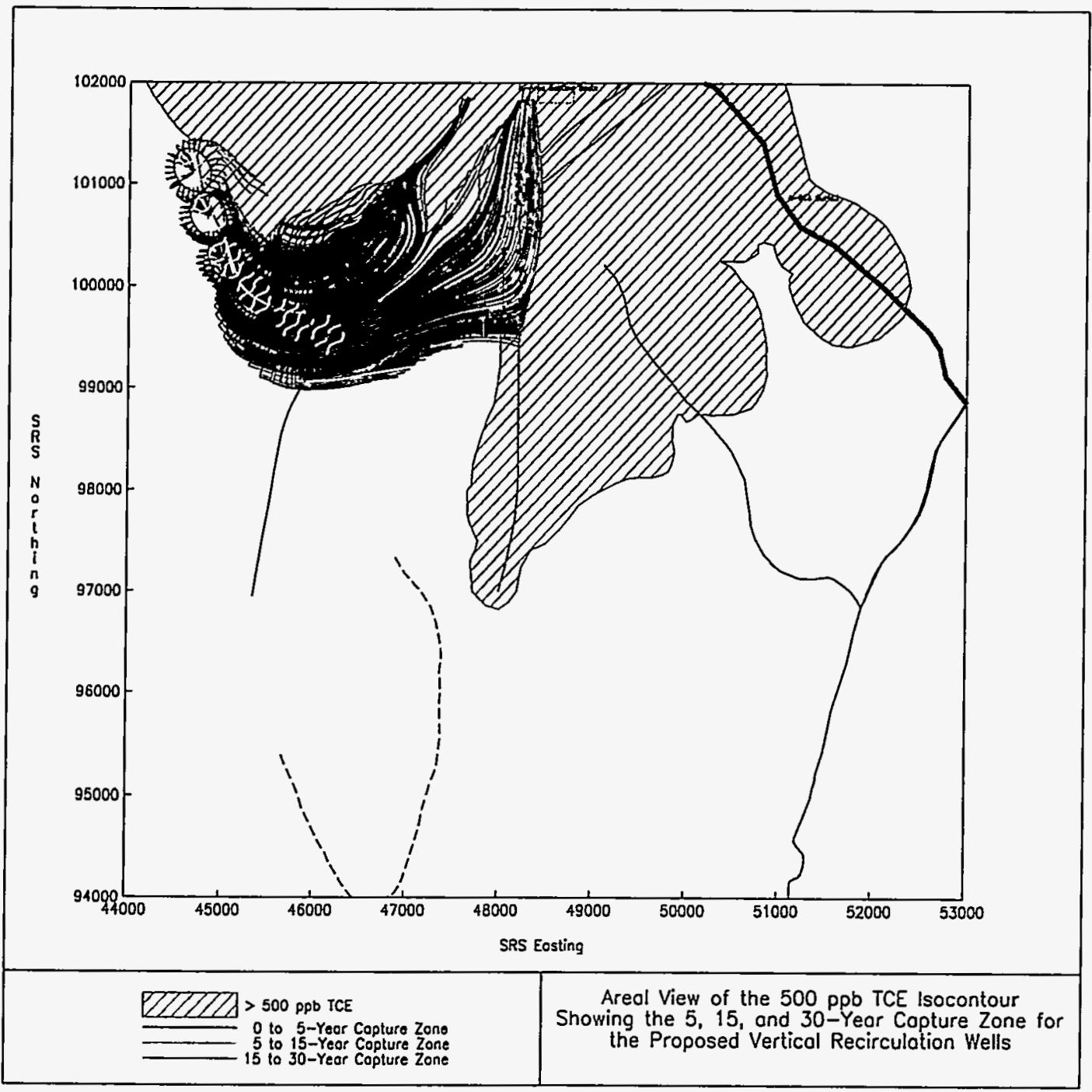

Figure 45: Plan View of the Capture Zone of the Dissolved Trichloroethylene Plume Resulting from a Series of 6 Vertical Recirculation Wells with a Design Flow-rate of $20 \mathrm{gpm}$ located along the Western Front of the $500 \mathrm{ppb}$ Isocontour. 


\section{Summary}

A numerical model has been developed to evaluate and provide preliminary information for the development of remediation technologies within the Western and Southern Sectors of the A/M Area. In order to design and develop this system the distribution of the dissolved trichloroethylene plume within the $A / M$ Area was examined. By incorporating quarterly monitoring well data, depth discrete soil head-space data, and the physical laws governing groundwater flow and contaminant transport with source history a refined representation of the distribution of trichloroethylene was developed. plume. A system of vertical recirculation wells has sited based upon this distribution and dimensioned to capture, contain, and remediate those portions of the dissolved solvent plume delineated by the 500 part per billion trichloroethylene isoconcentration contour in the Southern Sector of the A/M Area. Within the Southern Sector two fronts of remediation have been identified. The first series located on the Eastern from of the $500 \mathrm{ppb}$ plume consists of 8 wells beginning at the southern most position of the 500 part per billion trichloroethylene isoconcentration, very near soil boring MSS-2SB. Along the Western Front of the plume an additional series of 6 wells are recommended. These wells should be based along a line to the northeast beginning at MSB-49 and are required to capture the dissolved trichloroethylene plume originating from suspected DNAPL zones west of the M-Area Basin. Both sets of these wells were selected to operate at a design flow-rate of $20 \mathrm{gpm}$. During the development and analysis of the model a distinct division of groundwater flow patterns has been observed that coincides with the separation of the dissolved trichloroethylene plume between the the Southern and Western Sectors. 


\section{References}

Aadland, R. K., Gellisci, J. A., and Thayer, P. A. (1995a). Hydrogeologic Framework of West-Central South Carolina. Technical Report 5, State of South Carolina Department of Natural Resources Water Resources Division, Aiken, South Carolina, 29808.

Aadland, R. K., Lewis, S. E., and McAdams, T. D. (1995b). Hydrogeological Characterization Report for the A/M Area (U). Technical Report WSRC-RP-95-0052, Westinghouse Savannah River Company, Columbia, South Carolina.

Beaudoin, C. M., Schreuder, P., and Haselow, J. S. (1991). A Groundwater Flow Model for the A/M Area of the SRS (U). Technical Report WSRC-RP-91-0585, Westinghouse Savannah River Company, Aiken, South Carolina 29808.

Christensen, E. J. and Gordon, D. E. (1983). Technical Summary of Groundwater Quality Protection Program at Savannah River Plant Volume I - Site Geohydrology, and Solid and Hazardous Wates. Technical Report DPST-83-829, E. I. duPont de Nemours \& Co., Savannah River Laboratory, Aiken, South Carolina 29808.

Cohen, R. M. and Mercer, J. W. (1993). DNAPL Site Evaluation. CRC Press, 2000 Corporate Blvd., N.W., Boca Raton, Florida 33431.

Department of Energy (1987). Savannah River Site Hazardous Waste Permit. Permit SCI 980008989 , United States Department of Energy, Aiken, South Carolina 29808.

Dynamic Graphics Inc. (1995). EarthVision User's Guide, Version 3.0. Technical report, Dynamic Graphics Inc., 1015 Atlantic Ave., Alameda, California 94501.

Eddy, C. A., Looney, B. B., Hazen, T. C., Nichols, R. L., Fliermans, C. B., Parker, W. H., Dougherty, J. M., Kaback, D. S., and Simmons, J. L. (1993). Post-Test Evaluation of the Geology, Geochemistry, Microbiology, and Hydrology of the In Situ Air Stripping Demonstration Site at the Savannah River Site (U). Technical Report WSRC-TR-93-369, Westinghouse Savannah River Company, Aiken, South Carolina 29808.

Fallaw, W. (1991). Subsurface Stratigraphy and Structure of A/M Area. Final Report for Subcontract AX 824634, CDM Federal Programs Corporation, Westinghouse Savannah River Company, Aiken, South Carolina 29808.

Fallaw, W. and Sargent, K. A. (1982). Subsurface Geology of the A/M Areas at the Savannah River Plant. Final Report for Subcontract AX 715063, Geological Consulting Services, E. I. duPont de Nemours \& Co., Savannah River Laboratory, Aiken, South Carolina 29808.

Fetter, C. W. (1988). Applied Hydrogeology. Macmillan Publishing Company, 866 Third Avenue, New York New York 10022.

Fetter, C. W. (1993). Contaminant Hydrogeology. Macmillan Publishing Company, 866 Third Avenue, New York New York 10022.

Freeze, R. A. and Cherry, J. A. (1979). Groundwater. Prentice Hall, Englewood Cliffs, New Jersey 07632.

Gordon, D. E. (1982). Preliminary Technical Summary M-Area Groundwater Cleanup Facility. Technical Report DPST-82-69, E. I. duPont de Nemours \& Co., Savannah River Laboratory, Aiken, South Carolina 29808.

Gorelick, S. M. and Gvirtzman, H. (1993). In-Situ Vapor Stripping for Removing Volatile Organic Compounds from Groundwater. United States Patent 5,180,503, United States Department of Patent. 
Gvirtzman, H. and Gorelick, S. M. (1992). The Concept of In-Situ Vapor Stripping for Removing VOCs from Groundwater. Transport in Porous Media, 8:71-92.

Haselow, J. S., Beaudoin, C. M., and Schreuder, P. J. (1991). Zone of Capture Analysis for the A/M Area of the Savannah River Site (U). Technical Report WSRC-RP-91-1216, Westinghouse Savannah River Company, Aiken, South Carolina 29808.

Herrling, B. and Buermann, W. (1990). A New Method for In-Situ Remediation of Volatile Contaminants in Groundwater-Numerical Simulation of the Flow Regime. Computational Methods in Subsurface Hydrology, pages 299-304.

Herrling, B., Buermann, W., and Stramm, J. (1991a). In-Situ remediation of volatile contaminants in groundwater by a new system of Vacuum-Vaporizer Wells. In Weyer, K. U., editor, Subsurface Contamination by Immiscible Fluids, Rotterdam.

Herrling, B. and Stramm, J. (1991). Numerical Results of Calculated 3D Vertical Circulation Flows Around Wels with Two Screen Sections for In-Situ or On-Situ Aquifer Remediation. In International Conference on Computational Methods in Water Resources, Denver, Colorodo.

Herrling, B., Stramm, J., Alesi, E. J., Brinnel, P., Hirschberger, F., and Sick, M. (1991b). In-Situ Groundwater Remediation of Strippable Contaminants by Vaccuum Vaporizer (UVB): Operation of the Well and Report about Cleaned Industrial Sites. In Third Forum on Innovative Hazardous Waste Treatment Technologies: Domestic and International, Dallas, Texas. United States Department of Environmental Protection.

Herrling, B., Stramm,'J., and Buermann, W. (1991c). Hydraulic Circulation for In-Situ Bioreclamation and/or In-Situ Remediation of Strippable Contamination. In In Situ and On-Situ Bioreclamation, San Diego, California.

Hiergesell, R. A. (1992). Report of Data Generated During the Aquifer Test at RWM-16 (U). Technical Report ESH-EMS-92-0165, Westinghouse Savannah River Company, Aiken, South Carolina 29808.

Hiergesell, R. A. (1993). Hydrologic Analysis of Data for the Lost Lake Aquifer Zone of the Steed Pond Aquifer at Recovery Well RWM-16 (U). Technical Report WSRC-TR-92-529, Westinghouse Savannah River Company, Aiken, South Carolina 29808.

Hiergesell, R. A. and Pemberton, B. E. (1995). Final Report: Aquifer Testing with 2-Inch Diameter Wells in the A/M Area Southern Sector (U). Technical Report WSRC-TR-95-0365, Westinghouse Savannah River Company, Aiken, South Carolina 29808.

Jackson, D. G. and Aleman, S. E. (1995). Three Dimensional Zone of Capture Analysis for the A/M Area (U). Technical Report WSRC-RP-95-0843, Westinghouse Savannah River Company, Aiken, South Carolina 29808. .

Jackson, D. G., Looney, B. B., Bergren, C. L., Wells, D. G., and Beavers, B. A. (1996). Strategy for the A/M Area Production Well Modifications (U). Technical Report WSRC-RP-96-0074, Westinghouse Savannah River Company, Aiken, South Carolina 29808.

Lewis, S. E. and Aadland, R. K. (1992). Hydrogeologic Setting of A/M Area: Framework for Groundwater Transport (U). Technical Report WSRC-TR-92-355, Westinghouse Savannah River Company, Aiken, South Carolina 29808.

Lewis, S. E. and Aadland, R. K. (1994). Hydrogeologic Setting of A/M Area: Framework for Groundwater Transport (U). Technical Report WSRC-TR-92-355, Westinghouse Savannah River Company, Aiken, South Carolina 29808. 
Looney, B. B., Eddy, C. A., and Sims, W. R. (1993). Evaluation of Headspace Method for Volitile Constituents in Soils and Sediments. In Measuring and Interpreting VOC's in Soils: State of the Art and Research Needs, Las Vegas, Nevada 89193. US Environmental Protection Agency, Environmental Monitoring Systems Laboratory.

Looney, B. B. and Phifer, M. A. (1994). A/M Area Groundwater Corrective Action Southern Sector Remediation Technology Alternatives Evaluation (U). Technical Report WSRC-RP-94-607, Westinghouse Savannah River Company, Aiken, South Carolina 29808.

Looney, B. B., Rossabi, J. R., and Tuck, D. M. (1992). Assessing DNAPL contamination, A/M-Area, Savannah River Site: Phase I Results (U). Technical Report WSRC-RP-92-1302, Westinghouse Savannah River Company, Aiken, South Carolina 29808.

Marine, I. W. and Bledsoe, H. W. (1984). Supplemental Technical Summary M-Area Groundwater Investigation. Technical Report DPSTD-84-112, E. I. duPont de Nemours \& Co., Savannah River Laboratory, Aiken, South Carolina 29808.

Press, W. H., Teukolsky, S. A., Vetterling, W. T., and Flannery, B. P. (1992). Numerical Recipes in FORTRAN, The Art of Scientific Computing. Cambridge University Press, 40 West 20th Street, New York, New York 10011-4211, USA, second edition edition.

Snipes, D. S. (1991). Local Deviations in the Elevation of the Green Clay Interval at the Savannah River Site. Final Report for Contract AA00878, Funded by Westinghouse Savannah River Company, Aiken, South Carolina 29808.

S.S. Papadopulos \& Associates (1987). Evaluation of the Effectiveness of the M-Area Extraction System September 1985 to October 1986. Technical report, Prepared for E.I. DuPont deNemours \& Company by S.S. Papadopulos \& Associates, Rockville, Maryland 20852.

Van Pelt, R. S., Haselow, J. S., Jordan, J. E., Lewis, S. E., and Lott, T. L. (1993). Crouch Branch Aquifer Study, A/M Area Summary of Recent Findings, Observations, and Recommendations (U). Technical Report WSRC-RP-93-1214, Westinghouse Savannah River Company, Aiken, South Carolina 29808.

Van Pelt, R. S. and McAdams, T. D. (1995). A/M Area Western Sector: Summary of Phase I Characterization Soil Coring and Cone Penetrometer Testing (U). Technical Report WSRC-RP-95-57, Westinghouse Savannah River Company, Aiken, South Carolina 29808.

WSRC (1993a). A/M Area Crouch Branch (Cretaceous) Aquifer Characterization - Phase I: Soil Coring Report (U). Technical Report WSRC-RP-93-1241, Westinghouse Savannah River Company, Aiken, South Carolina 29808.

WSRC (1993b). RCRA Part B Permit Renewal Application, M-Area Hazardous Waste Management Facility. Report WSRC-IM-91-53, Westinghouse Savannah River Company, Aiken, South Carolina 29808.

WSRC (1993c). Savannah River Site A/M Area Southern Sector Characterization Cone Penetrometer Report (U). Technical Report WSRC-TR-93-188, Westinghouse Savannah River Company, Aiken, South Carolina 29808.

WSRC (1994a). A/M Area Crouch Branch (Cretaceous) Aquifer Characterization - Phase II: Soil Coring Report (U). Technical Report WSRC-RP-94-1107, Westinghouse Savannah River Company, Aiken, South Carolina 29808.

WSRC (1994b). A/M Area Phase VII: Western Sector Hydrogeological Characterization Report (U). Technical Report WSRC-TR-94-603, Westinghouse Savannah River Company, Aiken, South Carolina 29808. 
WSRC (1995a). The Savannh River Site's Groundwater Monitoring Program, First Quarter 1995 (U).

Technical Report ESH-EMS-950393, Westinghouse Savannah River Company, Aiken, South Carolina, 29808.

WSRC (1995b). The Savannh River Site's Groundwater Monitoring Program, Second Quarter 1995 (U). Technical Report ESH-EMS-950394, Westinghouse Savannah River Company, Aiken, South Carolina, 29808 .

WSRC (1996a). The Savannh River Site's Groundwater Monitoring Program, Fourth Quarter 1995 (U). Technical Report ESH-EMS-950396, Westinghouse Savannah River Company, Aiken, South Carolina, 29808.

WSRC (1996b). The Savannh River Site's Groundwater Monitoring Program, Third Quarter 1995 (U). Technical Report ESH-EMS-950395, Westinghouse Savannah River Company, Aiken, South Carolina, 29808. 
8 Appendix A: Vertical Distributions of Mud Fraction 


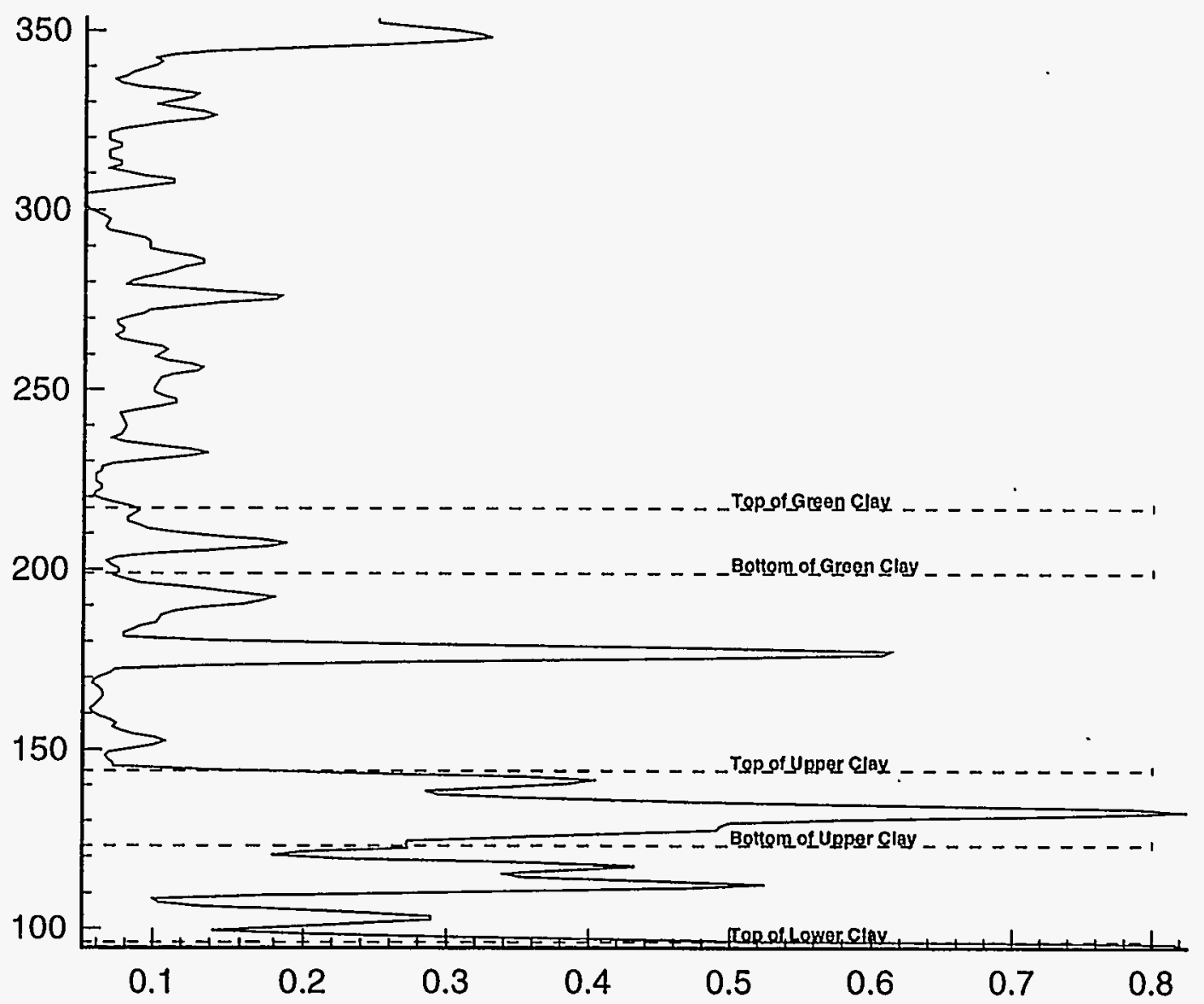


(2D) II Print II 29 Oct 1996 || /afs/srtc/u1/10901/Fusion/CorePlots/AMB_11B.plt II

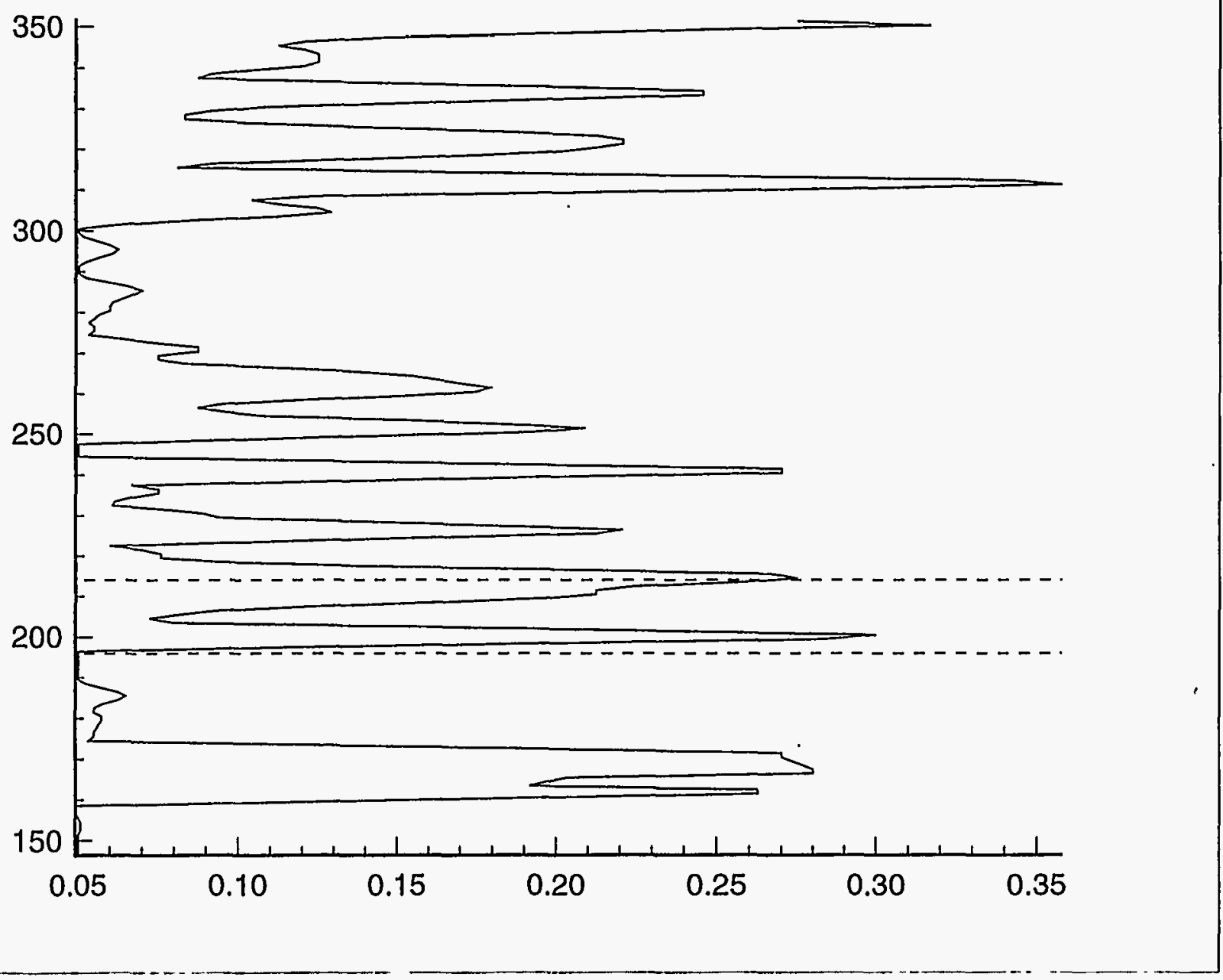




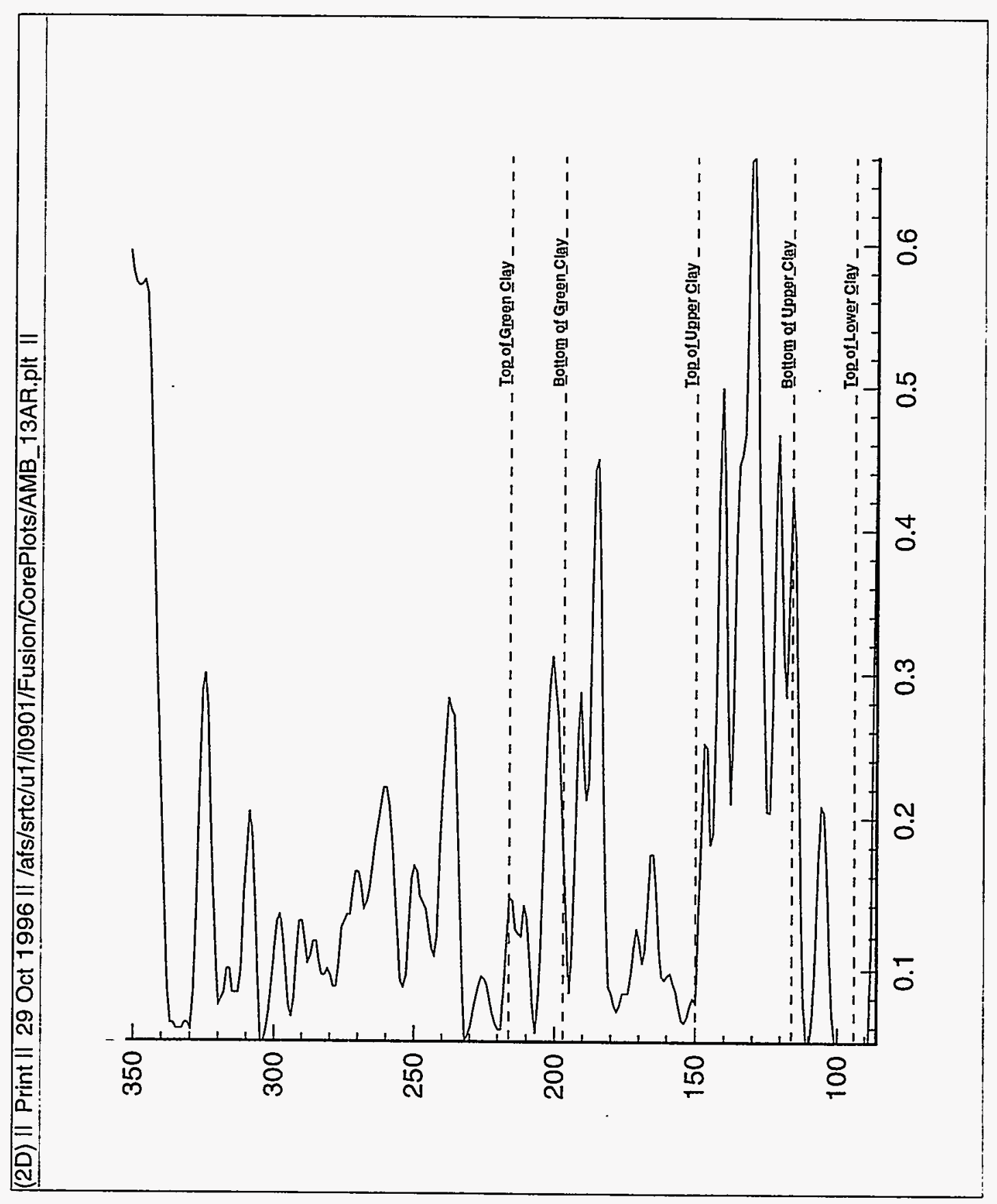




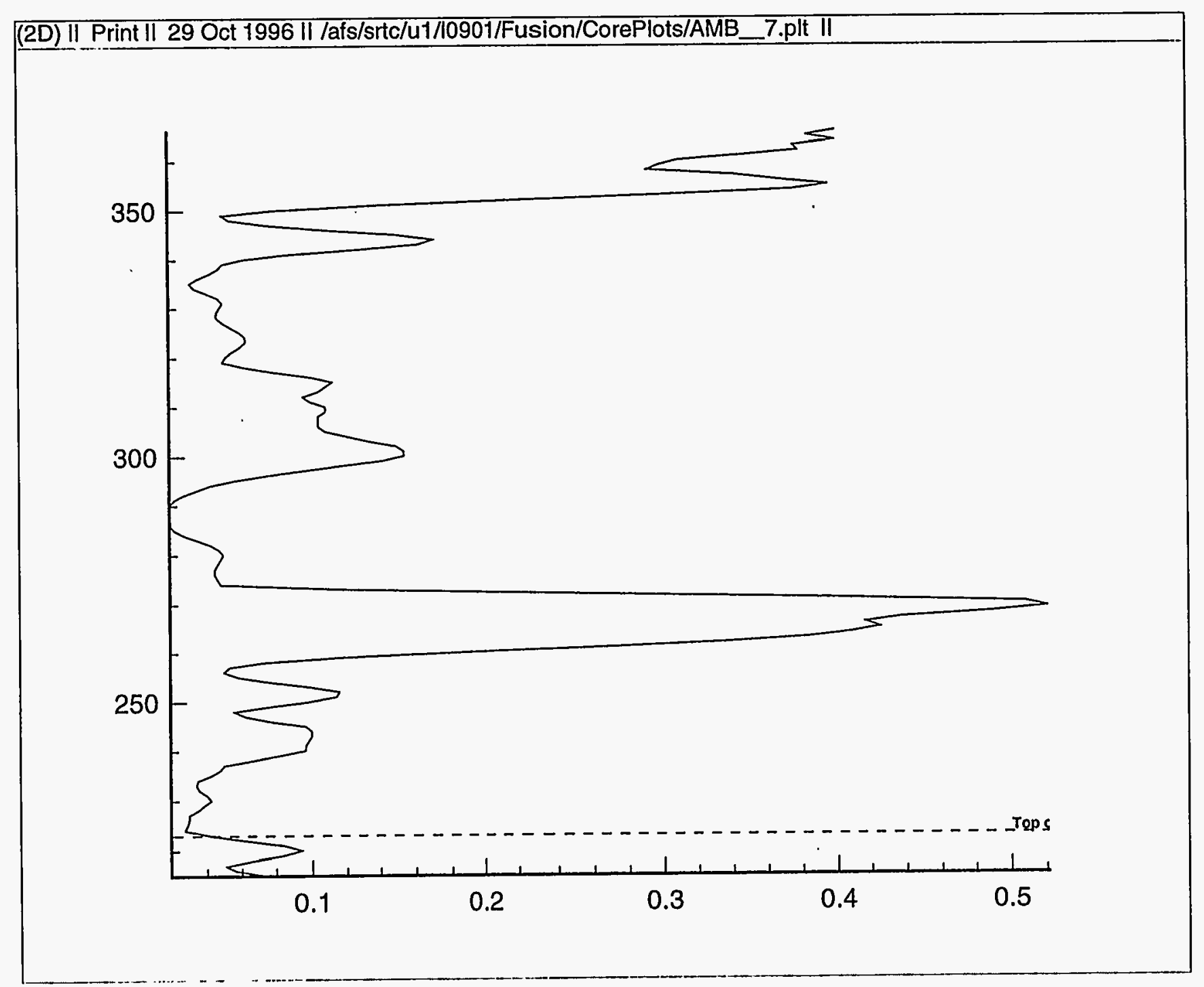




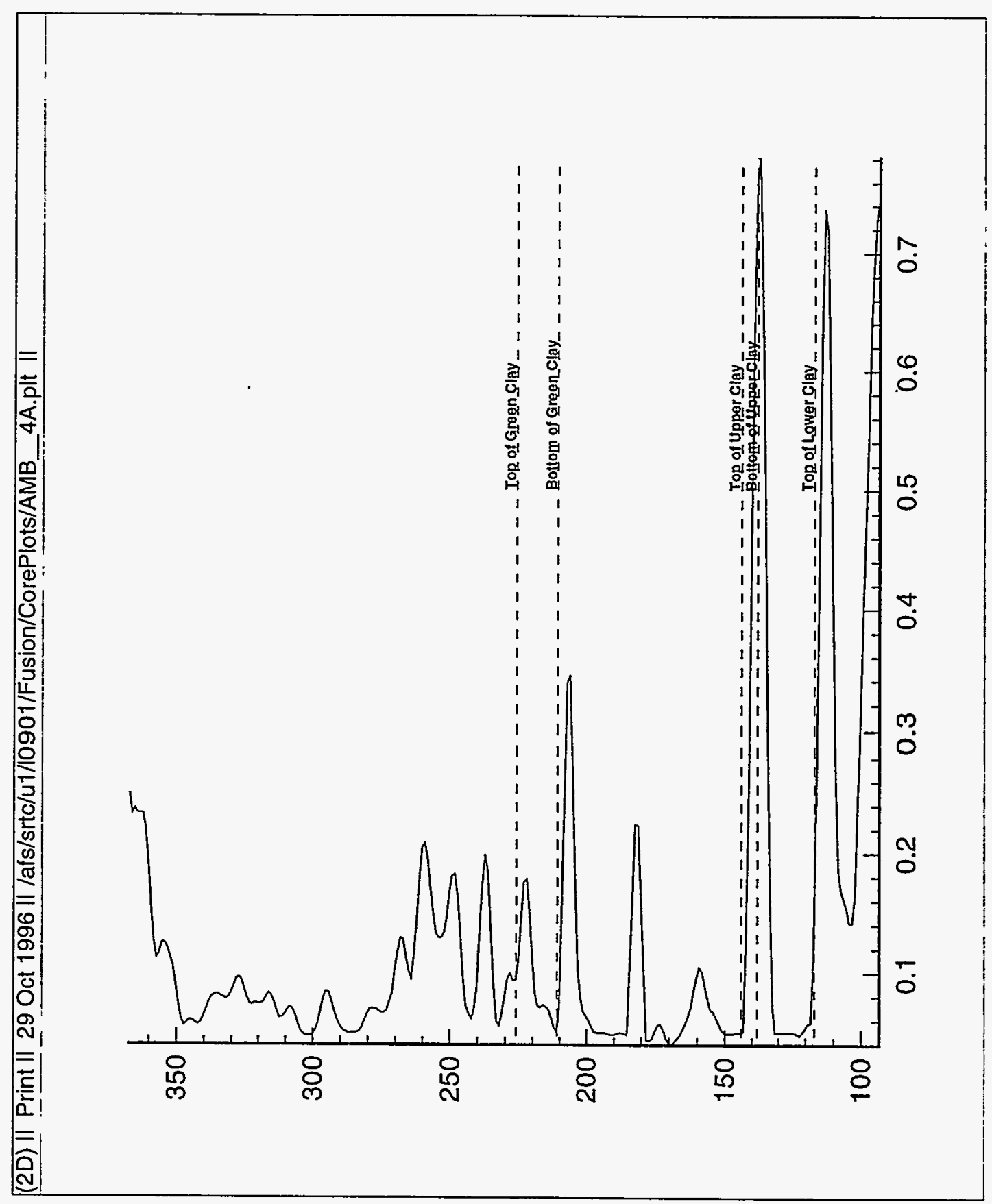




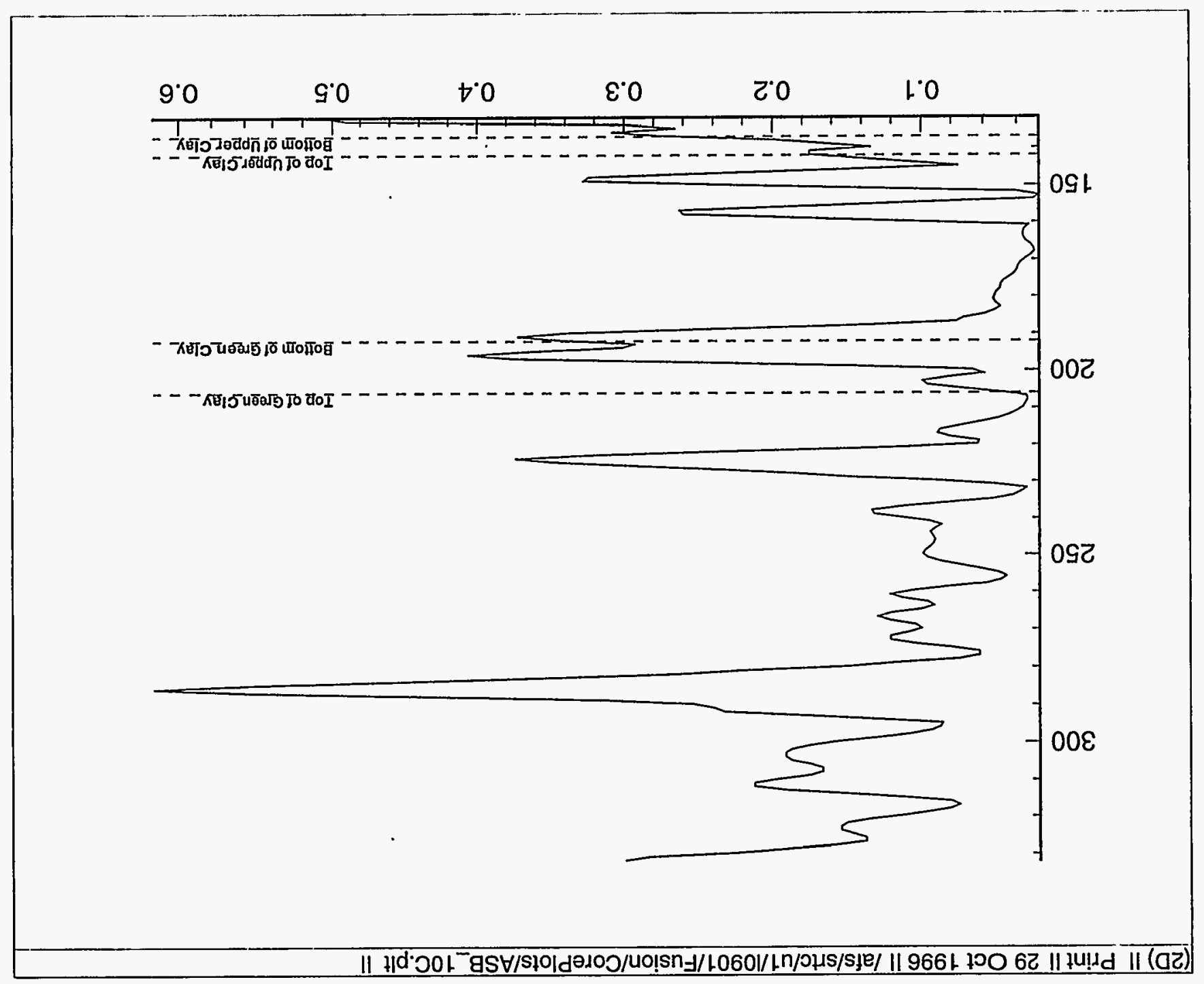




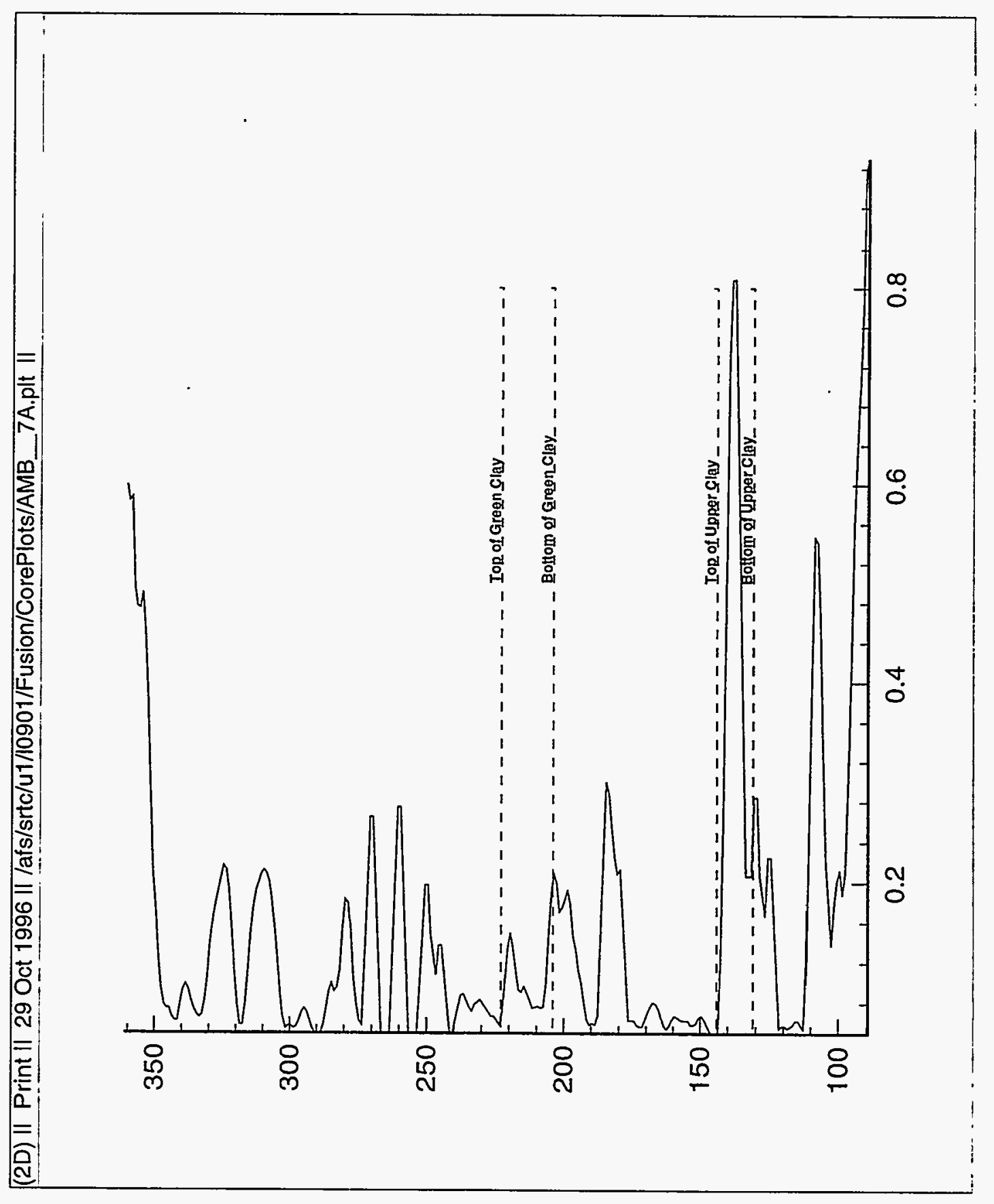




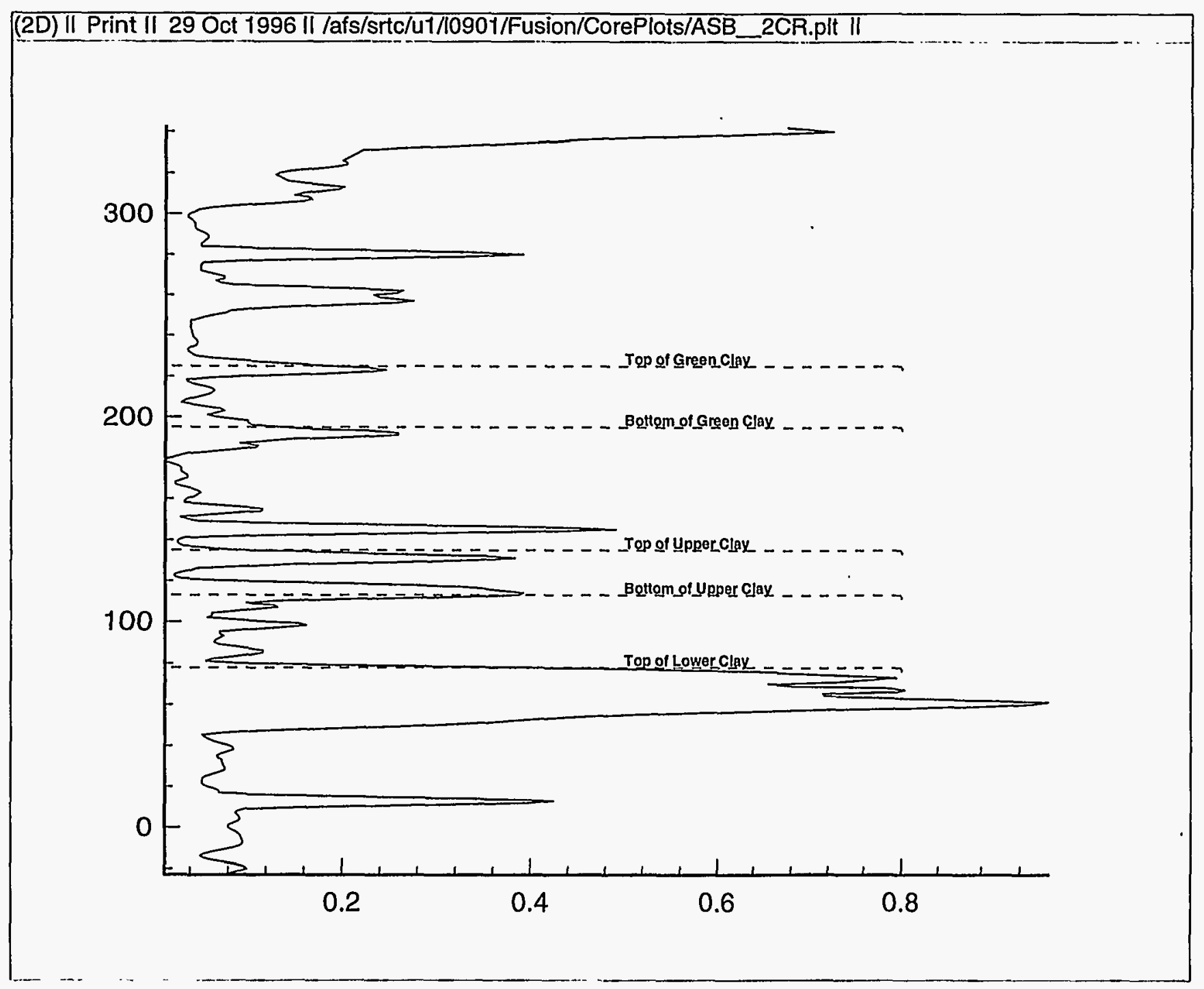




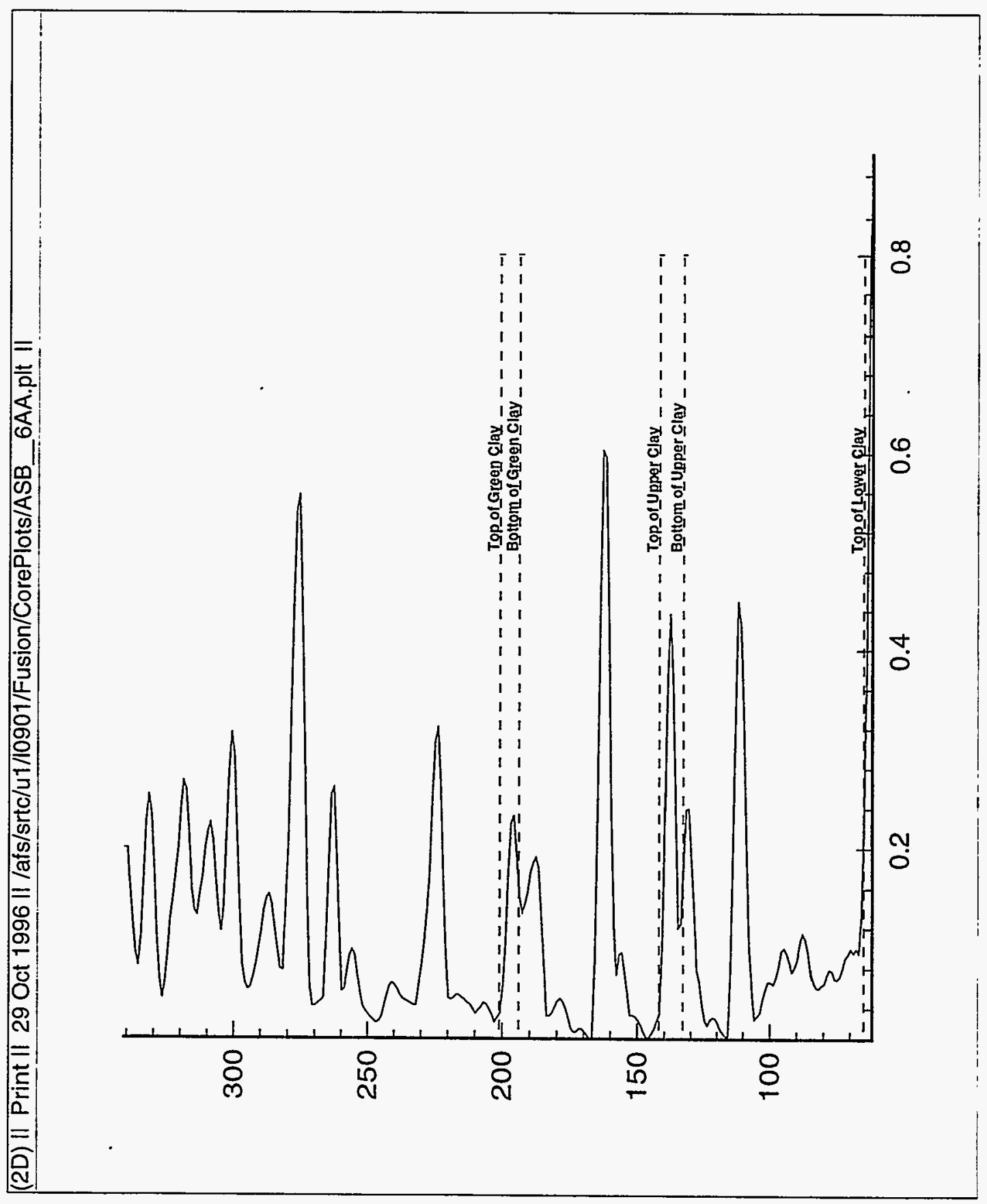




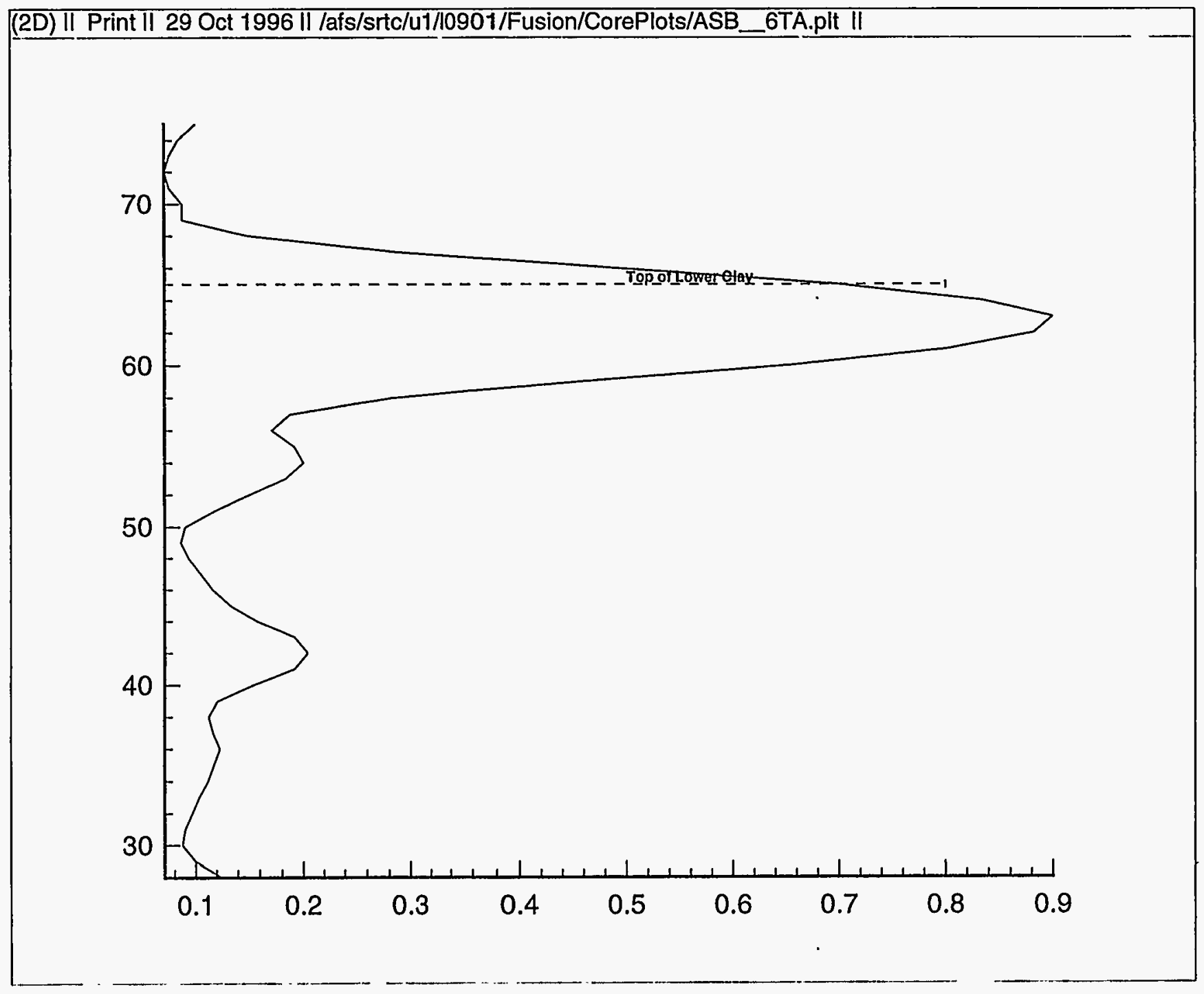




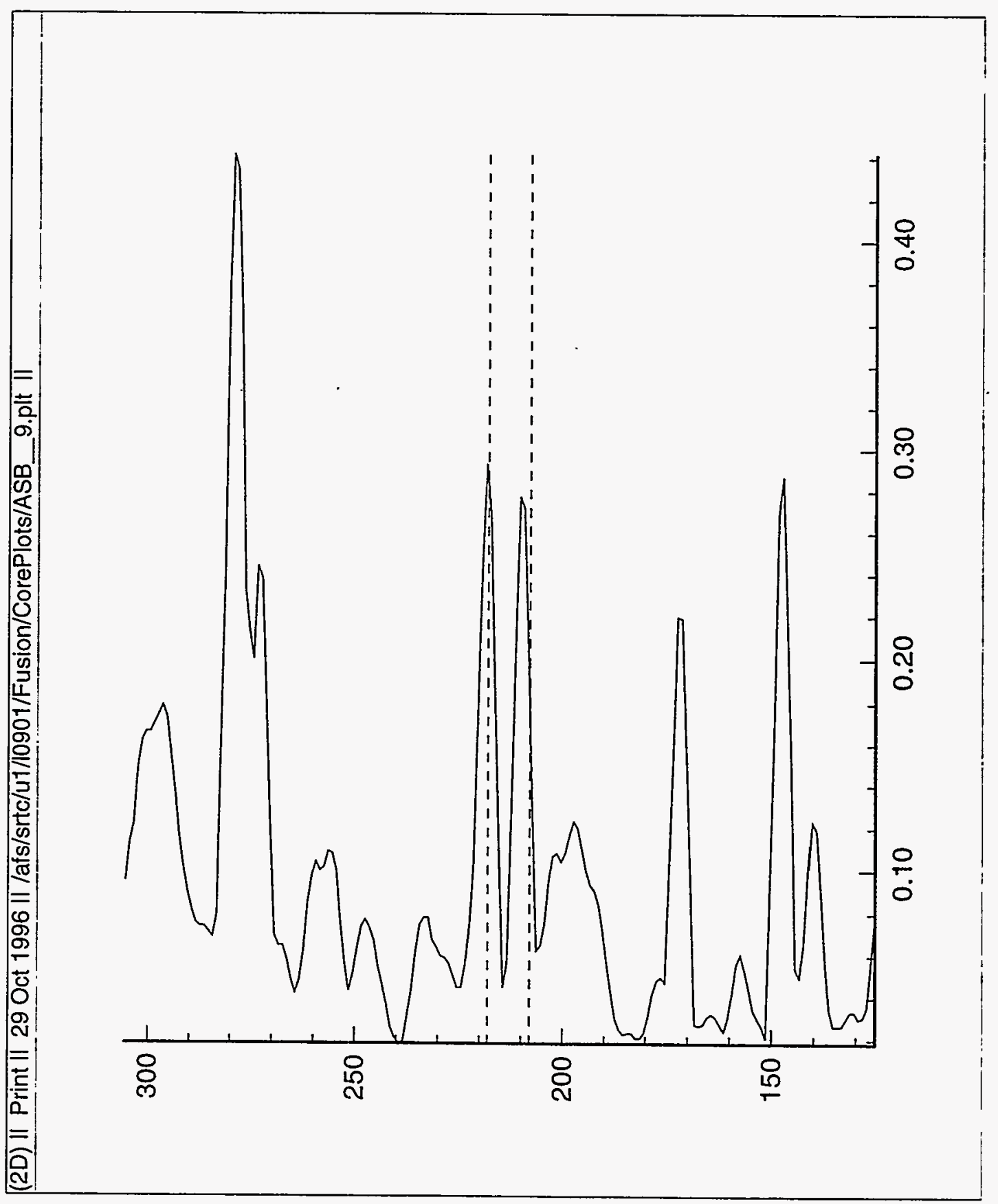




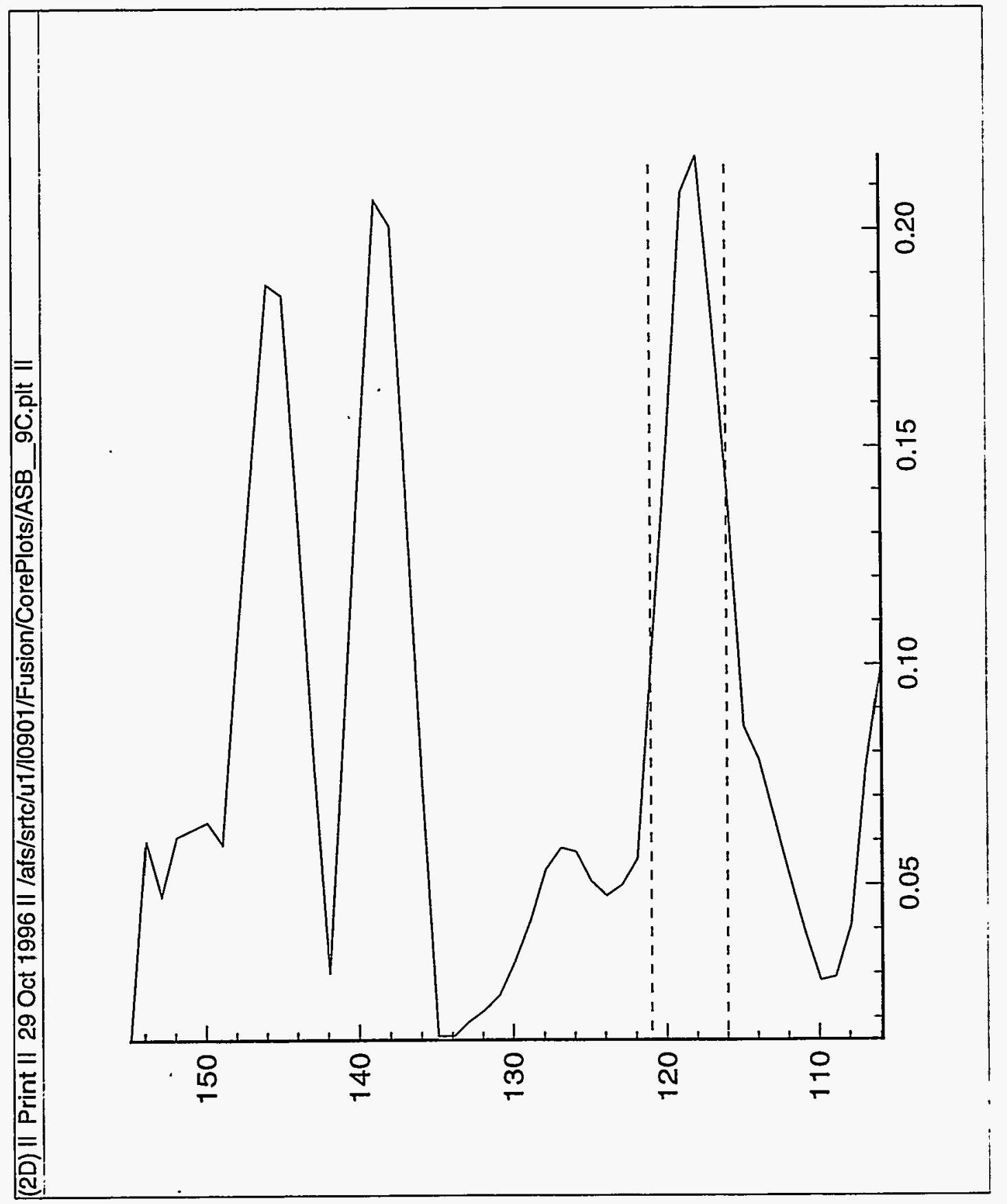




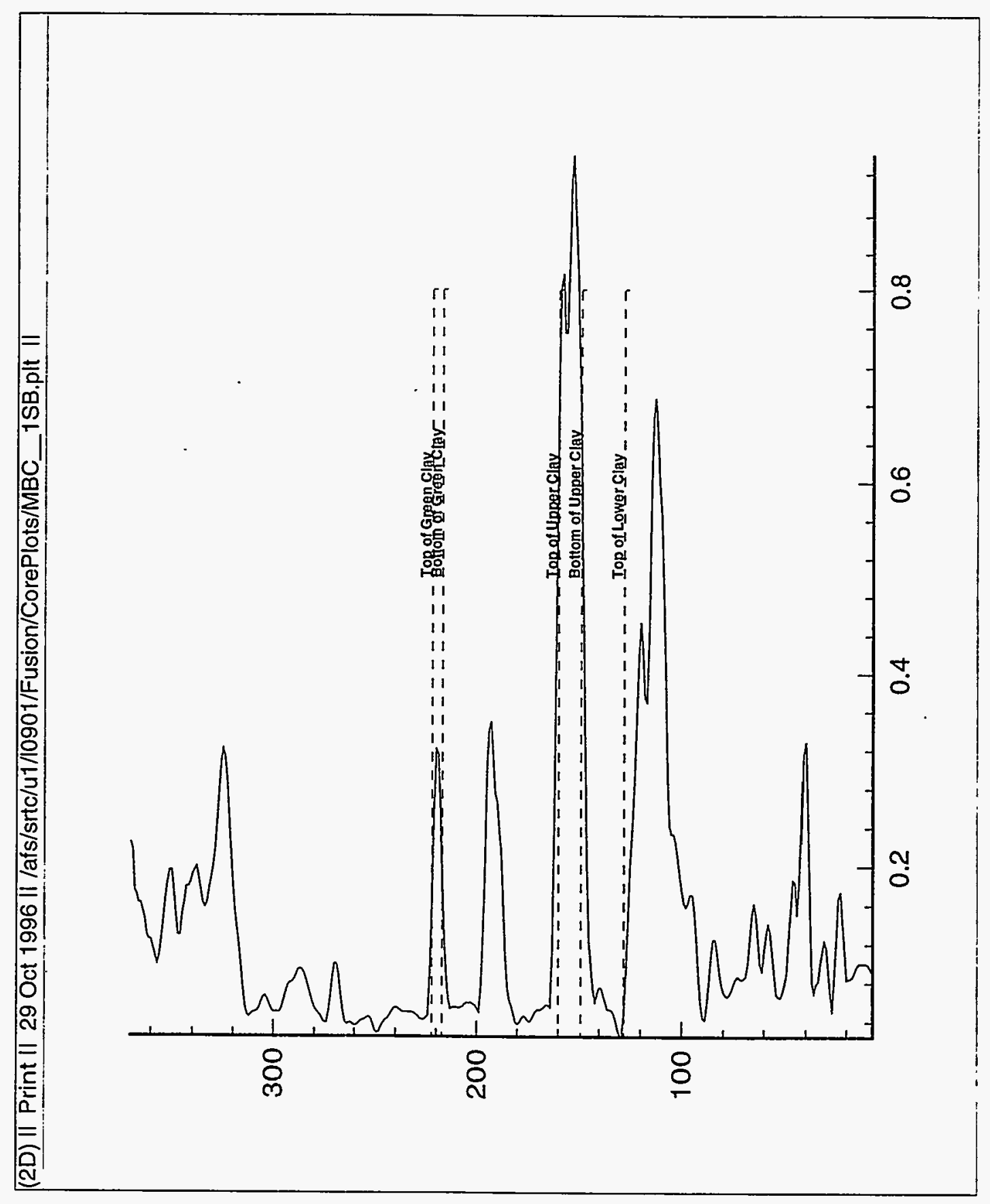




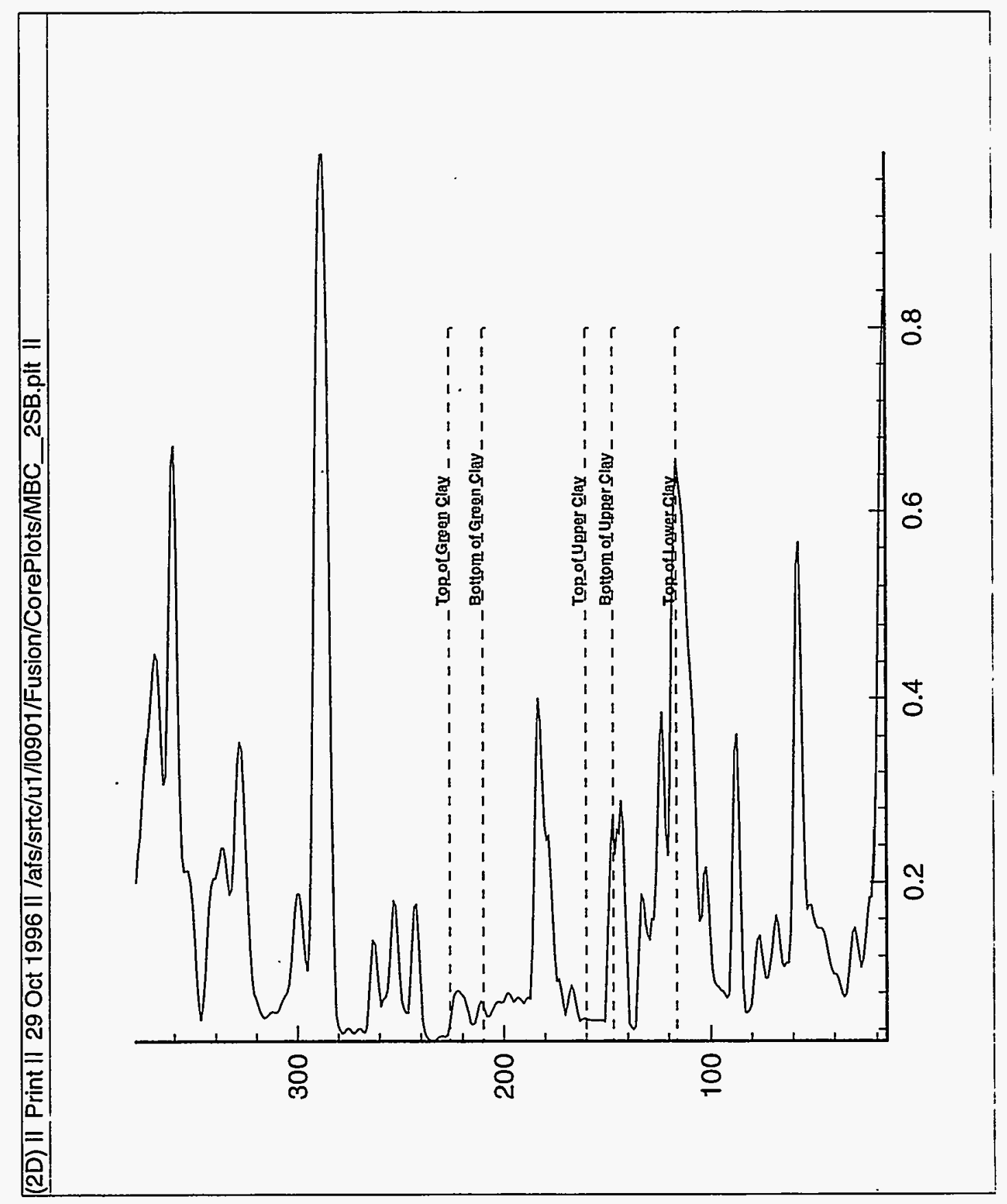




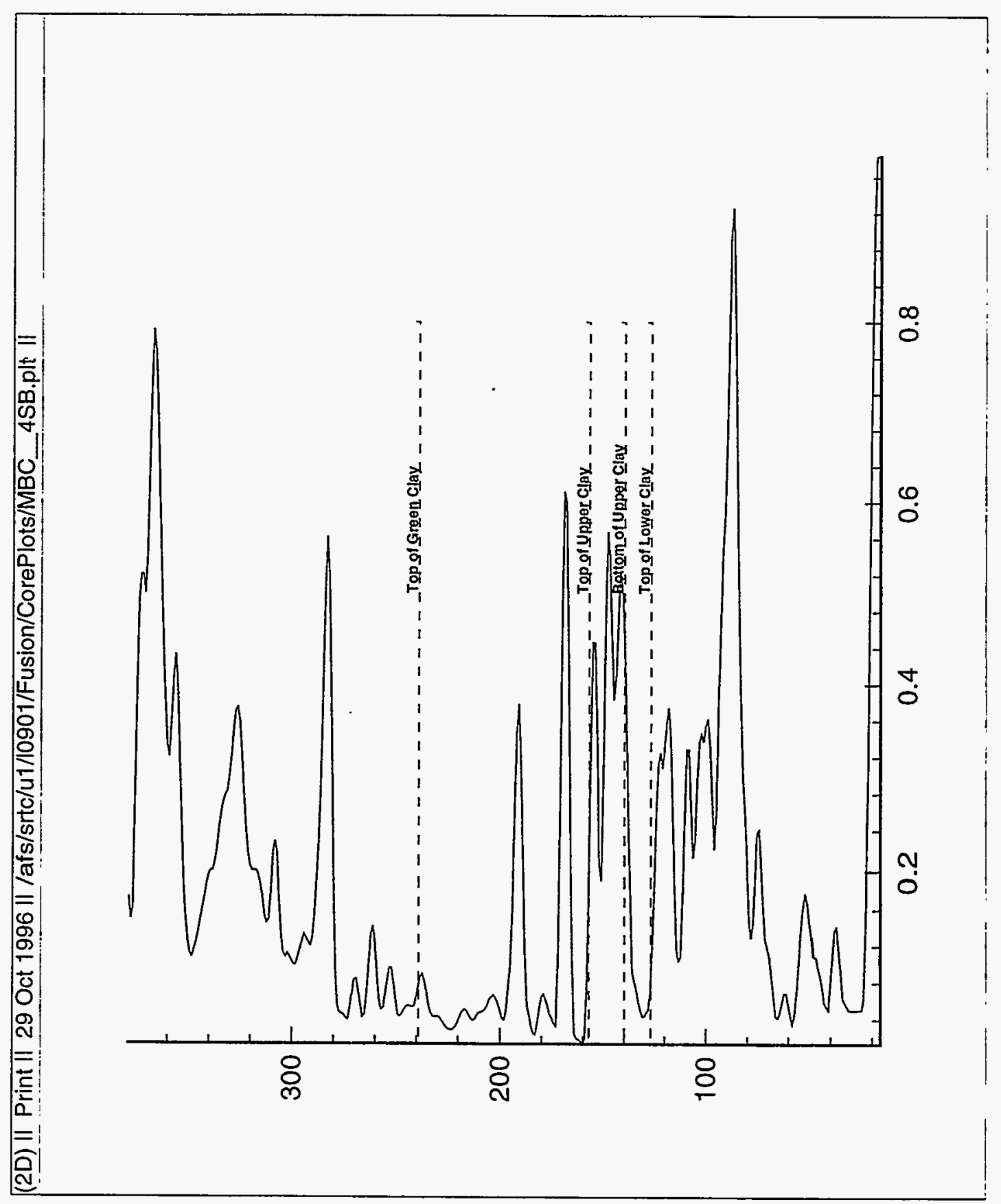




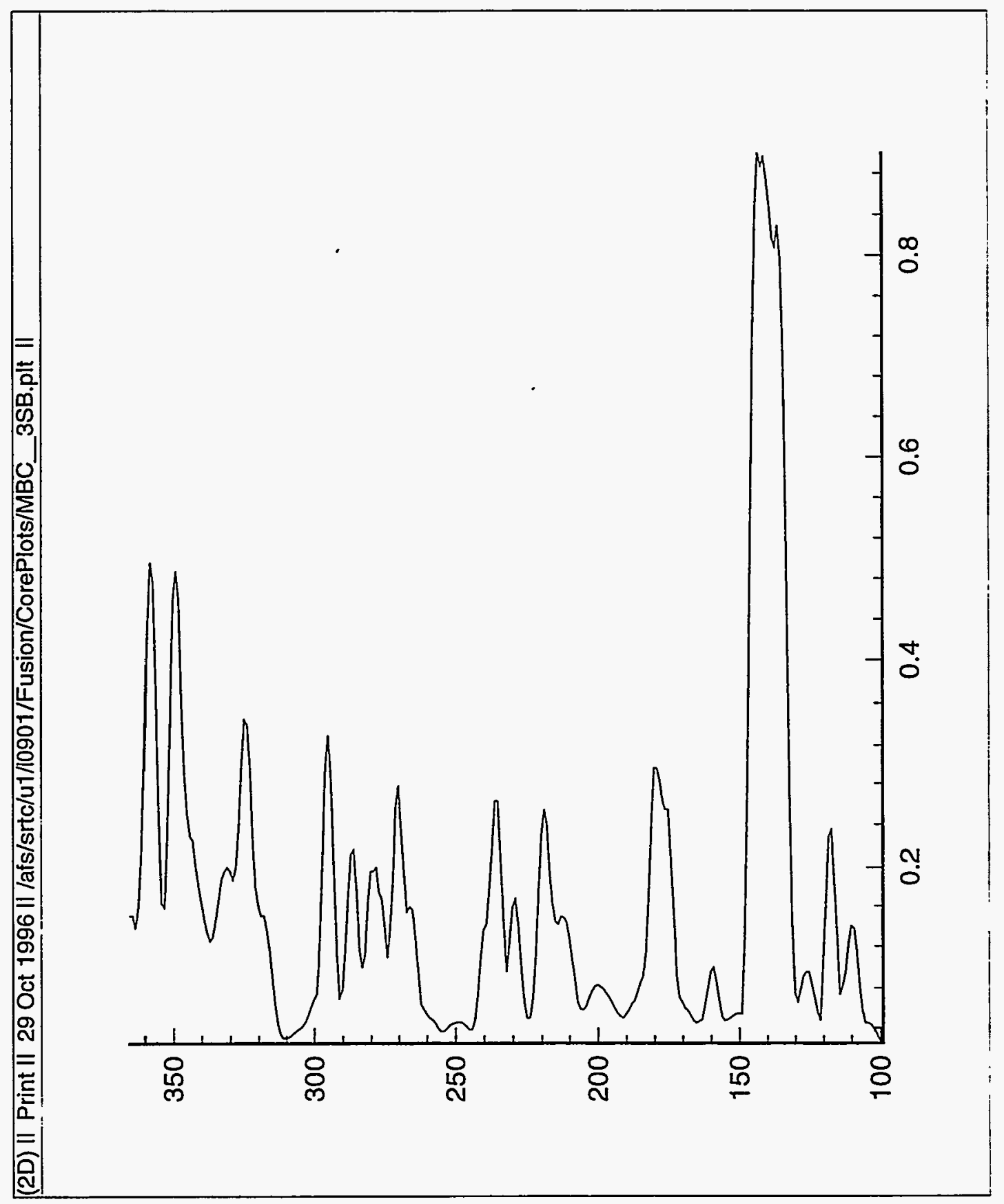




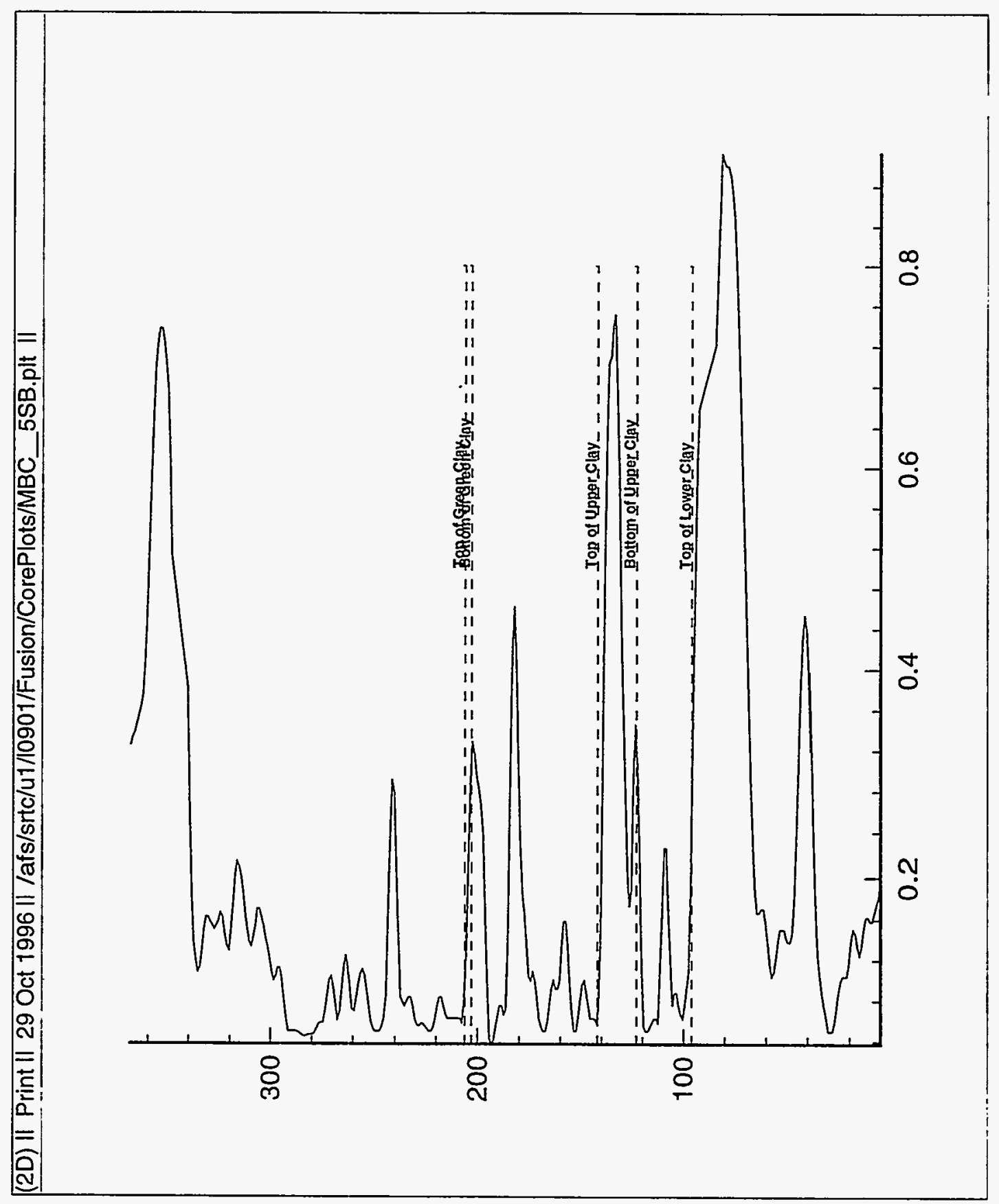




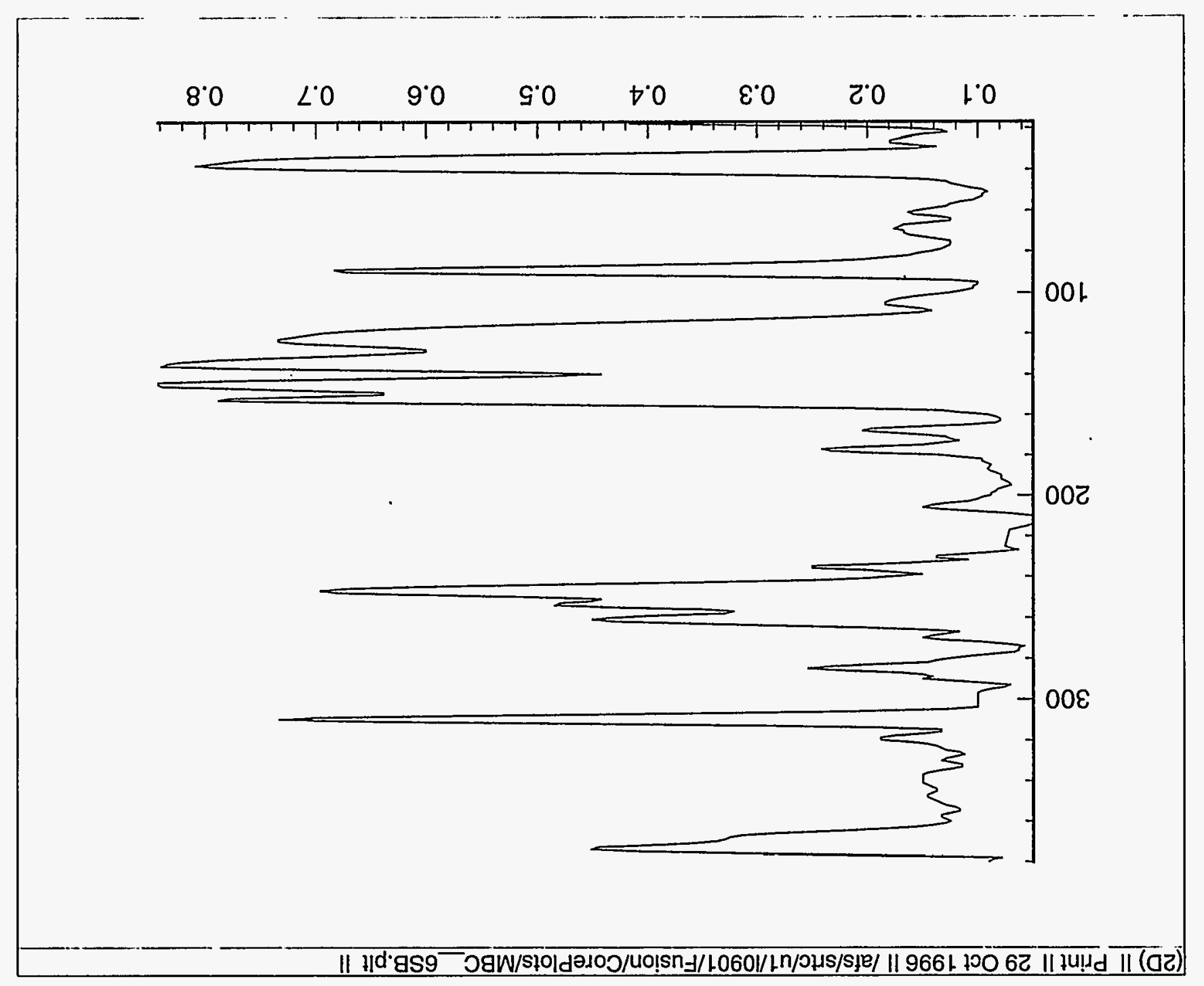




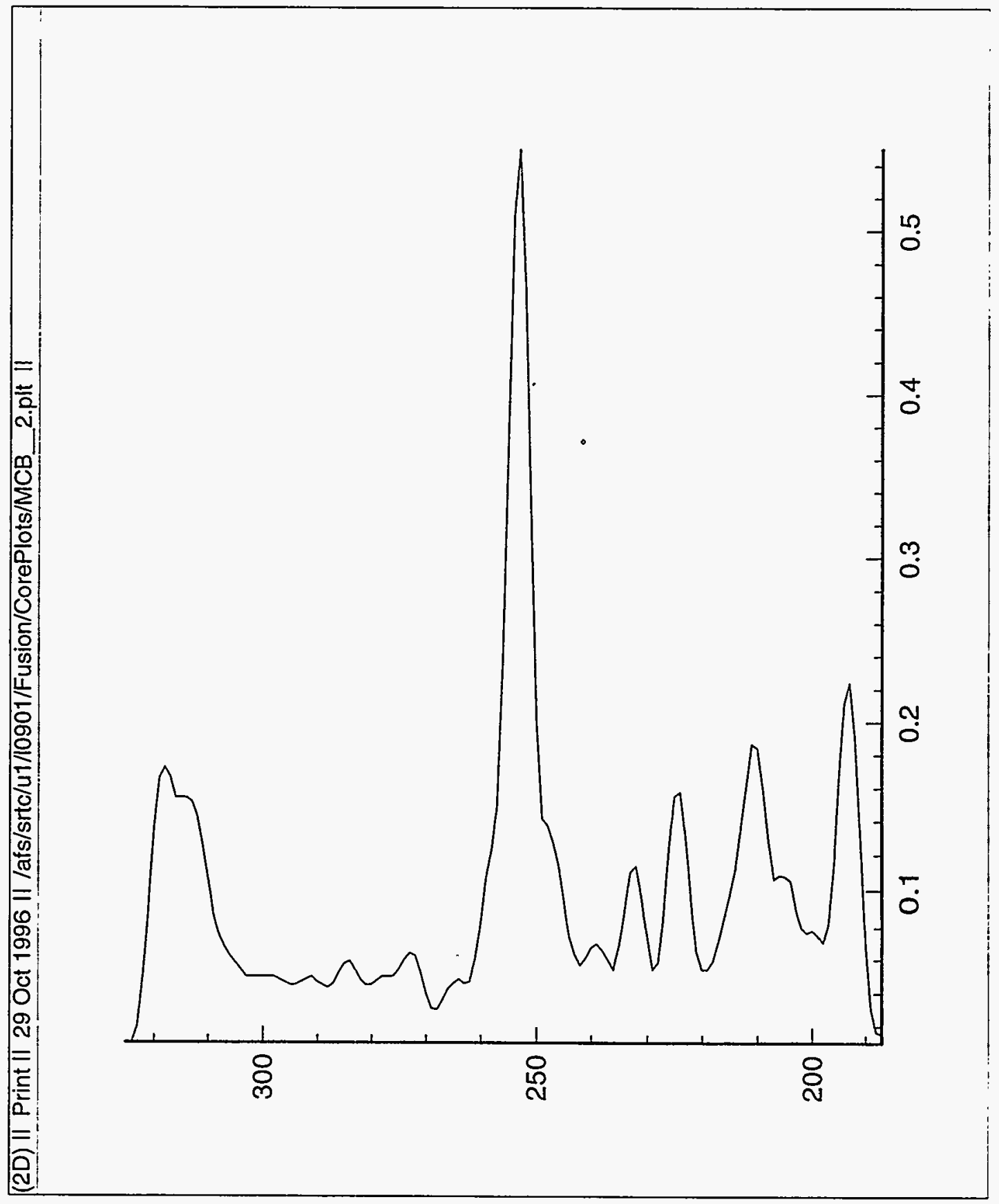




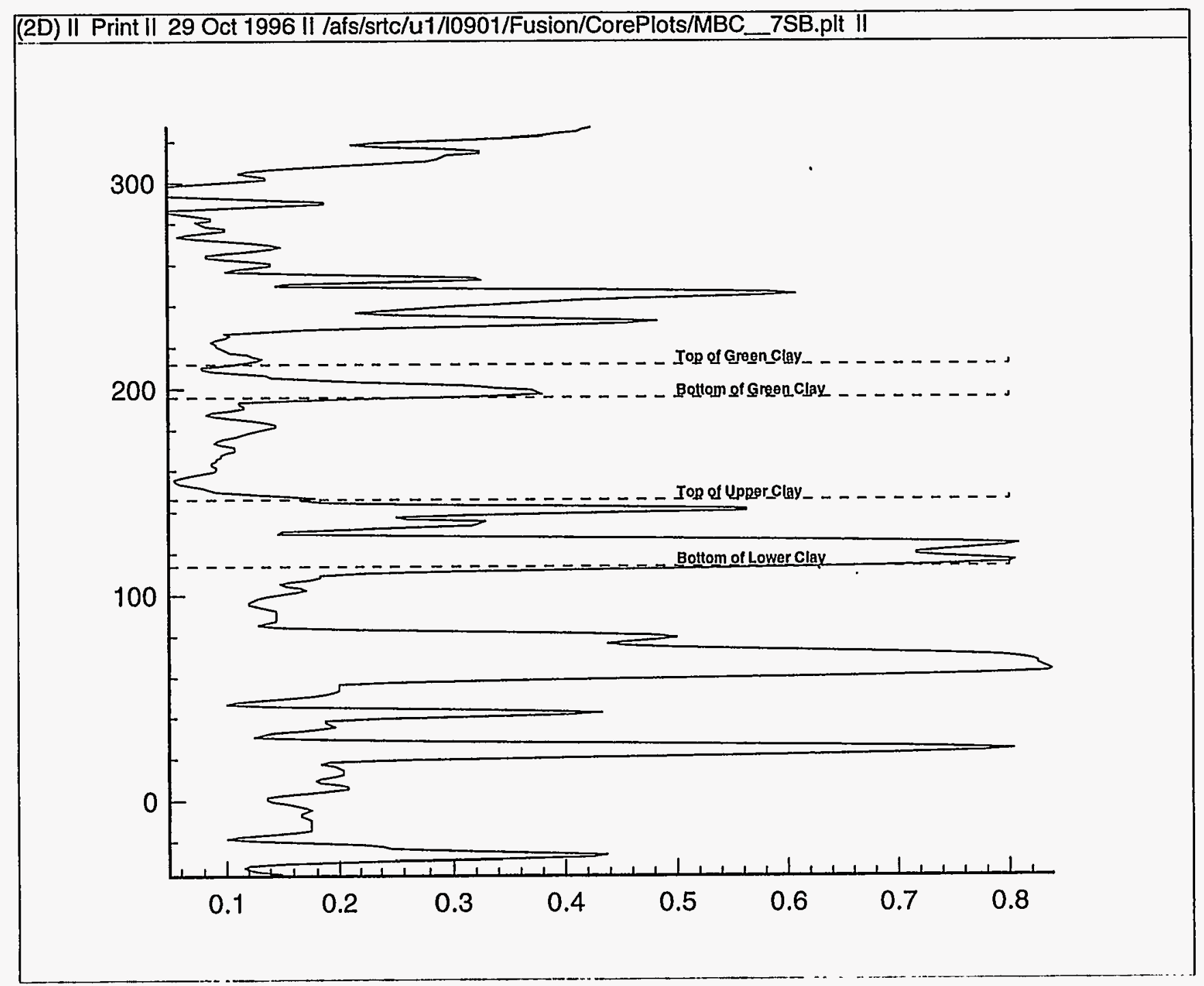




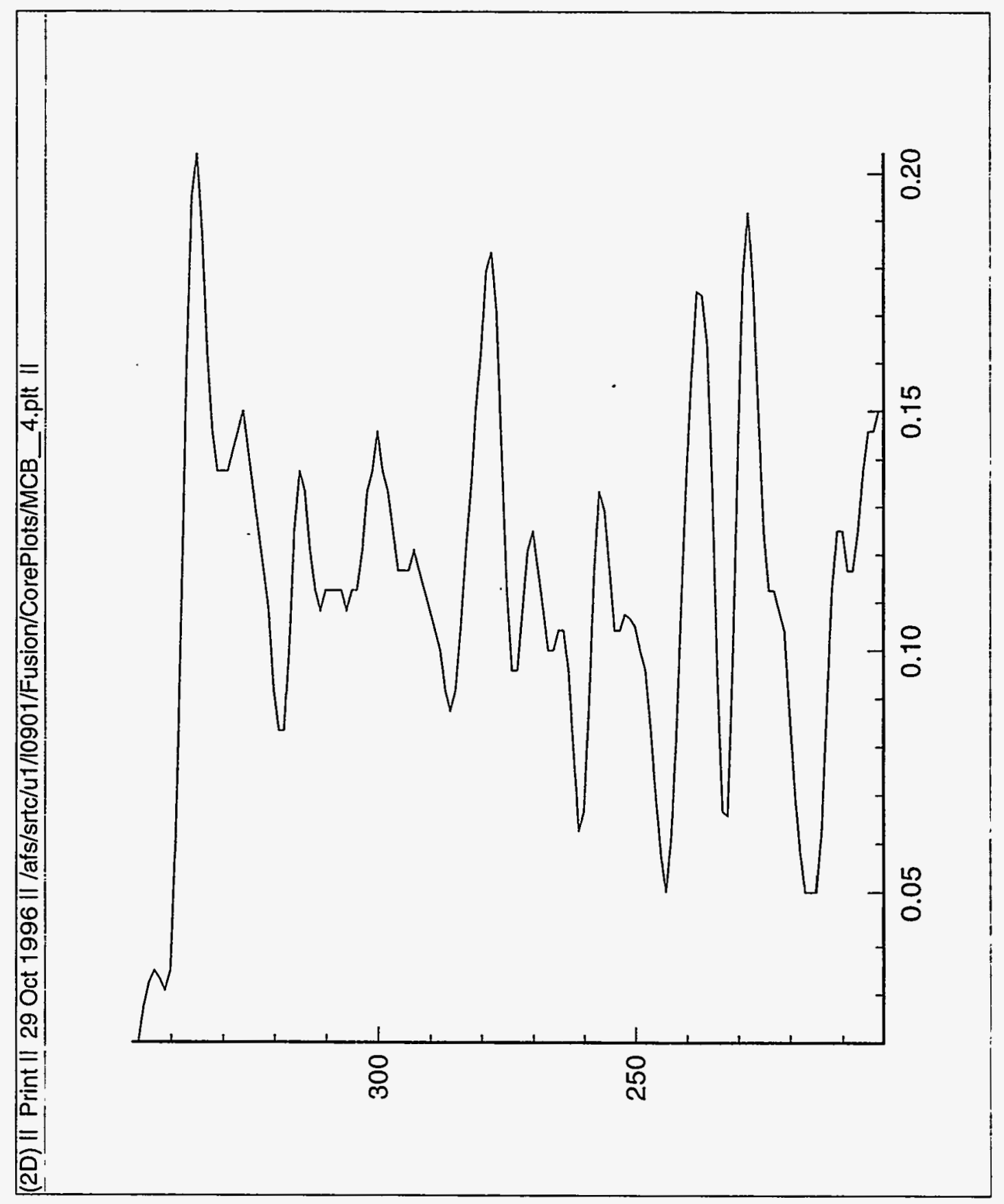




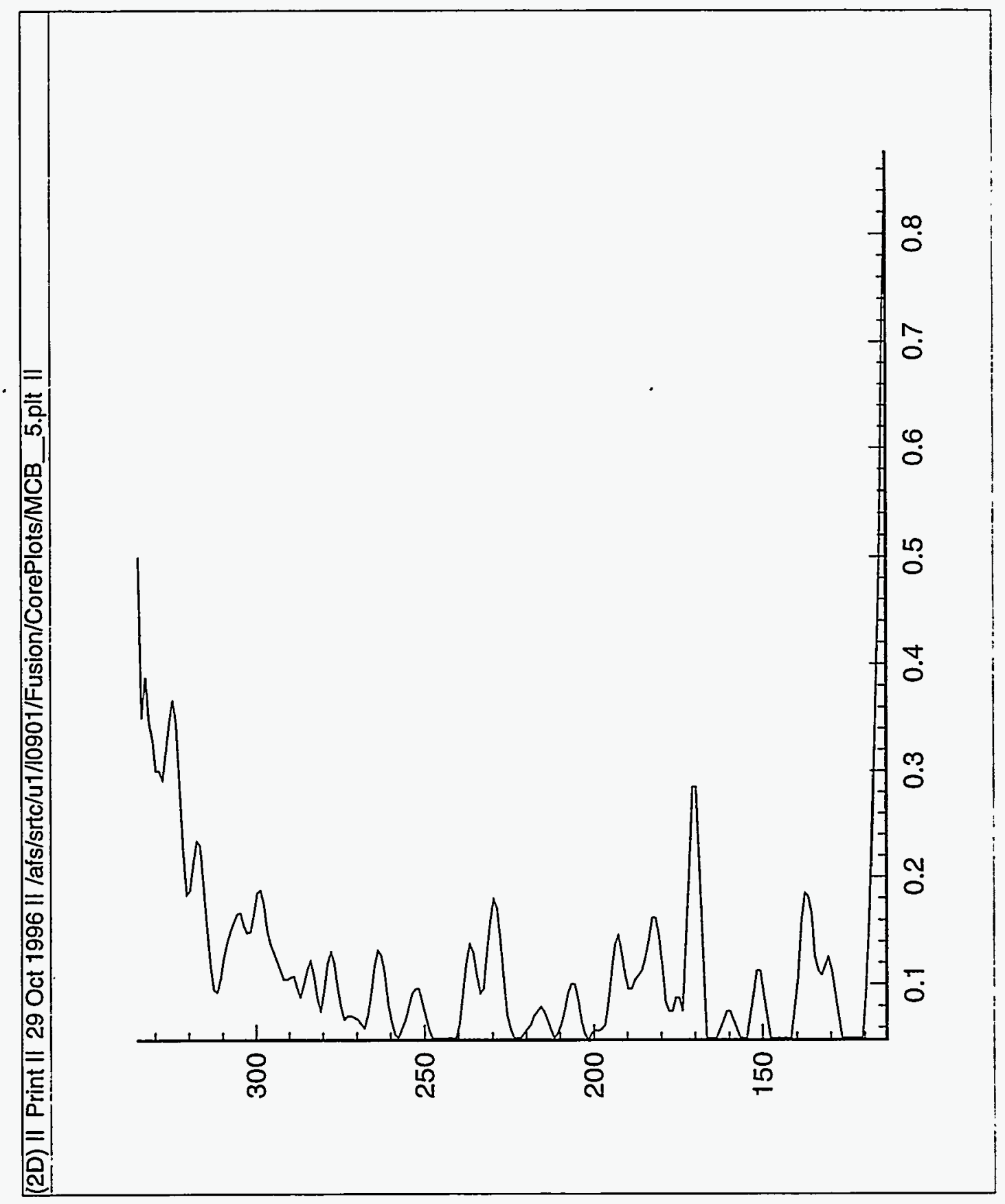




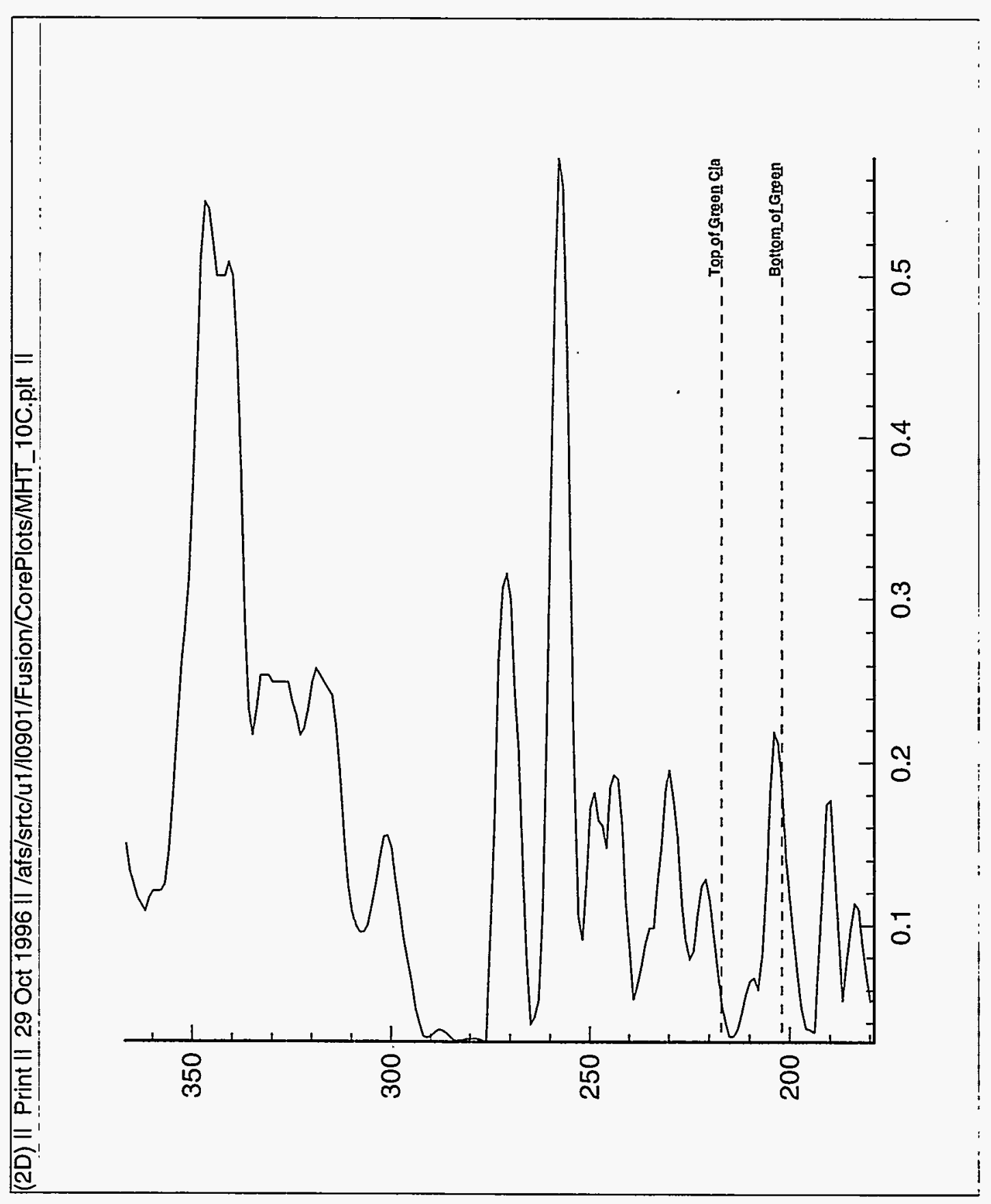




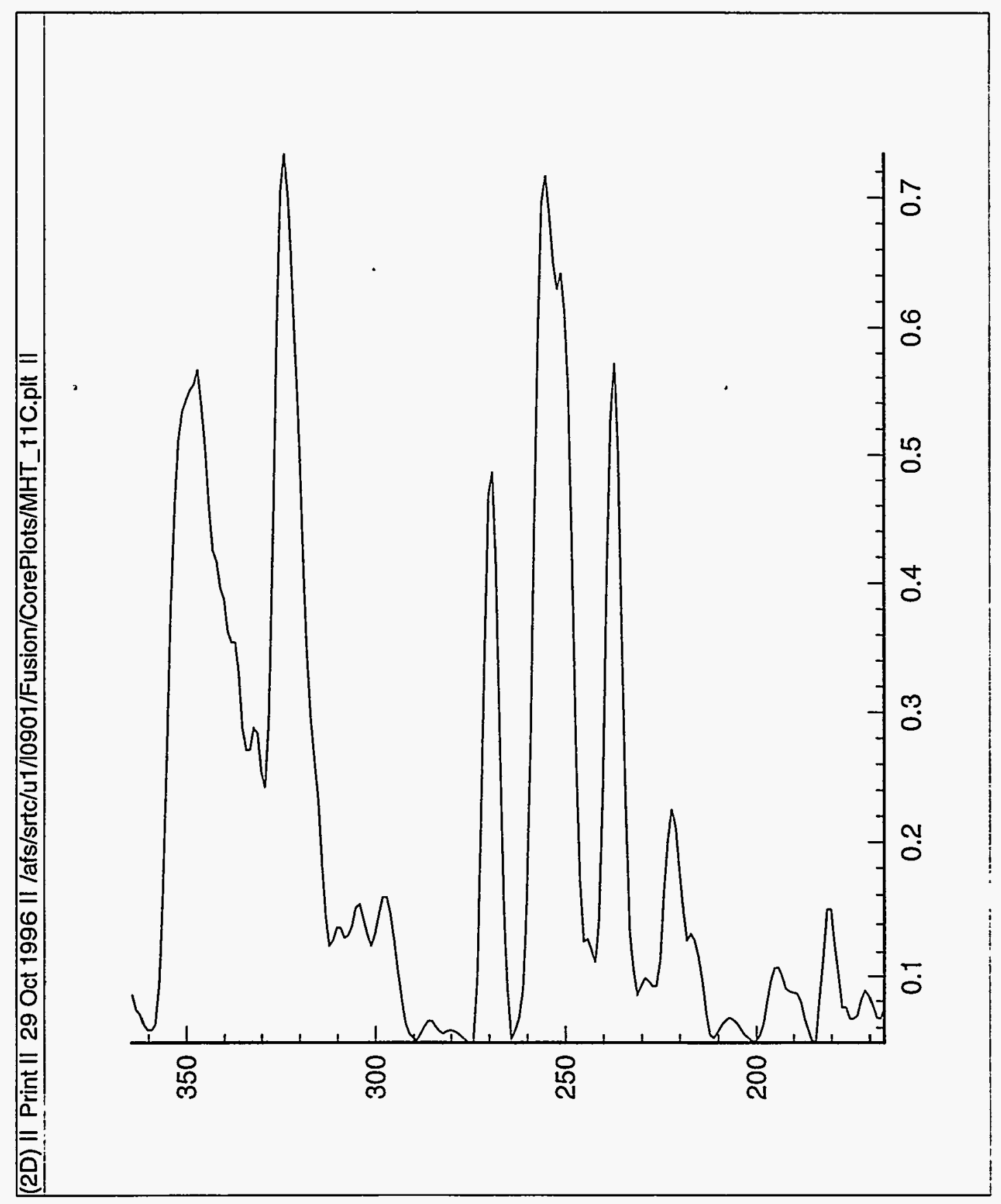




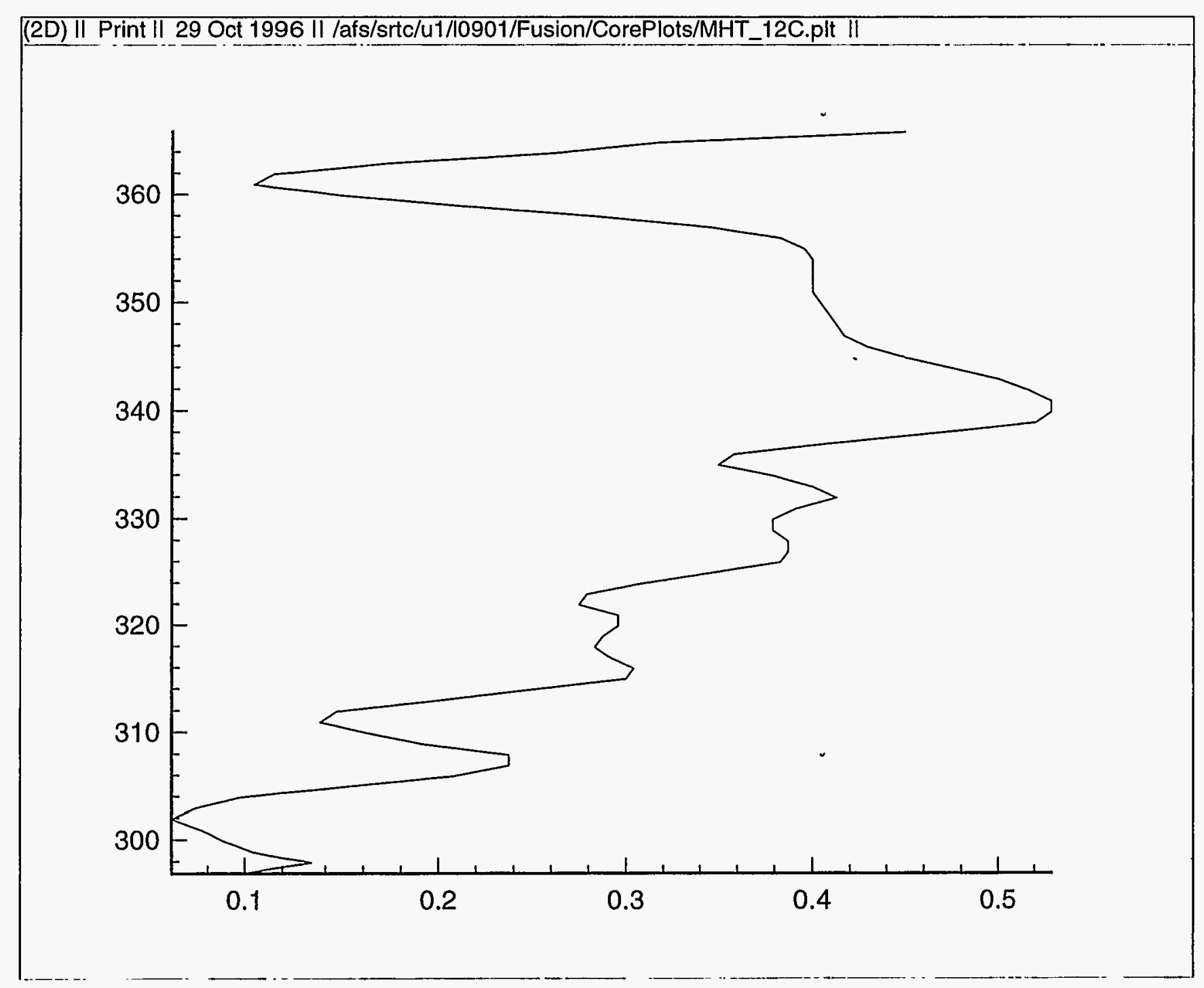




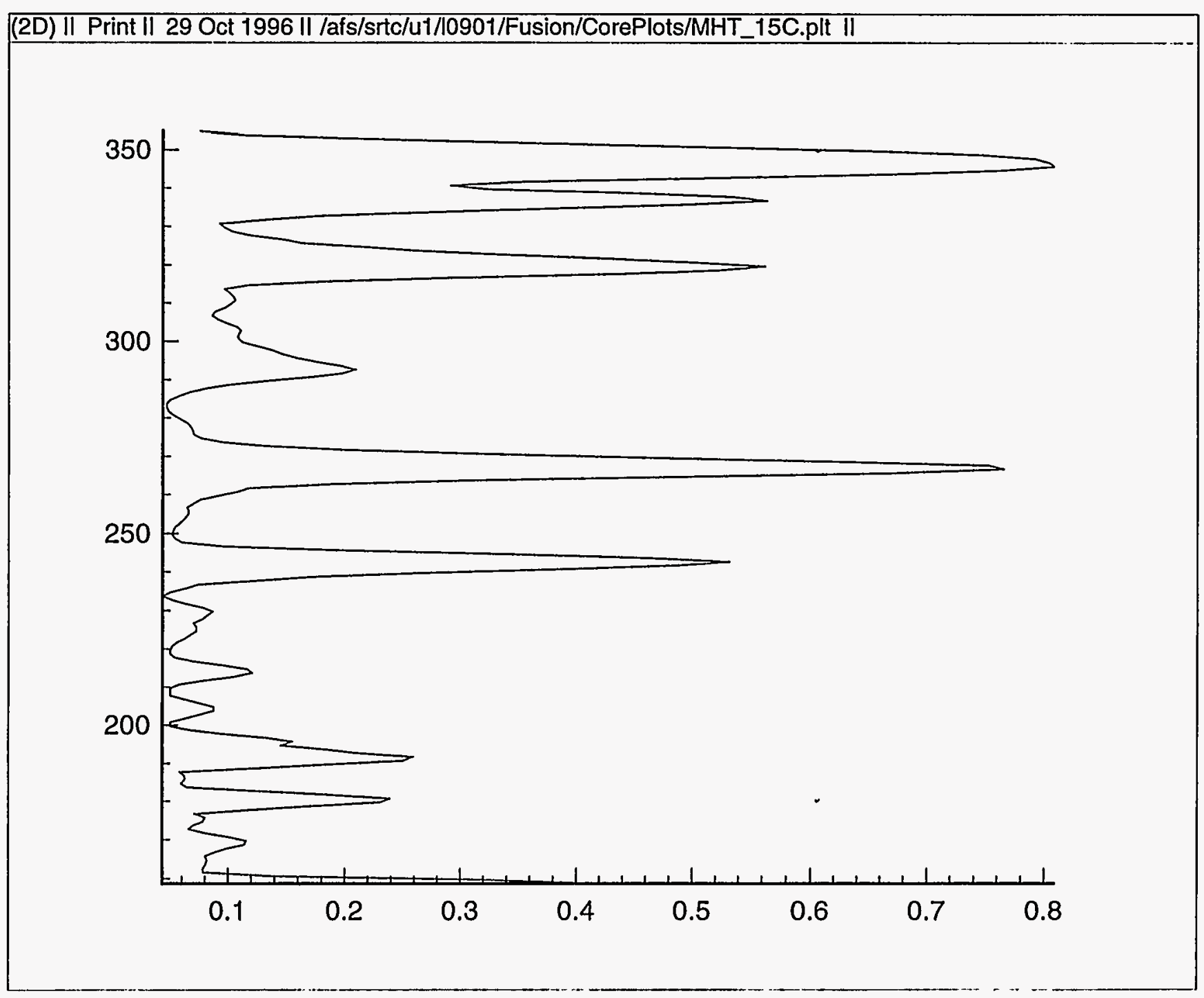




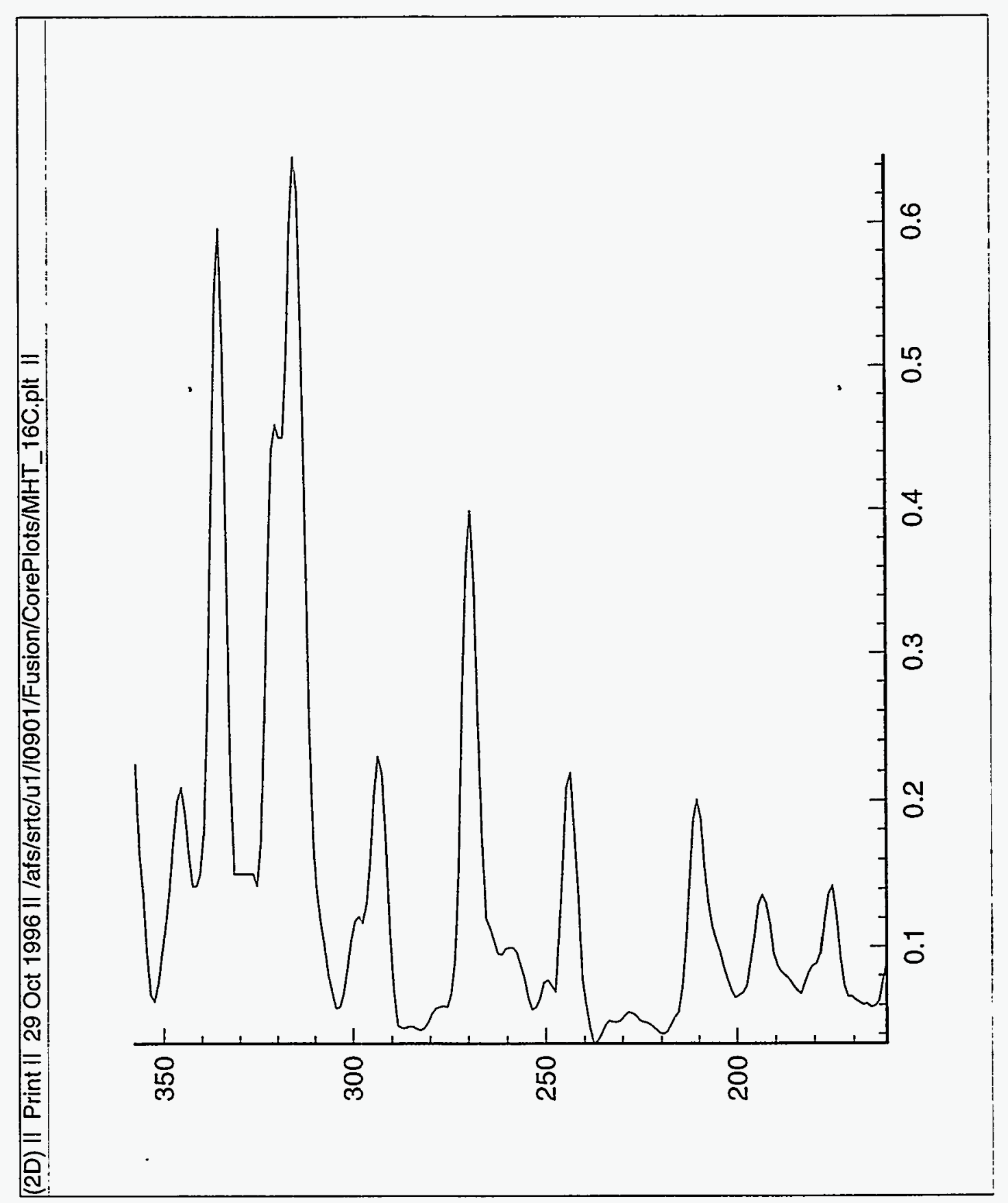




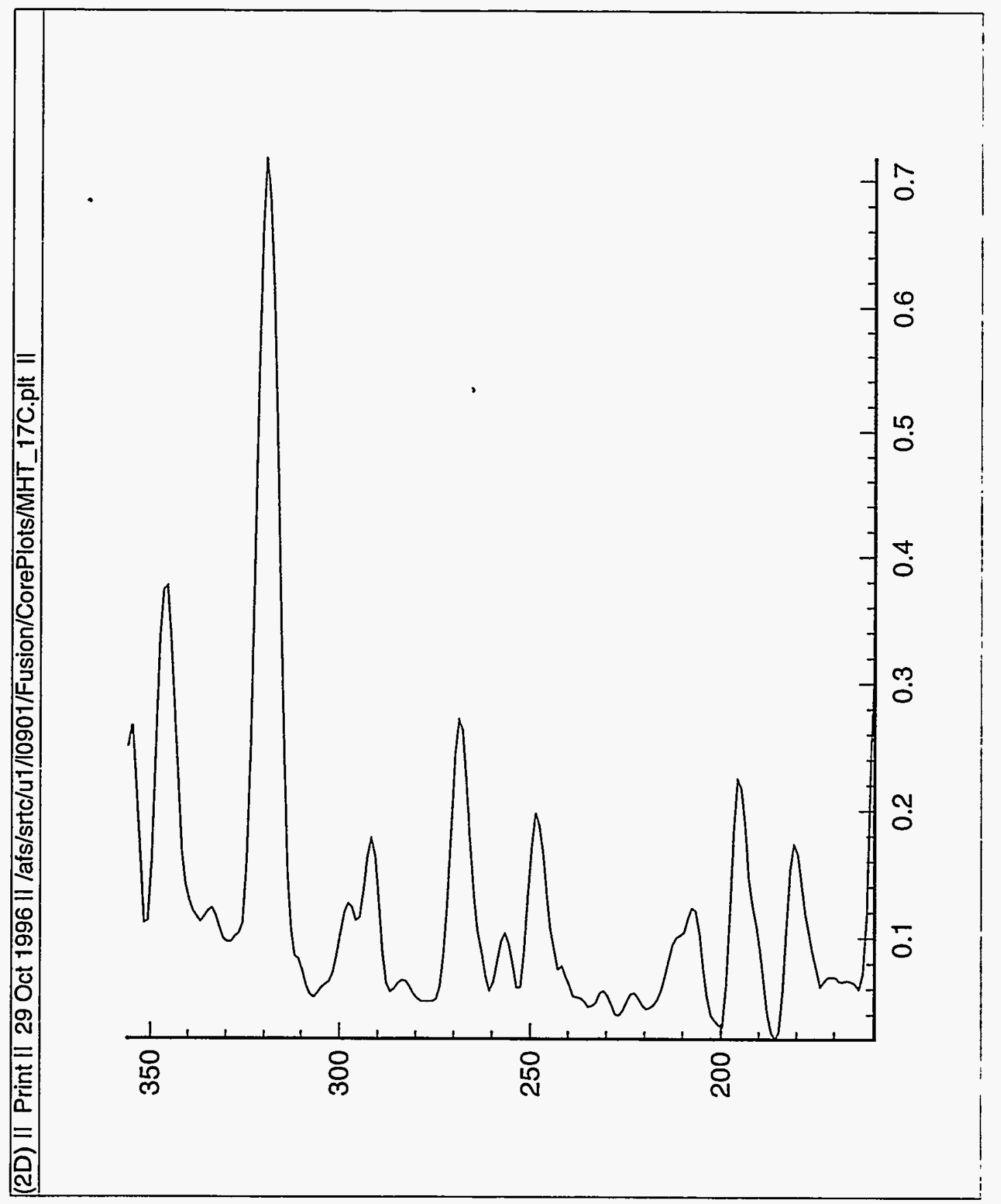




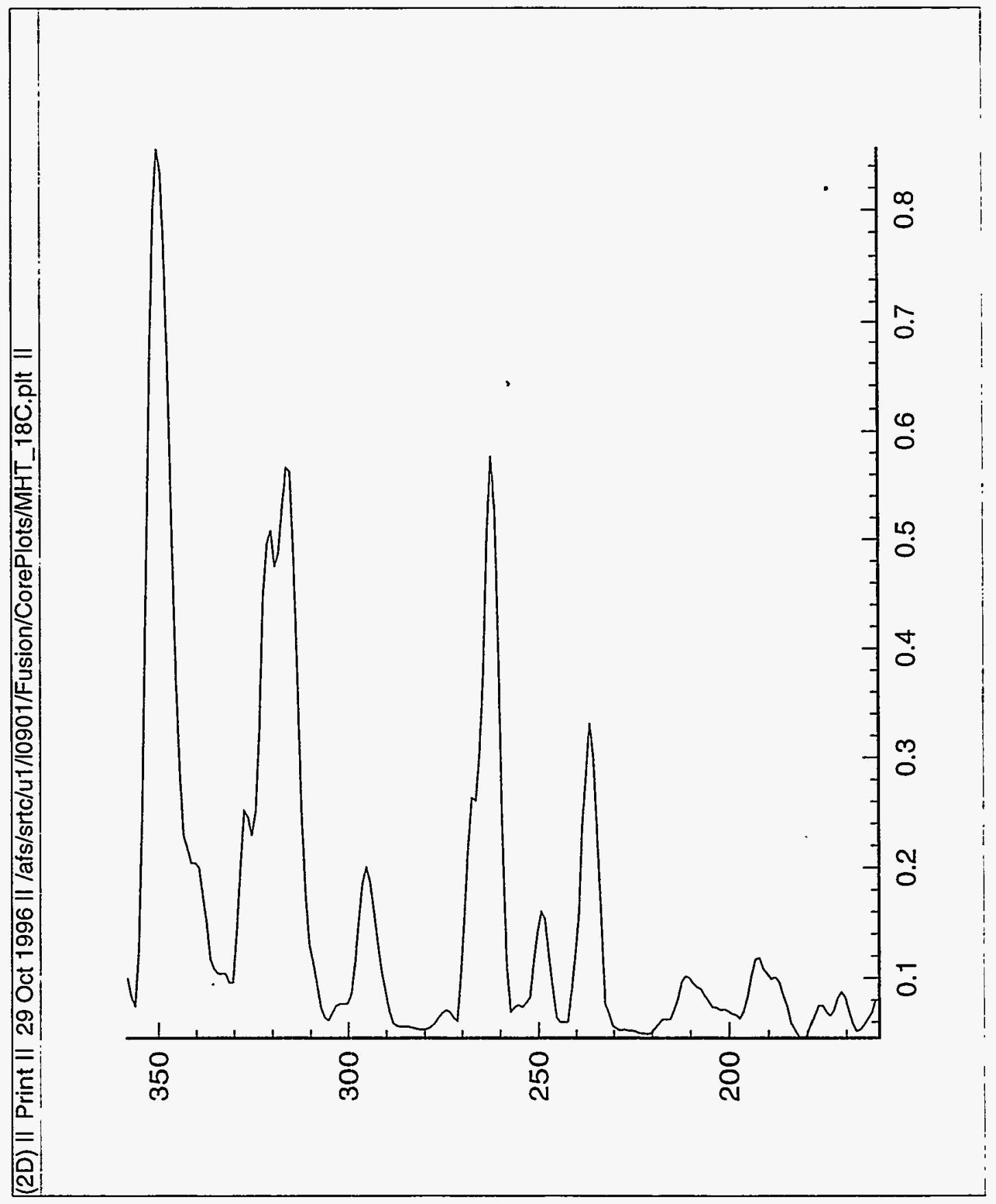




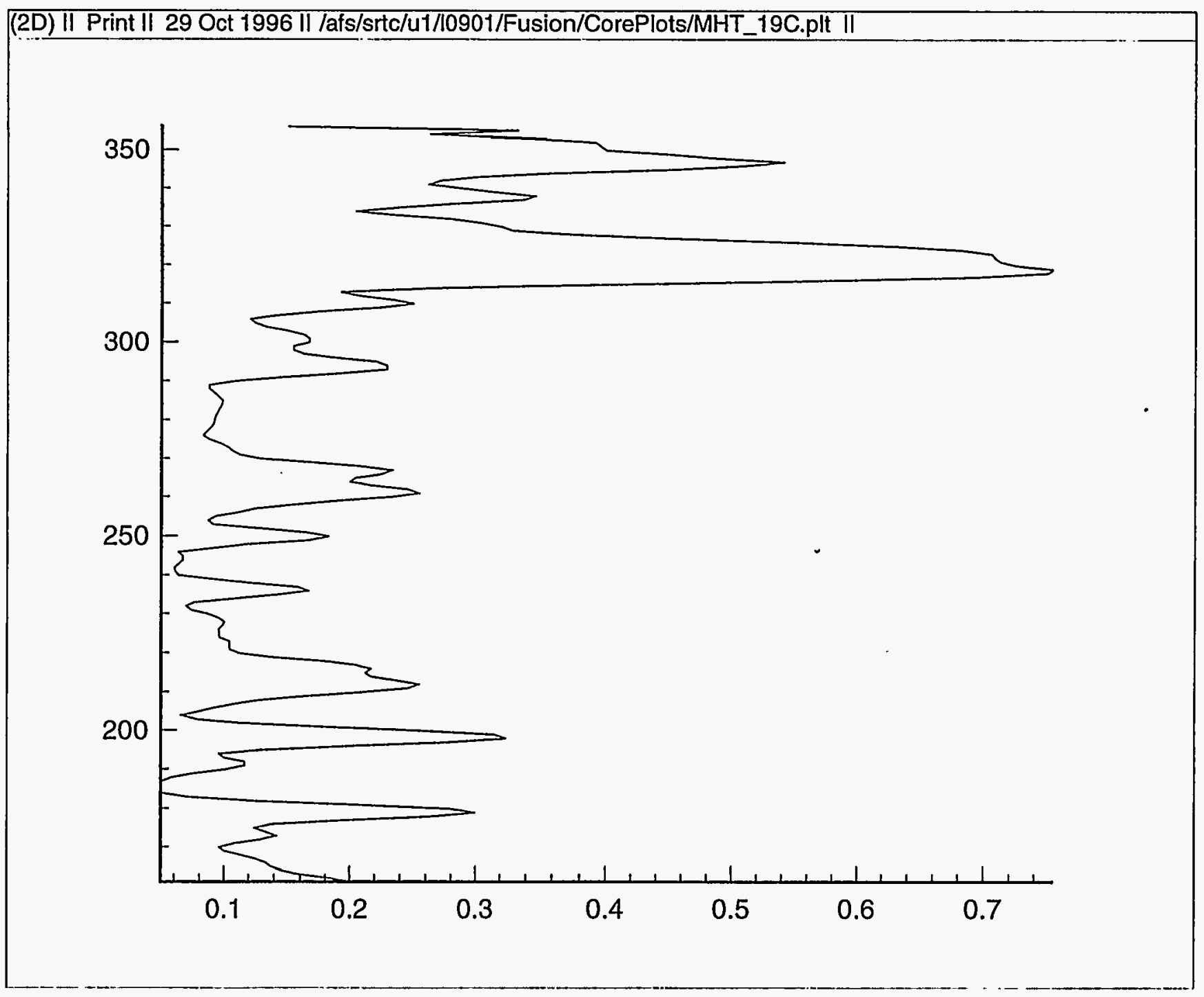




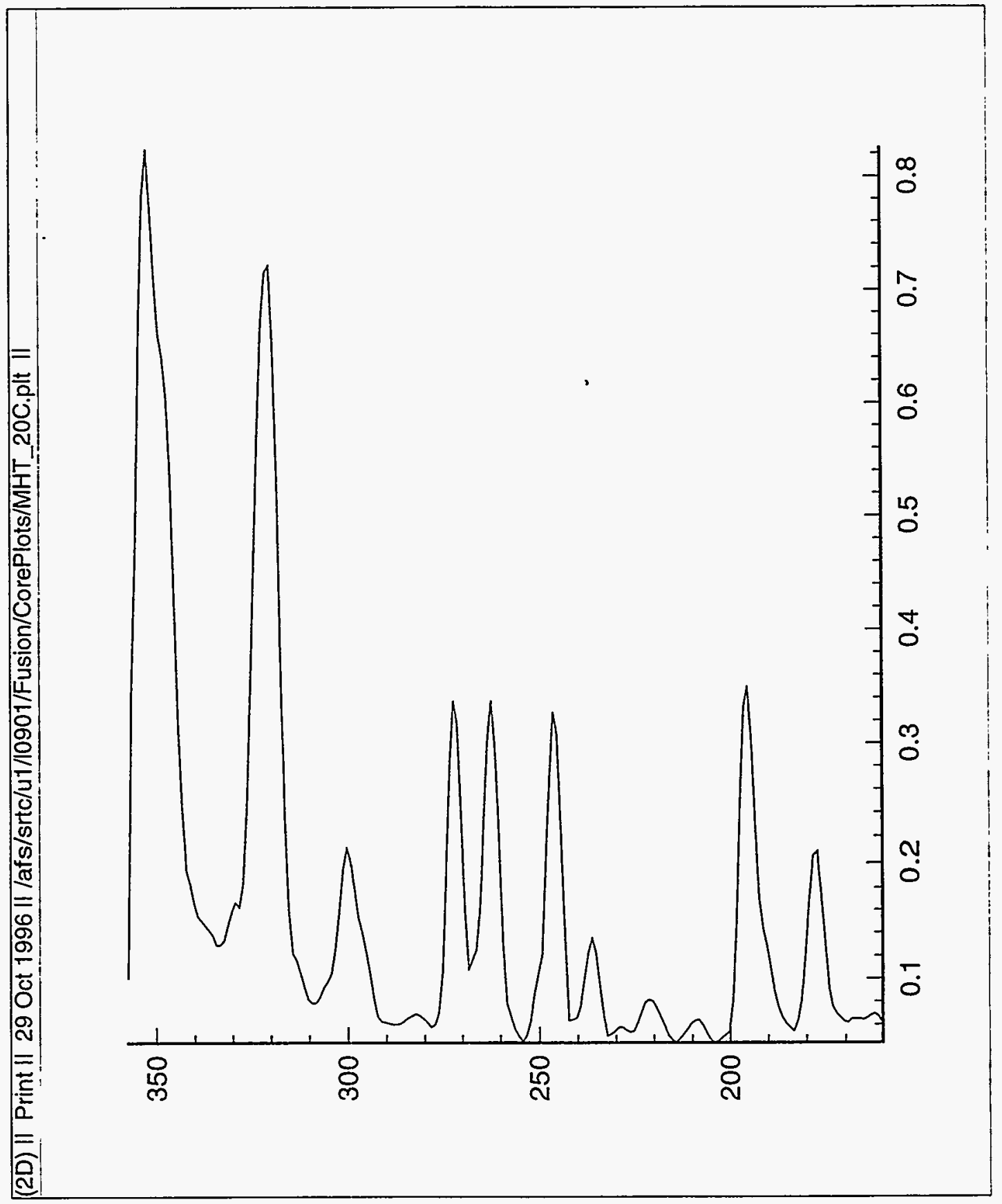




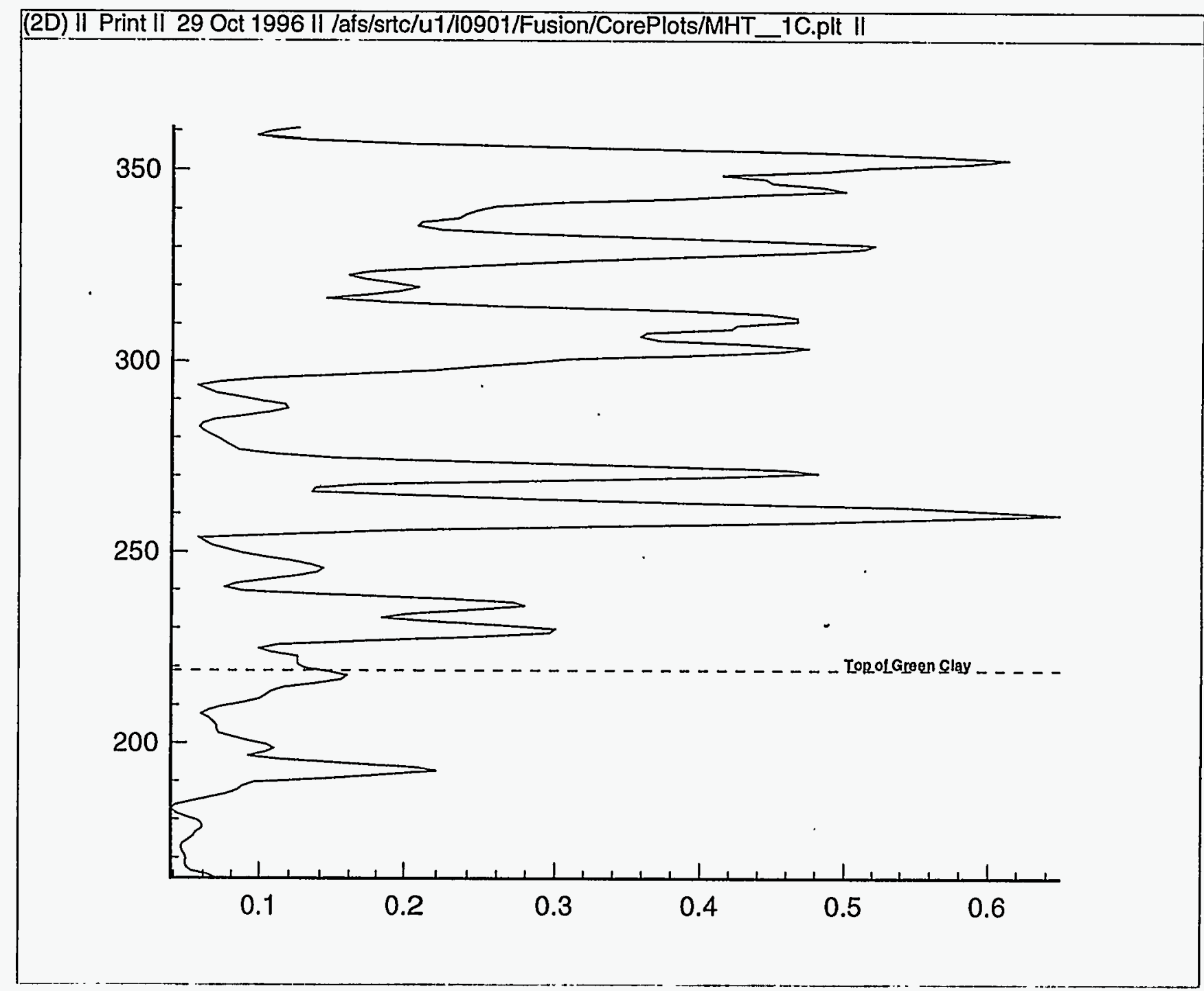




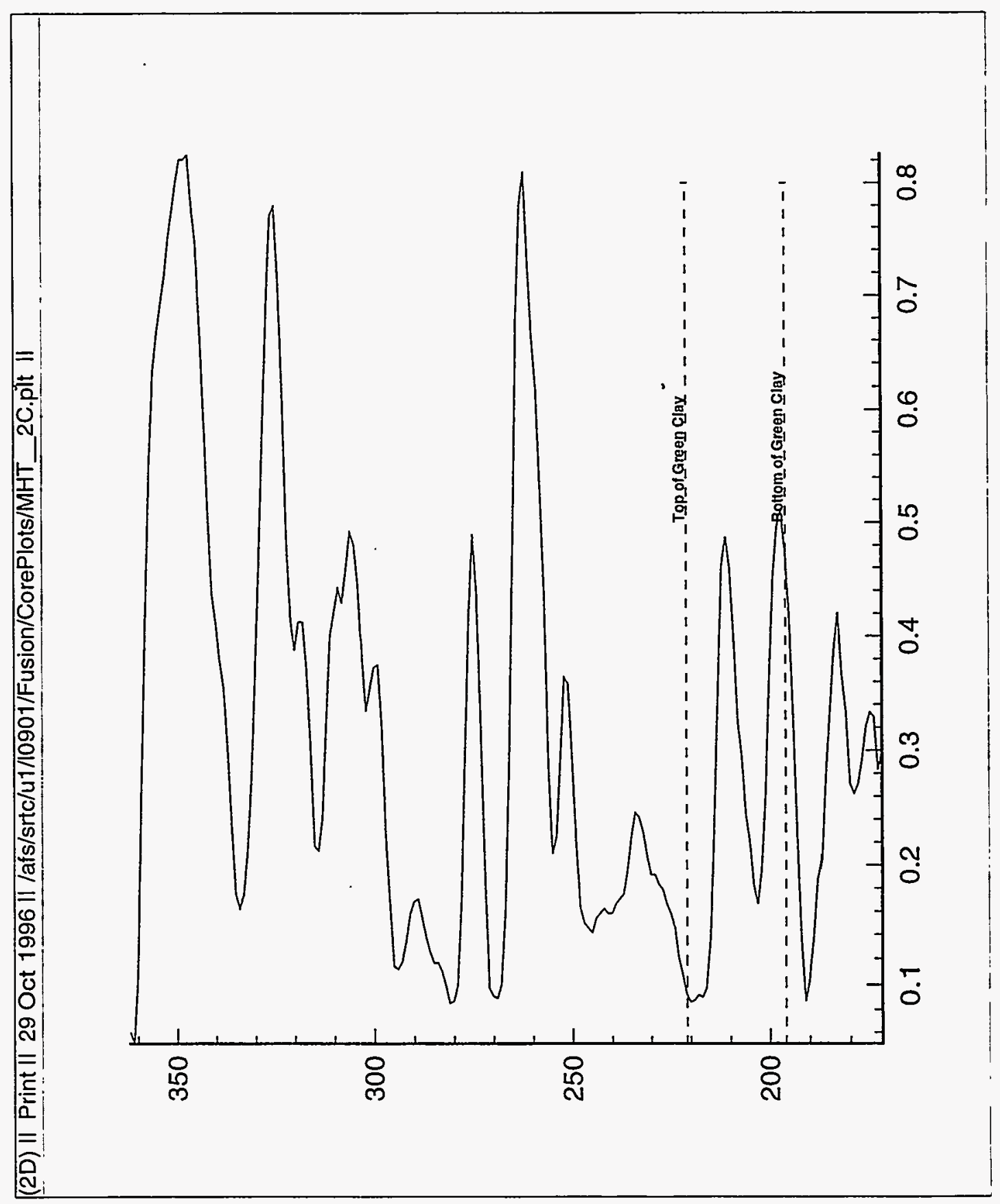




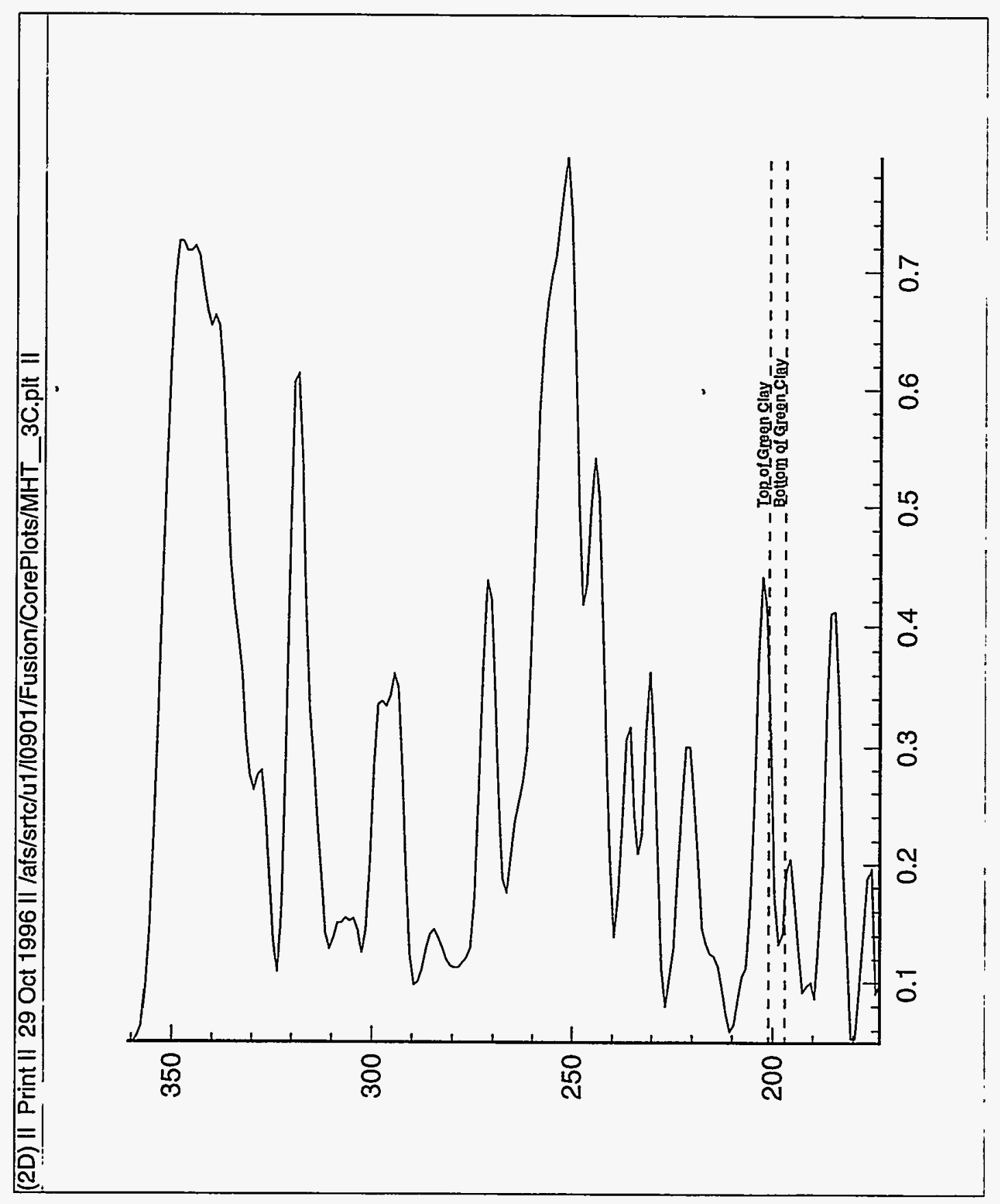




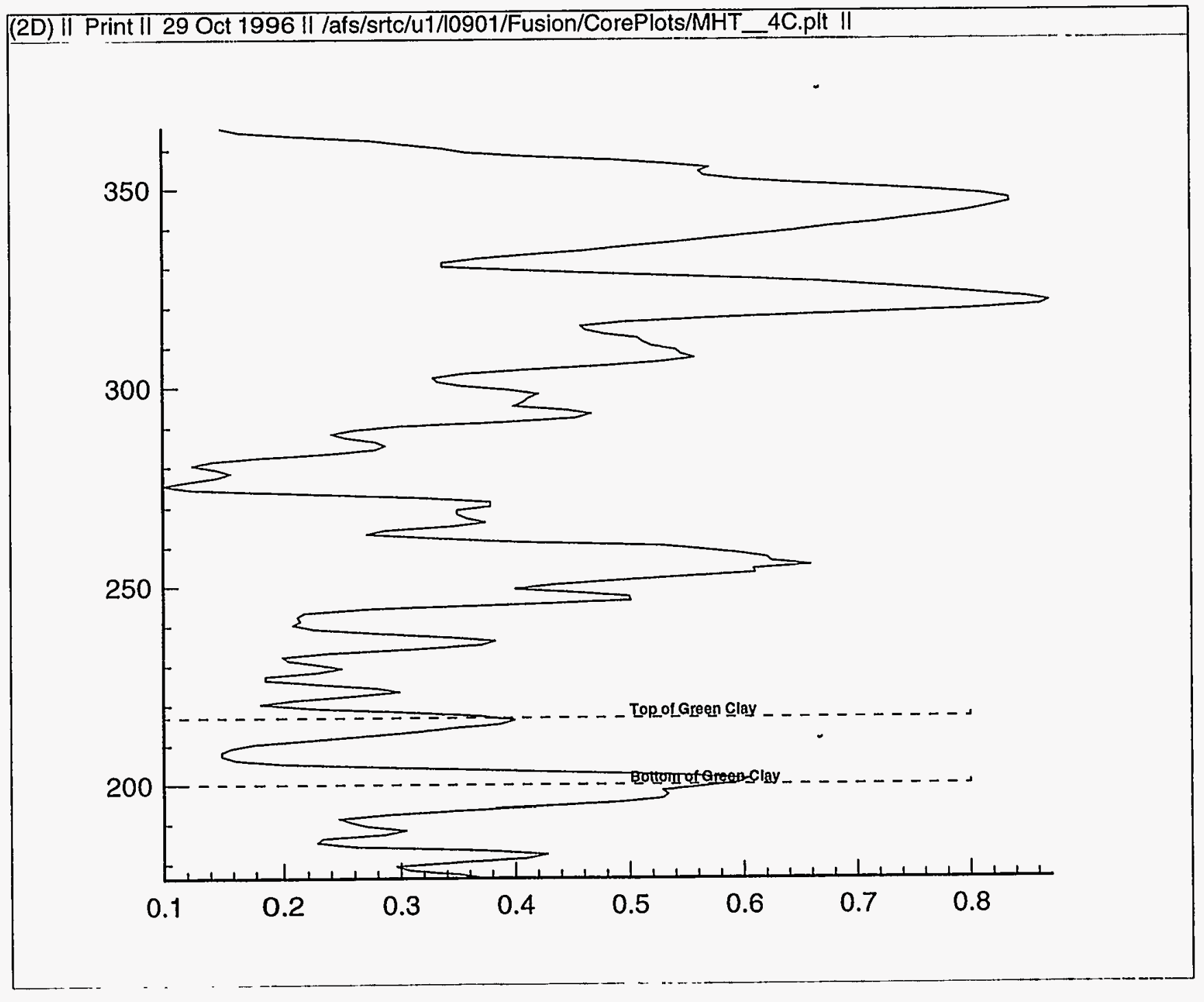




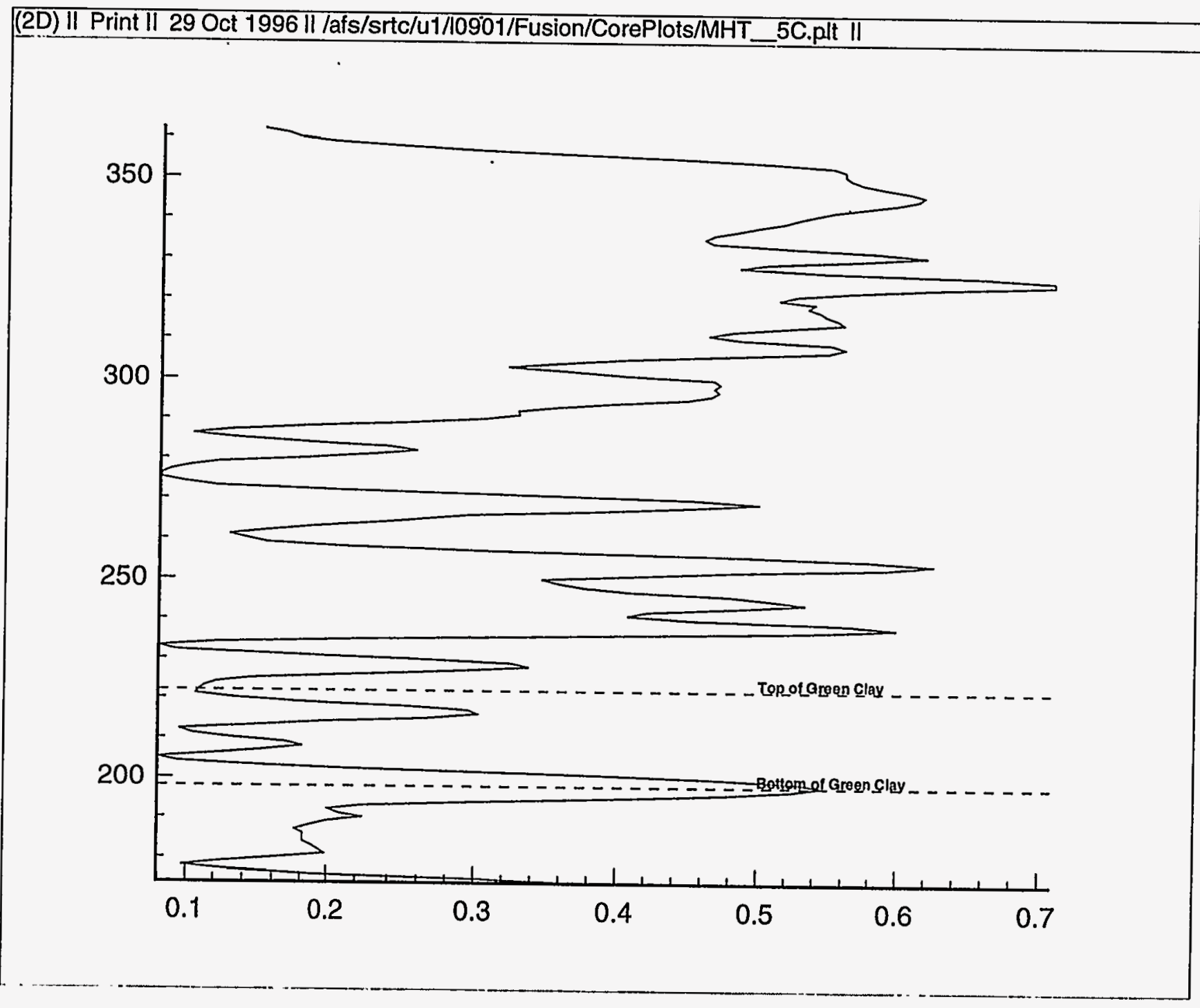




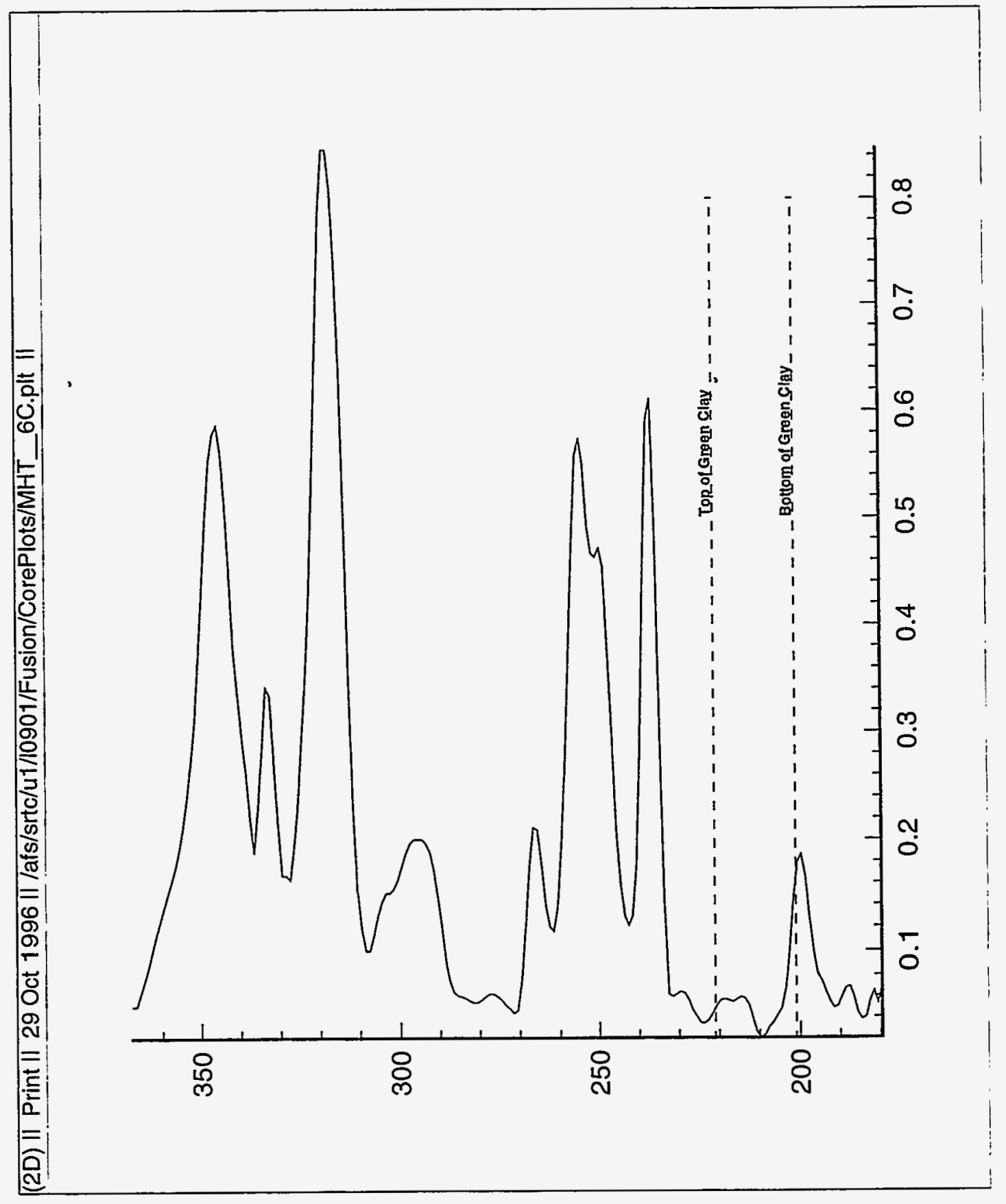




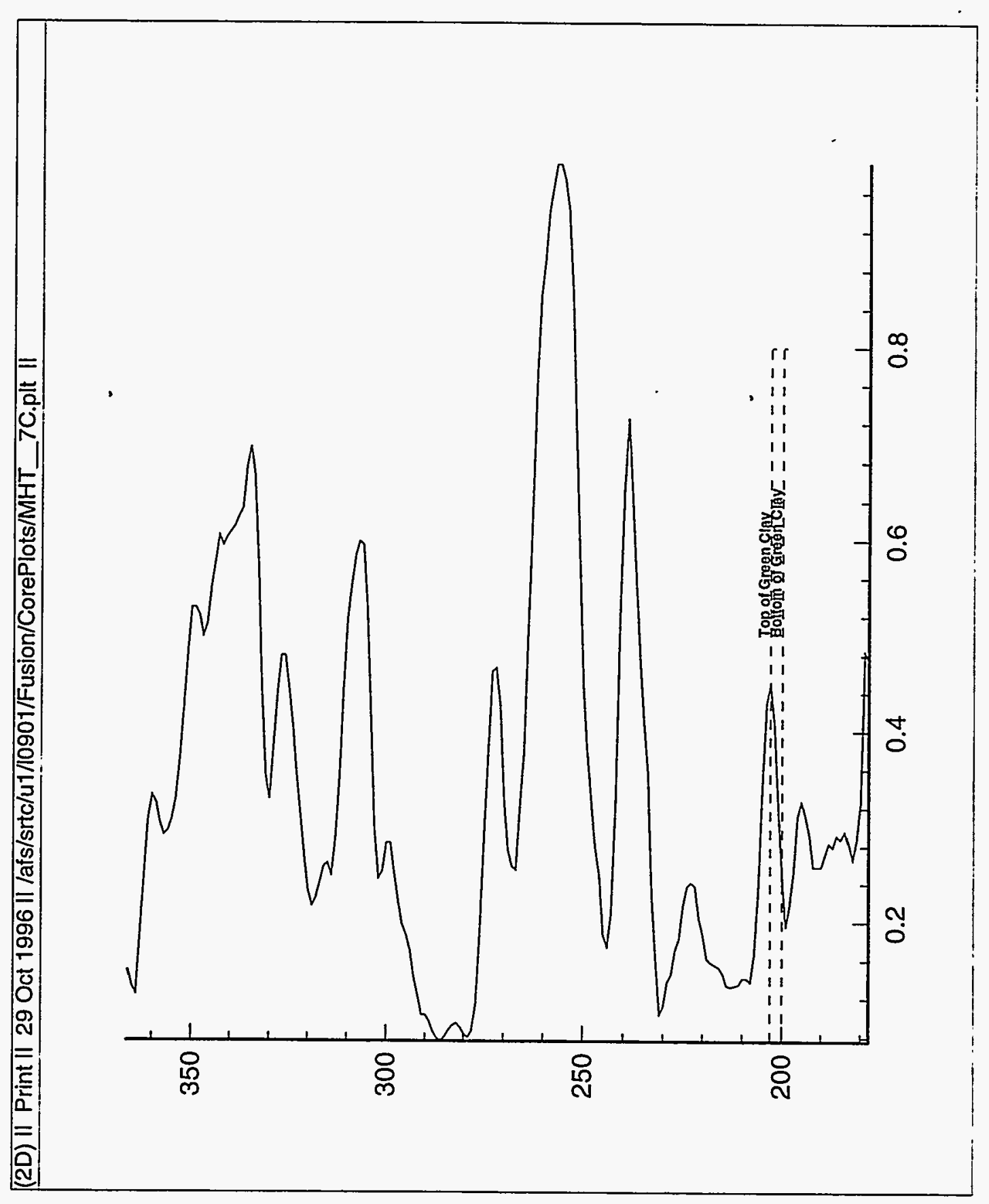




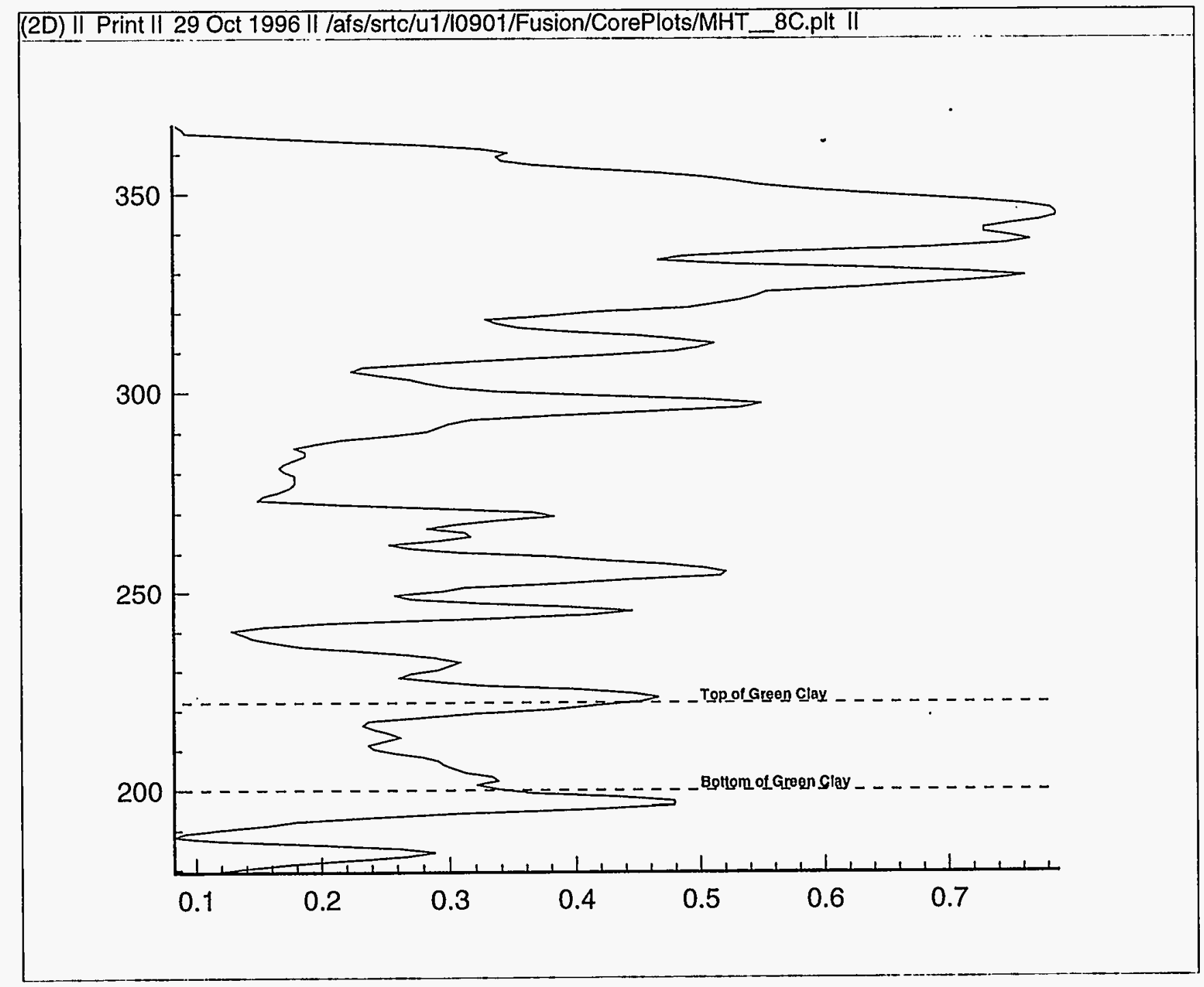




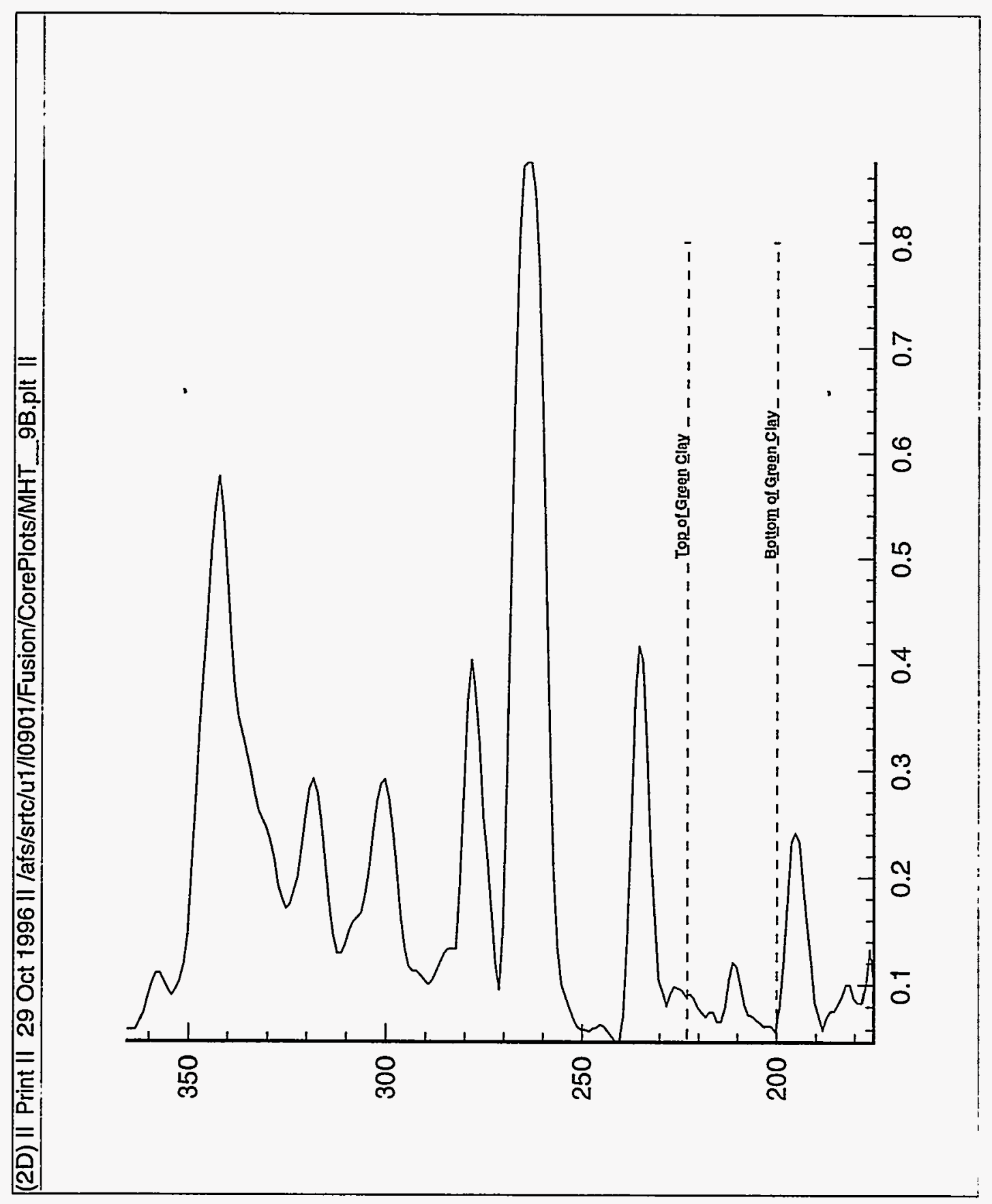




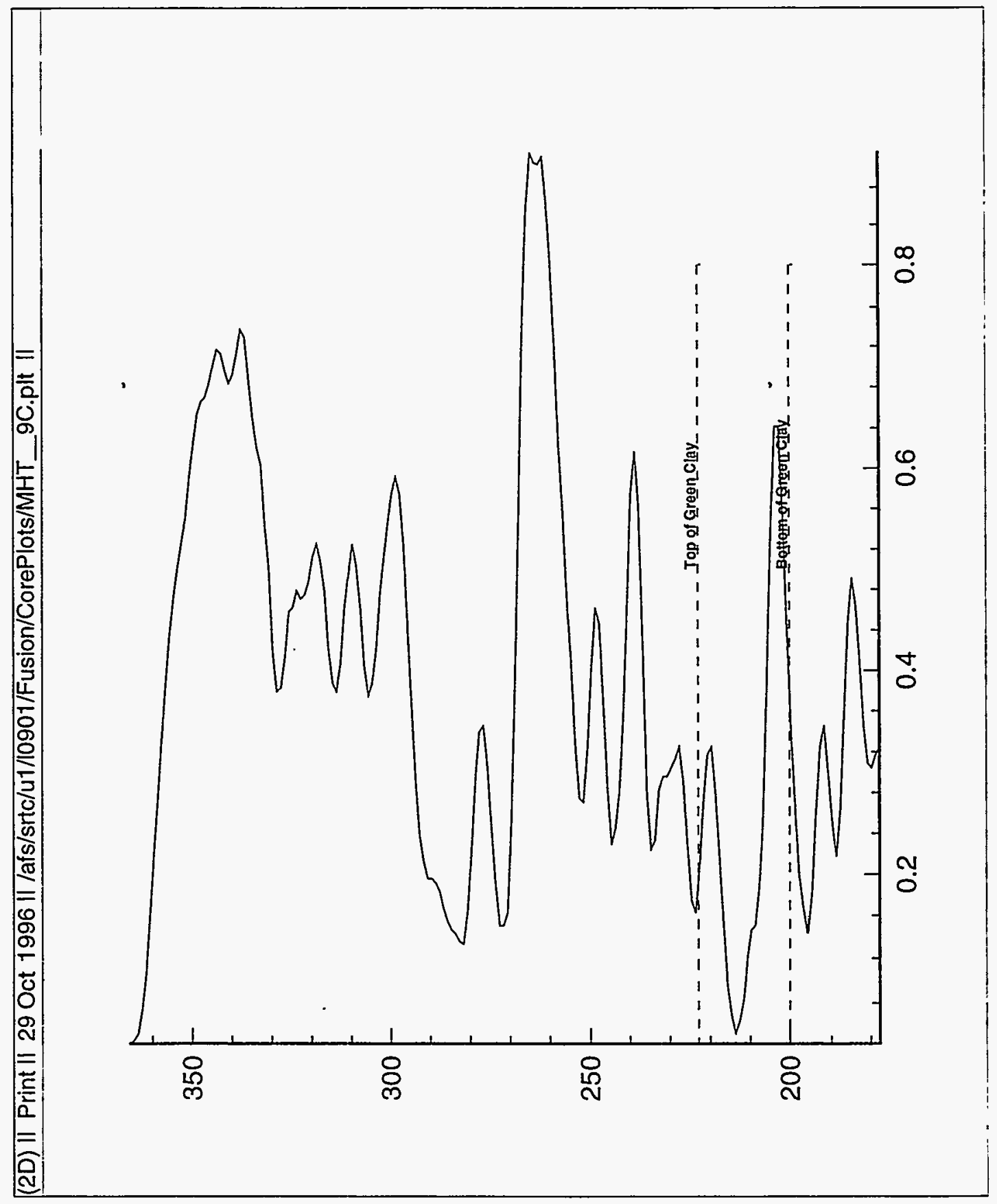




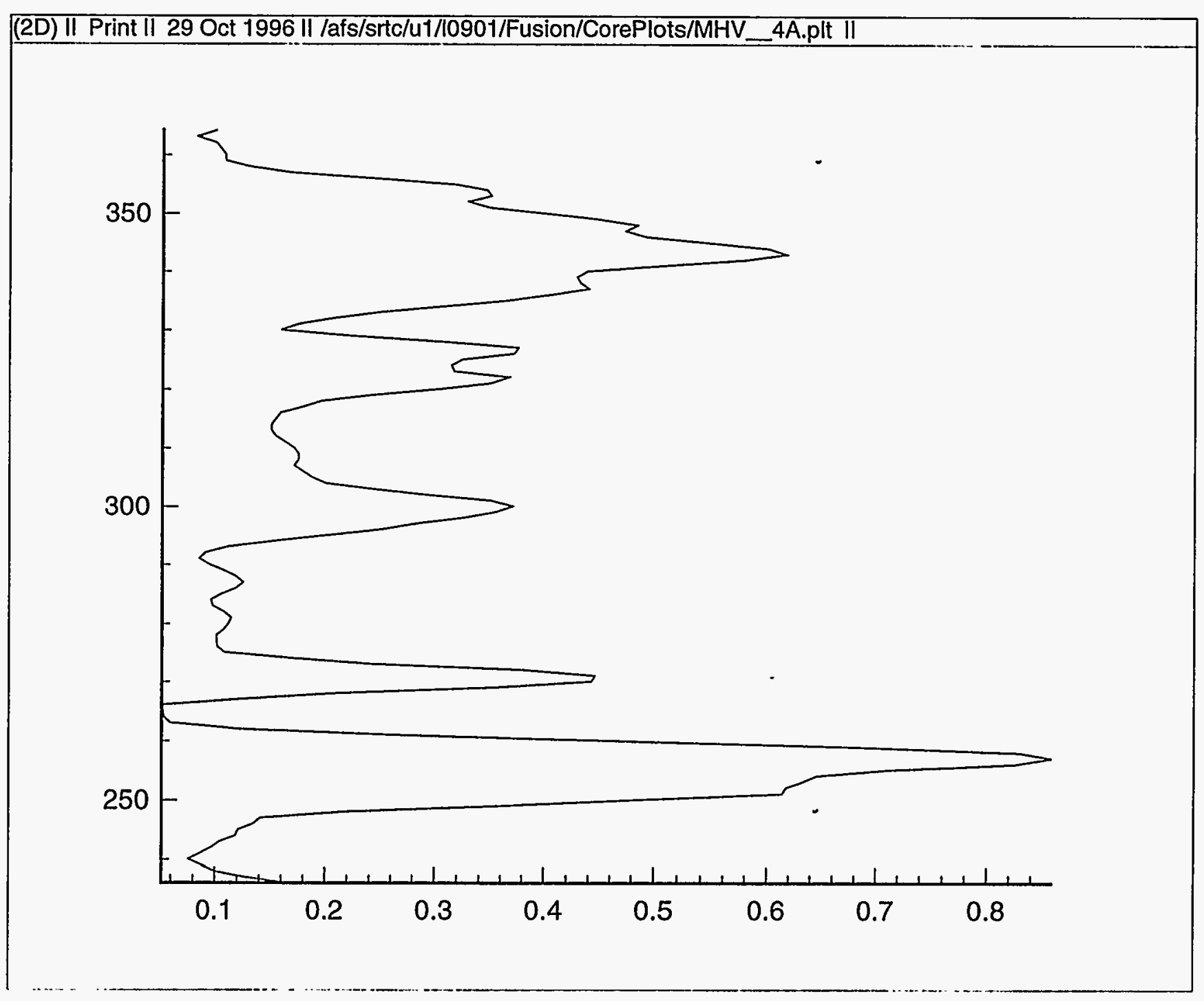




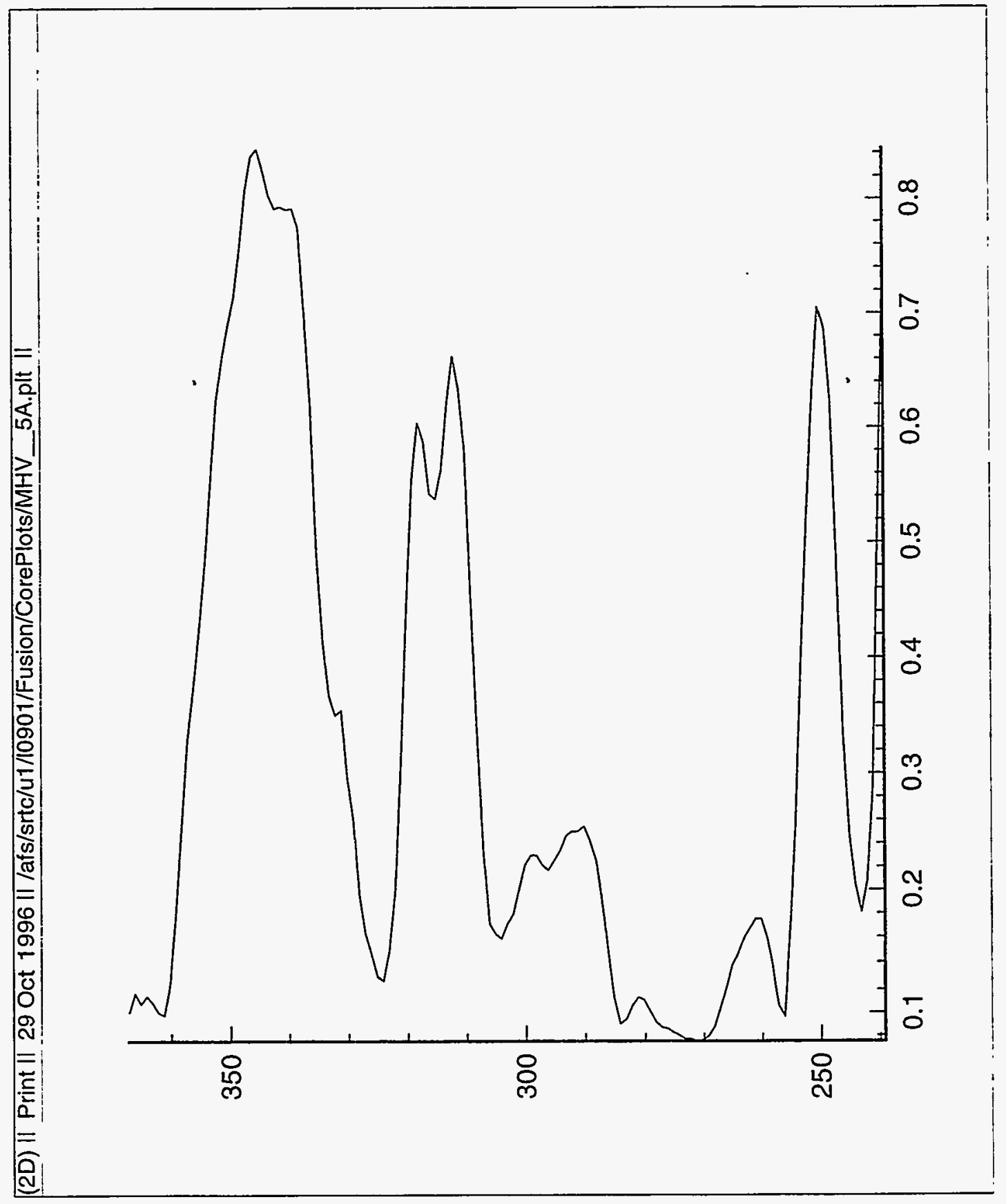




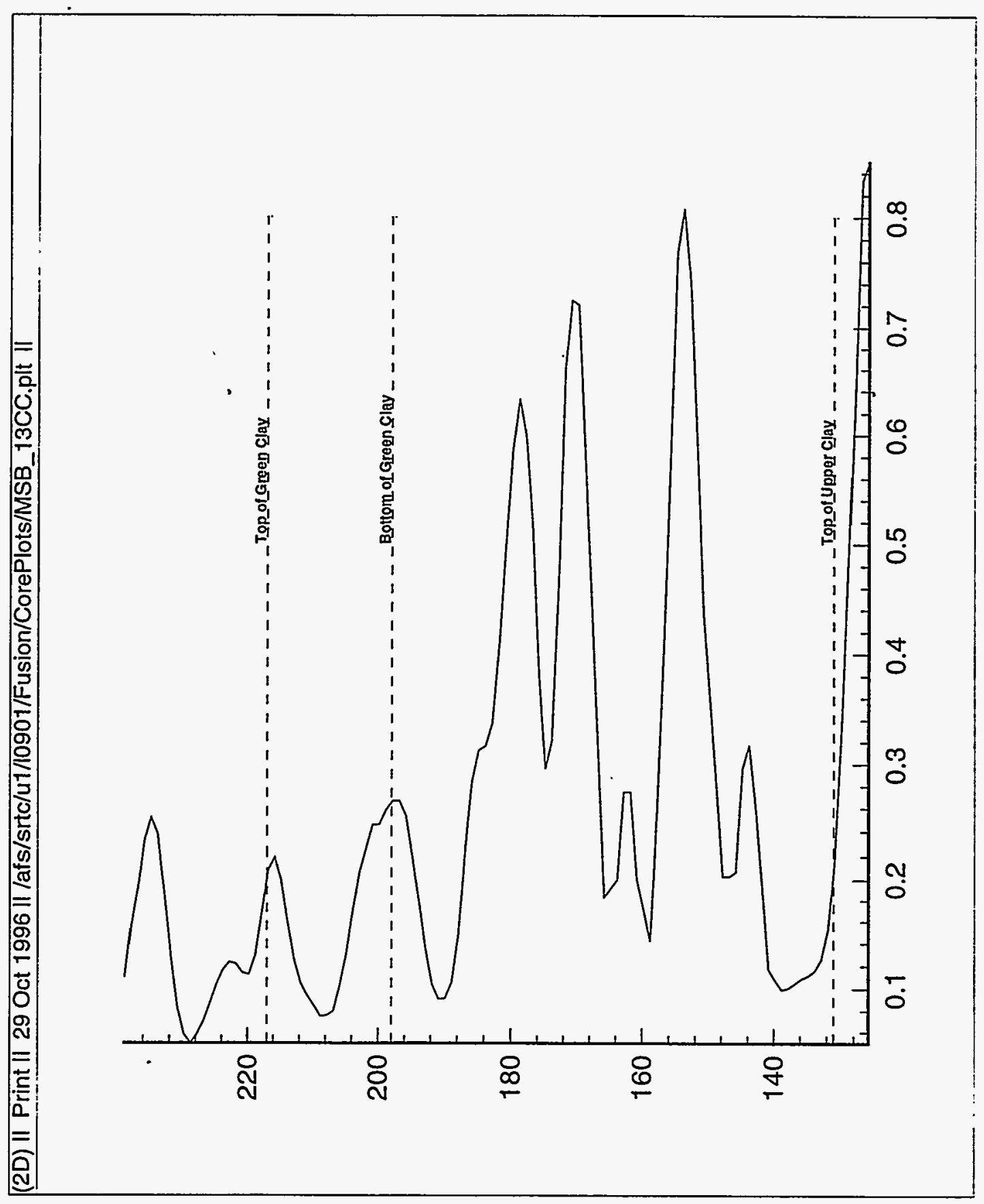




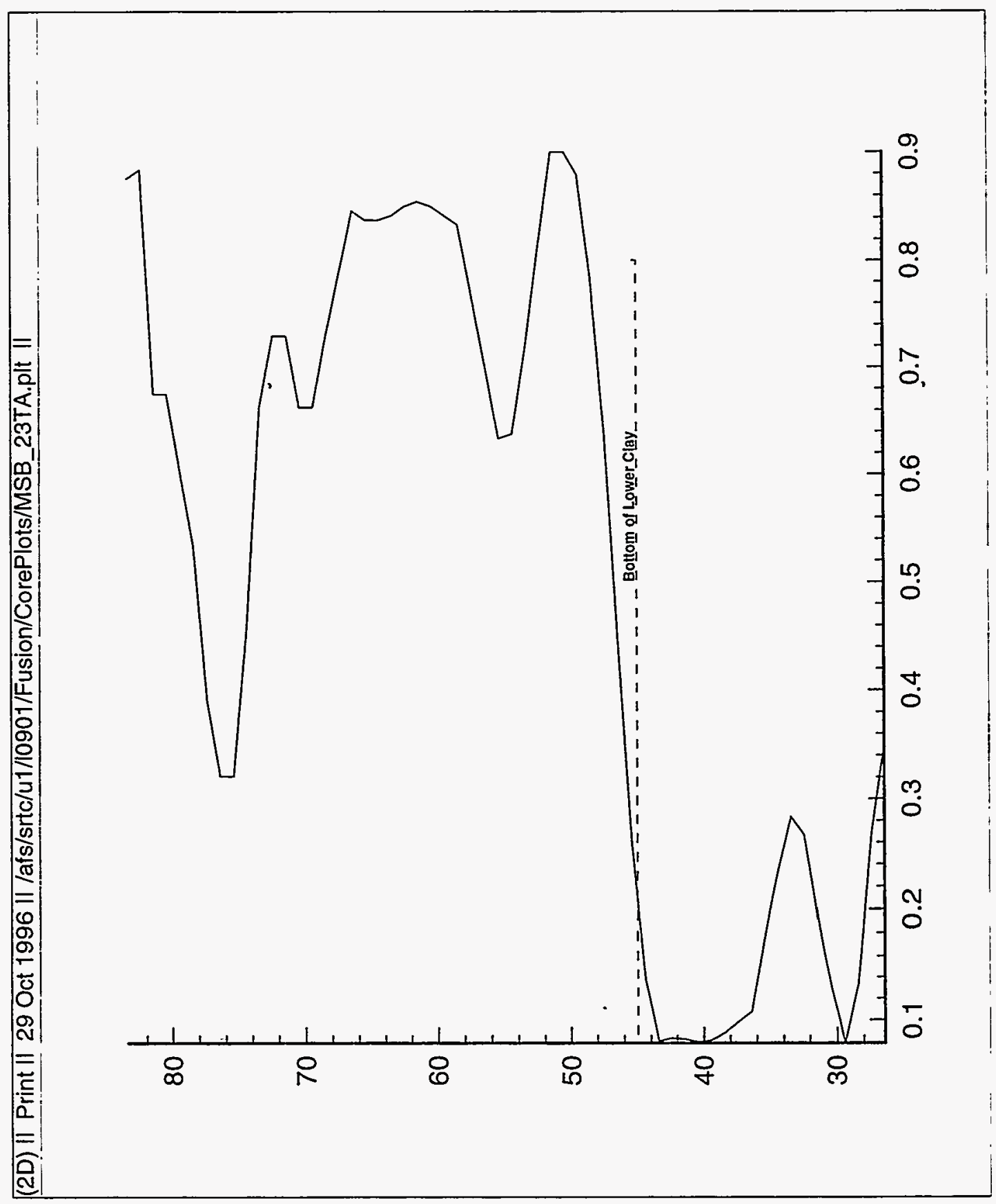




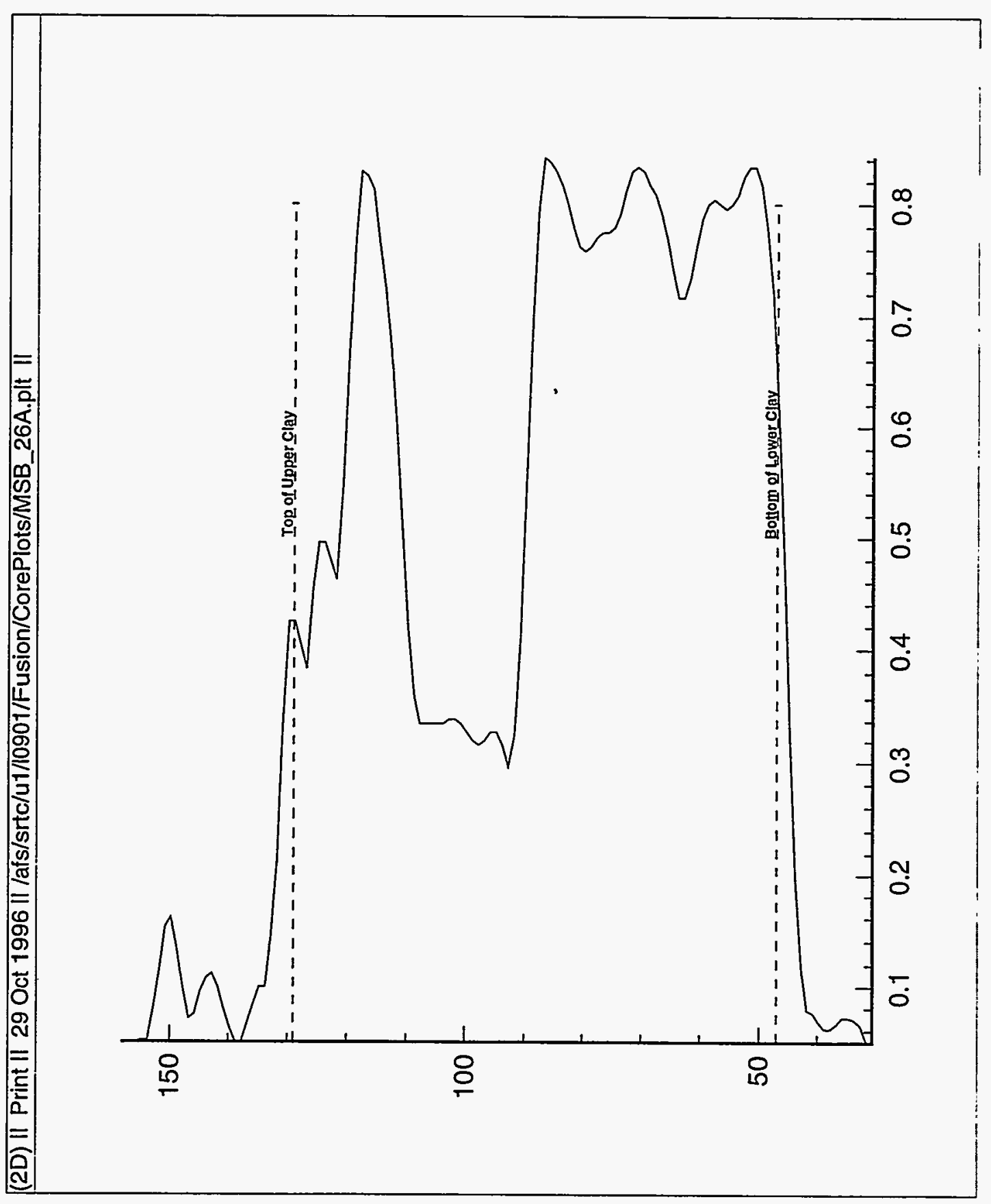




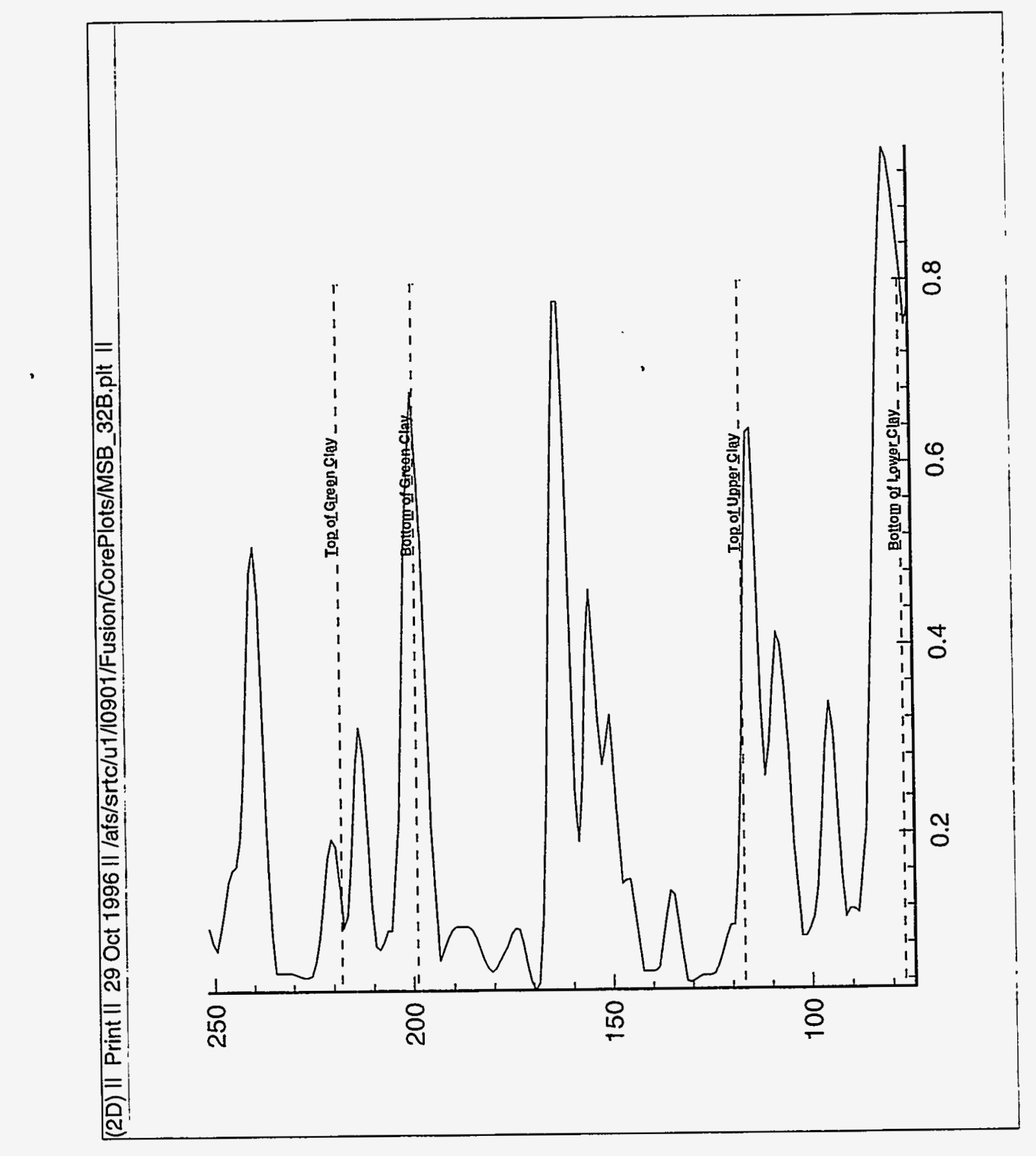




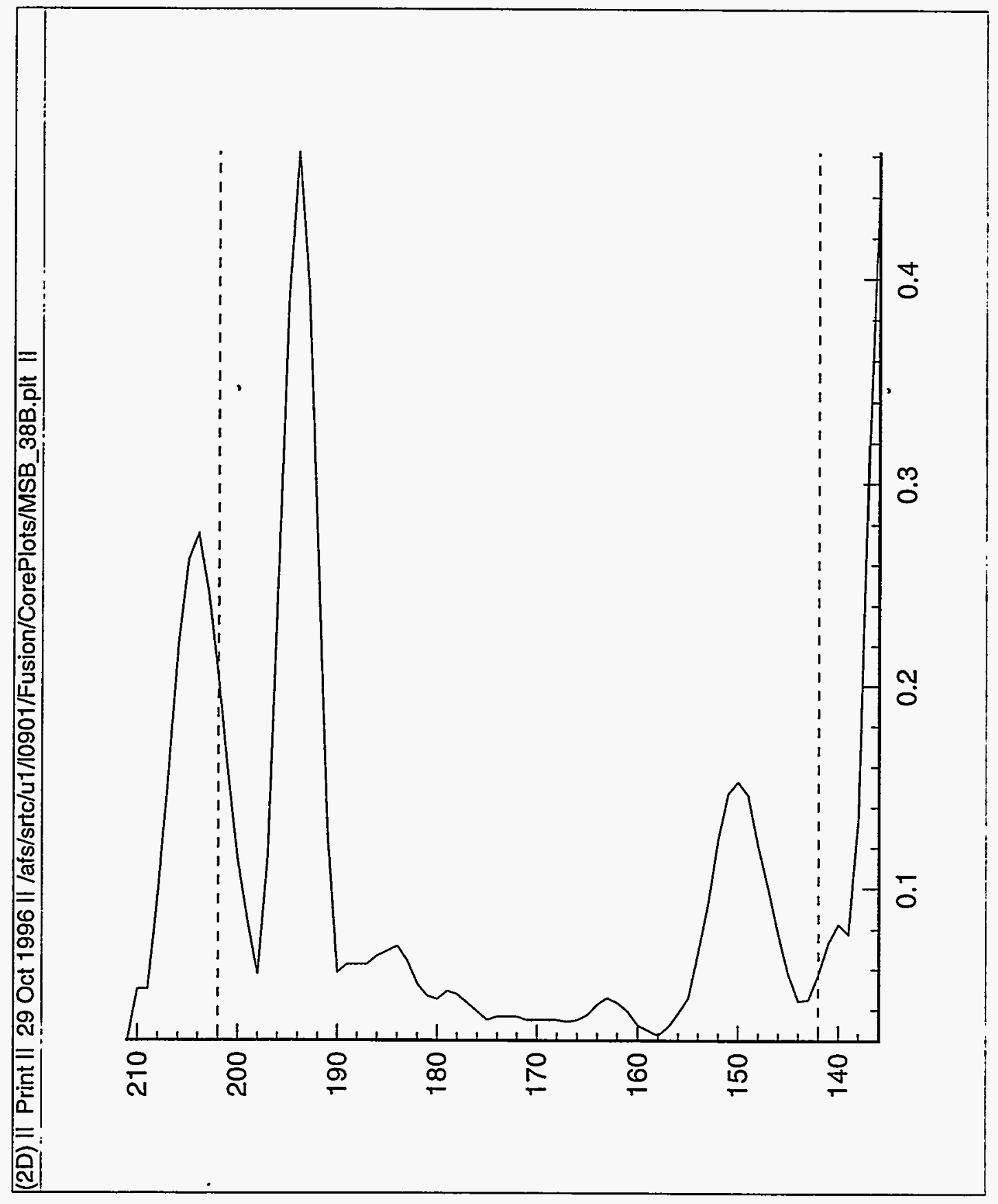




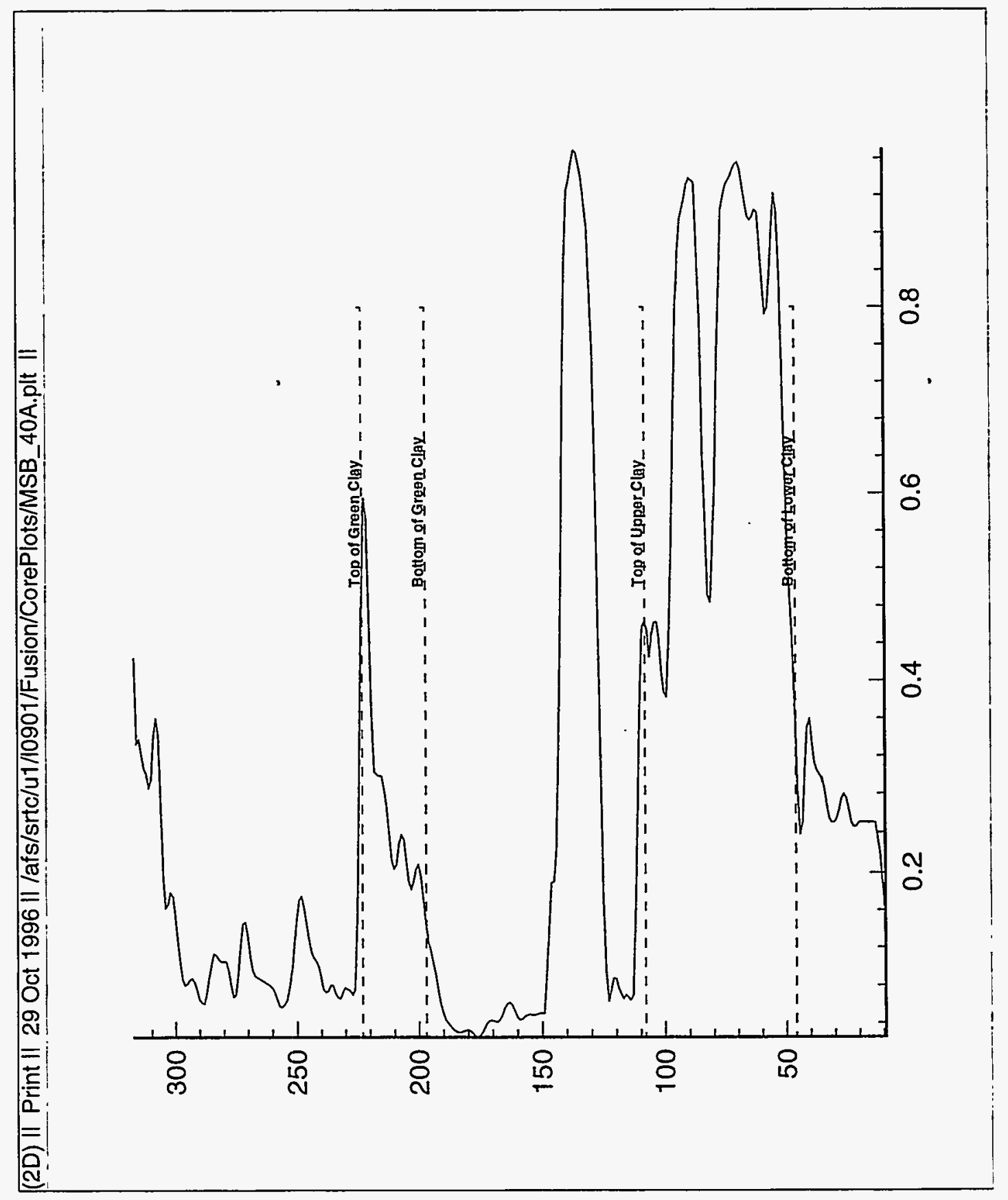




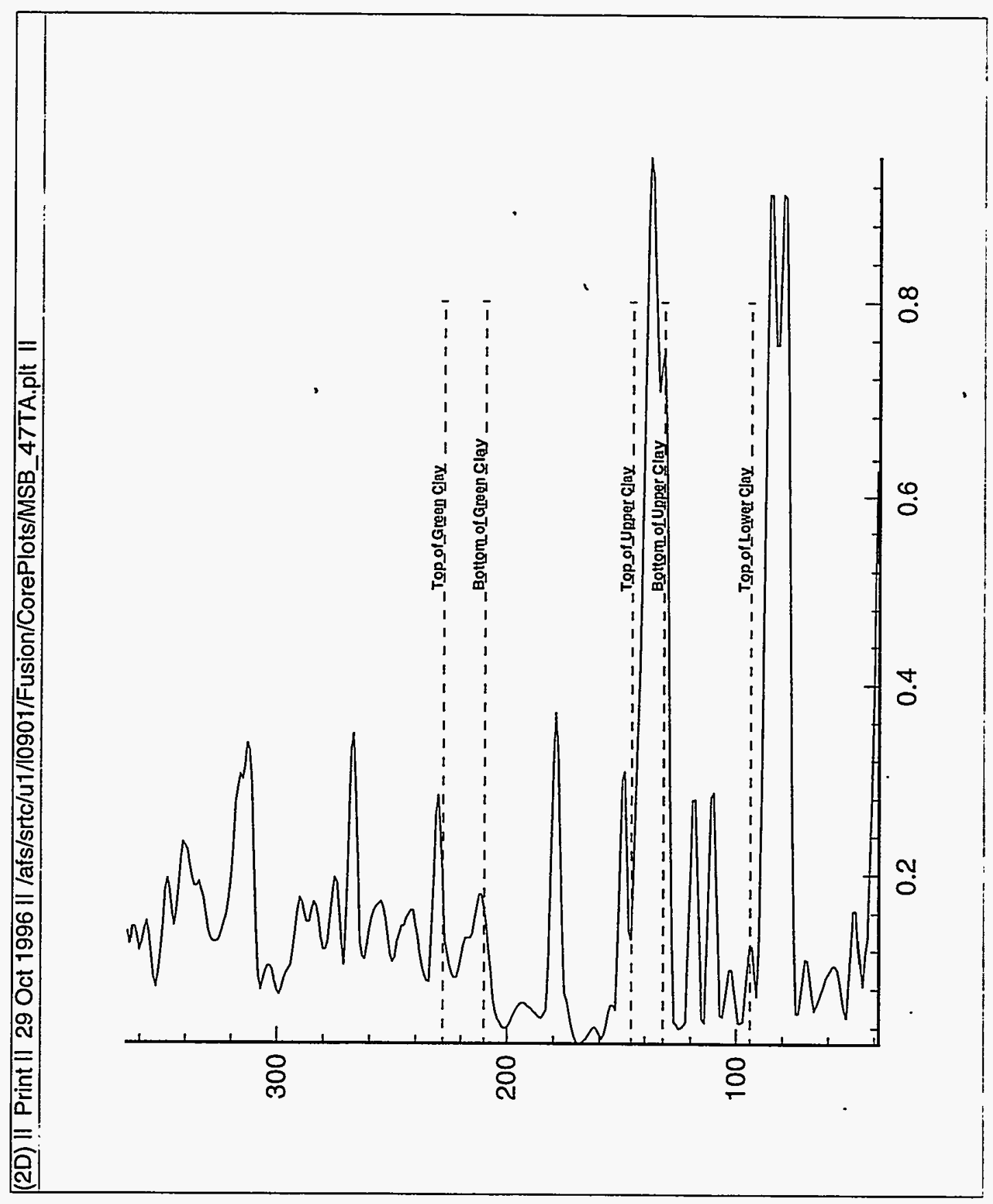




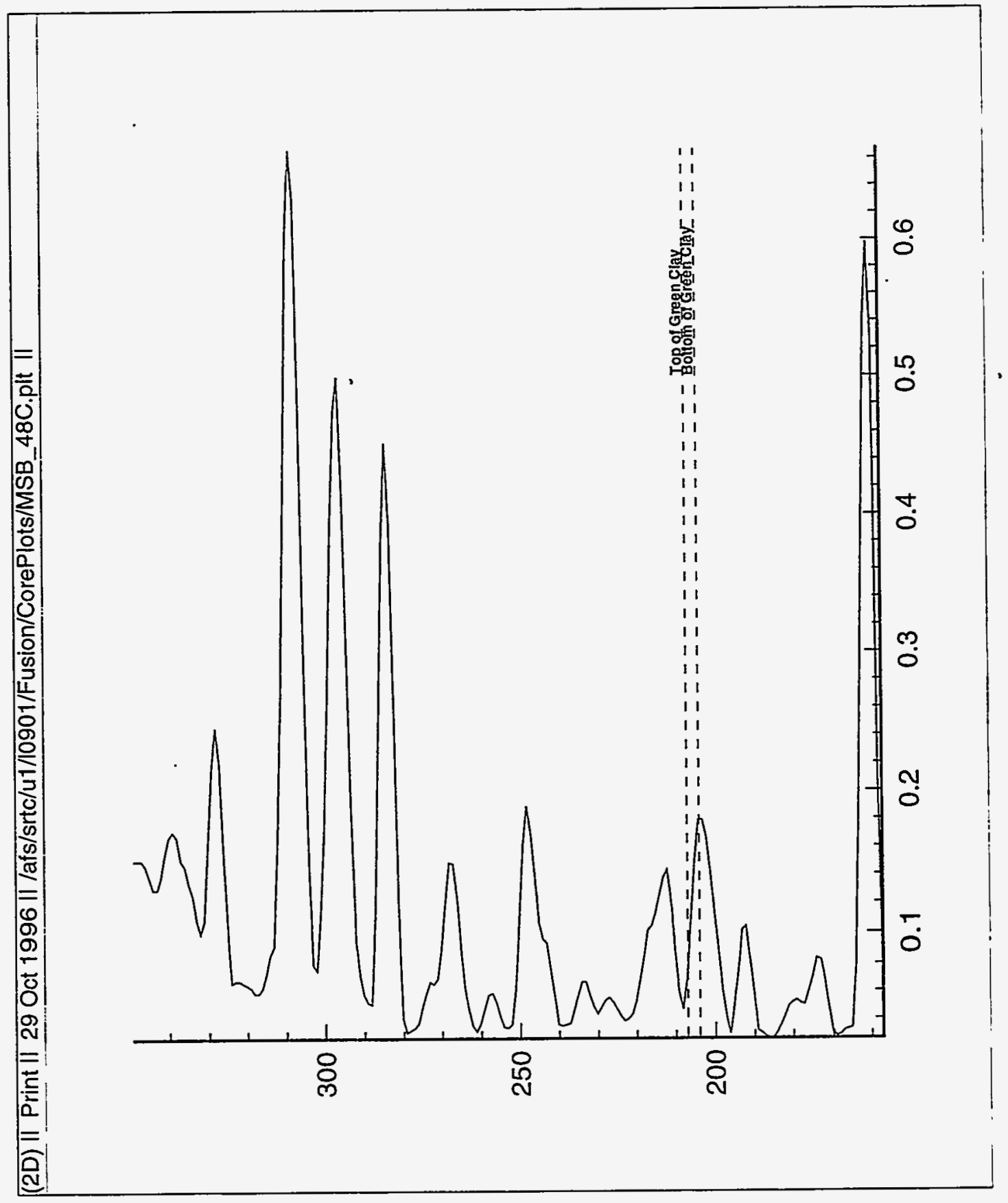




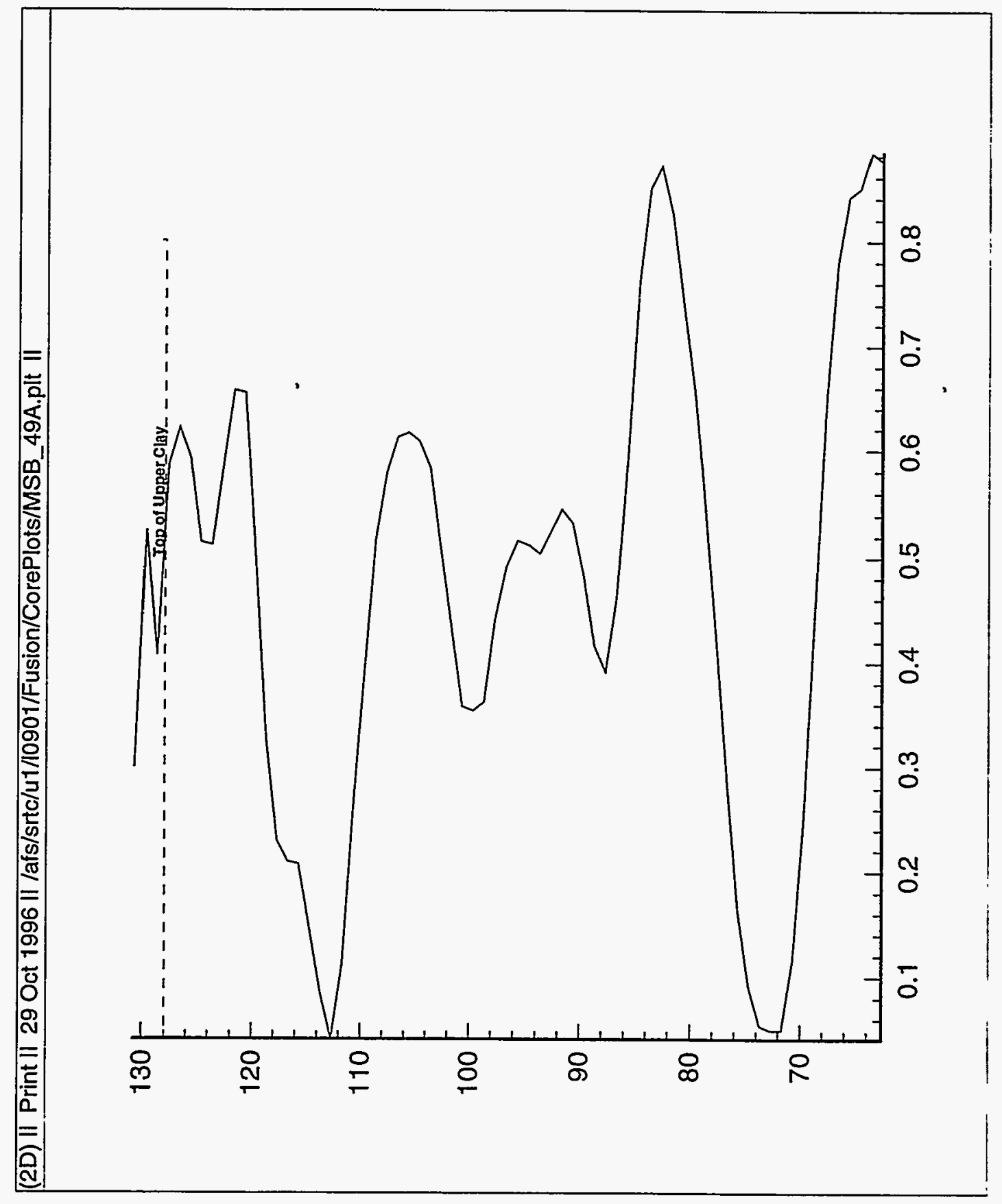




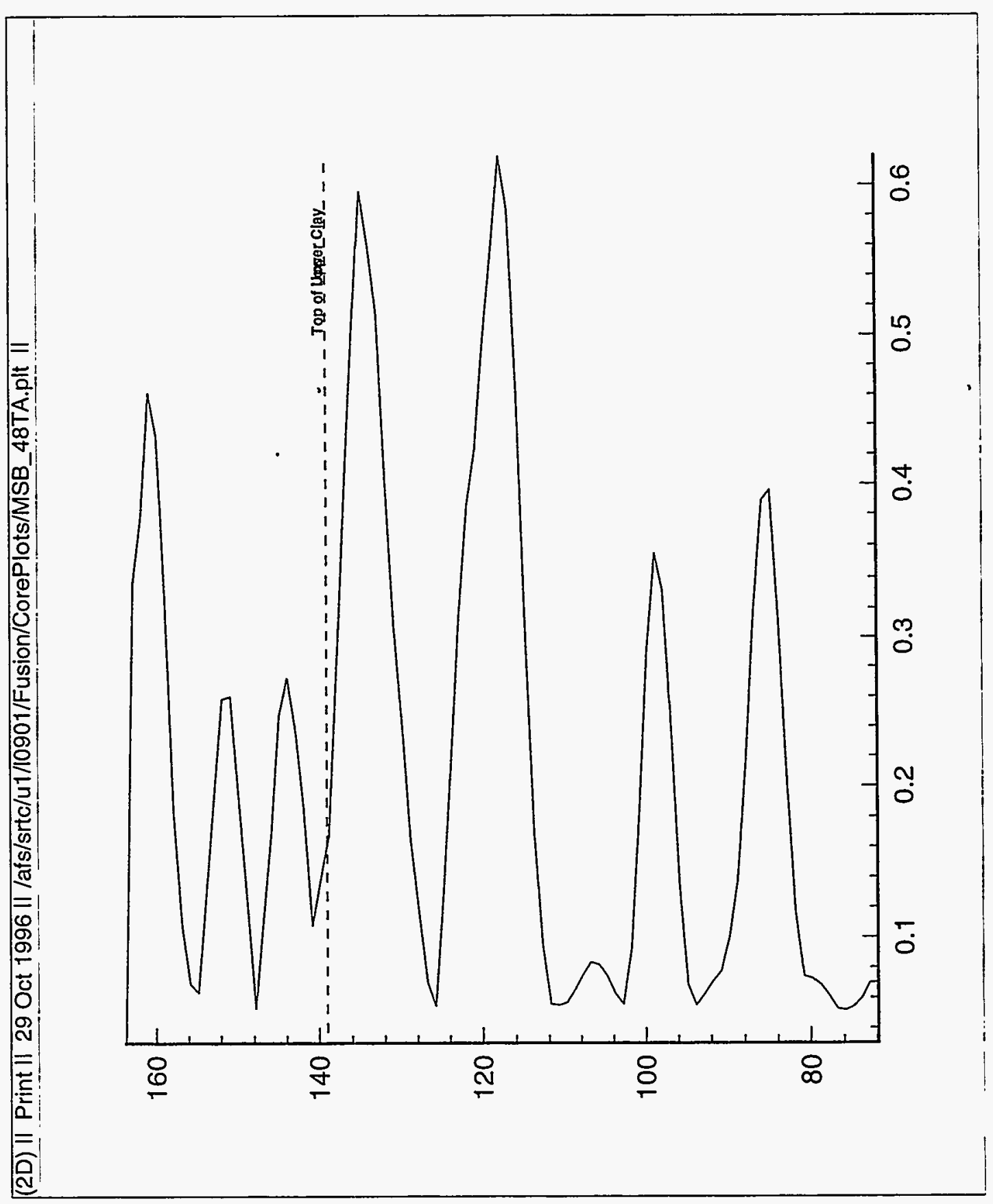




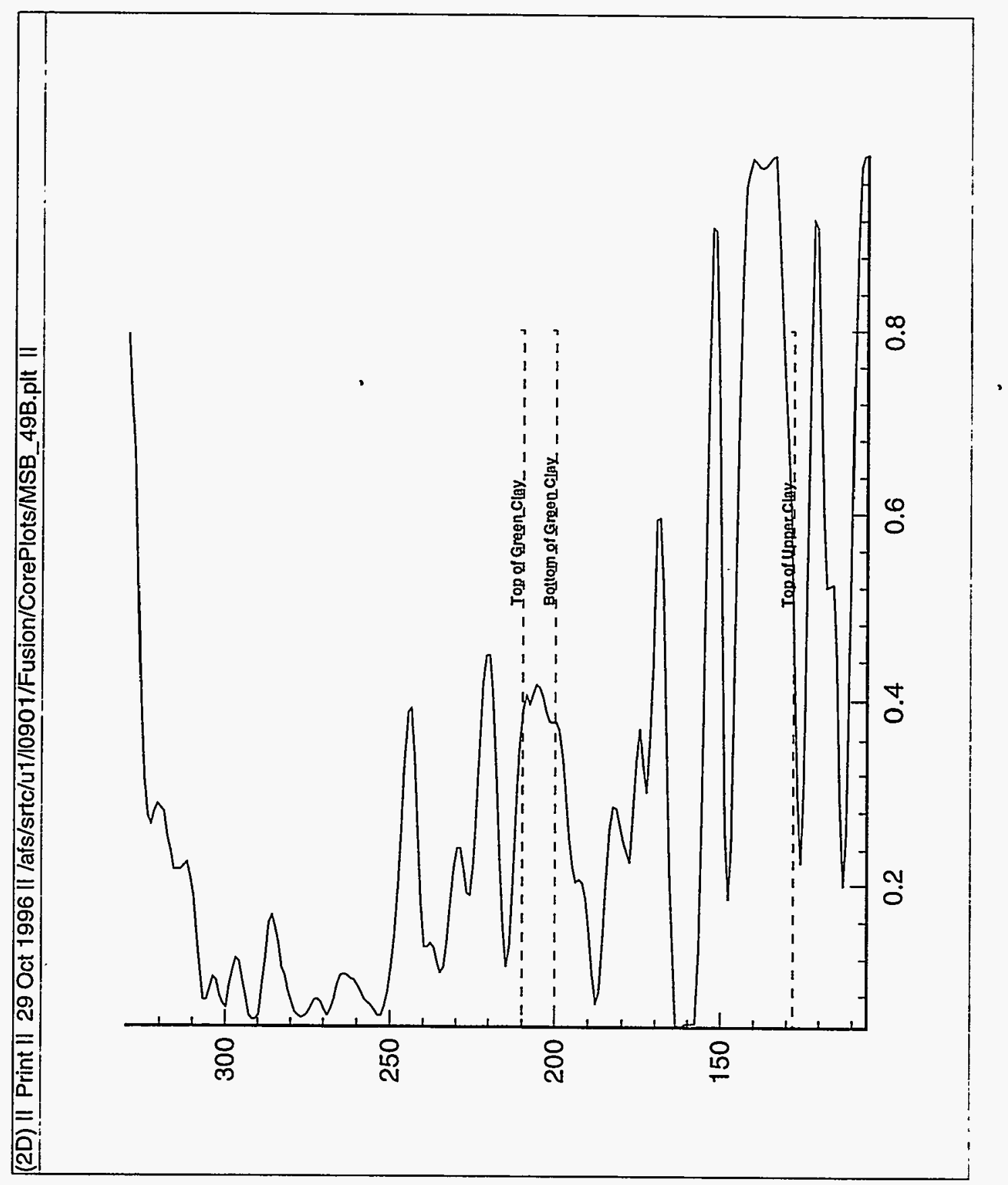




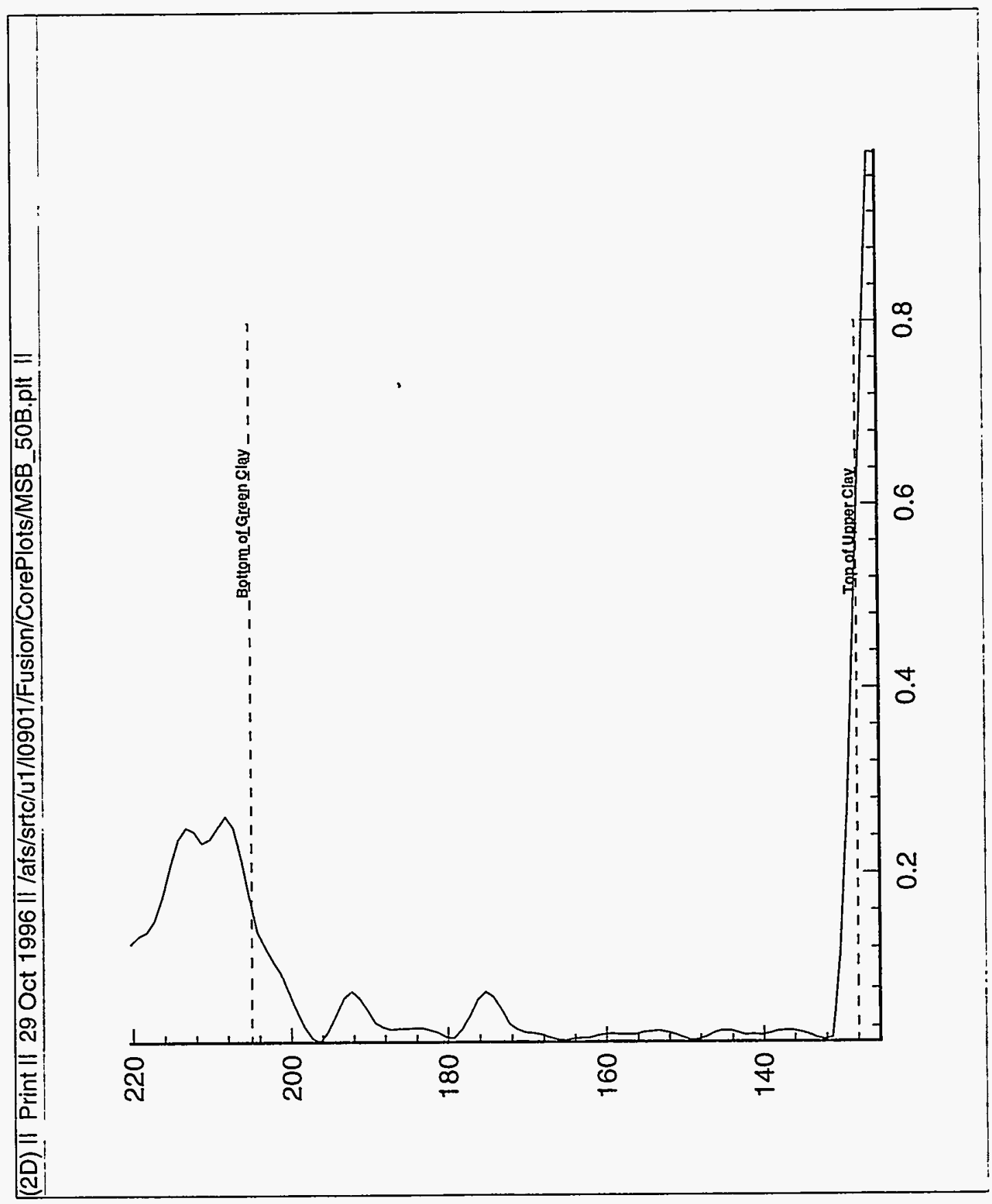




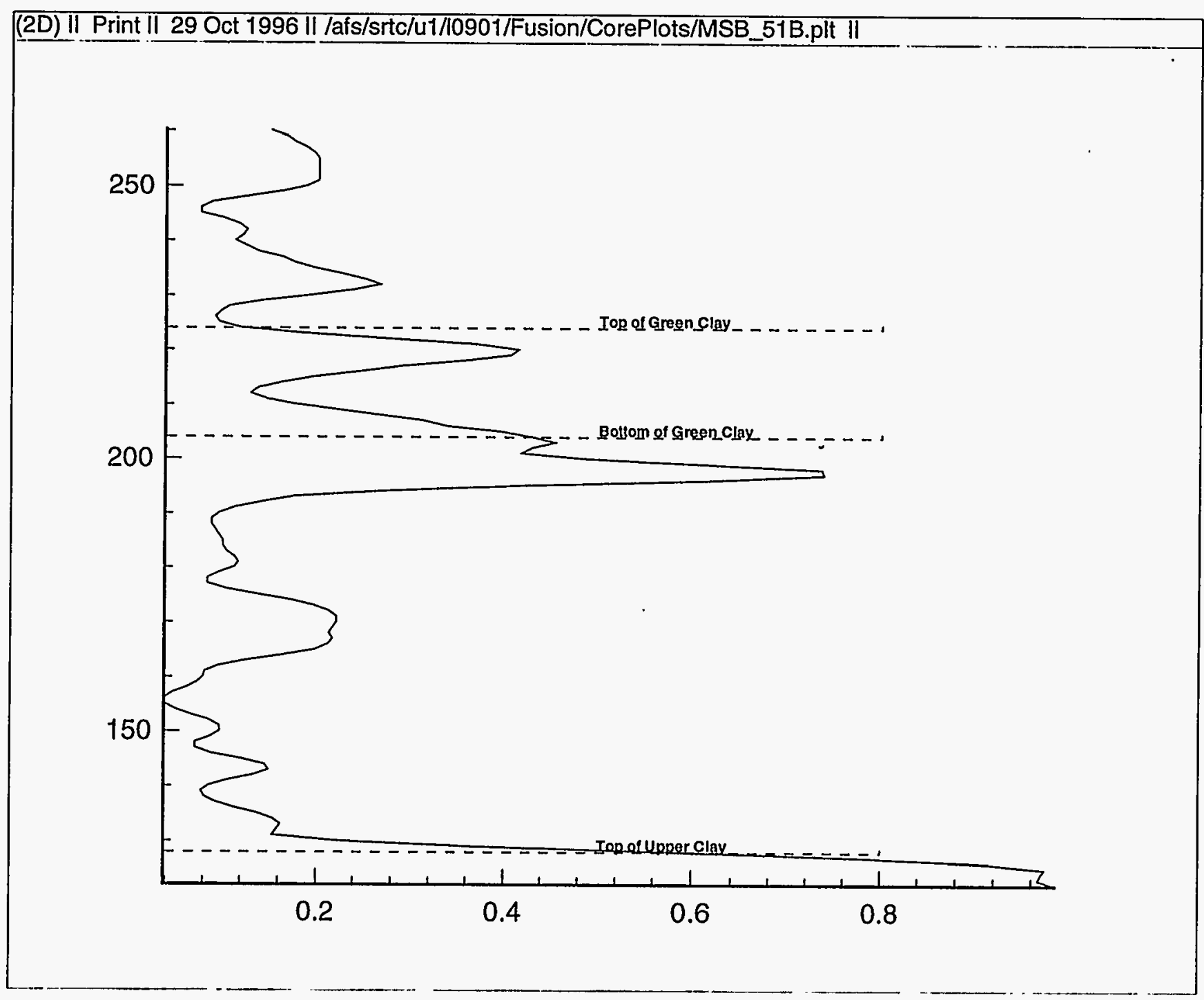




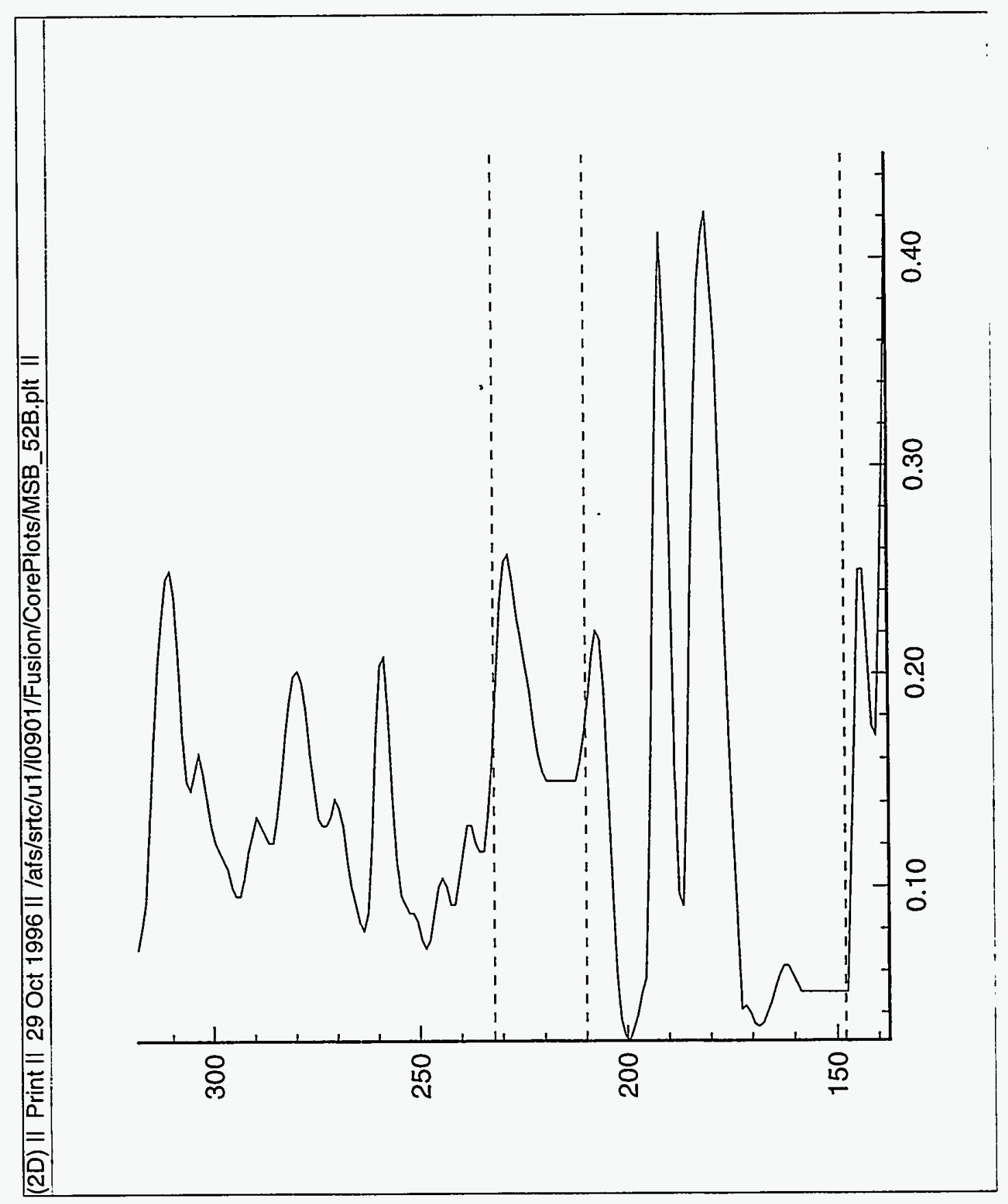




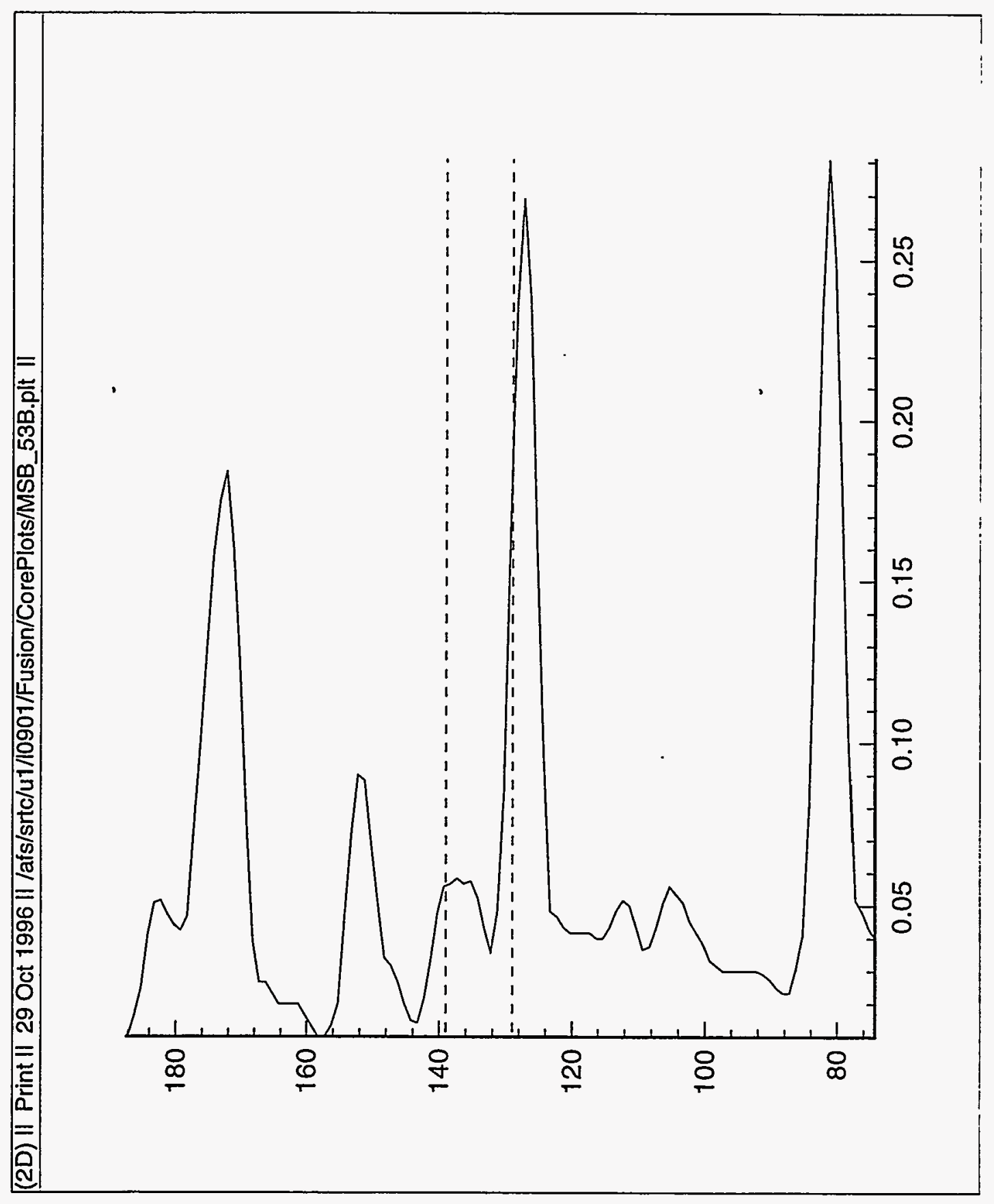




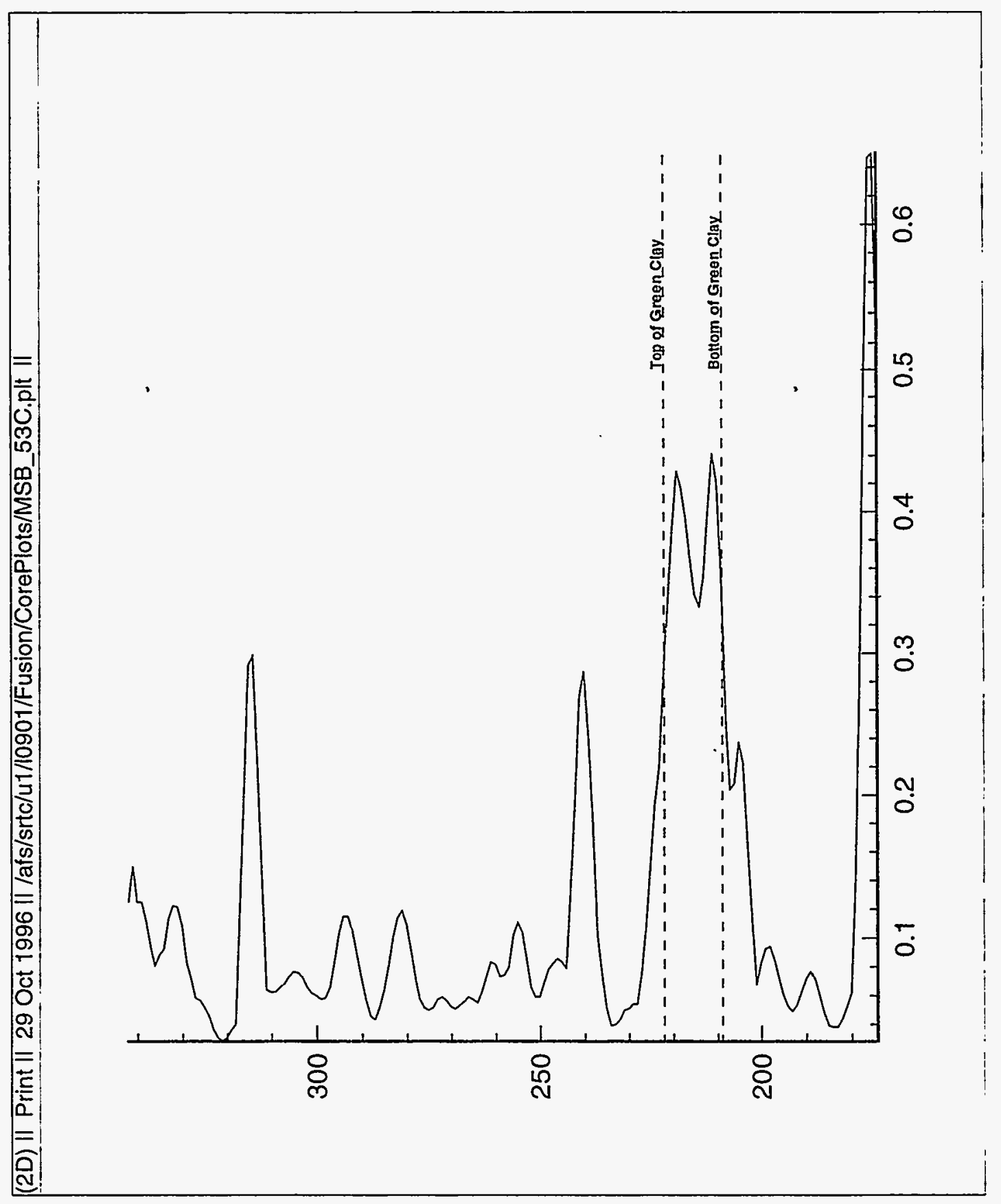




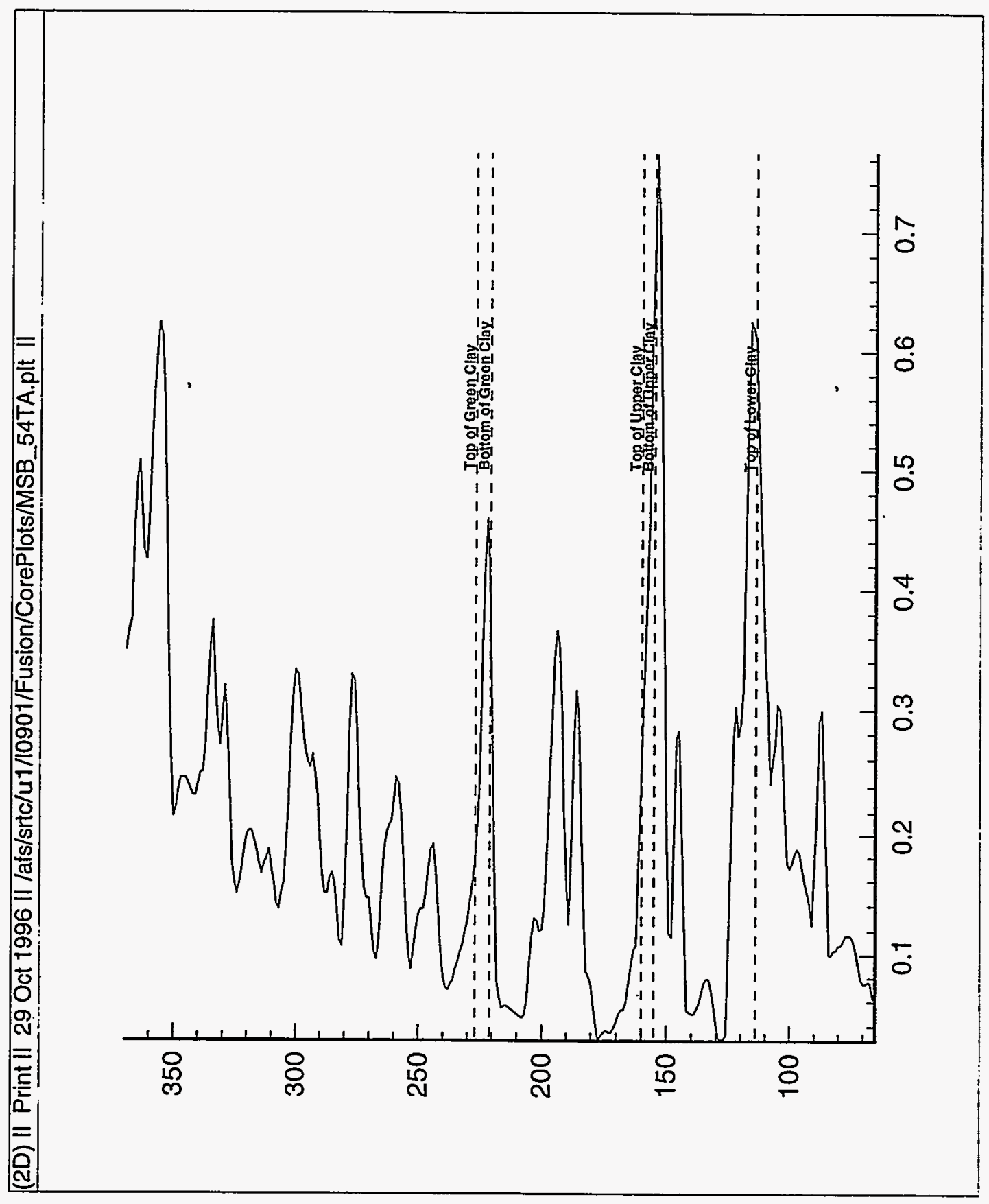




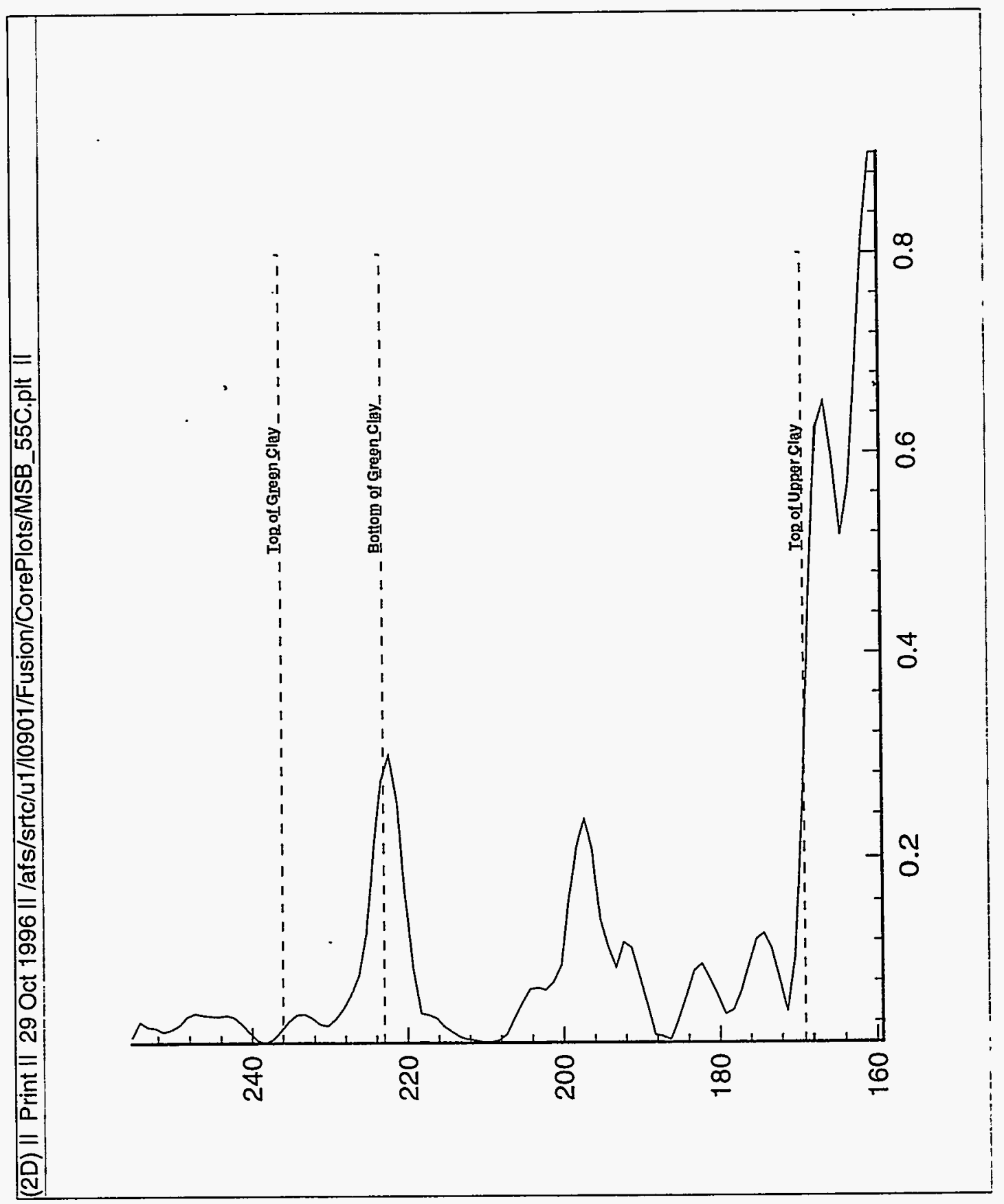




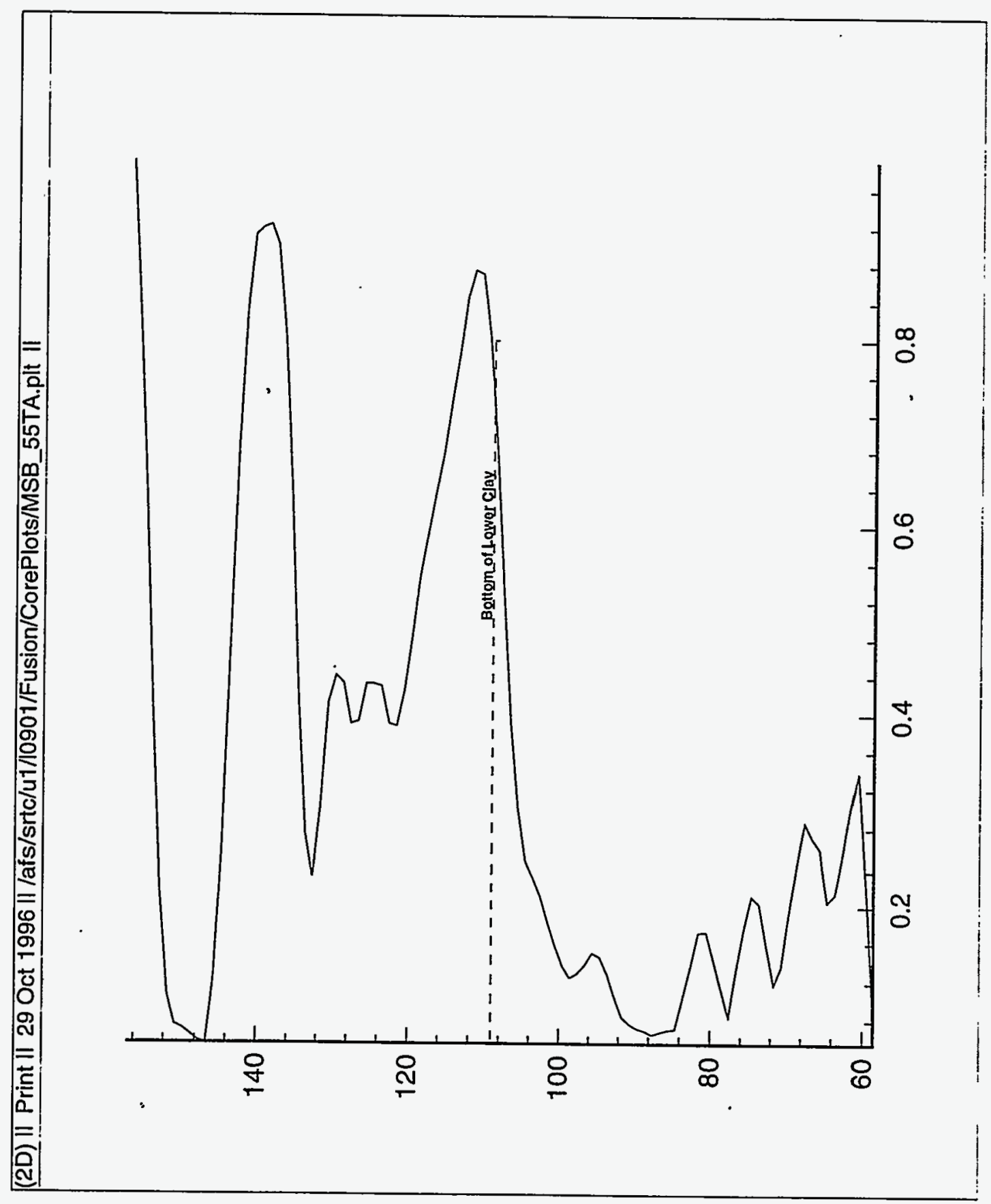




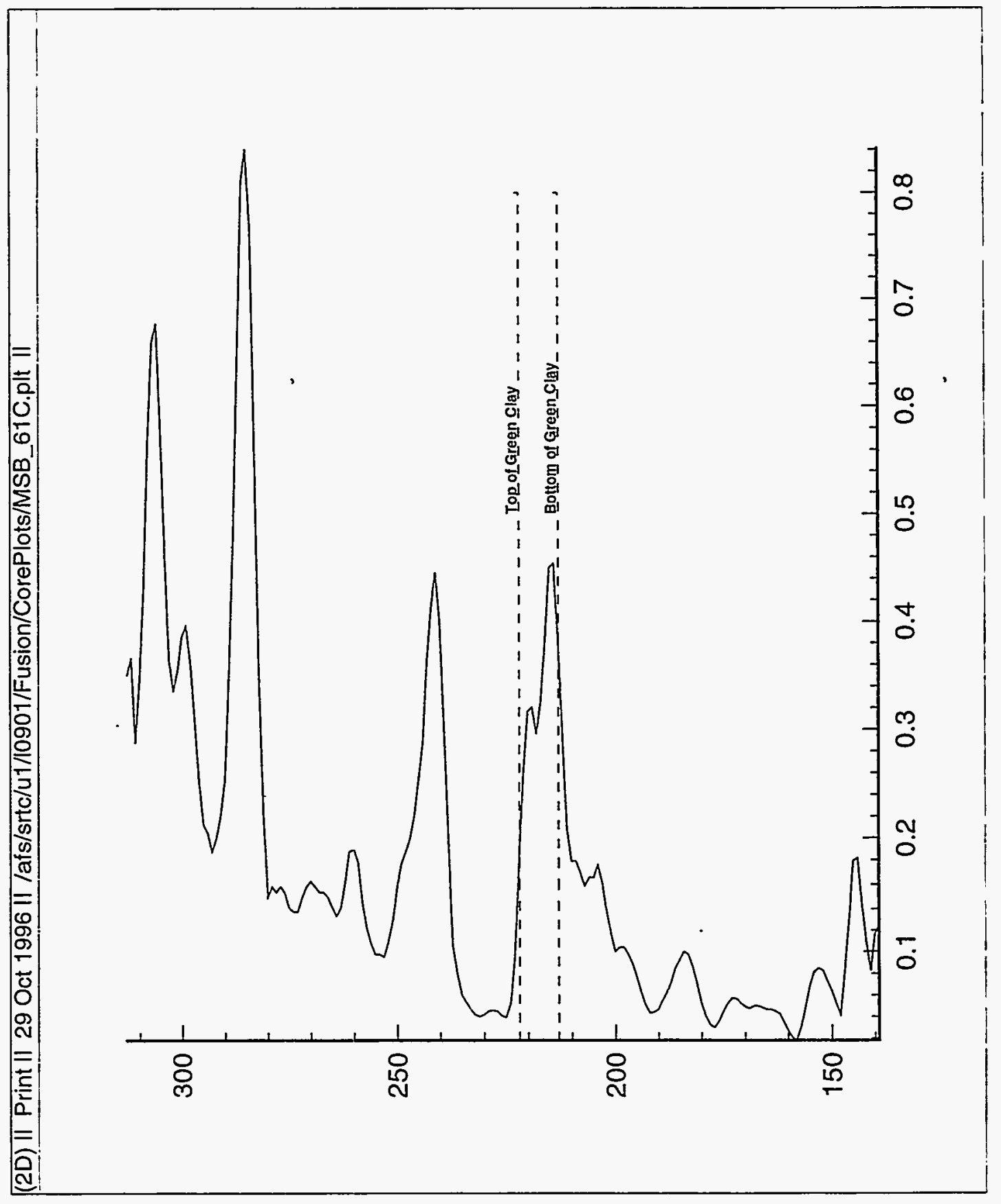




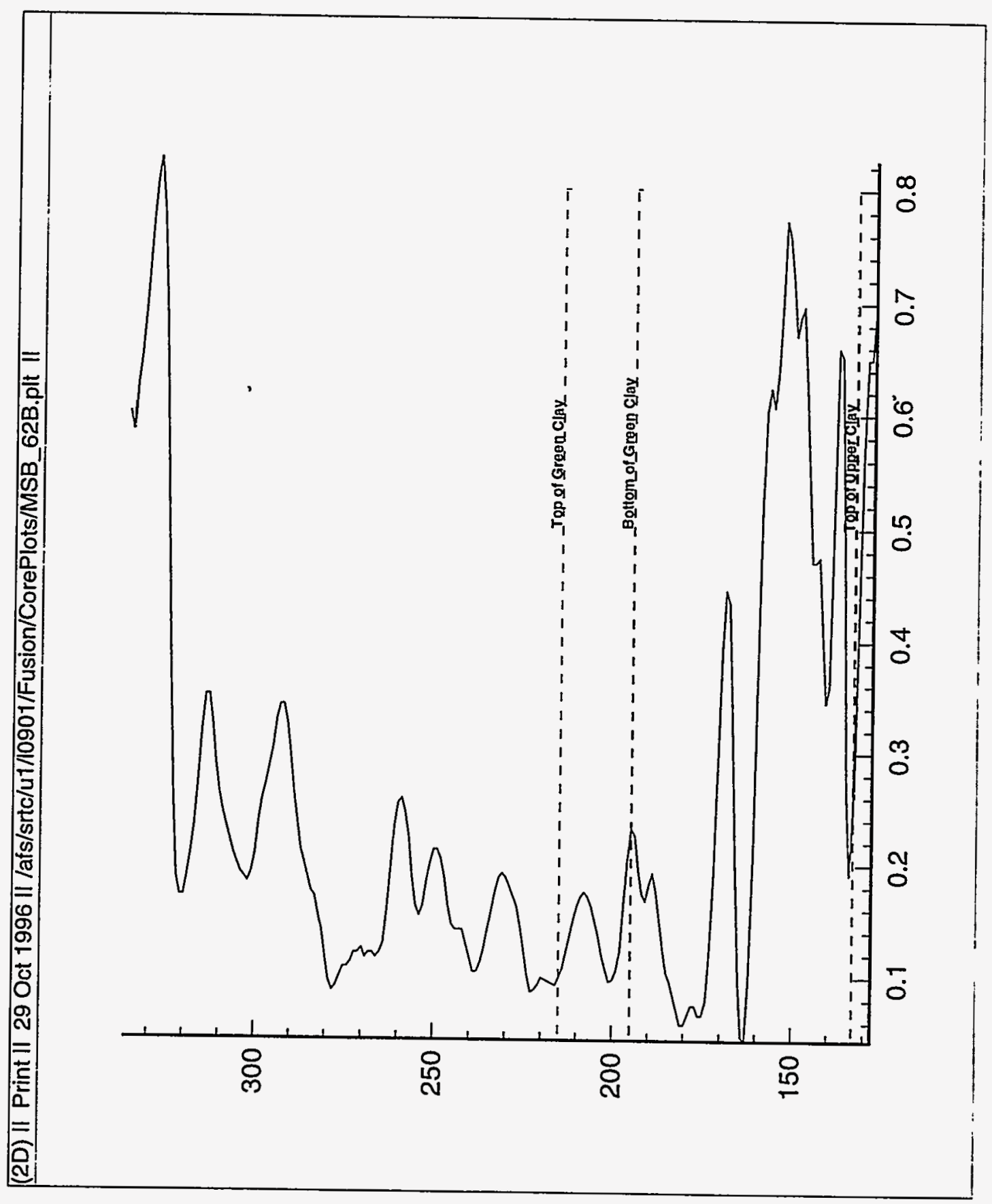




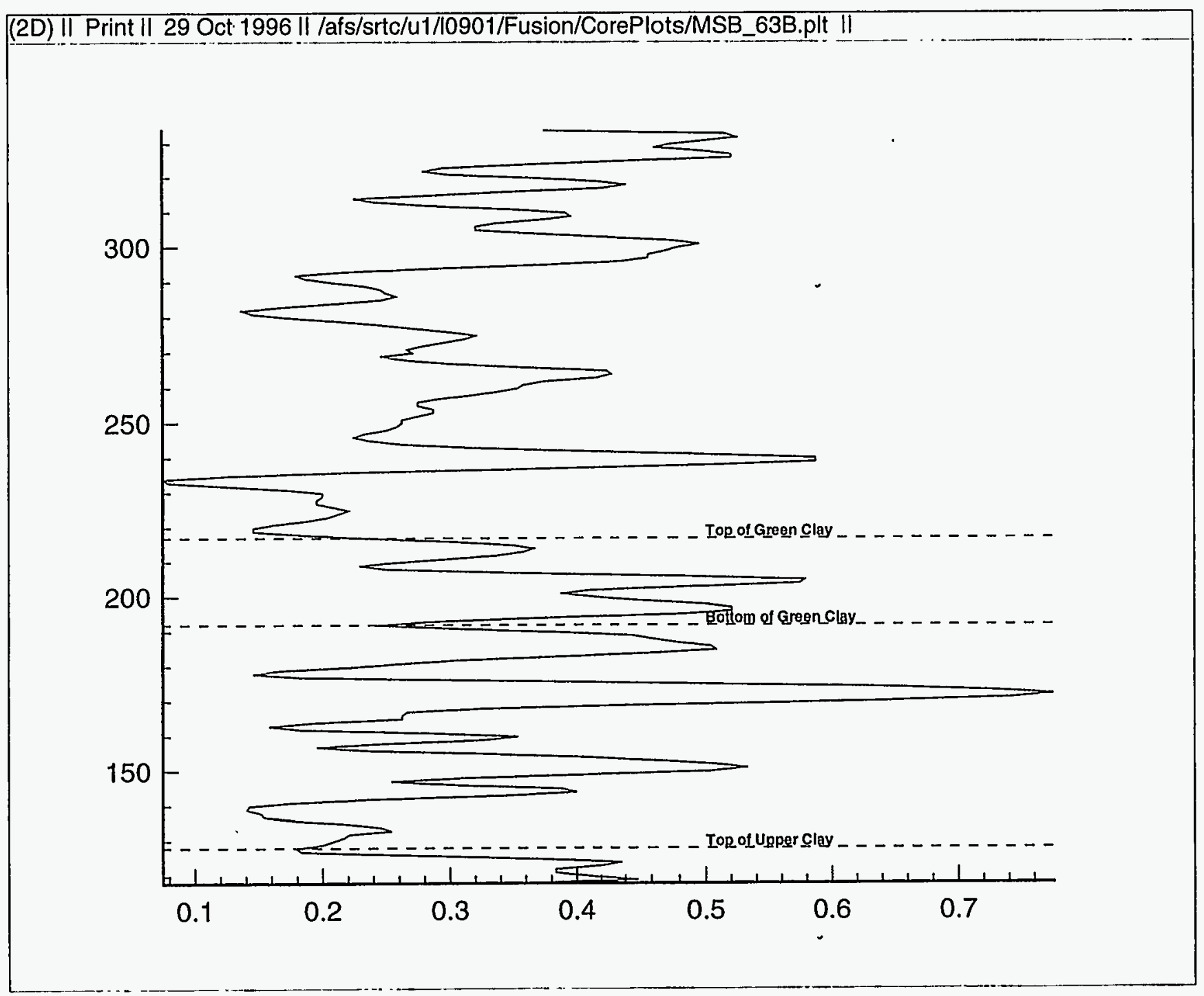




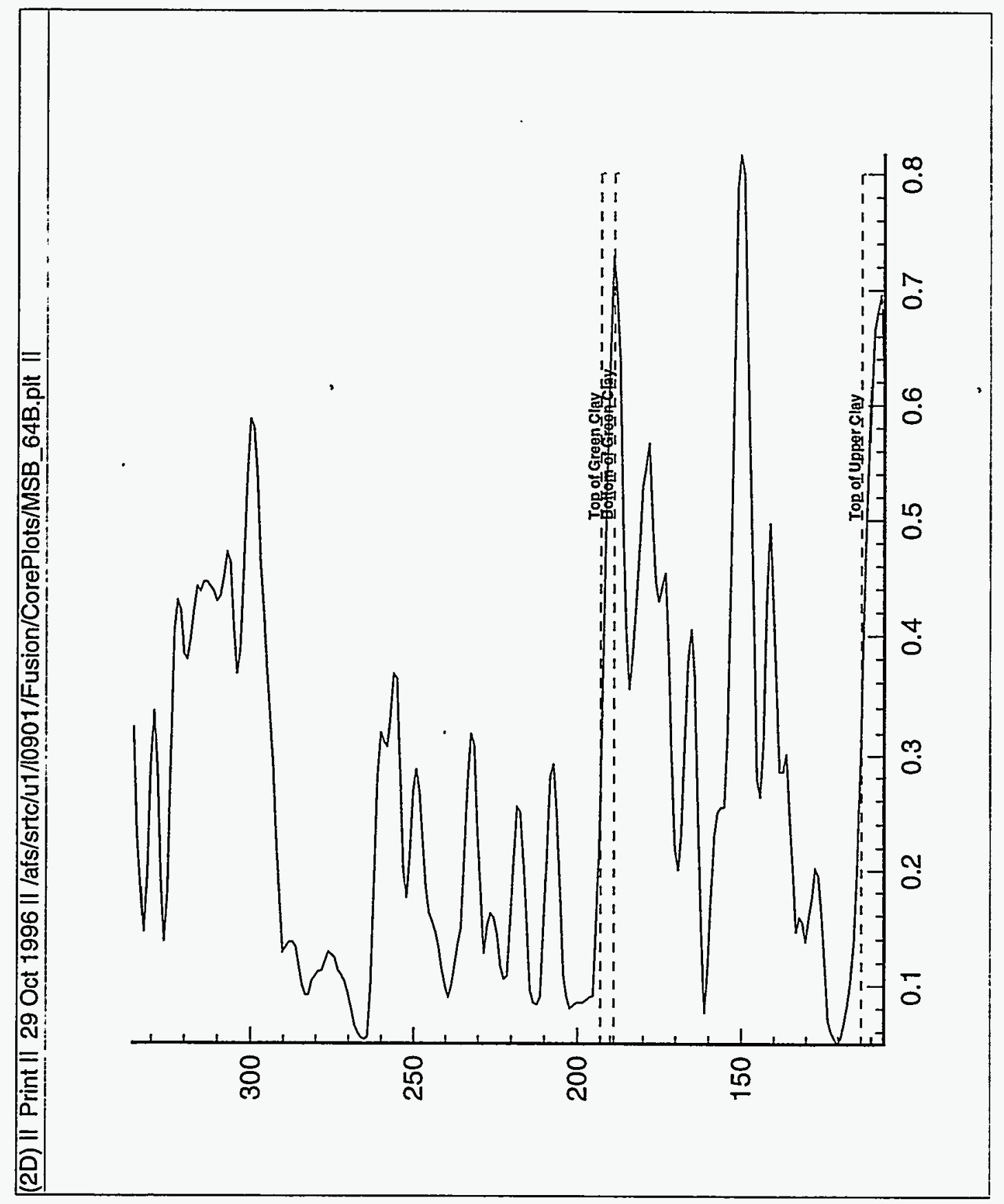




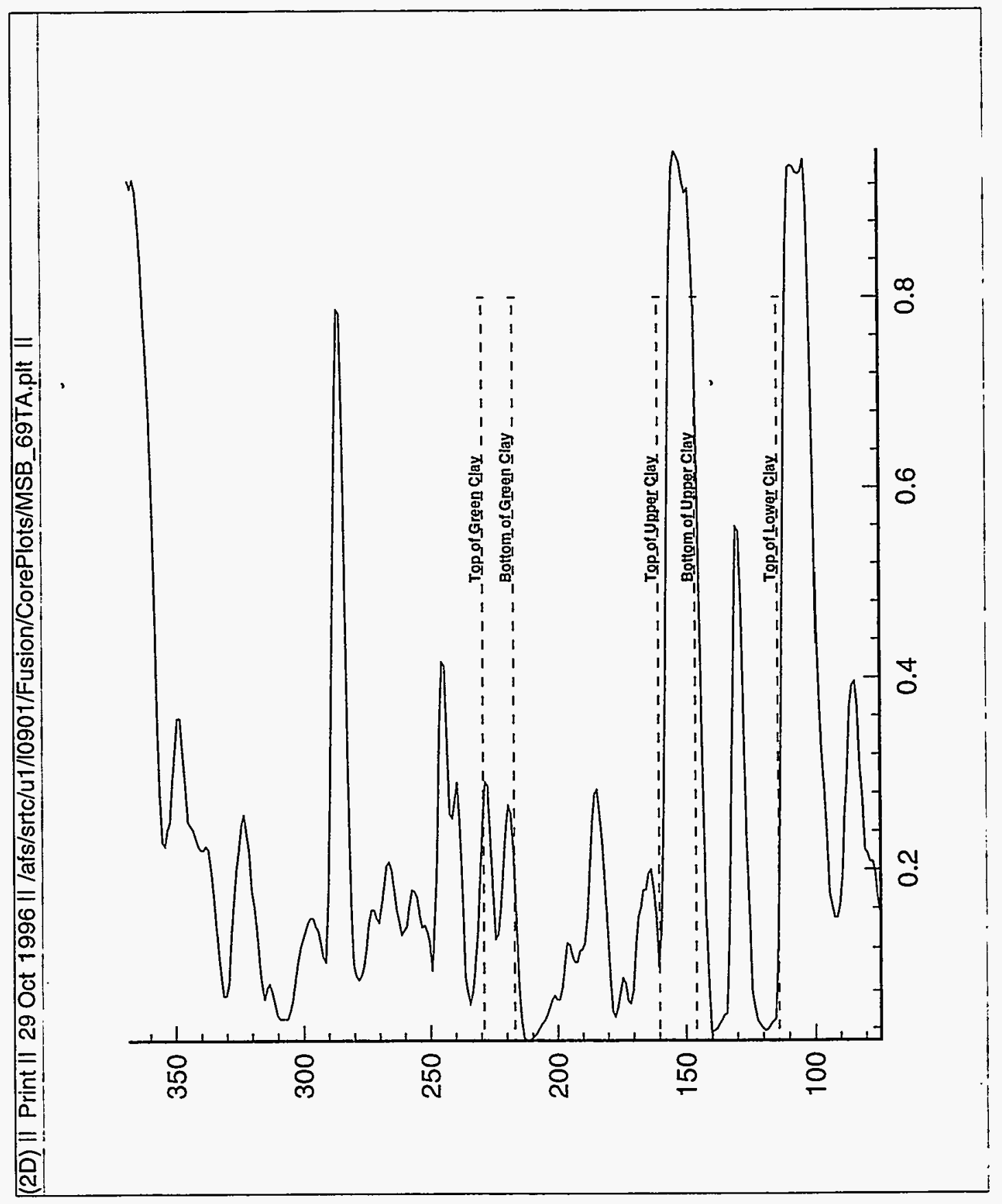




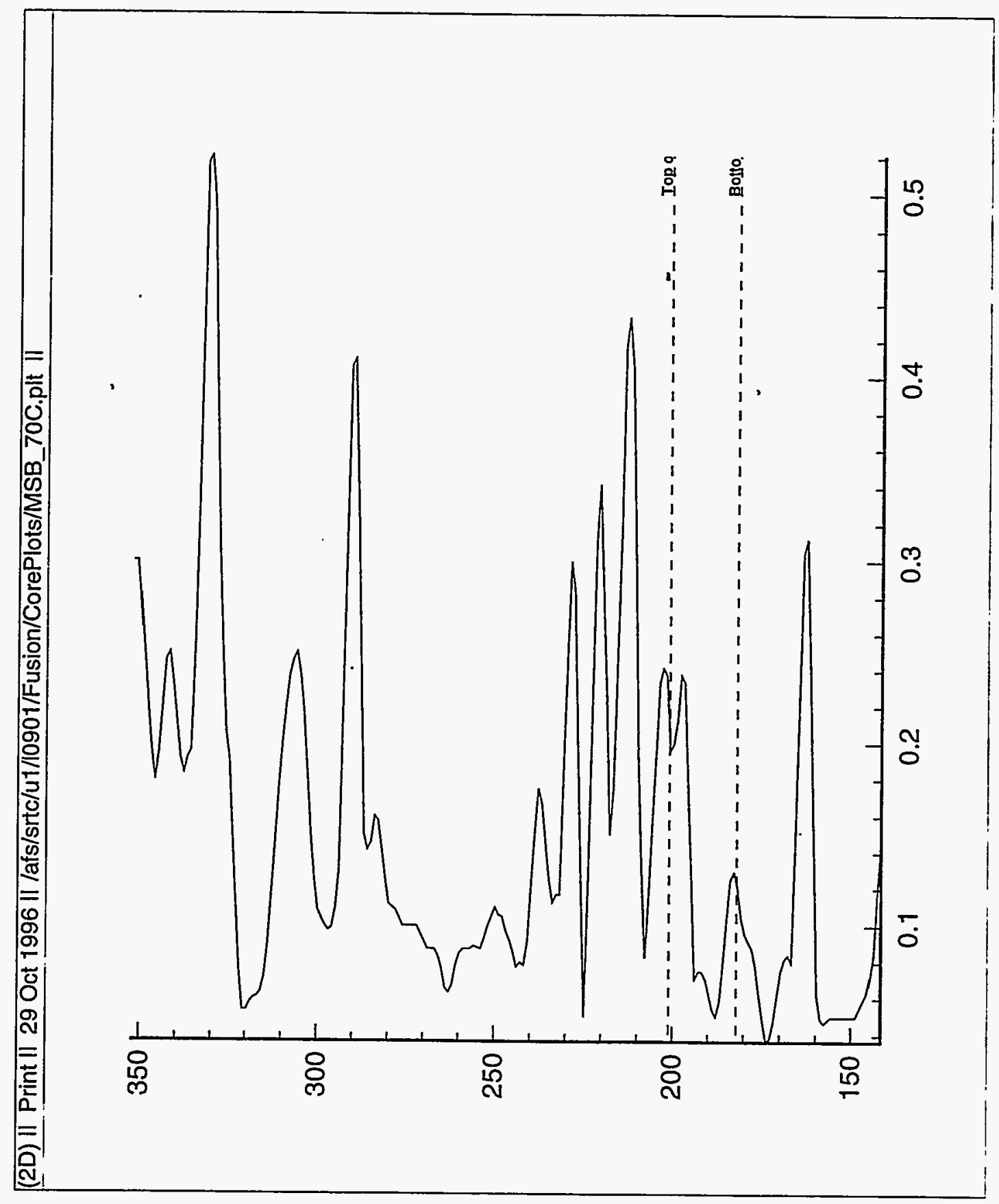




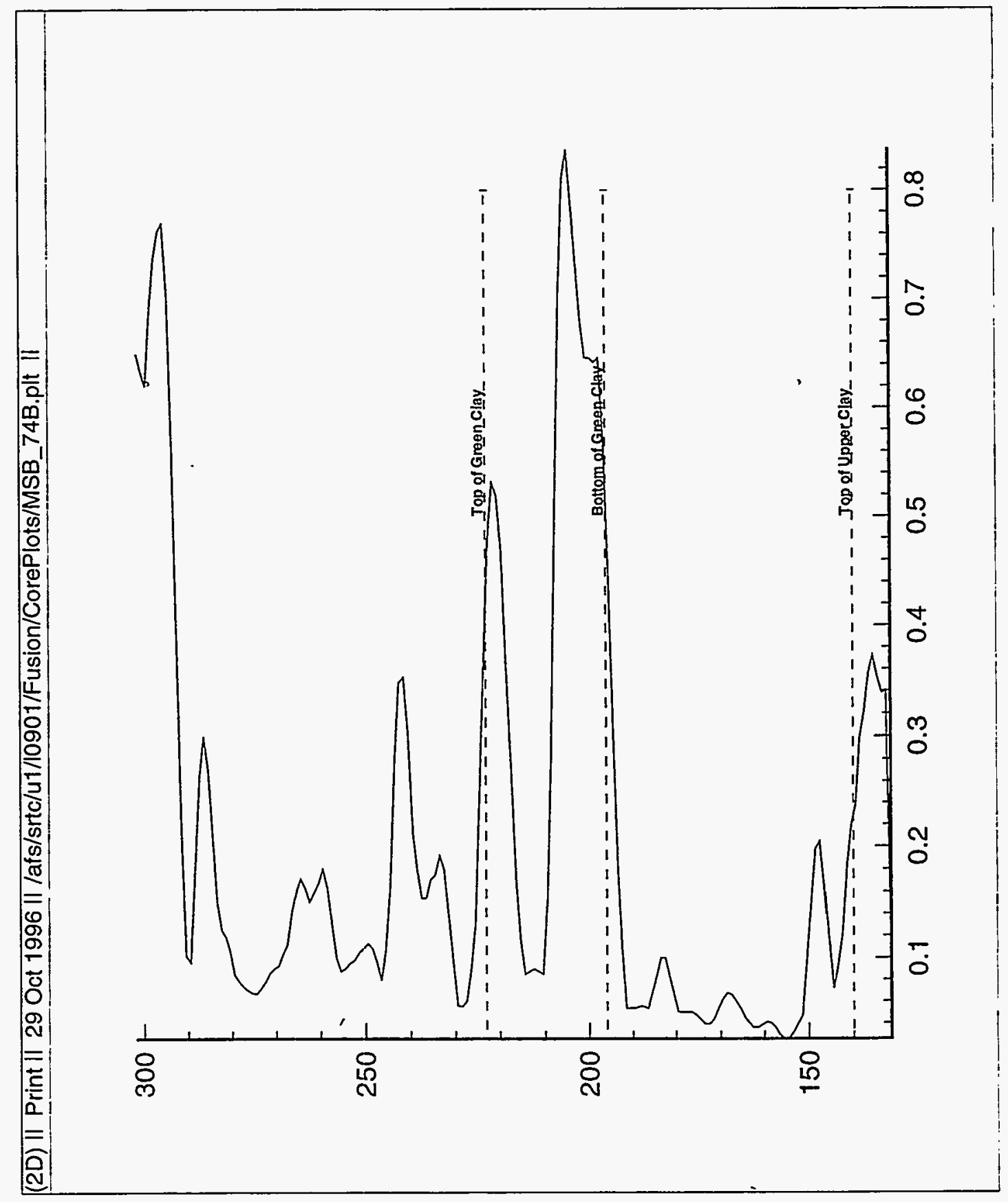




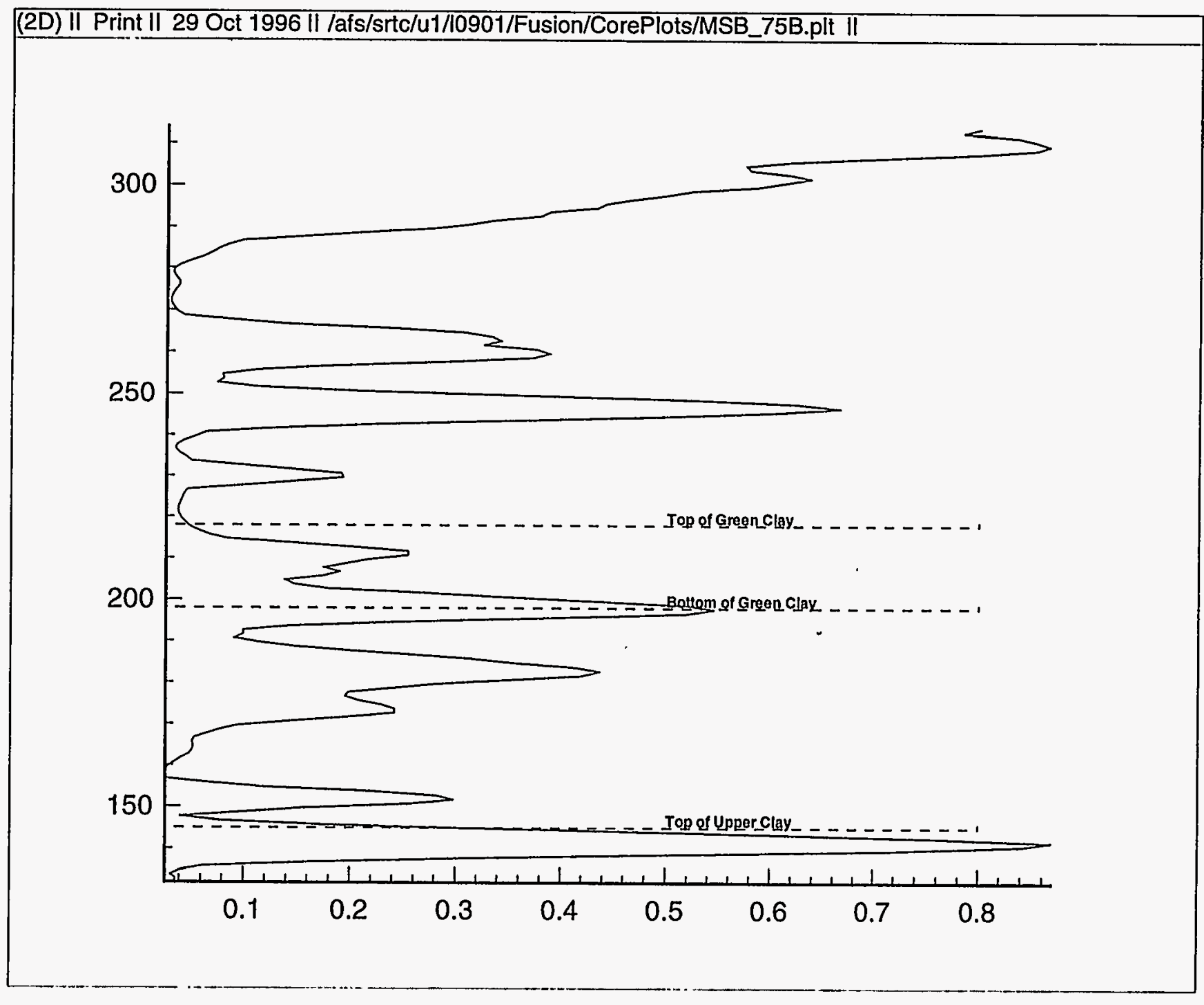




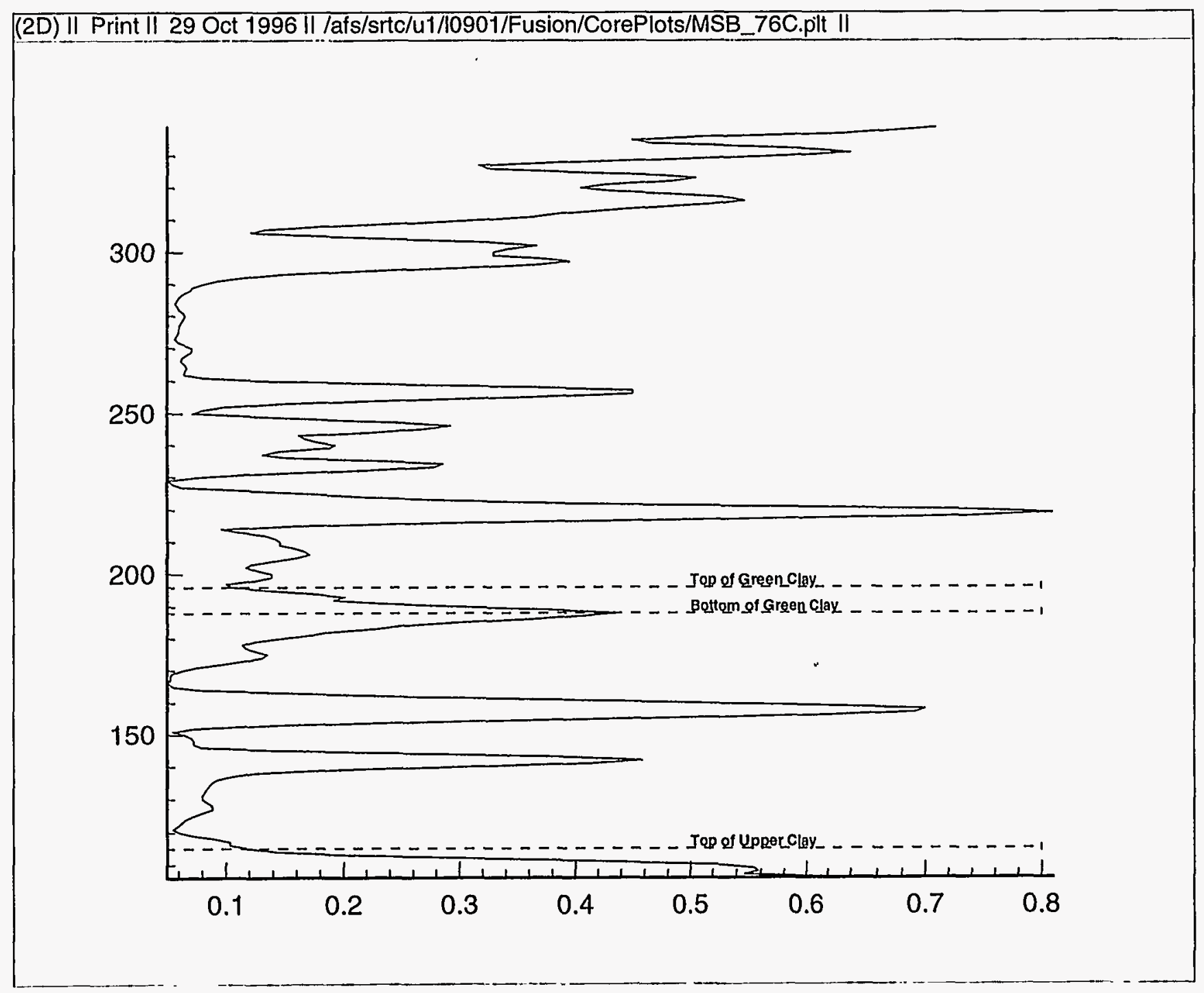




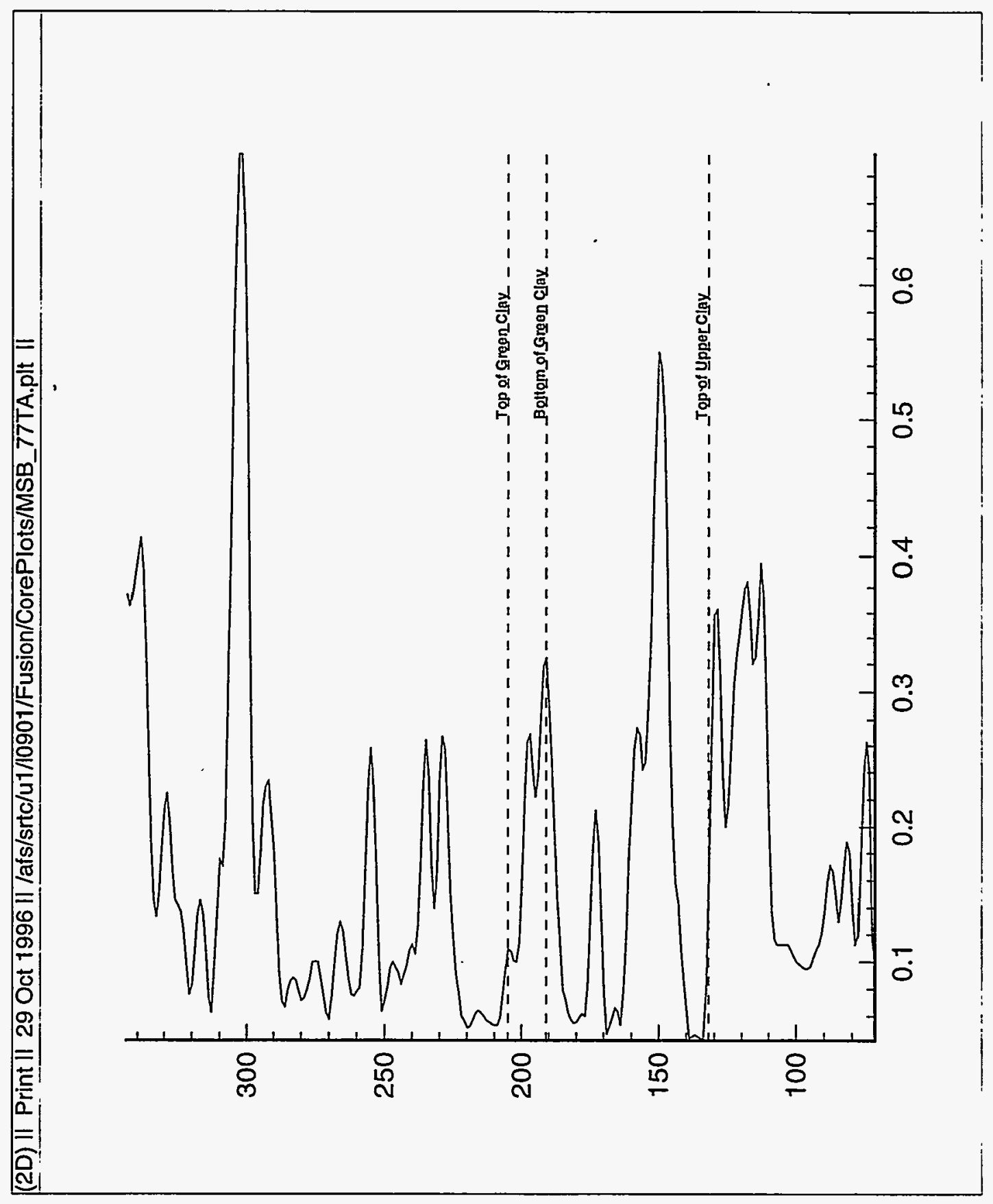




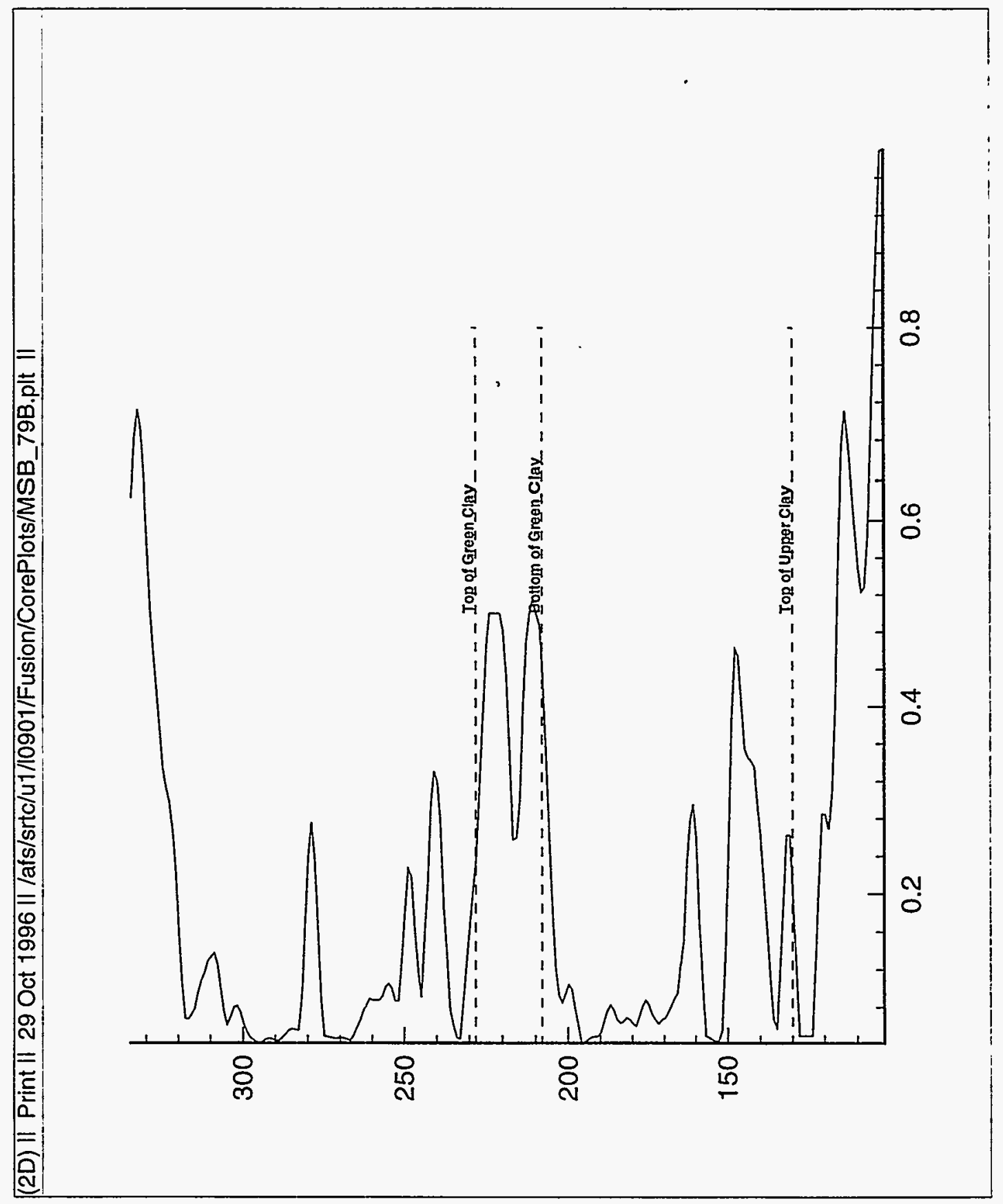




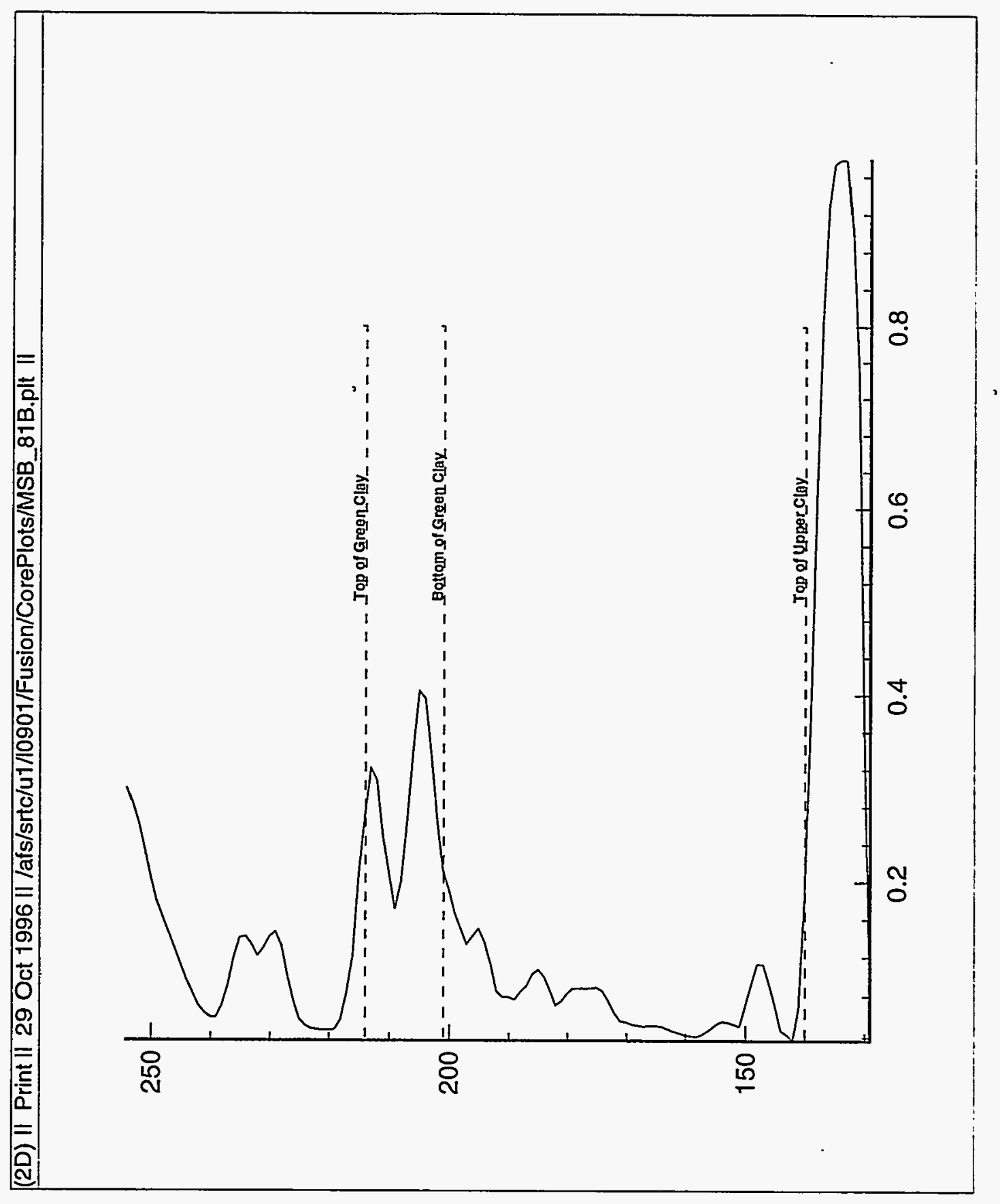




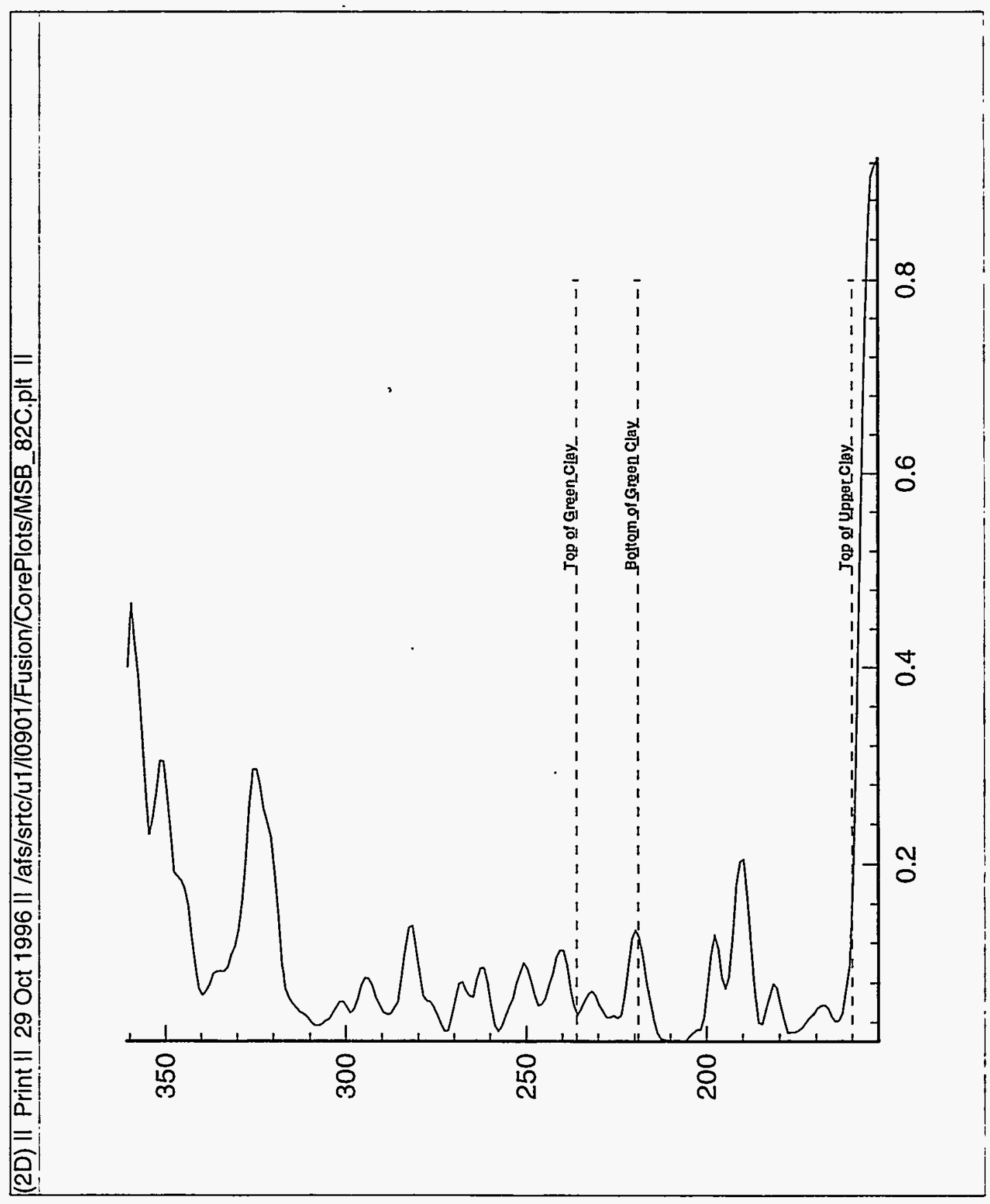




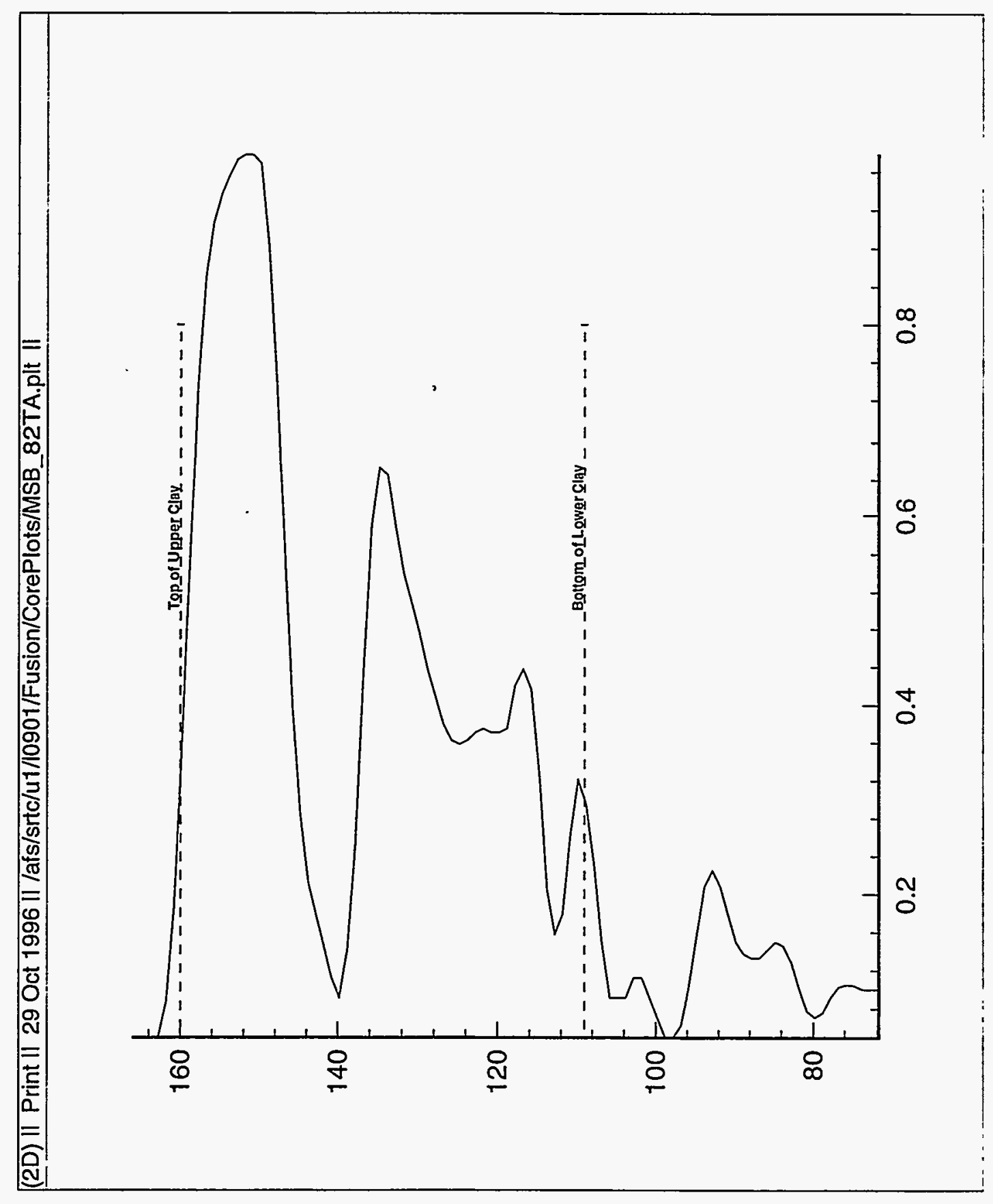




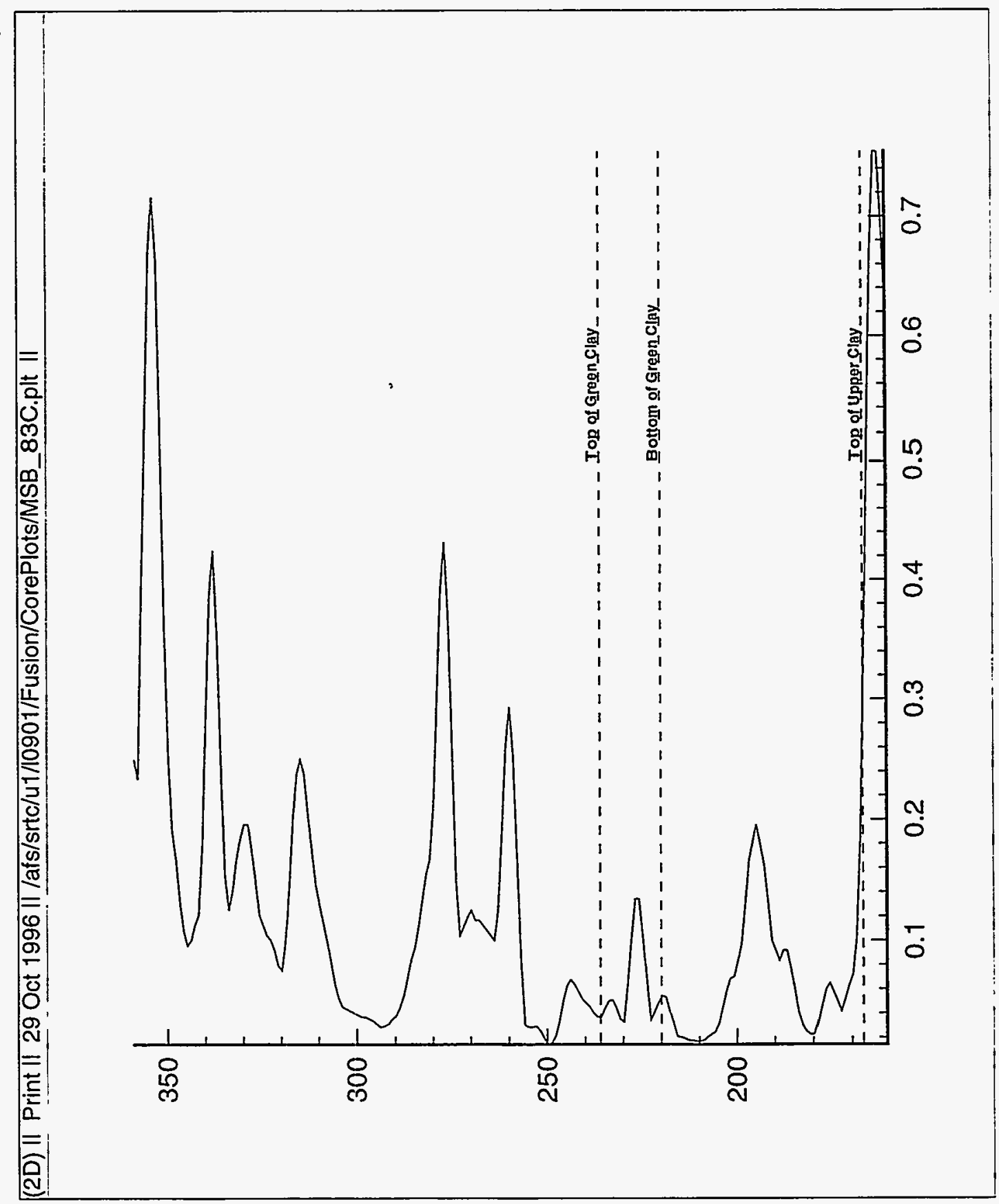




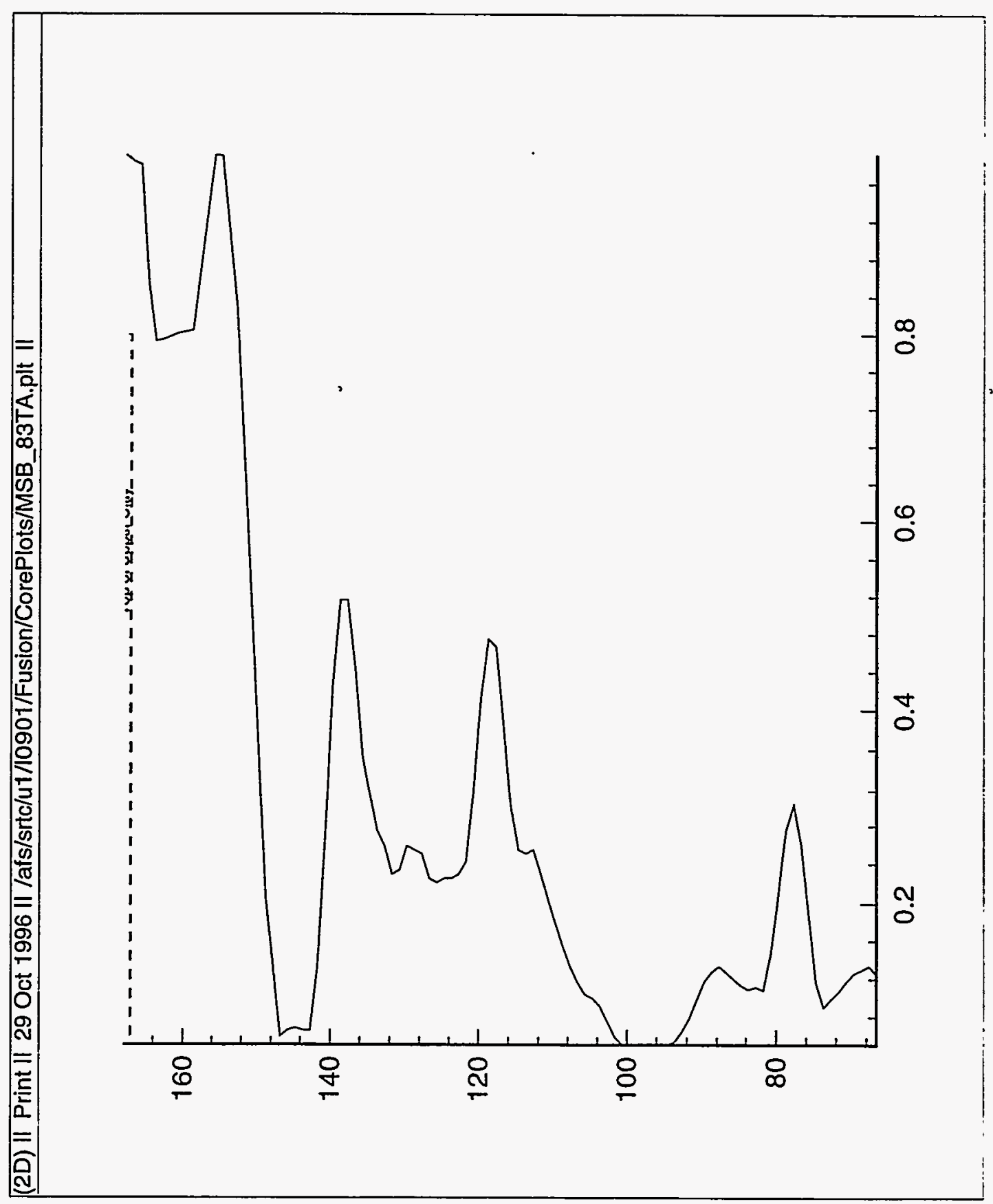




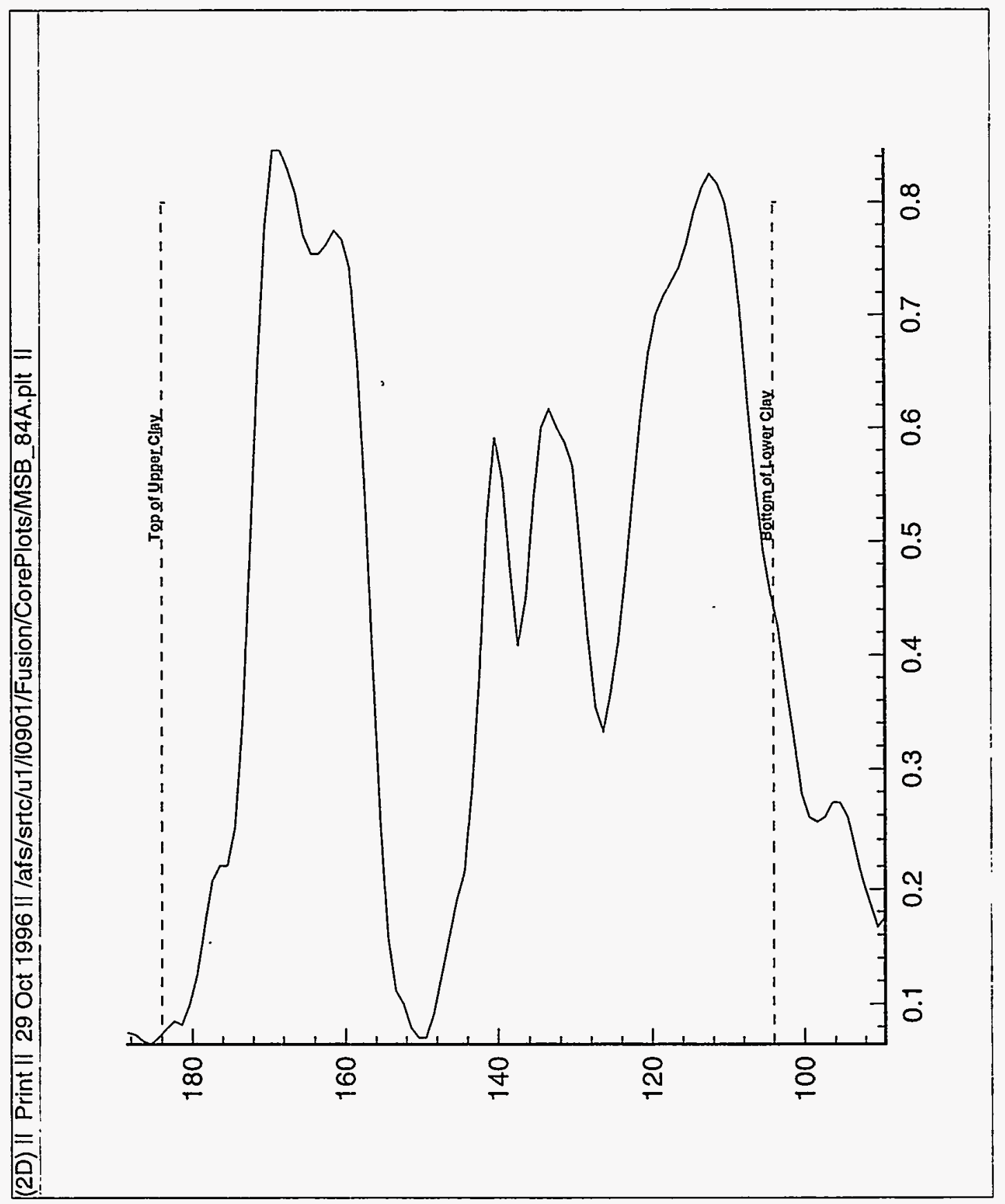




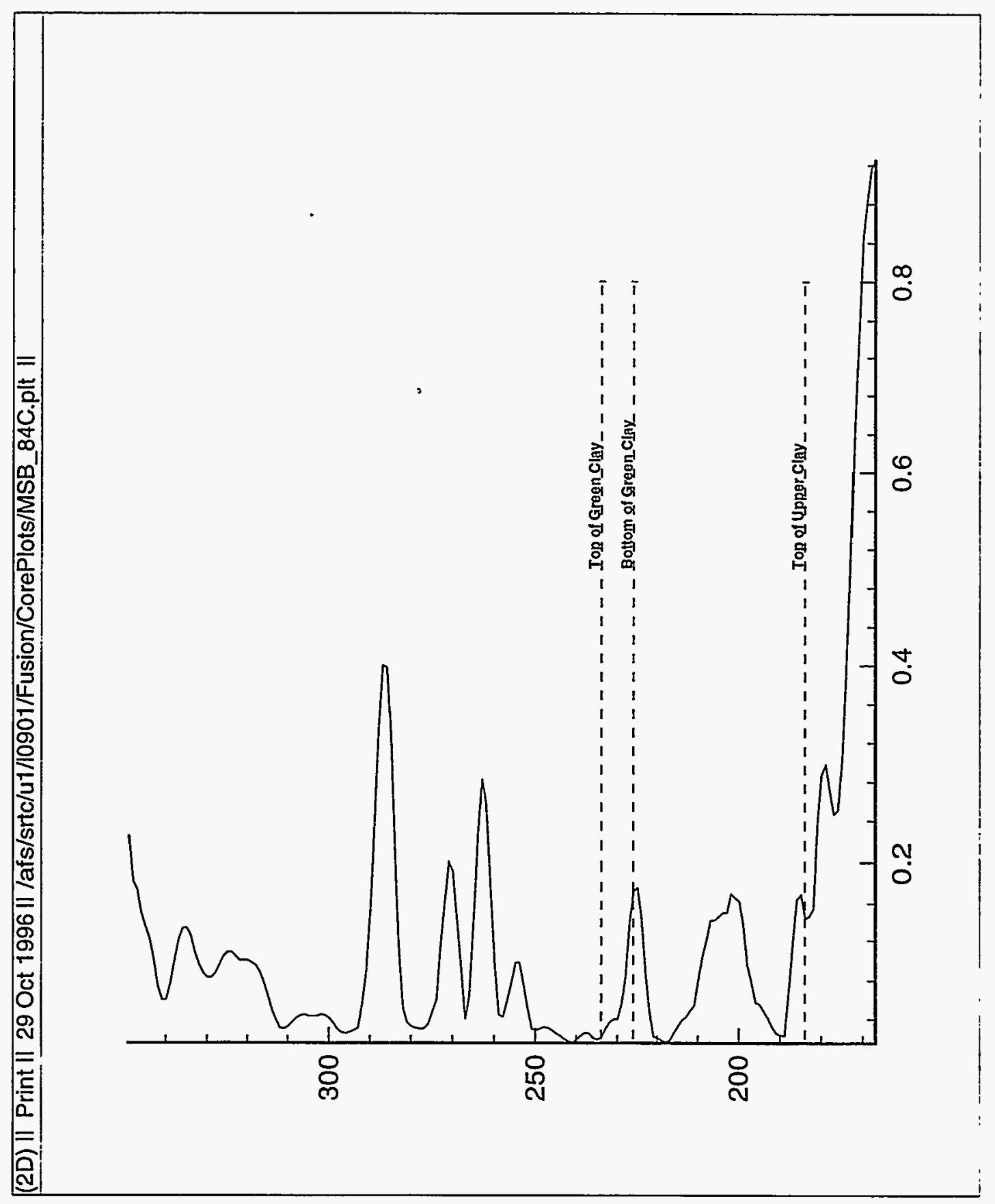




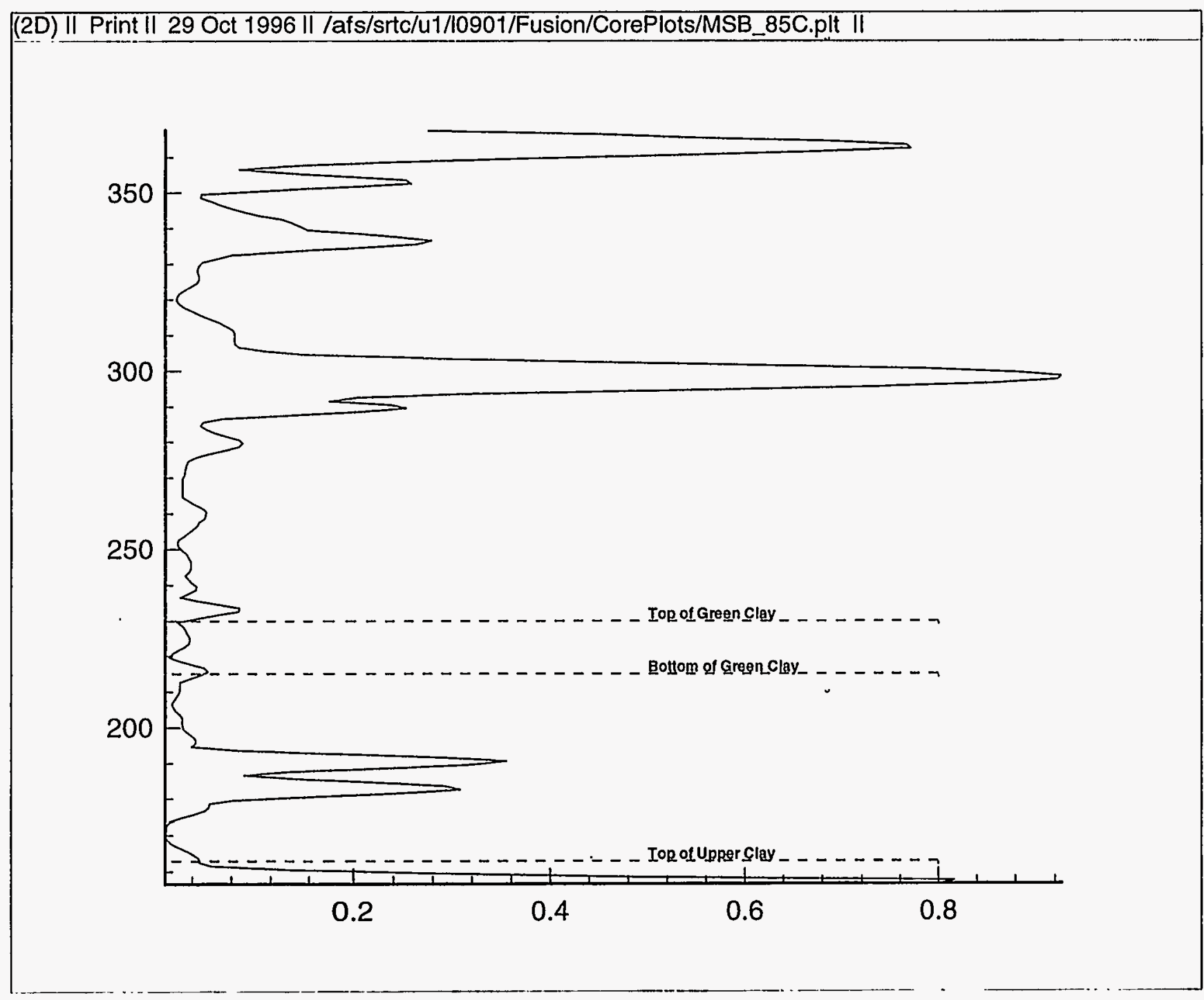




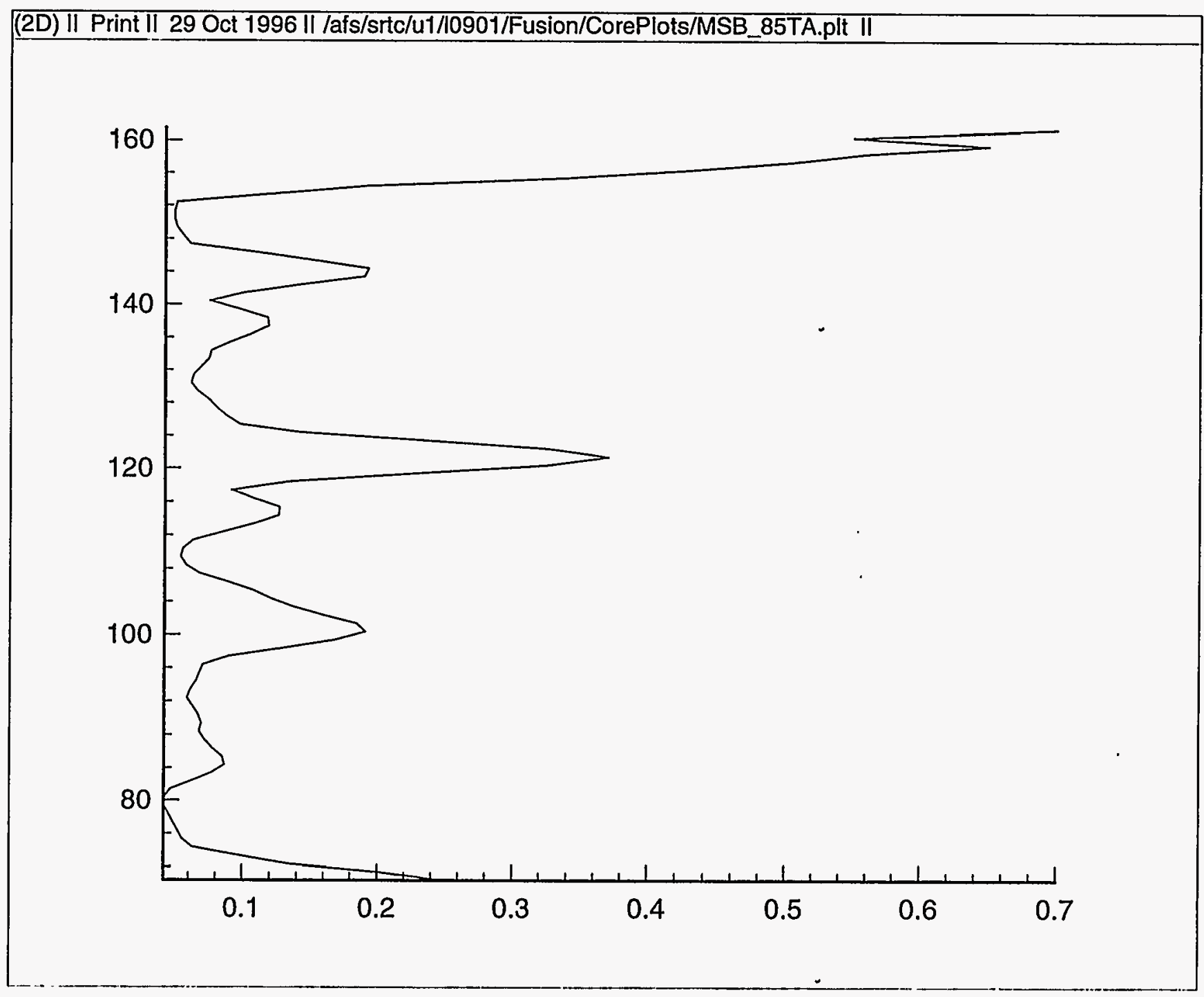




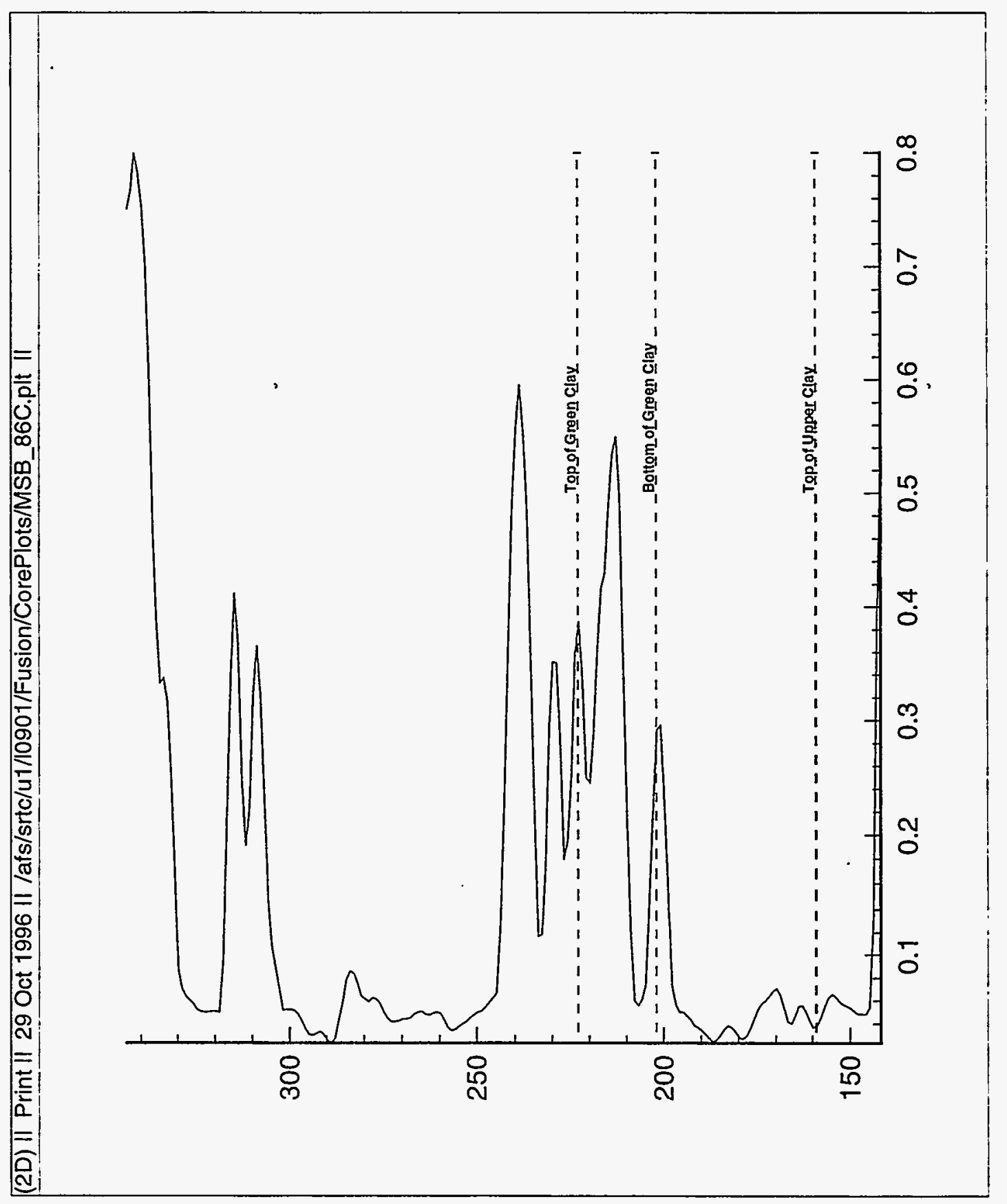




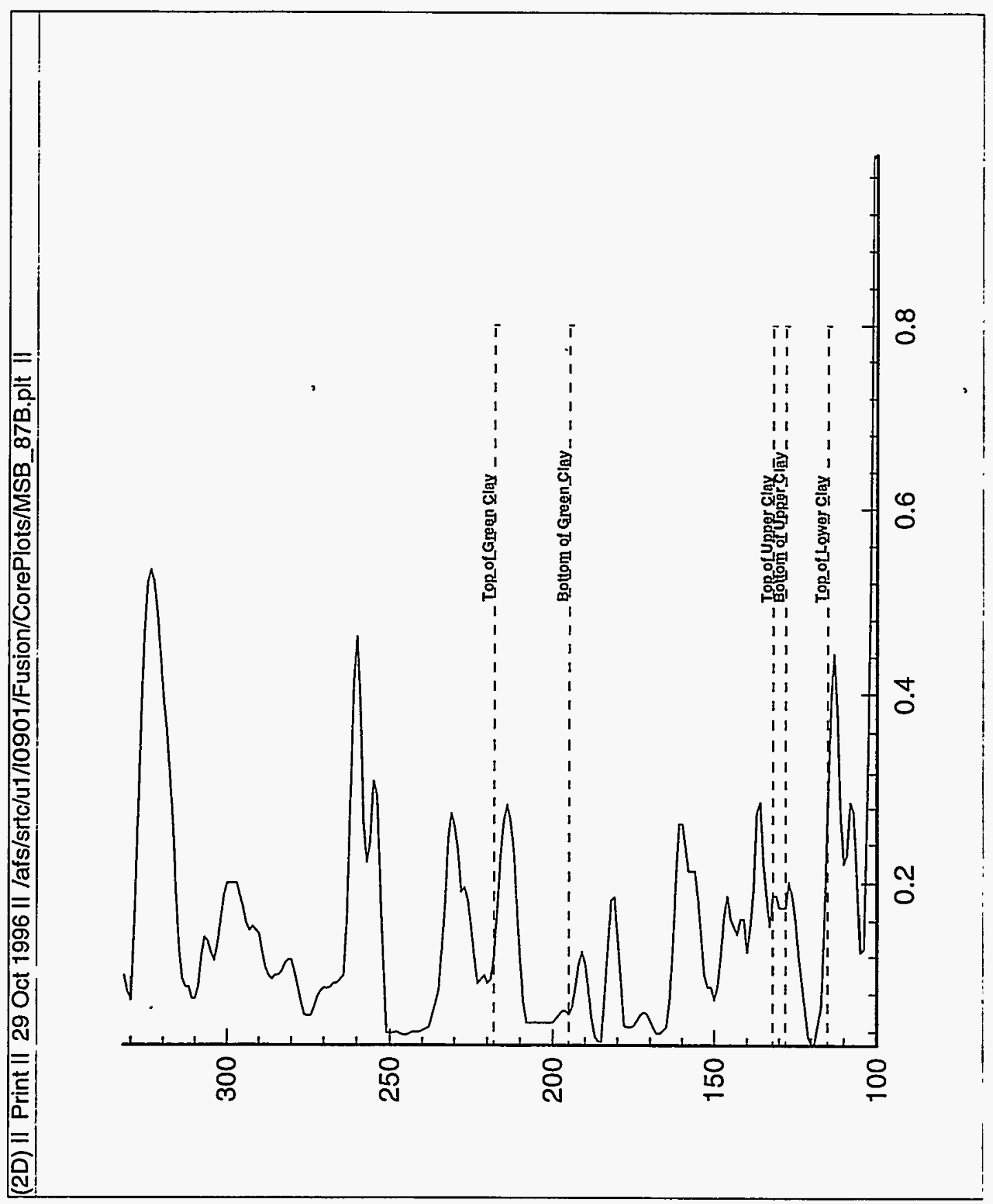




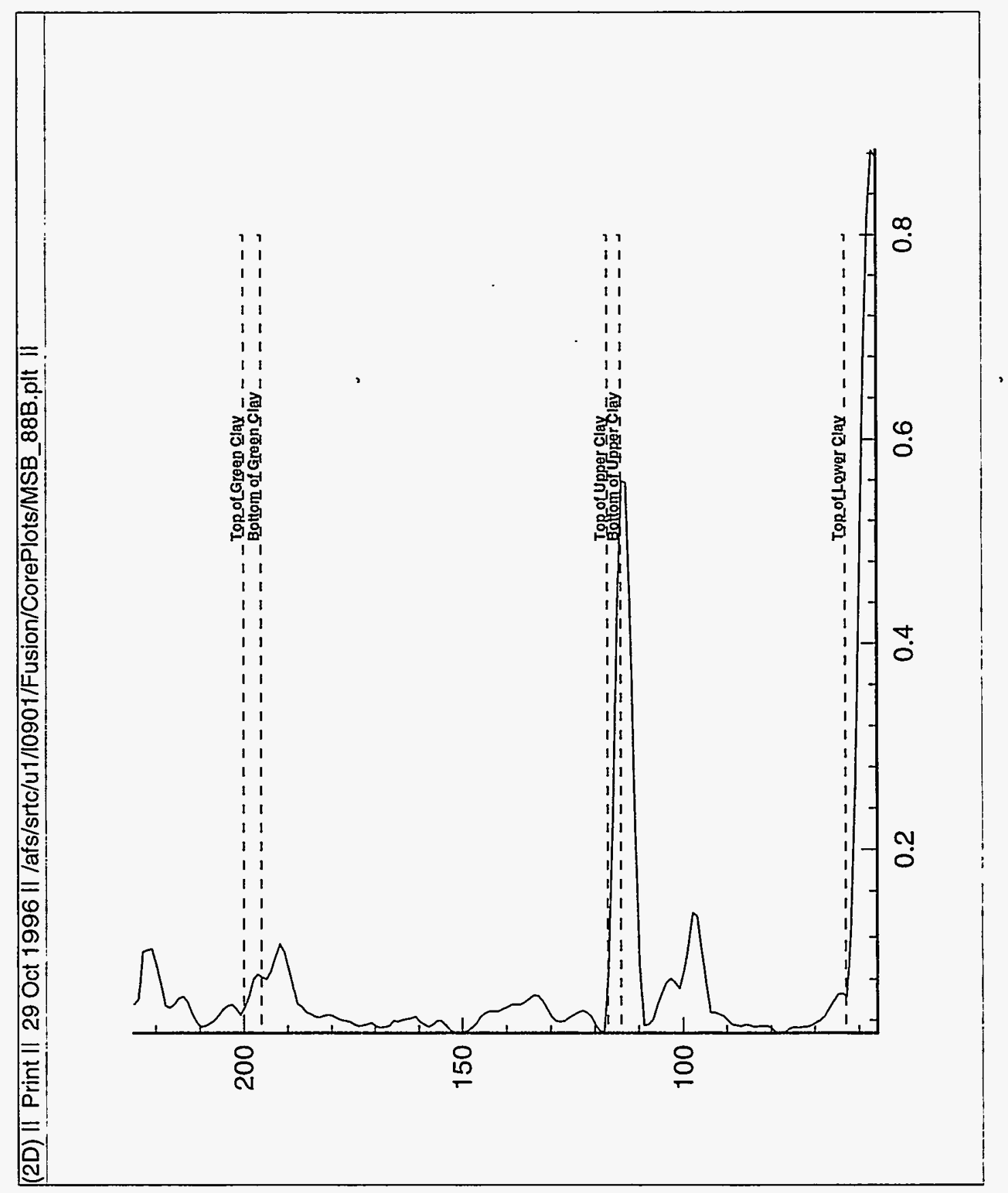




$$
\text { LwW }
$$




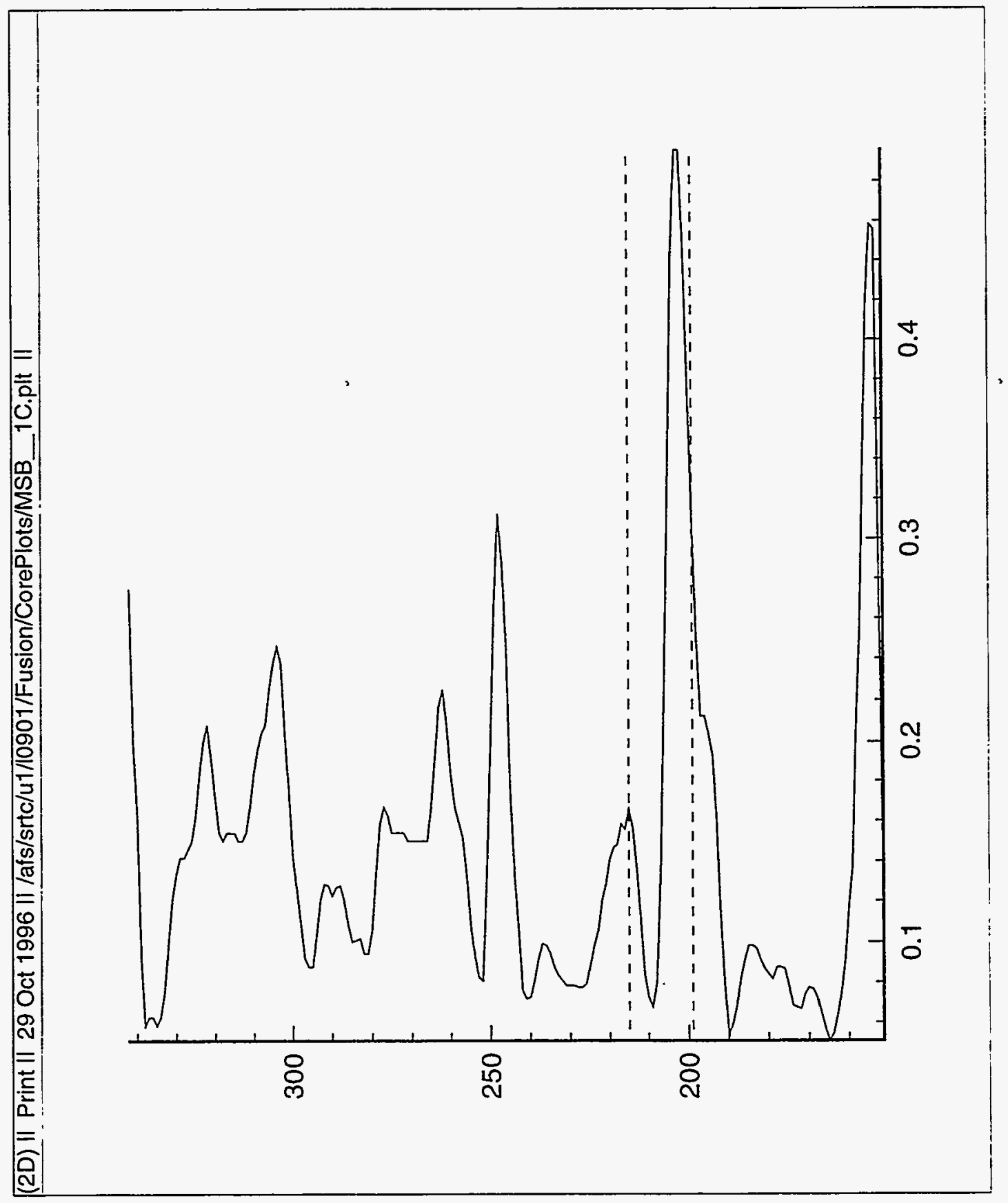




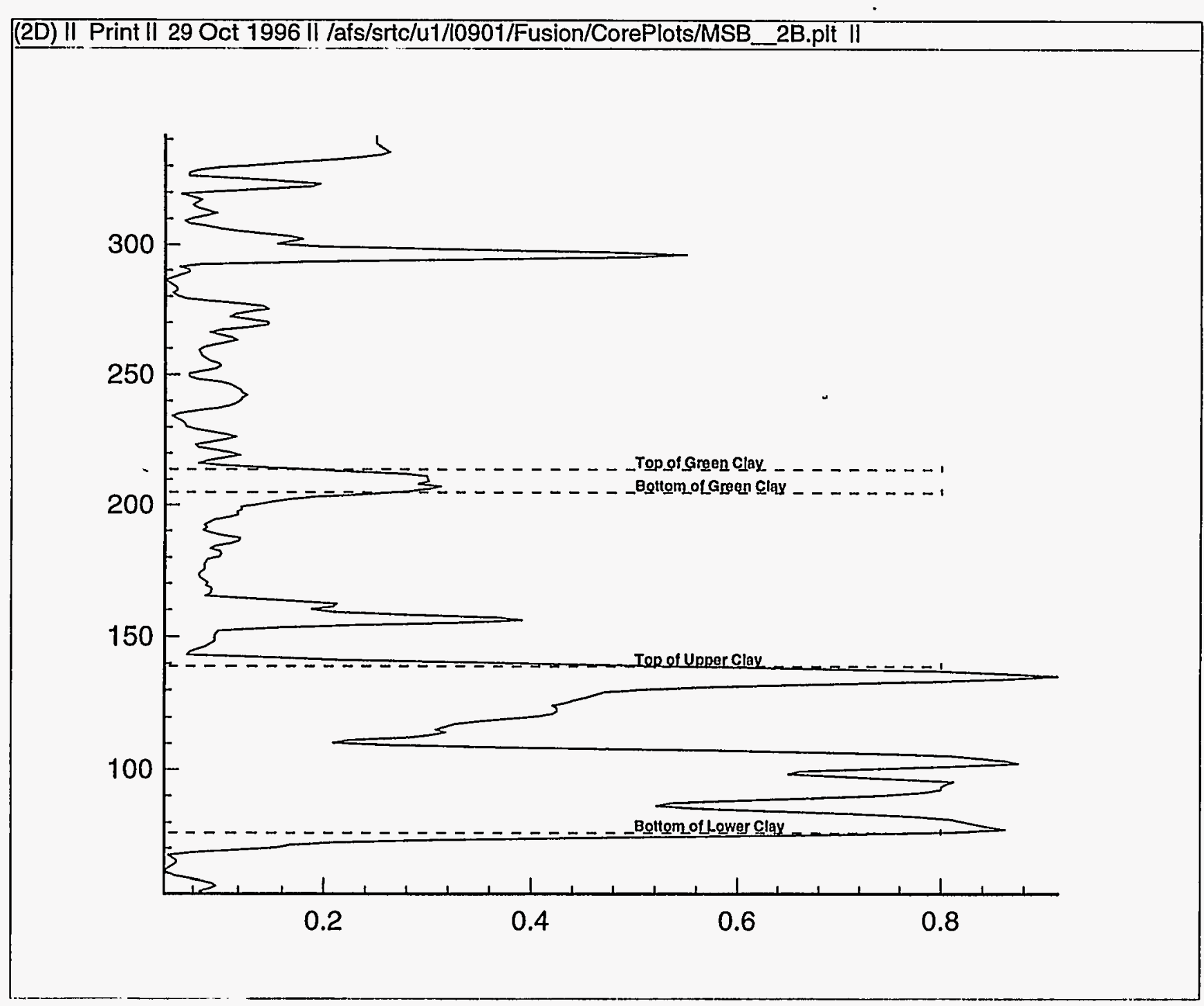




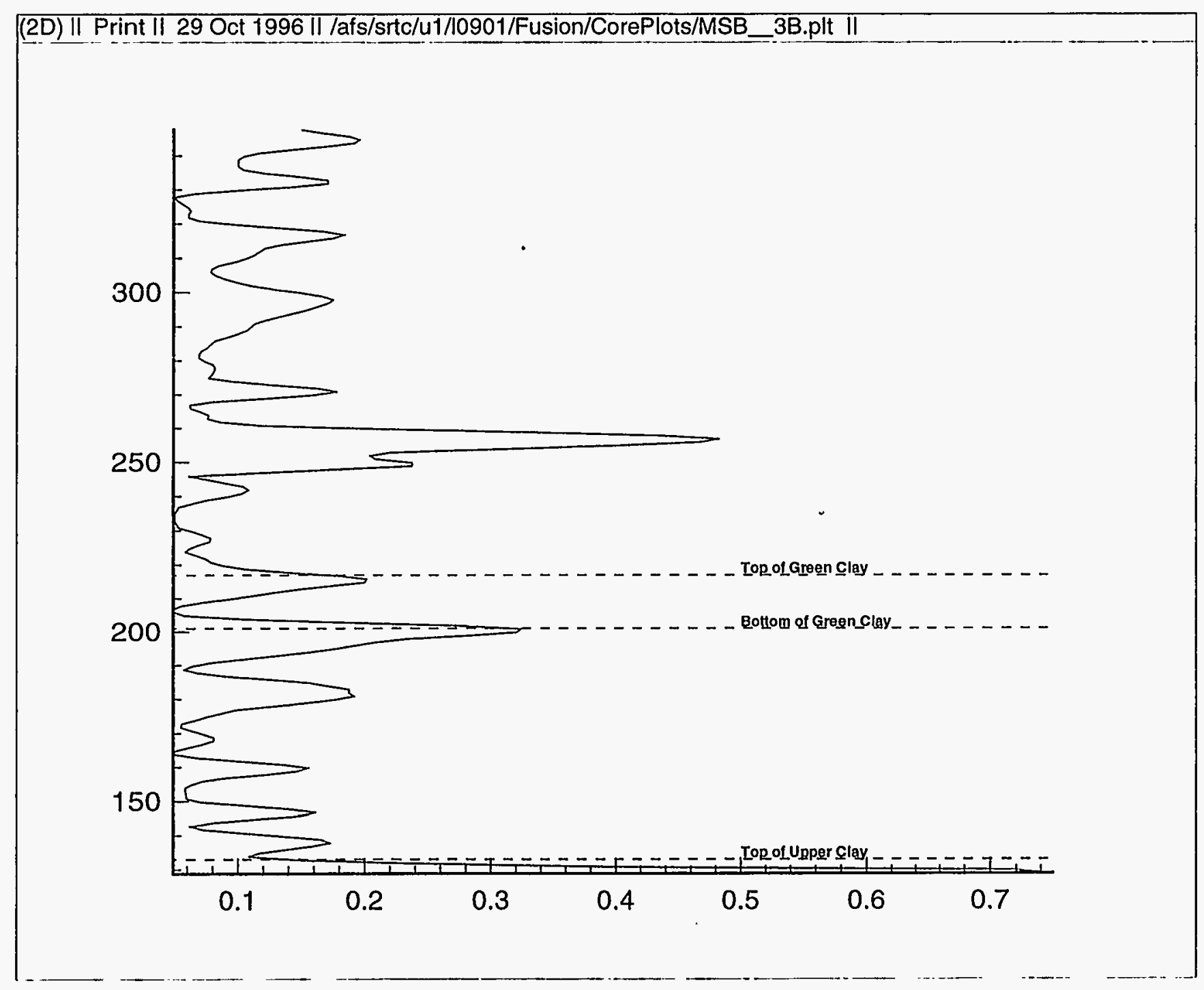




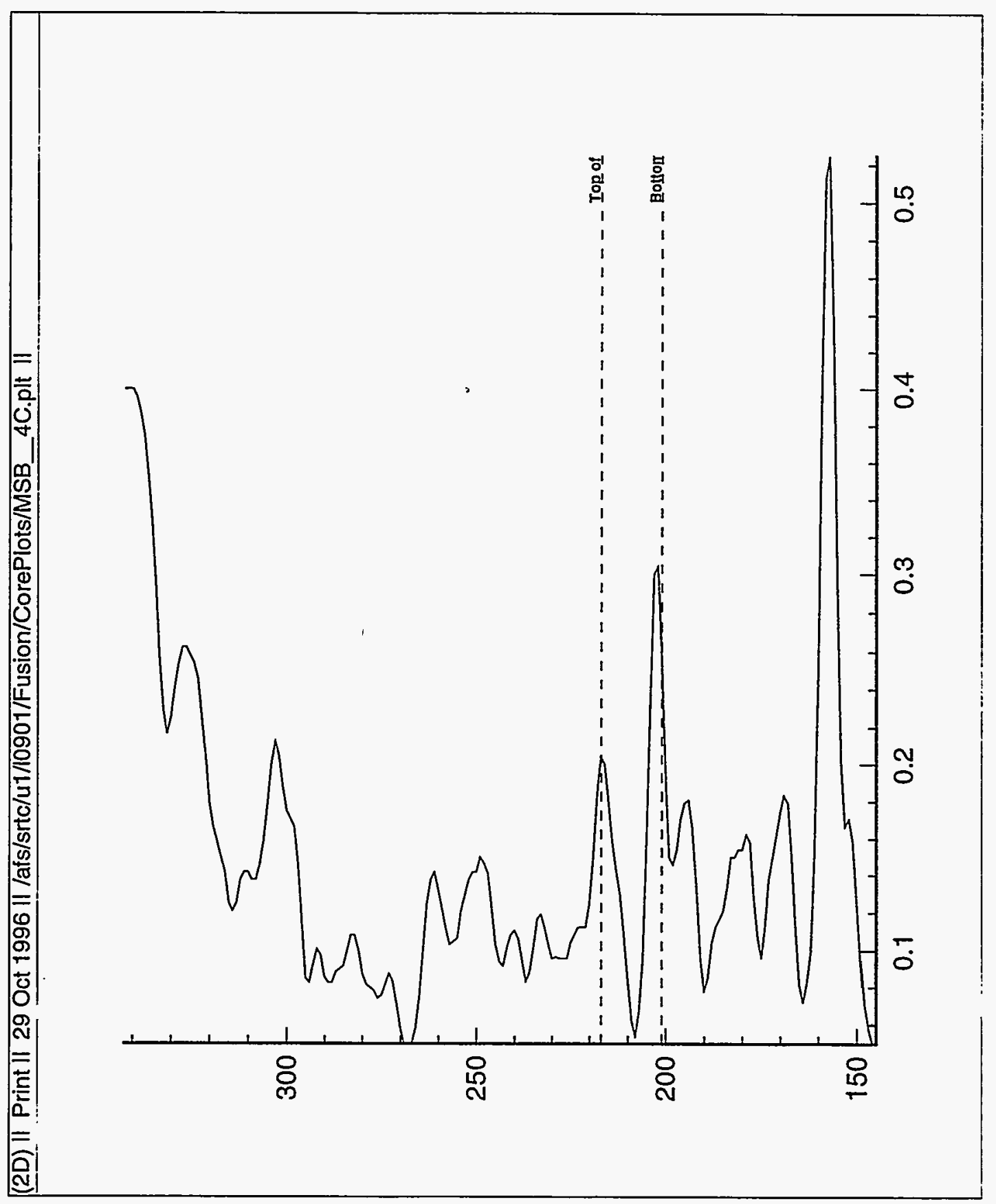




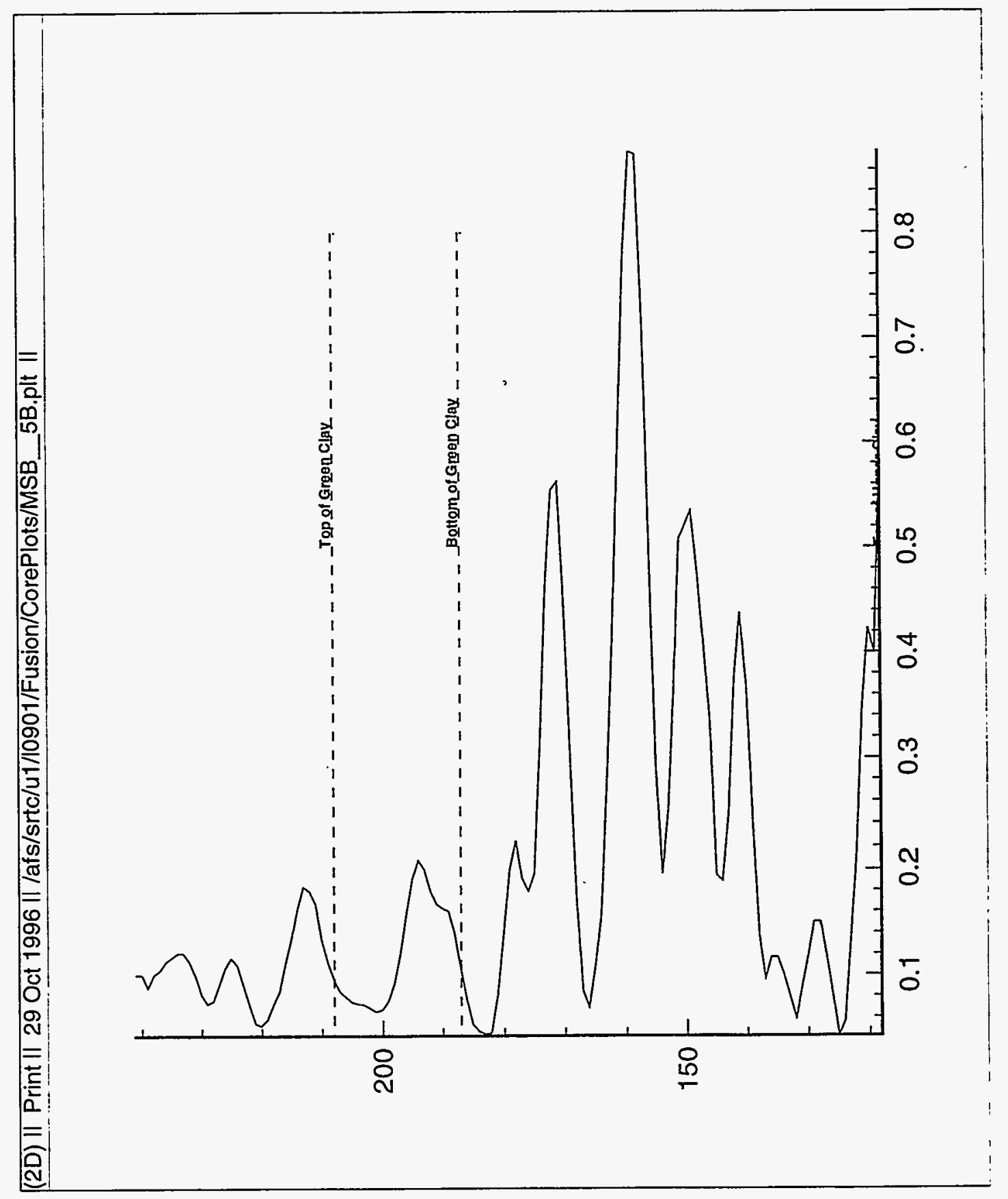




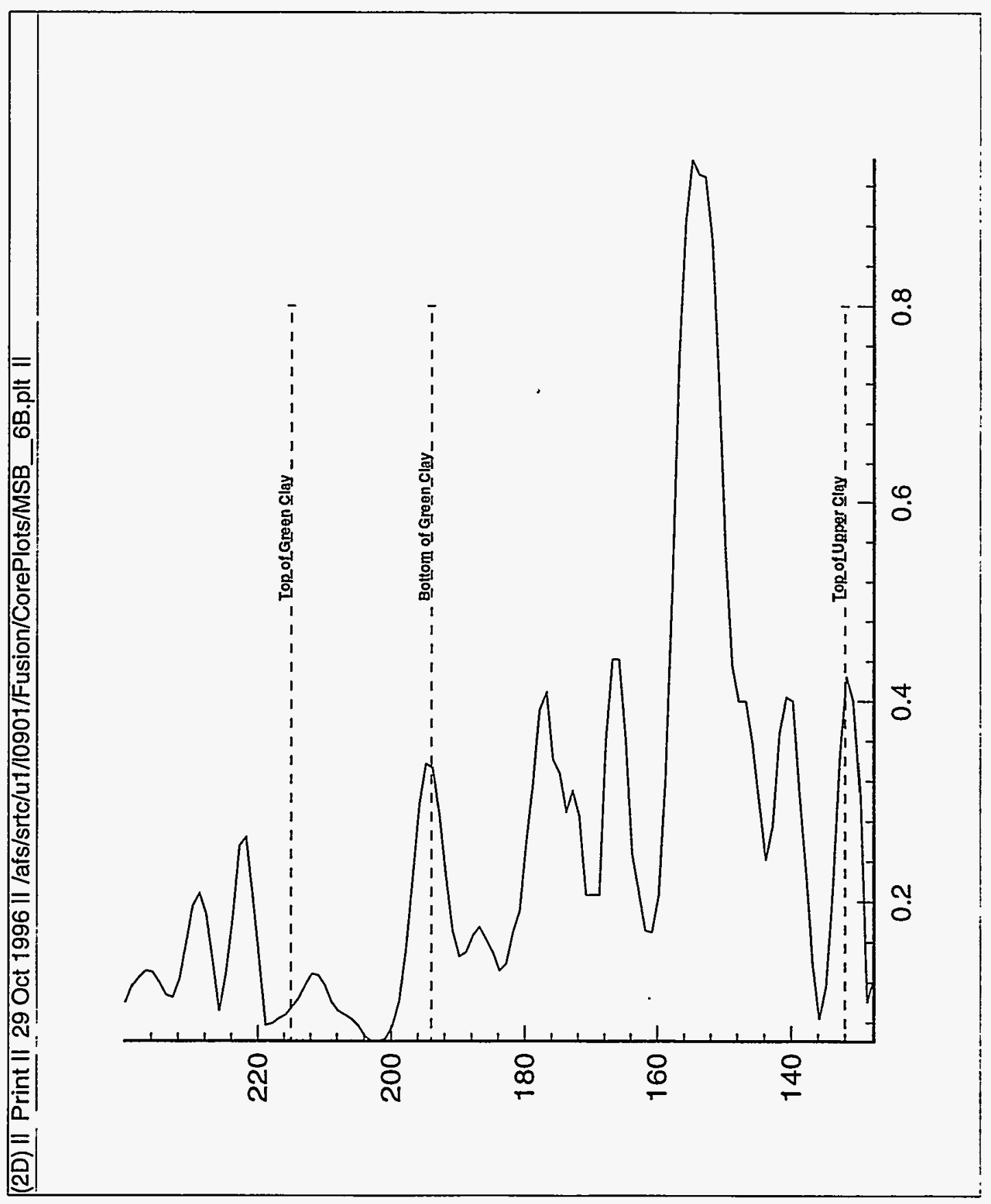


(2D) II Print II 29 Oct 1996 || /afs/srtc/u1/10901/Fusion/CorePlots/MSB_7B.plt II

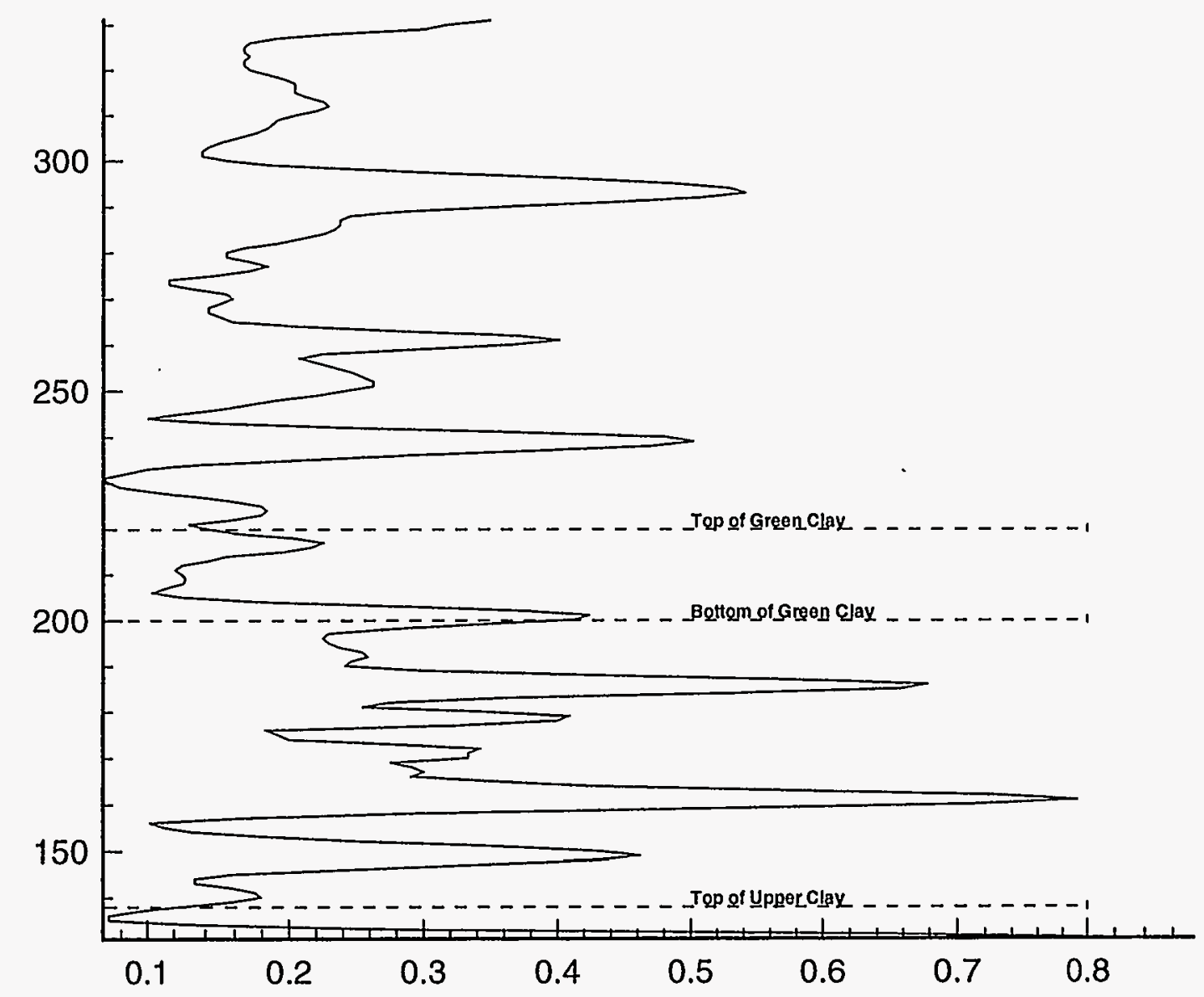




$$
\text { Wh }
$$




$$
\text { What : }
$$




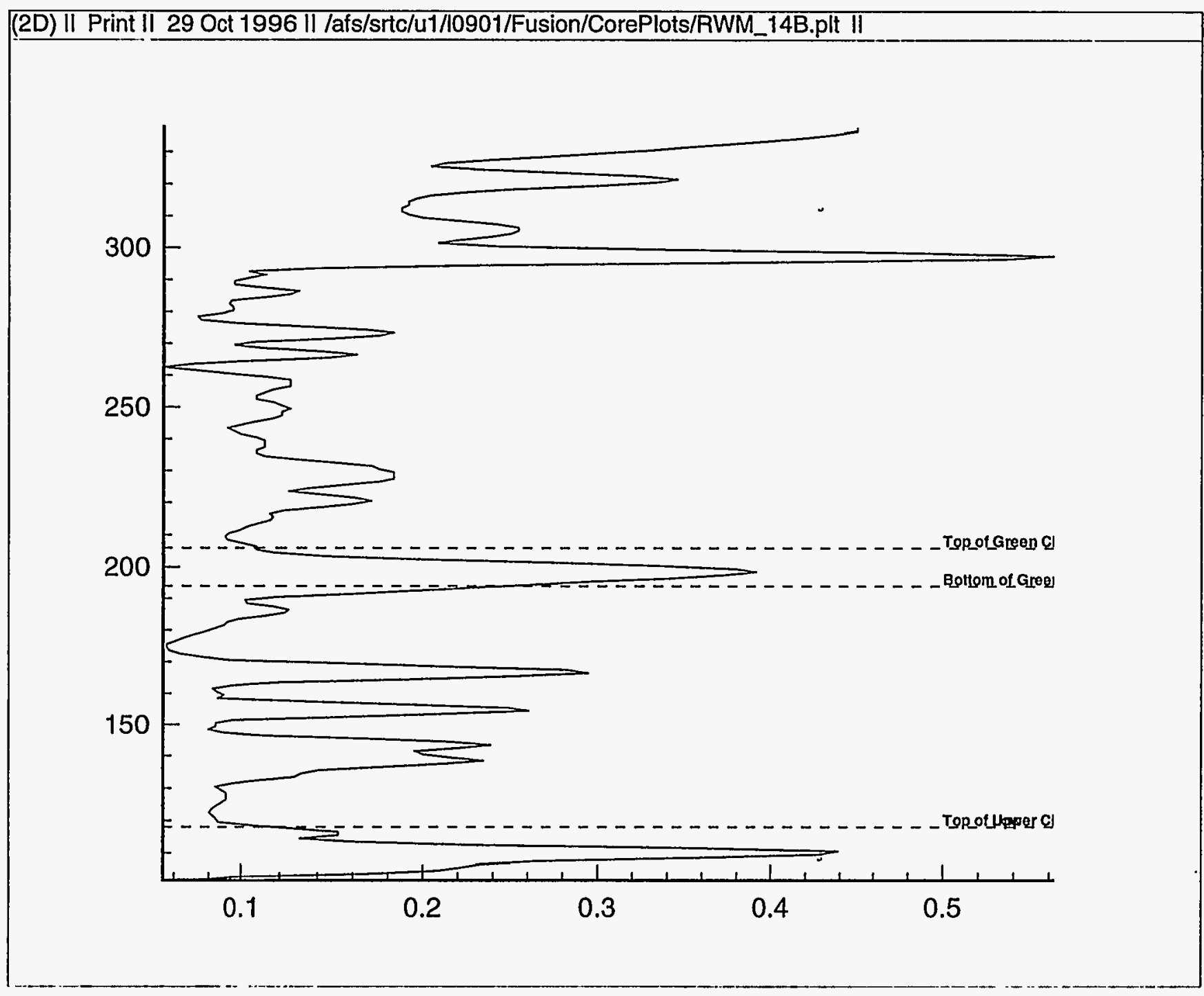




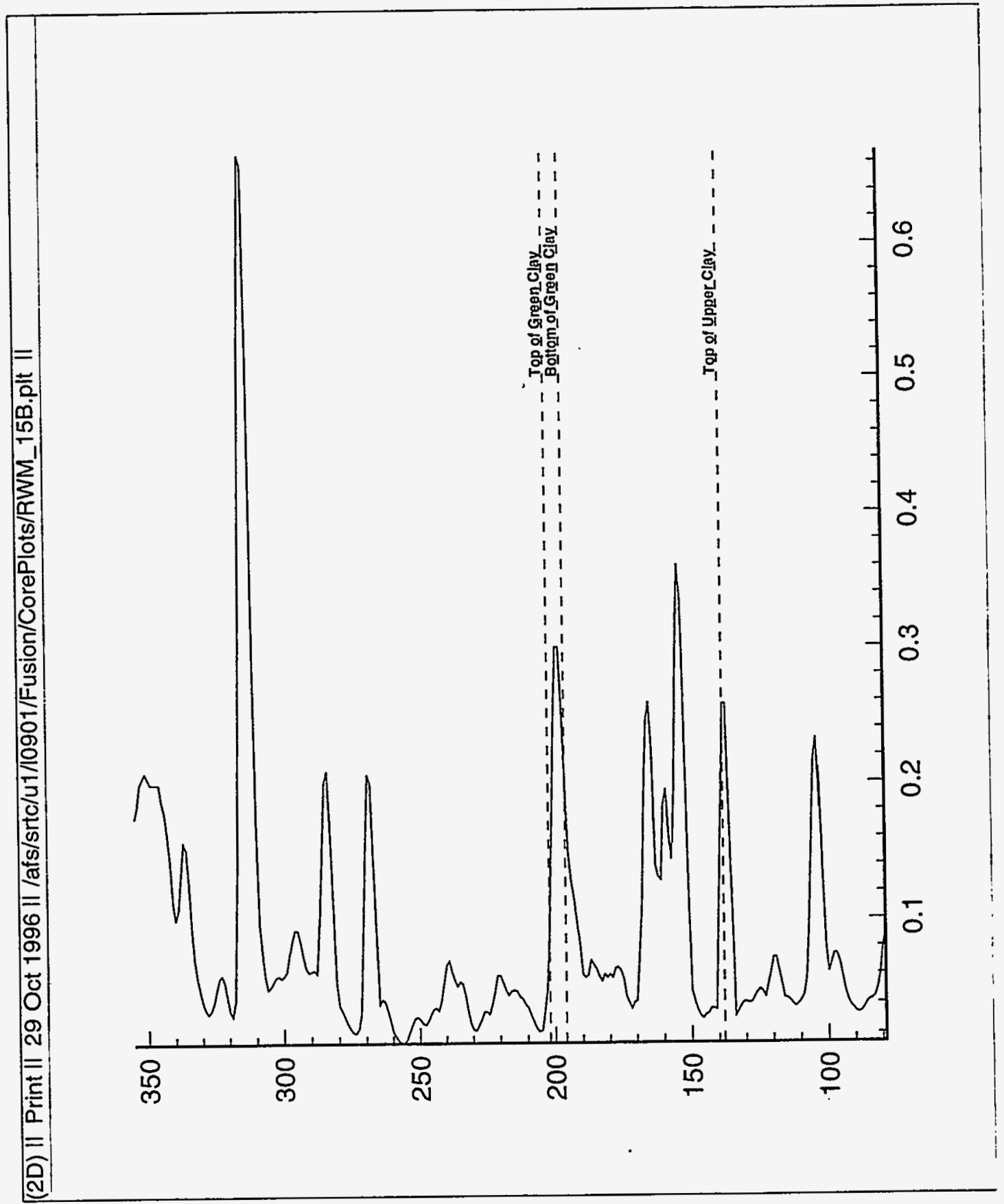




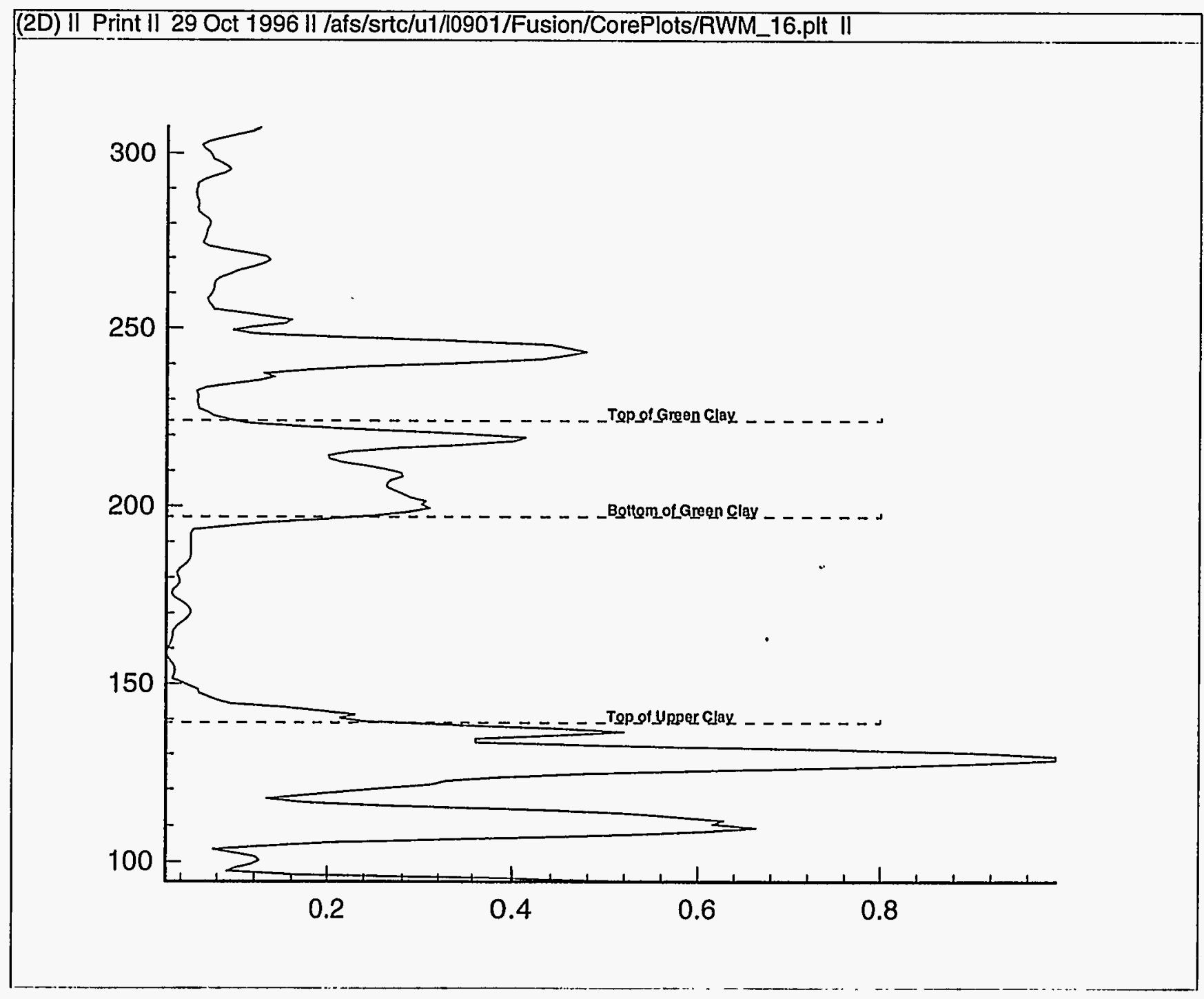




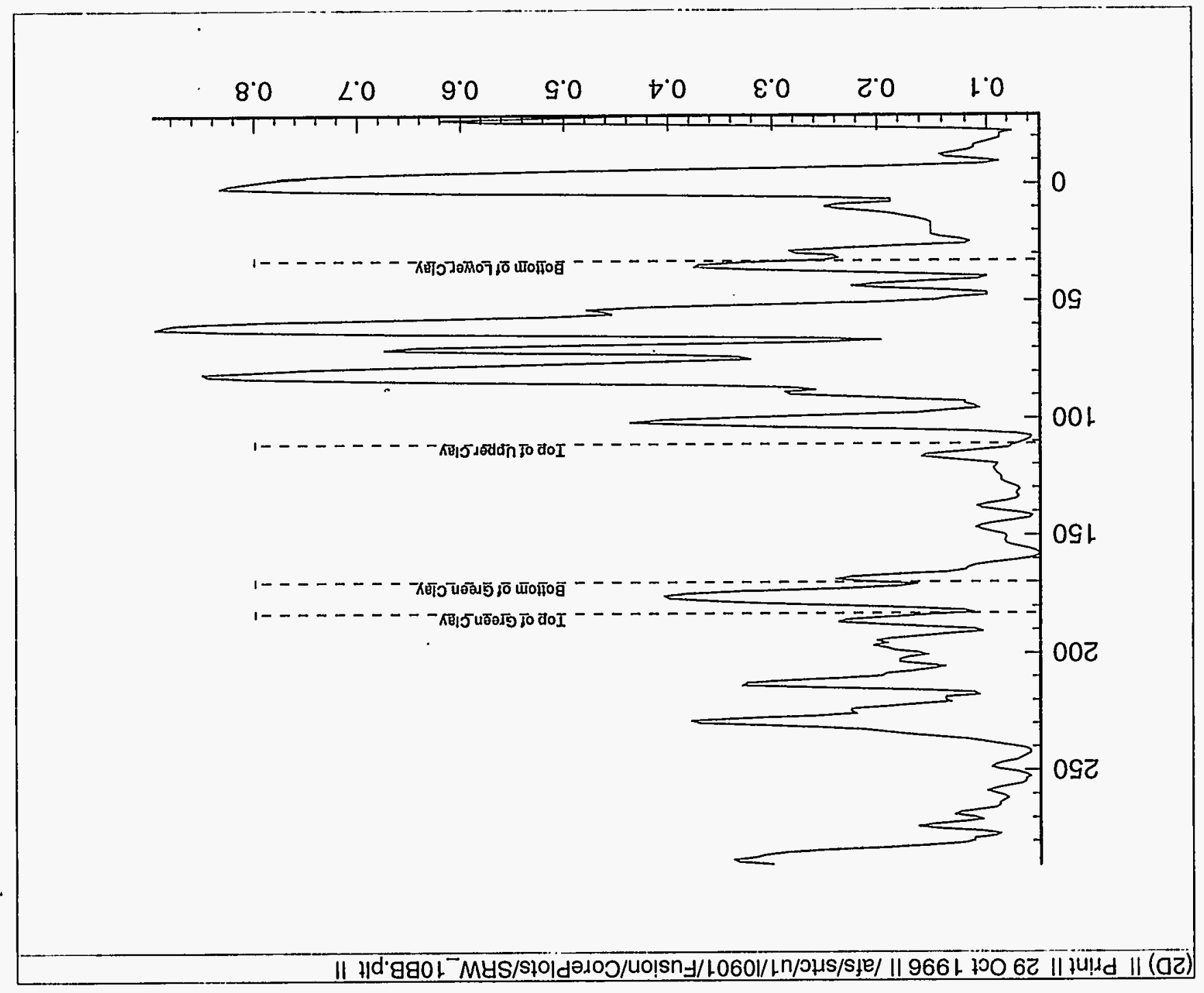




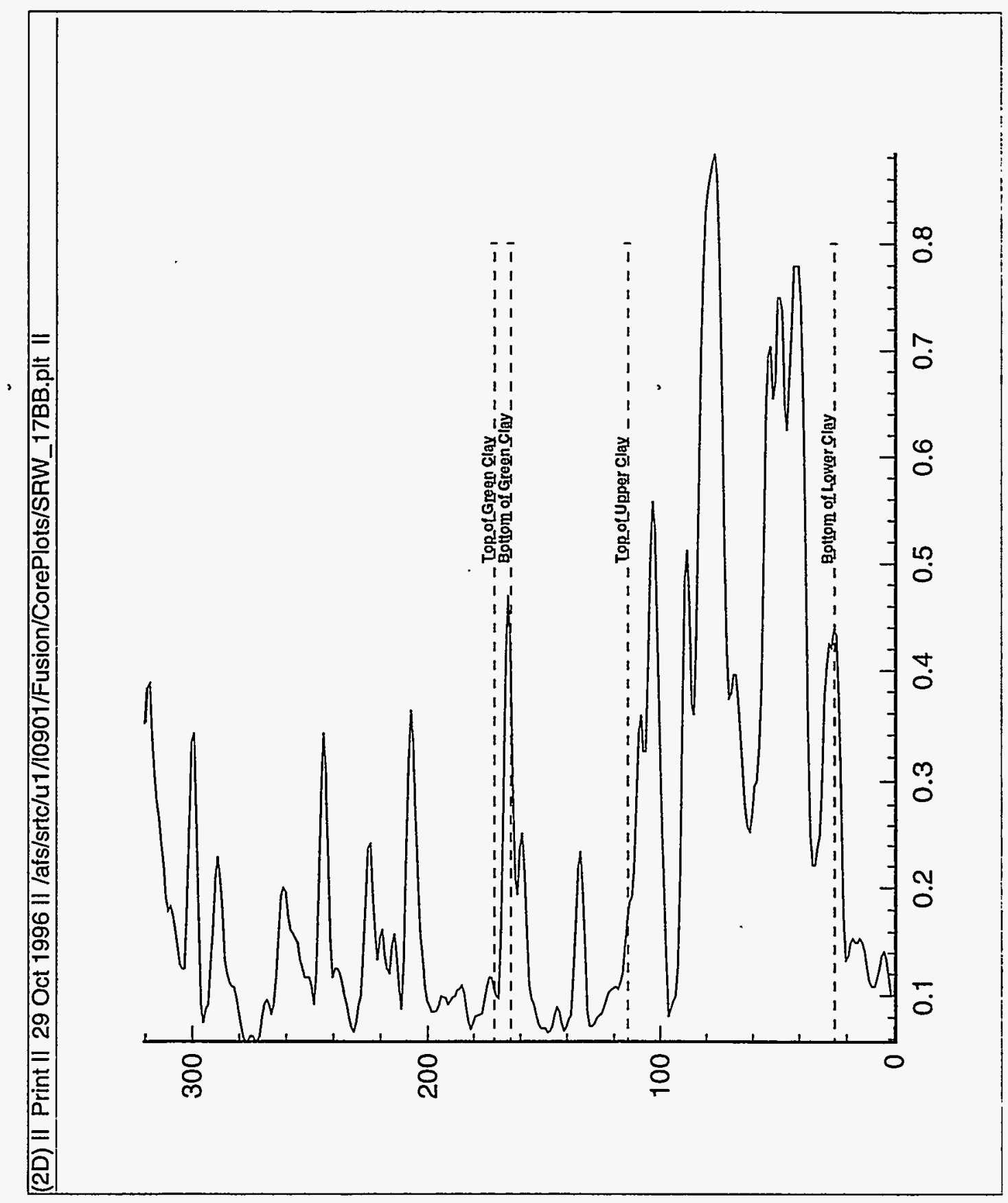




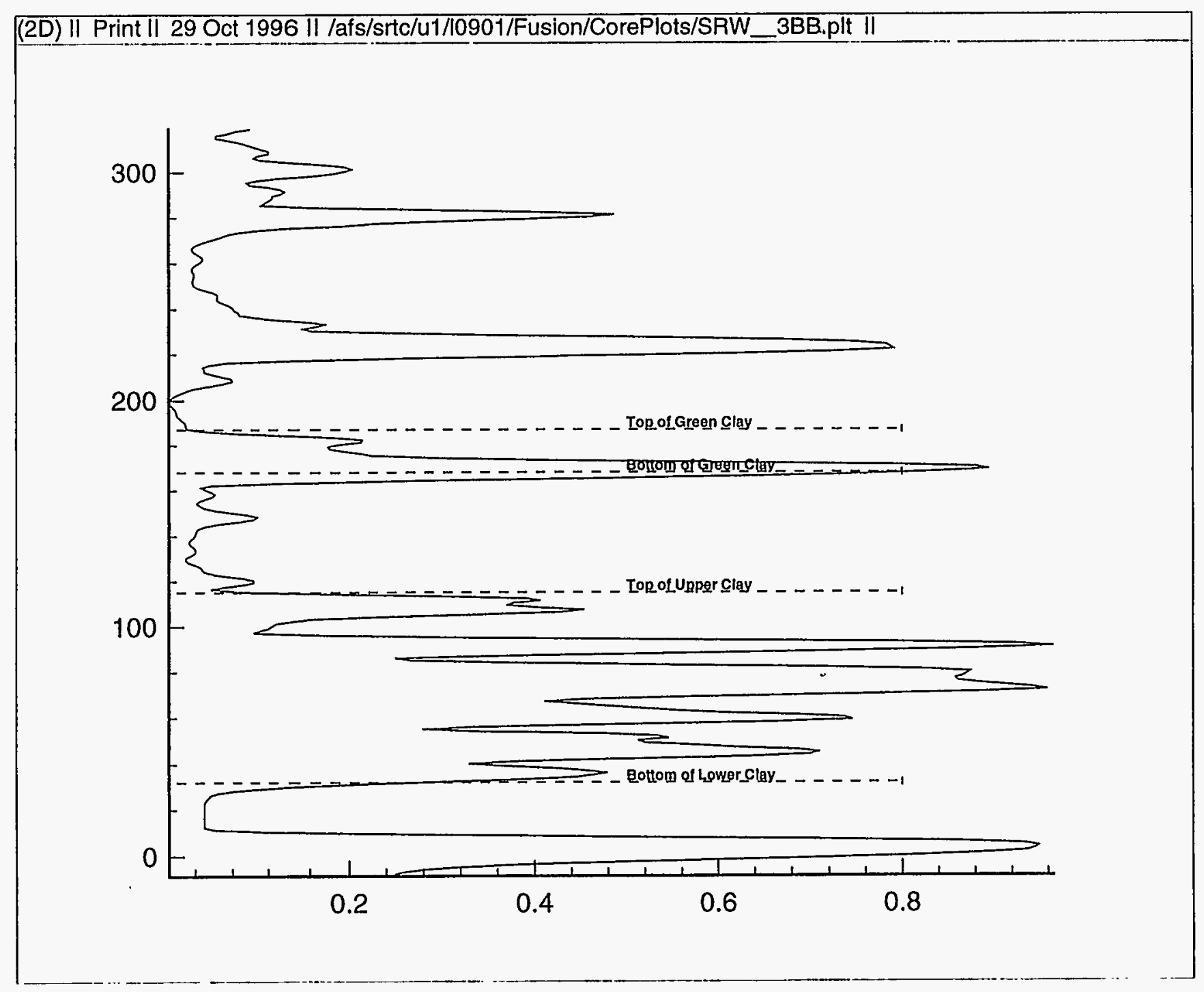




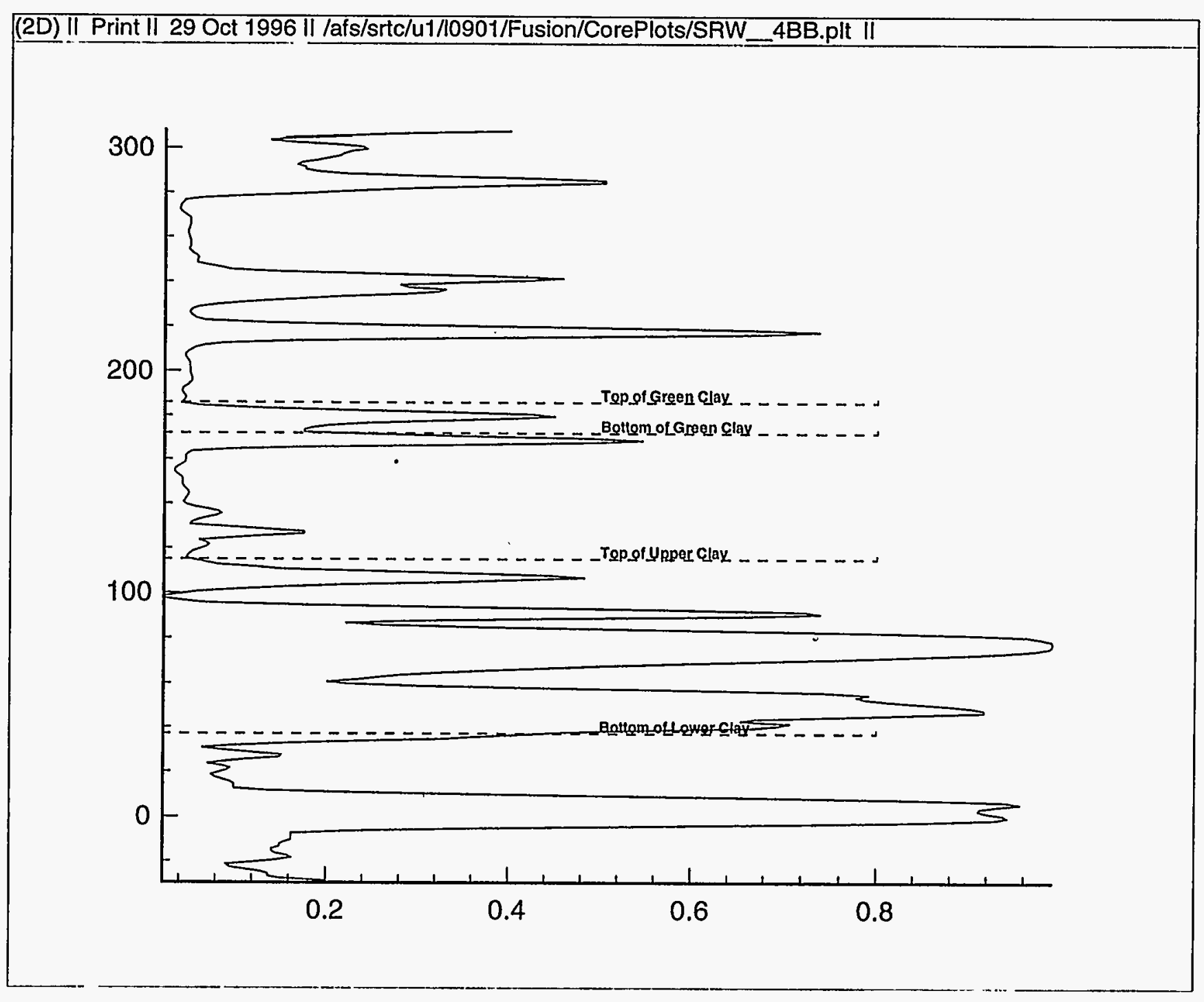




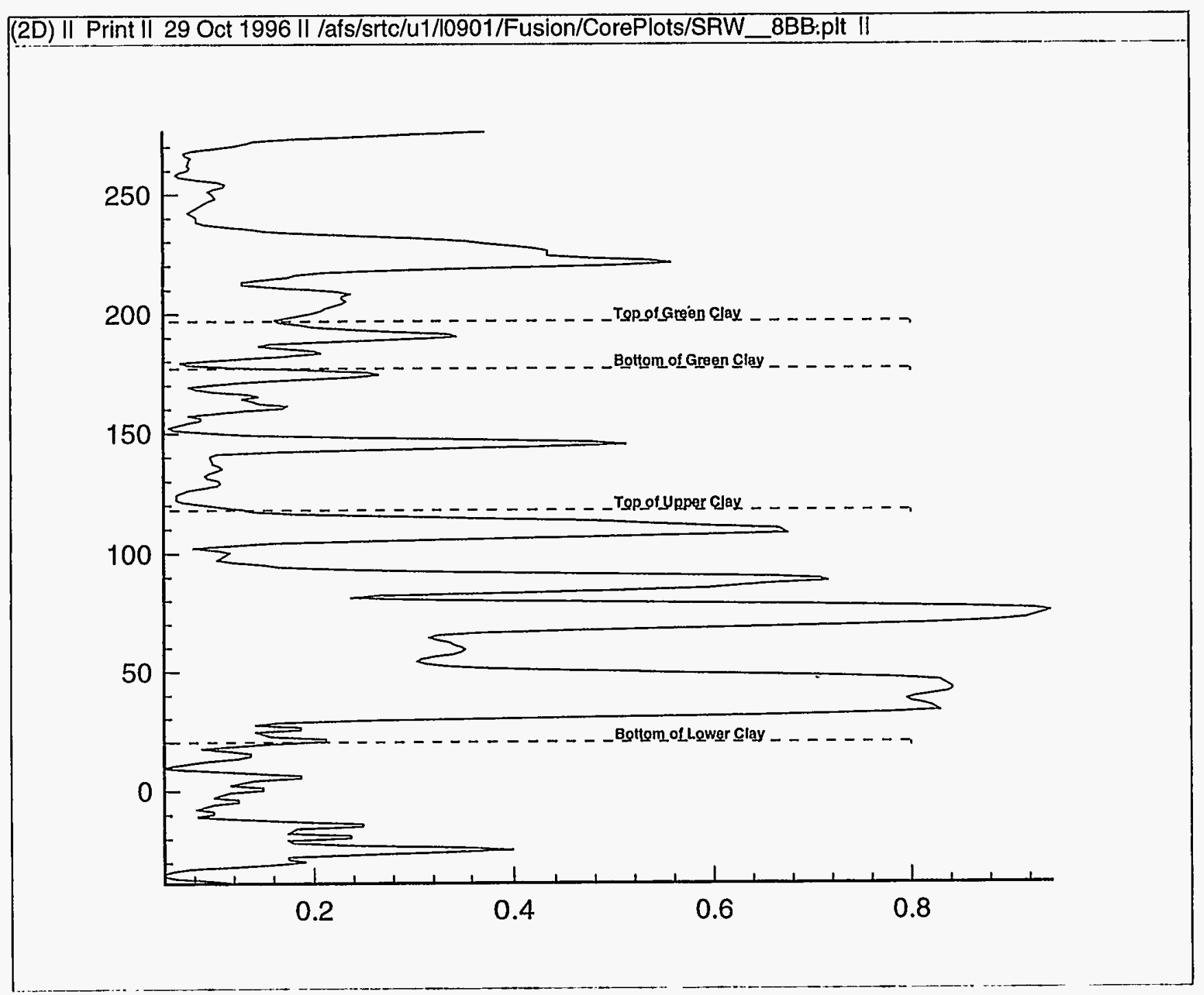

